


\section{F.3429 \\ . B475 \\ c1}

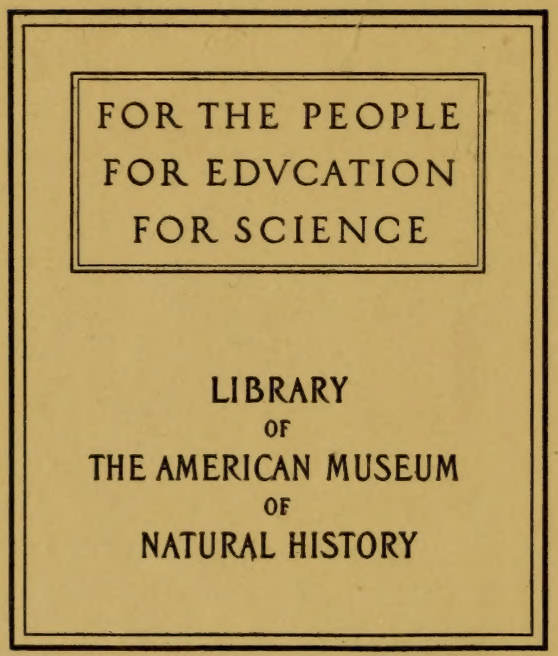






\title{
ANDEAN CULTURE HISTORY
}

\author{
By \\ WENDELL, C BENNETT \\ Professor of Anthropology, Yale University \\ and \\ JUNIUS B. BIRD \\ Associate Curator of Archaeology, American Museum of \\ Natural History
}

Handbook Series No. 15

NEW YORK 


\title{
PUBLICATION OF THE \\ ANTHROPOLOGICAL HANDBOOK FUND
}

\author{
COPYRIGHT 1949 BY
}

THE AMERICAN MUSEUM OF NATURAL HISTORY
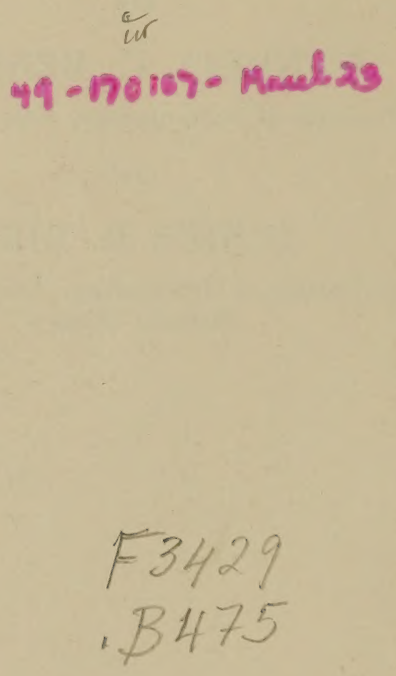

PRINTED IN UNITED STATES OF AMERICA BY

LANCASTER PRESS, INC., LANCASTER, PA. 


\section{PREFACE}

Collections from the indigenous Indian cultures, both past and present, from the whole continent of South America are exhibited in the South American hall in the American Museum of Natural History. In other words, this exhibition unit includes both ethnography, materials from contemporary Indian cultures, and archaeology, materials from past cultures and civilizations. By far the largest and most varied collections are from the pre-Spanish civilizations of Peru and Bolivia. This reflects the fact that the Central Andes was the most outstanding center of high civilization in South America for many centuries.

The present volume, although issued in the Handbook series of the Museum, is not intended to be a guide to the exhibits in the South American hall. Instead, it is a reconstructed history of pre-Spanish Peru, a summary of Indian cultures elsewhere in South America, and a general treatment of some outstanding techniques. Nonetheless in preparing this book the collections in the Museum have been kept in mind, so that the exhibits might serve as illustrations, and the Handbook might be used in a broad way for general information about them. Illustrations, unless otherwise noted, are of specimens in the Museum's collection or from Museum field-work.

As mentioned, the emphasis in this volume is on Peruvian prehistory. Consequently all other regions and materials are treated in less detail and their relationship to Peru is "stressed. The first part, The Setting, presents a brief review of the geography, the area cultural patterns, and the ar- 
chaeology of South America outside of Peru, but simultaneously stresses the cultural and environmental distinctness of the Peruvian unit. In other words, this part summarizes the physical and cultural setting of Peru in the total South American picture.

The second part is devoted principally to the history of Peruvian cultural development in preSpanish times, to which is appended a brief statement on Indian culture in the Spanish Colonial era and at present. The archaeological materials are arranged in an over-all historical sequence, from their earliest known beginnings to the Spanish conquest. This approach is valid because the cultural past of Peru forms a unit, even though there are many regional differences. In spite of the range and quantity of excavation carried out in Peru, there are still many gaps in our knowledge and many unrelated time sequences. Consequently certain liberties of interpretation have been taken, although every attempt has been made to keep speculation within reasonable bounds. Most archaeologists agree on the major trends, although each one varies somewhat in his interpretation of the precise time and space divisions.

The third part deals with ceramics, metallurgy, and textiles from a technical rather than an historical view. These techniques were well advanced in ancient Peru and are of interest in themselves.

This Handbook was originally projected as a joint account by the senior author, once Assistant Curator of South American Archaeology, and Mr. Junius Bird, now Associate Curator of Archaeology in the American Museum of Natural History. However, Mr. Bird became so engaged in enlarging the archae- 
ological history of Peru through extended field excavation, that the plan for joint authorship was abandoned. Consequently, Dr. Bennett prepared the first two parts, Mr. Bird the third. Both authors have reviewed the total text and selected the illustrations. Mr. Fred Scherer has prepared all maps, charts, and figures. Dr. Harry L. Shapiro, Chairman of the Department of Anthropology, likewise encouraged and directed this report. Señor Rafael Lareo Hoyle, Director of the Museo Lareo Herrera at Chiclín, Peru, not only furnished many excellent illustrations from his superb collections, but also provided many stimulating ideas for the interpretation of Peruvian prehistory. Many other archaeologists, both in this country and in South America, should also receive credit for ideas and materials. Their principal publications are listed in the bibliography, but this expresses only a fraction of the debt due them. Finally, Miss Bella Weitzner, Associate Curator of Ethnology, has once again provided her skilful editing and stimulating ideas for the production of this volume.

\section{Wendell C. Bennett Yale University Junius B. Bird}

American Museum of Natural History

JULY, 1947 



\title{
CONTENTS
}

\author{
PART 1
}

By Wendell C. BennetT

PREFACE . . . . . . . . . . . . . . 3

The Setting . . . . . . . . . . . . 13

The South Ameriean Enviromment . . . . . . 13

Early Migrants . . . . . . . . . . 21

Plant Domestication . . . . . . . . . 28

Southern Hunters . . . . . . . . . . 32

Tropical Agriculturists . . . . . . . . . 41

Lowland Arehaeology . . . . . . . . . 57

Andean Farmers . . . . . . . . 64

Northern Andean Arehaeology . . . . . . 70

Colombir . . . . . . . . . . 70

Eeuador . . . . . . . . . 80

Southern Andean Archaeology . . . . . . . 86

Northwest Argentina . . . . . . . 87

Chile . . . . . . . . . . . 90

PART 2

By Wendell C. Bennett

The Central Andes . . . . . . . . . . 95

Divisions . . . . . . . . . . . . . 95

Chronology . . . . . . . . . . 103

Early Farmers . . . . . . . . . . 116

C'ultist Period . . . . . . . . . . . 123

Experimenter Period . . . . . . . . . . 137

Mastercraftsman Period . . . . . . . . 153

Expansionist Period . . . . . . . . . 182

City Builler Period . . . . . . . . . 201

Imperialist Period . . . . . . . . . 215

Aftermath . . . . . . . . . . 239

PART 3

By JeNites B. Bird

Techniques * . . . . . . . . . . . 245

Ceramics. . . . . . . . . . 245

Metallurgy . . . . . . . . . . . 251 


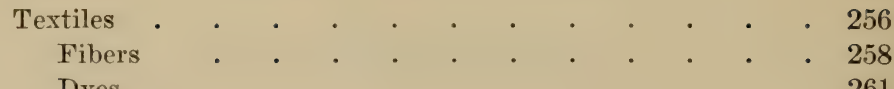

Dyes . . . . . . . . . . . . . 261

Spinning . . . . . . . . . . . . . 263

Looms and Weaving . . . . . . . . 265

Weaving Techniques and Chronology . . . . . 268

SELECTED Sources .

INDEX . . . . . . . . . . . . . 307 


\section{ILLUSTRATIONS}

1. Environmental regions of South America

2. Stemmed points associated with extinct animals in earliest oceupation level in South Chile caves . . . . .

3. Artifacts of oldest known coastal culture from northern Chile. a, Harpoon forepiece, points, and barbs; b, Stone seraping tools; c, Stone knife; d, Choppers ( 9 ); e, Stone, bone, and shell composite fishhooks and barbs; $f$, Thorn and shell hooks; g, Nitages in making shell looks and the tools used; h, Stone bowl . . . . . . . 27

4. South American cultural divisions . . . . . . . 33

5. Alacaluf dome-shaped hut and Ona windhreak. Morlels in the Museum

6. Yagua scene showing use of blowgun

7. (eremonial harkeloth costume from western Brazil . . 4!)

8. Shrunken human trophy heads from the Jivaro Indians . 54

9. Marajó pottery showing different types of incising and painting . . . . . . . . . . . . . .

10. Rio Napo urns and platter . . . . . . . . 60

11. Santarem vessels and figure urn from Marač́ . . . 62

12. Prehistorie ceramies from ('olombia. a, l, e-h, Quimbaya;

c, i, k, Santa Marta; j, Sinu; l, Mosquito effigy urn; 1. unknown . . . . . . . . . . . . 72

13. Chileha and Quimbaya goldwork from ('olomlia . . $\quad 77$

14. San Agustín stone earvings . . . . . . . . 7!)

15. Types of Ecuadorean pottery . . . . . . . 81

16. Stone seat from Manabí, Ecuador . . . . . . 8.5

17. Tablets and tube for mixing and inlabling snuff, Atarameño, North Chile

18. Principal valleys and major cultural divisions of the central Andes . . . . . . . . 94

19. Chronological chart for the Central Andes . . . . 112

20. Principal Early Farmer Period sites . . . . . . . 115

21. Ameriean Museum exeavation in a pre-ceramic agrieultural community midden, Huaca Prieta, Chicama Valley . . 119

22. Principal Cultist Period sites . . . . . . . 122

23. Cultist Period ceramic types . . . . . . . 127

24. Cultist Period goldwork from rhongovape and lone arti. facts from Chicama 
25. Building and carving of the Cultist Period. Upper left, modeled clay, Moxeke; lower left, Cerro Sechín; others, Chavín de Huántar

26. Principal sites of the Experimenter Period . . . . 138

27. Chiripa ceramies and house site, Experimenter Period . . 143

28. Salinar ceramies of the Experimenter Period . . . . 144

29. Paracas Cavernas ceramic style of the Experimenter Period. The tube at left is Pucara culture showing same technical treatment

30. Principal cultural divisions in the Mastercraftsman Period .

31. Recuay style stone statues of the Mastercraftsman Period

32. Pucara style stone earving of the Mastercraftsman Period .

33. Varieties of Mochica pottery of the Mastercraftsman Period

34. Interlocking and Nazea style ceramies of the Mastercraftsman Period. Top center, interlocking style . . .

35. Gold objects from a Paracas mummy bundle of the Mastercraftsman Period . . . . . . . . . 175

36. Principal centers of the Expansionist Period . . . . 183

37. Tiahuanaco ruins and decorated gateway . . . . 187

38. Typical wall construction and detail of sockets for cast copper eramps or tie bolts in stone paving at Tiahuanaco

39. Monolithic statue from Tiahuanaco. Discovered by Wendell C. Bennett

40. Coast and Highland Tiahuanaco vessels. Upper half, Coast Tiahuanaco; Lower half, Bolivian Highland sites . .

41. Miscellaneous prehistoric Peruvian artifacts: earved and painted box, pyrites mirror, combs, spoons, ear spools, and snuff tube

42. Principal centers of the City Builder period . . .
43. A fortress of the City Builder period at Paramonga, constructed of clay bricks . . . . . . . . 204

44. Clay arabesque wall decorations at the ruins of Chanchan .

45. Chimu blackware water jars. At left, two men boxing; center, an example of mold-pressed decoration; at right, two men on a balsa raft

46. City Builder ceramic styles from the Central and South
Coast. Top row, right, Negative painted Recuay vessel of the Mastercraftsman Period, others, two late vessels from Pachacamac; second row, Three vessels of Chancay Black-on-White style; bottom row, Four vessels of Iea style 
48. The famous Inea citadel of Machu Picehu

49. Types of Inea masonry. Top, Machu Pichu; lower left, Fortress of Sacsahuamán; lower right, a strect in Cuzco

50. Inea artifacts: lacquered wooden kero, ceremonial stone llama form container and bowl, two very typical pottery containers, a piteher and aryballoid water or beer jar .

51. Musical instruments, panpipes, flutes, whistles, and a horn .

52. Molds for ceramic manufacture . . . . . . .

53. Prehistoric Peruvian eopper, bronze, and silver objects. Ax and club heads, bolas weight, knires, chisels and ear spoons are cast; tweezers and pin are hammered . .

54. I)iagram of backstrap loom. a, Loom bars; b, Shed rod; e, Heildle rod; d, Batten or sword; e, Bobbin; f, Batck stray! g, Warp lashing; h, Heading string; i, Lease cord; j, Leash cord; k, Warp; l, Weft

55. Paracas Necropolis embroidery. Top, Poneho shirt with heary shoulder fringe; center, Mantle borders, with foundation fabric completely hiden by the embroidery; bottom, Half of a large mantle . . . . . .

56. Poncho shirt, shaped by inserting additional warp at center of fabric (North Chile); Cape, shaped by expanding the warp; upper half, cotton, warp faced; lower half, wool, eceentric tapestry; Boy's shirt, tapestry; Woman's work basket; Detail of interlocked warp loom . . .

57. Peruvian fabrics. Top, Gauze weaves, the center one from a Paracas Necropolis grave, the others later; center, Double eloth; bottom, Late period painted cotton compared with Paracas Necropolis painting; lower right, tie-dyeing 



\section{PART 1}

\section{THE SETTING}

\section{The South American Exvironamext}

The region designated as the Central Andes includes the Peruvian coast and highlands and most of the Bolivian highlands, particularly the high plateau around Lake Titicaca. The abundant archaeological remains in the Central Andes have long been intensively studied because this area, in spite of its striking environmental contrasts and its remarkable dirersity of materials, presents a unit of cultural development unmatched in intensity in South American prehistory. Here centered the Inca culture which, at its peak, maintained an empire that extended from Colombia in the north to Argentina and Chile in the south. The Spaniards described the Inca Empire as they found it flourishing in the early sixteenth century. The archaeologist projects the story backward from that date and can demonstrate that the basic components of the Inca culture were developed in the Central Andes many centuries before the Spanish conquest.

The major purpose of this account is to reconstruct the story of cultural development in the Central Andes from its earliest known manifestations to historic times. However, it seems profitable to begin with the South American scene as a whole and to describe the total physical and cultural environment within which the Central Andean cultures played so distinctive a role. It has long been recognized that topography and other features of the geographic environment may affect migration, trade, transportation, and expansion; that the natural re- 
sources present or absent in an area may influence cultural growth; and that culture and geographic environment are linked in many ways. The cultural environment is equally important. This involves knowledge of the size of a population, its technology, specialization, divisions of authority and over-all pattern. Likewise, it is hard to understand one group without a knowledge of its neighbors.

Topographically, the South American continent is divisible into three major zones: the Andes along the Pacific Coast, the tropical and temperate plains, and the highlands of east Brazil and the Guianas (Fig. 1). These major zones extend from north to south, a topographical factor that has long influenced migrations and cultural diffusions. Even the briefest examination reveals that there are many contrasting environments in South America. The rugged Andes rise in marked contrast to the flat plains of the Argentine Pampas. Northern Chile is an extreme desert; the Amazon and its tributaries flow through one of the greatest known stretches of tropical rain forest. However, in spite of size and environmental variety, in terms of pre-Spanish subsistence patterns large sections of South America could not be effectively utilized. Some of the richest agricultural areas, like the Argentine Pampas, were of little use to Indians who had no knowledge of the plow or other means of eradicating the deeprooted grasses. The extensive grazing lands now utilized had an insignificant value before the introduction of European domesticated animals.

The rugged Andes dominate western South America, extending from the Caribbean coast of Venezuela and Colombia, along the entire Pacific Coast to Cape Horn. Only in Bolivia do the Andes expand to much 
over one hundred miles in width. They vary from section to section. Three parallel ranges in Colombia reduce to two in Ecuador, break up into short diagonal chains in Peru, expand again to a pair in Bolivia, and narrow to a single range in Chile. Temperatures in the Andes are more or less consistent, reflecting altitude rather than latitude, so that most sections are cool to cold during the whole year, although freezing temperatures are rare in the habitable areas. Although trees grow in some sections, much of the region is unforested and may be classed either as grassland, bushland, or desert. The geographers recognize a northern, central, and southern division of the Andes and these are important in cultural considerations. The Northern Andes, which include Colombia, Ecuador, and a small part of Peru, are characterized by a double rainy season which supports wet rain forest in areas of high altitude between 10,000 feet and the snow line. Such highland areas are unfavorable for grazing llamas and alpacas, so that the two most important domesticated animals of pre-Spanish America were not permanently acquired by the people who occupied this northern region. The Central Andes have a contrasting rainy and dry season, resulting in a highland covered by a bunch grass, ideal for grazing, which makes the region environmentally distinct from the Northern Andes. From Bolivia southward, the Southern Andes are separated from the Central Andes by a desert strip which extends from north Chile to the Patagonian plateau. The limited habitable areas are not unlike those of the Central Andes.

The Andes everywhere present formidable mountain barriers with numerous peaks over twenty thou- 
sand feet in altitude and few passes under twelve thousand feet. The habitable sections are the intermont basins, high plateaus, and valley flats of the rivers that drain into the Amazon. These basins and flats, however, have well watered, fertile soil, and many resources contributing to cultural development, such as stone and clay usable for building materials, and easily mined copper, silver, gold, and tin. Many regions are extensive enough to support a reasonably large population, and distant enough from each other to permit easy defense without excessive isolation. Today, of course, the Andes present difficult transportation problems, but in preSpanish times when travel was essentially on foot, the mountains did not constitute a great obstacle. Today wild food plant and animal life are limited in the Andes, due in part to the fact that intensive agriculturists have occupied the region for over two thousand years. However, since many domesticated plants and at least two domesticated animals appear to be indigenous to this region, it seems reasonable to assume that wild forms were abundant at one time.

Although not very extensive, the plains along the Pacific Coast present a considerable contrast in environment. In Ecuador and Colombia, where they are widest, they lie within the tropics, with characteristic high temperatures, excessive rainfall, and jungle forest coverage. In Colombia, therefore, the envirommental contrast between the plains and the highlands prevented much cultural interchange. The narrow coastal plains of southern Ecuador, Peru, and northern Chile form the west crast desert. This climatic change is attributed to the effect of the cold Humboldt current which enols the air of the 
on-shore winds sufficiently so that there is no precipitation over the hot coastal land and desert conditions result. The aridity increases in intensity from north to south, reaching its maximum in the Atacama desert of north Chile. The habitable portions of the west coast, except for small fishing sites, are limited to the valleys of the rivers that have their source in the mountains and flow rapidly to the $\mathrm{Pa}$ cific. In terms of gross environment, the contrast between the desert coast and the high Andes seems enormous; but in terms of Indian subsistence patterns it is not very significant. In fact, the coastal valleys and highland basins share such favorable features as rich, easily cultivated soils, an absence of deep-rooted grasses or forest coverage, a relatively genial climate, and sufficient water supply to permit controlled irrigation. The Central Valley of Chile is an alluvium filled trough lying between the main Andes and a low coastal range. Here the climate is classed as Mediterranean; the soils are rich and the rains abundant. Following the introduction of European plants and animals, the Central Valley became the garden spot of Chile. The long southern archipelago of Chile is a continuation of the coastal mountain range. The climate is cold and wet; the coverage, wet rain forest. This region was inhabited by small groups of fishermen who spent most of their lives in canoes.

East of the Southern Andes are the high semidesert table-lands of Patagonia where the winds blow constantly. The soil is shallow and not very fertile, trees are rare, and most of the area is classed as grassland. North of Patagonia are the Argentine Pampas with their rich soil, low elevation, and temperate climate. The Pampas are the finest 
grasslands in South America, famed today for their cereals and beef. In the past, however, grasslands were not favorable to native digging-stick cultivation, so that the distinction between the Pampas and Patagonia was not of special significance. Instead, this region was oceupied by hunters who pursued such wild fauna as the guanaco and the rhea, or ostrich, and watherers who collected seeds and roots.

The transition from the temperate to the tropical lowlands is illustrated by that great area known as the Gran Chaco which includes parts of Argentina, Paraguar, and Bolivia. This uninterrupted flat plain is characterized by a concentrated rainy season and an exceedingly contrasting dry season which results in a greatly varied vegetal coverage. It includes sections of grassland, parkland, bushland, and, along the rivers, tropical forest. The rivers are full of fish and some hunting of game is possible, but, on the whole, this area was never very attractive either to hunters or agriculturists.

The Amazon lowlands lie in the true tropies. The region is mostly below a thousand feet elevation. The rainfall is excessive; temperatures are consistently high; and tropical forest is characteristic. The Amazon River with its numerous tributaries forms a network over the whole area so that with any form of watereraft, transportation was no problem. There is a reasonable amount of wild animal life, abundant fish in the rivers, and some wild edible roots and fruits. However, these tropical forests were probably never very enticing to simple hunters and certainly they were not extensively occunied until suitable plants had been domesticated. Even for agriculturists the region offers no great attraetion since the soils are thin and poor: clearing a field 
is an arduous task, and the protection of a village is difficult.

The llanos or flats of the Orinoco River in Venezuela are in some ways similar to the Amazonian lowlands, but irregularities in the distribution of rainfall produce a coverage of grass and scattered trees, rather than dense tropical forest. In cultural terms, however, the two regions do not contrast markedly. This is also true of the highlands which cover most of the Guianas and parts of Brazil and Venezuela. These are old, badly eroded mountains, completely surrounded by tropical forest. The higher sections, however, are not very favorable for agriculture, so that the contrast between highlands and tropical lowlands never became culturally important.

The east Brazil highlands cover an enormous area and present a number of internal divisions. Grasslands and scattered trees are typical and the variety of plant life is great. The climate is subtropical with ample rainfall and little variation in temperature throughout the year. In the past, game and wild life were apparently sufficiently abundant to attract land hunters and gatherers.

South America can, then, be divided into a dozen major environmental zones, which can be further subdivided with ease. However, from the point of view of this historical summary, such detailed subdivision is unnecessary because, by the time of the European conquest, the whole continent was dominated by three basic cultural patterns: the Southern Hunters, the Tropical Agriculturists, and the Andean Farmers. Furthermore, this broad review demonstrates that despite some of its internal contrasts, the Central Andes forms a distinctive en- 
virommental zone, a miqueness even more marked when the contrasting cultural factors are considered.

\section{Early Migrants}

South America was first populated by nomadic hunters, fishermen, and aatherers with no knowledge of agriculture, metals, or pottery. All the known evidence indicates that the Isthmus of Panama was the migration route of these land nomads to the South American continent. The only alternative possibility is by way of the chain of Caribbean islands, a route which presupposes a knowledge of watercraft, for the antiquity of which we still lack proof, in spite of the important development of water trarel in the Amazon area and the Chilean archipelago.

Land hunters and gatherers who migrated to South America via Panama could easily enter the Andean highlands by way of the Cauca and Magdalena rivers, both of which flow from south to north. Some groups may have migrated eastward into Venezuela, but further expansion in that direction was probably blocked by the Amazon jumgle where there is, as yet, no evidence for the antiquity of a hunting-gathering culture pattern. The same line of reasoning applies to the Pacific Coast of Colombia and Ecuador which is also a tropical jungle. The highlands would, however, offer a reasonable quantity of game and wild food sufficient to support a hunting and gathering people. Furthermore, once adjustment had been made to the Andean enviromment, there would be no major barriers to a continued southward micration. Small groups may have moved to favorable fishing sites on the arid Pacific Coast, but these minor movements would not 
affect the main direction of migration. Once Argentina had been reached, a rapid spread throughout the Pampas and Patagonia, even to distant Tierra del Fuego, probably occurred since this great expanse of grassland presented many favorable possibilities for hunters and gatherers. From northern Argentina it would be easy to enter the open park country of the east Brazil highlands. The fishing potentials of the Chilean archipelago were probably exploited as soon as water travel was perfected.

This reconstruction of the probable migration routes of the early hunting people is based partially on geographic logic, but it is confirmed by the meager archaeological and historical evidence. The earliest remains of man yet found are in the Andean highlands, the east Brazil highlands, and in southern Patagonia. Furthermore, at the time of the European conquest hunting and gathering peoples still occupied the east Brazil highlands, the Pampas, Patagonia, and the Chilean archipelago.

The archaeological evidence for these early migrations consists of human skeletal remains found in association with extinct fauna and cultural remains excavated in the camping and fishing sites. In 1835 the Danish naturalist, T. W. Lund, explored some eight hundred caves in the Lagoa Santa region of Minas Geraes in the east Brazil highlands. These caves contained not only the bones of extinct Pleistocene fauna, but assorted human remains some of which represented physical types distinct from those of the modern Indians. A recent excavation of the Confins Cave in the same region has confirmed the results of the earlier work. The mouth of this cave was completely sealed by fallen debris. Excavations in the alluvial deposits on the cave floor 
encountered at about two meters depth the skull of a fossil horse, the molars and bones of a young mastodon, and a human skeleton which, although in extended position, was not an intrusive burial. The geologists dated this deposit as of the post-Pluvial period and pointed out that the associated extinct fauna did not imply extreme antiquity. The human skull is long-headed and has a slightly projecting face, a low forehead, and prominent cheek bones. These, in general, are the characteristics of the established Lagoa Santa type. Another early fossilized human skull was found at Punín in the highlands of Ecuador in 1923. Here old volcanic ash beds contained many Pleistocene type animals such as the horse, sloth, mastodon, deer, and camel. The skull was found in one of the ash beds, although not in direct association with the fossil fauna. It is low, long, and similar in other respects to the Lagoa Santa type.

Surface campsites with chipped stone artifacts, that may represent the tools of early hunters, have been found in several parts of the Andes. In a recent survey in the highlands of Peru, a series of rock-shelters were discovered near. Huancayo. The floor deposits have no pottery, but contain a variety of crude and finely chipped stone points, sidescrapers, and endscrapers, as well as flaked blades and some flint cores.

Many finds of fossil man and early campsites have been reported for Patagonia, but few of these are based on scientific excarations. The best evidence comes from the extreme southern part of Patagonia near the Straits of Magellan. Here two caves, Palli Aike and Fell's, excavated by Junius Bird, contained stratified remains of five distinct periods of 
habitation. Both caves were below lava outcrops on the semi-desert plains. The two caves furnish evidence for an historical reconstruction.

Their first occupants used stemmed projectile points, many rough scrapers, lava cylinders, and a variety of bone flaking tools (Fig. 2). Bones of

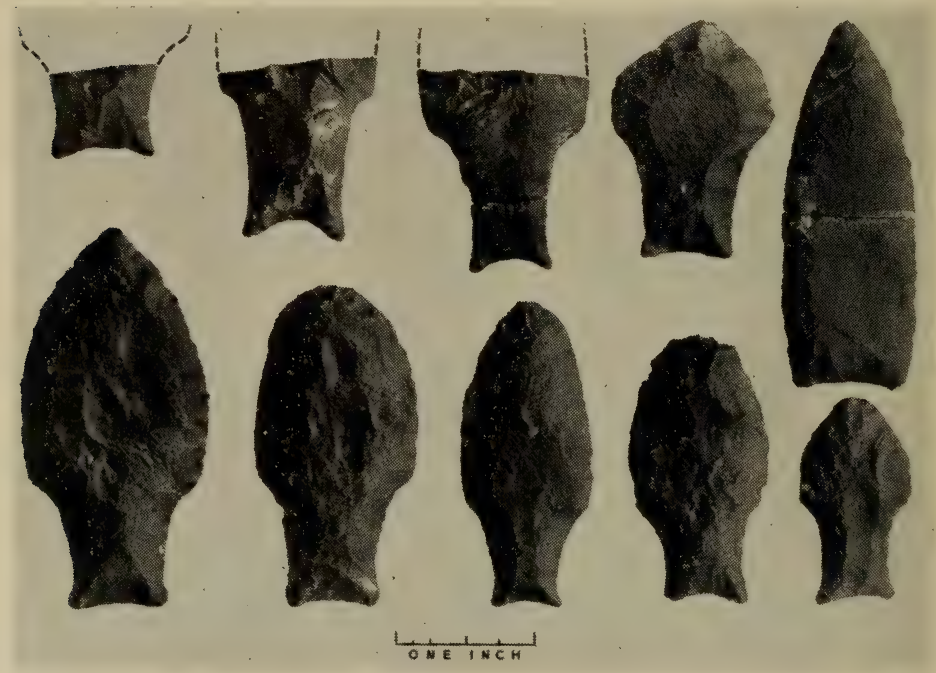

Fig. 2. Stemmed points associated with extinct animals in earliest occupation level in South Chile caves.

guanaco and of the extinct ground sloth and native American horse in the same level show that these animals were eaten in abundance. In several contemporary human burials the bodies had all been cremated. One skull, patiently reconstructed, is long headed and somewhat resembles the Lagoa Santa type. A sterile level formed of slabs which had fallen from the roof of the cave isolated the remains of this first period of occupation. In the 
second period of occupation the fossil animals were not present, but fox and bird bones were common. The artifacts were limited to a few chipped flakes and scrapers, erude bone points, and polished bone awls. The third period of occupation marked the appearance of stemless stone points and the first use of bolas, mostly small ones for hunting birds. The graves contained several skeletons covered with red paint. In the fourth occupational period, small arrowheads were present, thus demonstrating that the bow and arrow was later here than the bolas. Shell and bone beads, some incised, were used for ornaments. The final occupants made small stemmed arrowpoints, bone beads, combs, spatulas, pressure flaking tools and other artifacts, all similar to those of the Ona Indians of Tierra del Fuego. Thus these cares present a sequence of occupation from the early hunters up to the historic Ona.

Bird's excavations of shell middens on the shores of Beagle Channel also proved a relative antiquity for some of the fishing groups in southern Tierra del Fuego and the archipelago. The earliest occupants used mussel shell knives, single barbed harpoon points, bird bone beads, whetstones, notched pebhle fishline sinkers, and rough stone choppers or hand axes. The technique of pressure flaking stone artifacts was completely lacking. This is surprising for apparently bolas and the idea of using the small hafted endscrapers or flensing tools were obtained from contacts with the inland peoples at a time which would correspond roughly to the fourth period of occupation of Fell's Cave.

On the extreme north coast of Chile, Bird found additional evidence of early fishing cultures in stratified shell middens near Arica, Pisagua, and Taltal. 
This showed that long prior to the introduction of agriculture people had been able to survive on this desert coast by depending on the sea for food. Two distinct periods of occupation were determined. The first, designated as the Shell Fishhook culture after the most distinctive artifact, contained composite fishhooks with stone weights and bone barbs, harpoons with detachable forepieces, bone barbs, stone points, small lava bowls, and a variety of scrapers (Fig. 3). The occupants of the second period used bone fish harpoons, thorn fishhooks instead of the earlier shell hooks, sinkers, bolas, chipped stone points, and spear-throwers. In spite of the suggestion of some writers these north Chilean coastal cultures are unrelated to those of Patagonia.

The association of extinct fauna with some of these finds suggests certain antiquity. Bird also made a series of calculations in southern Patagonia in order to estimate antiquity. One set, based on the rise of land level in relation to the sea, revealed a land rise of two and a half feet in historic times. Using this as a criterion for finds on still higher beach levels, he estimated eighteen hundred years for the earliest occupation of the early shell midden and about fifty-one hundred years for Fell's Cave. These estimates do not appear to be extreme, and, considering the location of these finds in the southernmost part of South America, it is not unreasonable to assume that the first land nomads arrived elsewhere at a considerably earlier date.

There is little direct information about succeeding migrations, although small groups presumably continued to enter South America over a long period of time. The earliest fossil finds correspond to the long-headed physical type. However, the higher 


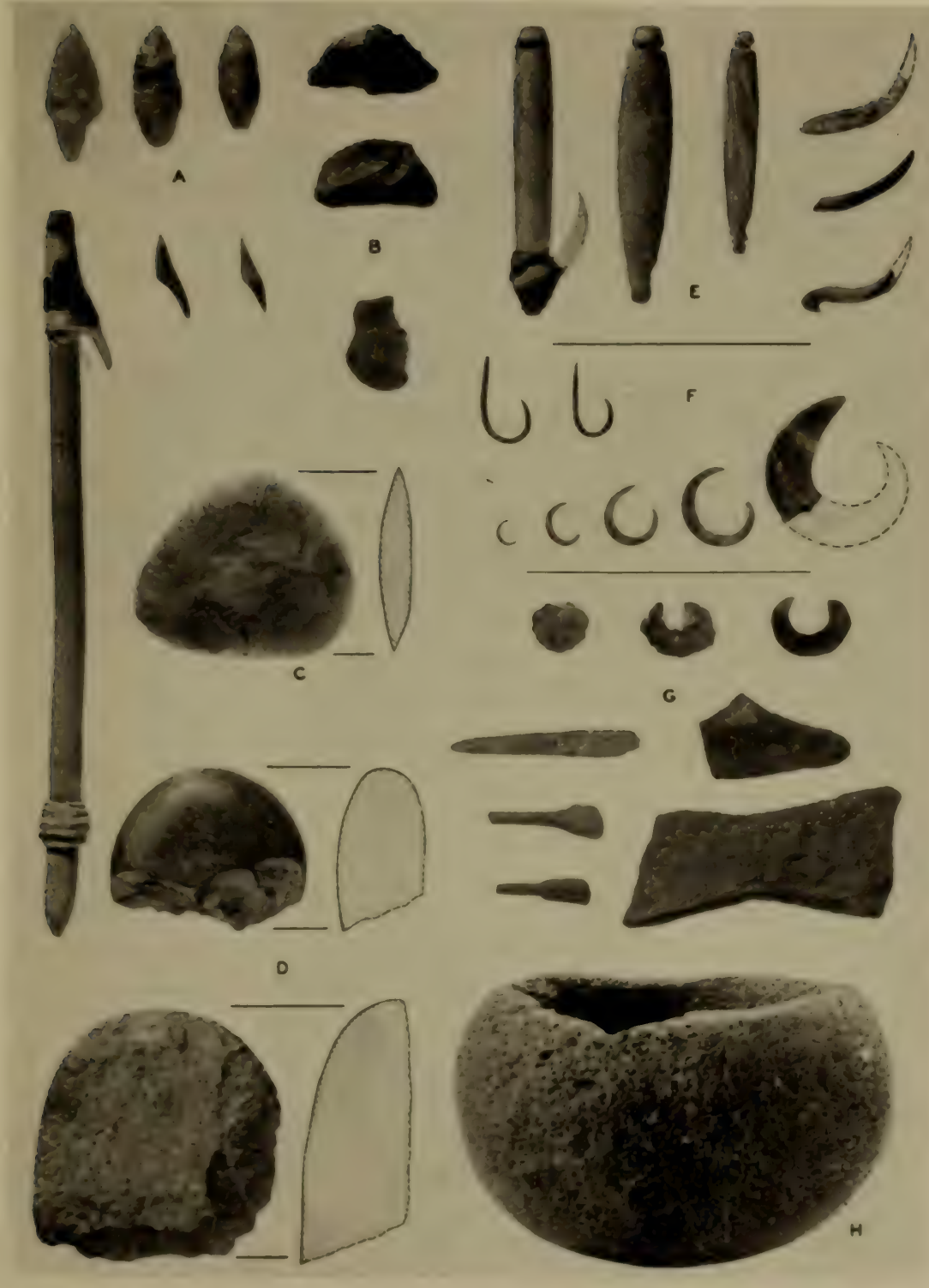

Fig. 3. Artifacts of oldest known coastal culture from northern chile. a, Harpon forepiece, points, and barlos; b, stone seraping tools; c. Stone knife; d. Choppers (?); $e$, Stone, hone, and shell composite fishhooks and harhs: $f$, Thorn and shell hooks; g, Stages in making shell hooks and the tools used; h, Stone bowl. 
civilizations in both Middle and South America are represented by a short, round-headed physical type, implying more recent migrations. Likewise the wide spread of food plants and other elements common to the higher civilization throughout large parts of the Americas, as well as the known penetration of Arawaks and Caribs into the West Indies from South America, all indicates that migrations in one direction or another were a continuing pattern.

\section{Plant Domestication}

The hunting-gathering culture pattern persisted in southern South America up to historic times, but the other two major South American patterns were dependent upon the domestication of plants and the development of agriculture. The plants domesticated in the New World, except for the gourd, and perhaps cotton, are seemingly indigenous species for the greater part not related to those utilized in Asia or other parts of the Old World. This then poses the problem of determining the New World center or centers in which various plants were domesticated, a problem which involves the technical knowledge of the botanists and the archaeologists. Formerly, it was believed that three of the more important New World plants, maize, beans, and squash, were first domesticated in Mexico and spread as a unit from that center. Recent botanical work casts considerable doubt on this theory and suggests, instead, a South American center of domestication not only for maize but for many other plants. In fact, some botanists claim that all the widely distributed plants of a single species, such as maize, sweet potatoes, peppers, peanuts, manioc, and tobacco, are South American, probably lowland in origin. The 
most credible center of origin for maize is in the grasslands marginal to the tropical forest, such as the Chaco. The plants which are represented by two or more species, like squash, beans, tomatoes, and cotton, were probably domesticated independently in South and Middle America. Other plants, such as the Andean coca, potato, quinoa, and oca, seem essentially local in origin.

If we grant the concepts of multiple centers of original domestication of plants and secondary centers of intensive cultivation, it is no longer necessary to assume that the diffusion of agriculture was accompanied by mass migrations of peoples. Thus the question of precise centers of domestication becomes one of academic interest only and attention can be shifted to those regions in which intensified agriculture was the basic source of subsistence. For example, if we accept the botanical evidence that the Chaco was the center of origin for maize, we find, nevertheless, that it inspired no great cultural development in that region. But once maize was transplanted to the fertile soils of the Central Andes, it became the basis for a higher civilization.

Estimates of the time period when plants were first domesticated are very vague. A moderate antiquity is implied by the wide Now World distribution of some of the basic plants. The botanists point out that the total process of domestication could have been accomplished in a few thousand years so that there is no necessity for revising the present estimates of the length of man's residence in the New World. More speceifically, domesticated plants have been found at Peruvian coastal sites which contain no evidence of pottery. Since pottery sequencess have a long range, this implies a respoctable an- 
tiquity for the domestication of plants on the relative time scale for this region.

Table 1 lists the principal pre-Columbian domesticated plants in Andean South America. Some are particularly suited to the warmer lowlands, others grow best in the highlands or in the sandy desert regions. Most of these plants were cultivated in the Central Andes wherever the local environment was favorable. The range of local environments, plus a systematic exchange of food products, provided the ancient inhabitants of the Central Andes with a wider variety of domesticated food plants than were available to any other peoples of South America.

\section{TABLE I}

Principal Pre-Columbian Domesticated Plants in the Highland Area 1

Seed Crops

Common Name Botanical Name

Occurrence

Maize Zea mays

Lupine

Lupinus tauris

All areas

Quinoa

Chenopodium quinoa

Highlands

Cañahua

Chenopodium pallidicaule

Highlands

Amaranth Amaranthus sp.

Highlands

Highlands

\section{Beans}

Kidney

Scarlet runner or ayecote

Lima

Jack
Phaseolus vulgaris

Phaseolus multiflorus

(or coccineus)

Phaseolus lunatus

Canavalia ensiformis
General

Cauca River

Coast

Coast

1 Based on Table 1, Handbook of South American Indians, Volume 2, The Andean Civilization. Bureau of American Ethnology, Bulletin 143, Washington, 1946. 
TABLE I-Continued

Fruits

$\begin{array}{lll}\text { Aroeado } & \text { Persea Americana } & \text { Tropical } \\ \text { Pacai, guaba } & \text { Inga edulis } & \text { Tropical } \\ \text { Pineapple } & \text { Ananas saticus } & \text { Tropical } \\ \text { Soursop } & \text { Annona muricata } & \text { Lowlands } \\ \text { Pepino } & \text { Solanum mauricatum } & \text { Temperate }\end{array}$

Roots

\begin{tabular}{|c|c|c|}
\hline Potato & Solanum tuberosum & Chile Coast \\
\hline Potato & Solanum anidgenum & Highlands \\
\hline Oea & Oxalis tuberosa & Highlands \\
\hline Elluco & Cllucus tuberosus & Highlands \\
\hline Mashua & Tropaeolum tuberosum & Highlands \\
\hline Achira & Canna edulis & $\begin{array}{l}\text { Coast; temperate } \\
\text { valleys }\end{array}$ \\
\hline Arracacha & $\begin{array}{l}\text { Arracacia xanthorrhiza } \\
\quad \text { (or esculenta) }\end{array}$ & Temperate valleys \\
\hline Yacon & Polymnia edulis & Temperate valleys \\
\hline Sweet manioc & Manihot utilissima & Tropical lowlands \\
\hline Peanut & Arachis hypogaea & Lowlands \\
\hline \multirow[t]{2}{*}{ Sweet potato } & Ipomoea batatas & Tropical lowlands \\
\hline & Miscellaneou & \\
\hline Gourd & Lagenaria & General \\
\hline Squash & Cucurbita maxima & General \\
\hline Peppers, a ji & Сарвісит аппит & Merlium elimates \\
\hline $\begin{array}{c}\text { Cacao, ehoco- } \\
\text { late bean }\end{array}$ & Theobroma cacao & Low valleys \\
\hline Cotton & $\begin{array}{l}\text { Gossypium hirsutum } \\
\quad \text { (var. marie-galante) }\end{array}$ & Tropical Coast \\
\hline \multirow[t]{2}{*}{ Cotton } & Gossypium barbadense & General \\
\hline & Nareoties & \\
\hline Tobaceo & Nicotiana tabacum & General \\
\hline Tobaceo & Nicotiana rustica & Highlands \\
\hline Coea & Erythroxylon coca & Warm valleys \\
\hline
\end{tabular}

Domesticated animals, with the exception of the dog, were unknown in most parts of South America. The guinea pig had a wide Andean distribution, but 
was not of major importance. In the Central Andes, however, two animals, the llama and the alpaca, were domesticated at an early date, presumably from wild forms related to the guanaco and the vicuña. The llama and the alpaca contributed greatly to the Central Andean economy since they grazed on the high grasslands which could not be used for agriculture. Both animals were not only useful for transportation but furnished wool, meat, hides, fertilizer, fuel, sinews, and even bones for making tools. Unlike many domesticated plants that are adaptable to different environments, the llama and the alpaca were largely restricted to the terrain of the high dry grasslands which include the Central Andes and parts of Northwest Argentina.

By the time of the European conquest of South America, three major culture patterns had emerged: one still based on hunting and gathering, the other two on agriculture. A semi-nomadic agricultural pattern was developed in the tropical forest region, while in the Andes the intensive farming permitted a sedentary life. These three basic patterns are briefly summarized in order to provide a cultural setting for the more detailed treatment of the Central Andes which will follow.

\section{Southern Hunters}

Roughly in the year 1500 all of southern South America and most of the east Brazil highlands were occupied by Indians who were basically dependent on hunting, fishing, or gathering for their subsistence. Among the better known tribes are the Alacaluf and Yahgan of the Chilean archipelago, the Ona of Tierra del Fuego, the Tehuelche of Patagonia, the Puelche and Querandi of the Pampas, the 


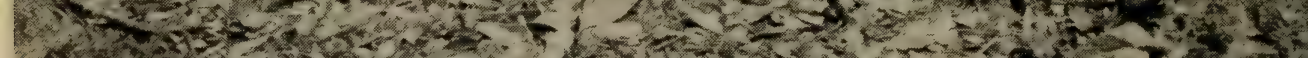

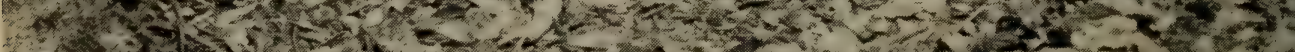

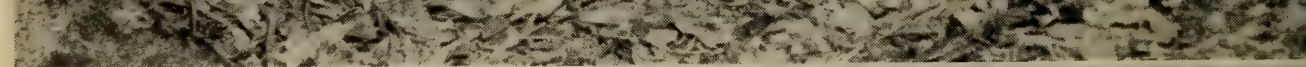

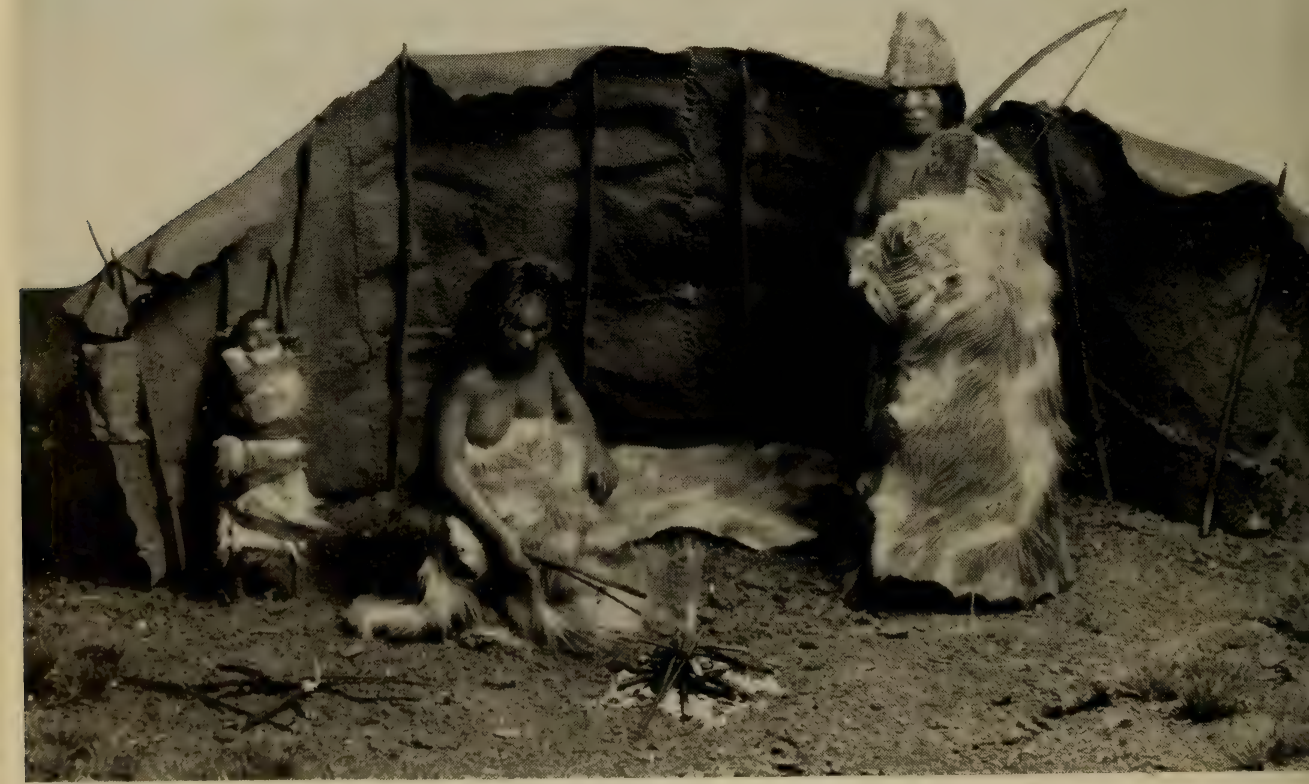

Fig. 5. Alacaluf dome-shaped hut and Ona windbreak. Models in the Museum. 
house covering had to be carried on the back. With introduction of the horse, houses became more elaborate. Canoes, used only in the archipelago, were constructed of three cigar-shaped pieces of beech bark sewn together and held taut by split saplings which served as thwarts and gunwales. Sod and earth fireplaces were built in the bottom of the canoe. The women propelled the canoes with wooden paddles.

Despite the rigors of the climate, the Southern Hunters wore very simple clothing. The Ona male costume consisted of a cape, moccasins, and rarely, leggings; all of which were made from guanaco skins. A headband was worn for decoration rather than warmth. The Canoe Indians made similar clothing of sealskin, but their capes were much shorter than those of the Ona, so that they could be worn in the canoes. Both groups greased their bodies for protection against the cold and sometimes added simple painted designs for ornamentation. In east Brazil, where the climate was more genial, no clothing was worn, but considerable attention was paid to body painting, to lip and earplugs, and innumerable varieties of feather ornaments.

The material equipment of all of these nomads was limited to utensils and implements easily transportable or easily manufactured; their handicrafts can in no sense be called elaborate. Fire was made with a hand drill, except by the Ona and the Yahgan, who were unique in Sonth America in using flint and pyrites. They also used simple stick fire tongs for moving hot stmes, hammerstones, and a stone on which animal bones were broken so that the grease would coagulate. The Canoe Indians made bark bailing buckets, dip nets for fishing, and five types 
of baskets. Their principal tools were bone bark removers, hafted shell scrapers, bone awls, and pumice stones for polishing. The Ona seldom made baskets, but used skin bags to carry water, for storage, and to transport necessary equipment. They also used hafted stone knives, fleshers, wood scrapers, awls, pressure flakers, and polishers. Virtually all of these tools were needed to make their bows and arrows. The latter were beautifully finished, tapering at each end, and were perhaps the finest arrows made by any group in America. The equipment of the Patagonians was equally simple, although they had, in addition, stone mortars for grinding seeds, and possibly made wooden bowls, cups, and spoons. Even in east Brazil, where the life was less nomadic, material equipment was meager. The neighboring Amazonian tribes made hammocks, mats, wooden stools, cloth, and pottery, but none of these penetrated into east Brazil. Instead, the people of this area made simple mortars and vessels of wood and bamboo, bark bags and nets, and one type of waterproof basket.

In Patagonia and extreme southern South America, social organization was based on family units that were loosely organized into territorial bands. The Yahgan recognized five districts, not politically organized but differing slightly in dialect. Large assemblages of people for any purpose were rare because of the limited food supplies, and territorial chiefs, if recognized at all, were of secondary importance. The life erises of birth, marriage, and death were family affairs surrounded by extremely simple ritual. Only the puberty initiation involved a number of families. The Ona restricted this ceremony to boys, combining it with initiation into the 
men's secret society. The most elaborate Tahgan ceremonies were puberty rites for both boys and girls and those comnected with the men's secret society which they borrowed from the Ona. A distinctive lodge was constructed for these occasions. The novices were isolated, given special instruction, and subjected to specific ordeals to test their fitness for the transition from childhood to adulthood. The older men dressed in skin and bark costumes decorated to represent chosen spirits that were supposed to terrify the women:-

Recent studies in east Brazil report a more elaborate type of social organization, although its antiquity is still unknown. Modern villages, of circular or U-shaped plan, have as many as three hundred inhabitants, but inter-village organization is weak or non-existent. Within the village the members are assigned to different halves, or moieties, for the purposes of regulating marriage, performing ceremonies, and competing in games. The divisions differ for each purpose. For example, the Canella Indians have one division for regulating marriage. A child belongs to his mother's group and must marry someone from the opposite moiety. Another dual division for ceremonies functions during the rainy season. All boys go through a prolonged initiation ceremony which takes about ten years for completion. Each group of initiates belongs throughout life to his age class and the various classes are assigned to one of two groups for competition in games. There are also six men's societies, semi-secret in nature, again arranged in two sets of three each. All of these divisions and societies perform seasonal ceremonies, own property, and compete in various ways. The village recognizes 
one or more chiefs, but the chieftaincy is a position of prestige rather than real power.

The ceremonies of east Brazil are intimately associated with religious rituals and concepts. Elsewhere the religious beliefs and practices of the Southern Hunters were simpler. Most tribes recognized a supreme god and numerous lesser deities such as the spirits of the forest and ancestral ghosts. Medicinemen and sorcerers, men who had received special inspiration as well as formal training, were important. They cured the sick, cast evil spells, and predicted weather changes, employing special paraphernalia and such devices as going into a trance, singing, fasting, and posturing to achieve their goals.

Contact with European civilization caused profound changes in these hunting groups, eliminating some, strengthening others. The horse was introduced some time before 1700 to the Indians of Patagonia, increasing their mobility and effectiveness in hunting and permitting larger numbers to assemble. Warlike tendencies emerged and leadership became important. Foreign equipment, including such trappings as saddles, bits, spurs, and stirrups, was also introduced; new techniques of working metal were learned; and many other new items hitherto unknown. After the introduction of horse transportation, the simple skin houses were enlarged so that as many as forty or fifty guanaco hides formed the cover. The size of camps increased to include two or three thousand inhabitants. Ceremonies, particularly those surrounding birth, puberty, marriage, and death, became far more elaborate. The tribes now engaged in stealing cattle and raiding border settlements. The history of Indian wars in 
Argentina is similar to the history of warfare on the plains of the Cnited States, and the Indian threat was not eliminated finally until 1880 .

\section{Tropical Agriculturists}

The culture pattern of the Tropical Agriculturists is characterized by semi-nomadism, the slash and burn method of clearing fields, the psychological importance of hunting, fishing, and warfare, a weak political structure based on band organization, and a number of distinctive crafts. By 1500 this basic pattern was widely distributed over most of the tropical forest, which includes the tropies of Brazil, eastern Bolivia, Peru, Ecuador, and Colombia; the llanos of Venezuela; most of the Guiana Highlands; part of the east Brazil highlands; the West Indies; and the Caribbean and Pacific coasts of Colombia. A few tribes in the tropies do not conform to this pattern which suggests, although by no means proves, that it may not have been the earliest in the area. Some of these simple "underlying" tribes are the Maku on the Japurá River, the Warrau on the delta of the Orinoco, the Sirionó of eastern Bolivia, and the Shiriana on the Venezuelan-Brazilian border.

The complex network of tropical rivers permitted a great mobility for canoe travelers and consequently a wide cultural diffusion, but, in spite of this, too much cultural uniformity would not be expected in so rast an area. Some of the differences are due to diversity of cultural origins; others are based on linguistic, geographic, and cultural factors. For example, there are three widespread linguistic stocks-Carib, north of the Amazon; Tupi-Guaraní, south of the Amazon; and Arawak, peripheral; but 
along the eastern margin of the Andes are a large number of small linguistic stocks which suggest that before the spread of the major ones the linguistic picture was complicated indeed.

The basic culture pattern of the Tropical Agriculturists, irrespective of subdivisions, contrasts with that of the Southern Hunters and the Andean Farmers. Consequently, a generalized picture is presented here, allowing for regional variation where necessary. Because of their great number, the selection of specific tribes for illustration is difficult. However, the following have been chosen for special emphasis: the Wapisiana, Macusi, and the Barama River Caribs of the Guianas; the Goajiro of Venezuela; the Tupinamba, Tapirapé, and other Guaraní groups of Brazil; and the Bora, Witoto, Campa, Yagua, Jívaro, and Chama of the upper Amazon.

From an objective point of view, agriculture was the principal economic basis for life in the tropical forest, but the Indians placed greater emphasis on hunting. Except for the heavy labor of clearing the fields, agricultural work was left to the women. Religious and magical practices surrounded hunting rather than planting. As a consequence, agricultural techniques were not too advanced and because of the wasteful methods, fields were utilized for a few seasons only. The villages were moved at regular intervals, although this practice was motivated by the diminishing of the game supply rather than by the exhaustion of the fields. The fields were cleared by the slash and burn technique. The larger trees were cut down and the underbrush burned. Then the seeds were planted, using a simple diggingstick which also served as hoe, shovel, and rake. Manioc was the principal crop, but corn, sweet po- 
tatoes, yams, peppers, peanuts, beans, and cotton were important. Little effort was expended on cultivation, so that harvesting was the next major activity.

The bitter or poison manioc, or cassava, common throughout Brazil, contains hydrocyanic acid which has the advantage of supplying the plant with its own insecticide, but must be removed. The process and equipment for preparing bitter manioc are similar wherever it is grown. The tubers are soaked in water, peeled with shell scrapers, and grated on a special curved board with projecting points of wood or stone. The grated pulp is then placed in a long narrow cylindrical basket with a loop handle at each end. One loop is hooked over a branch of a tree, the pulp squeezed by means of a log lever in the lower loop, and the poisonous juice drained into a jar. Later, it is boiled until the poison has evaporated and the residue, now in the form of tapioca, is served as a sance. The dried pulp is taken from the squeezer, mixed with water to form a batter, and cooked on a large eylindrical clay platter into cassava pancakes. Corn and some other foods are placed in large $\log$ mortars and ground with extremely long wooden pestles. In eastern Bolivia, food was ground with a wooden rocker in a hollowedout trough mortar of wood.

Hunting, as previously stated, was perhaps of greater psychological than economic importance, but it consumed a major part of the men's time and attention and brought considerable prestige. The principal animals, none too abundant, were deer, tapirs, pecearies, monkeys, birds, and several local rodents. The hunting weapons were a long bow, arrows with specialized points for different game, 
wooden paddle clubs with sharpened edges, spears, and blowguns. The Guiana blowgun was made of a section of bamboo tubing covered with pitch and bound tightly. The upper Amazon blowgun consisted of two pieces of chonta palm, grooved on the inside for the bore, and bound together with bast (Fig. 6). The mouthpiece was of carved bone.

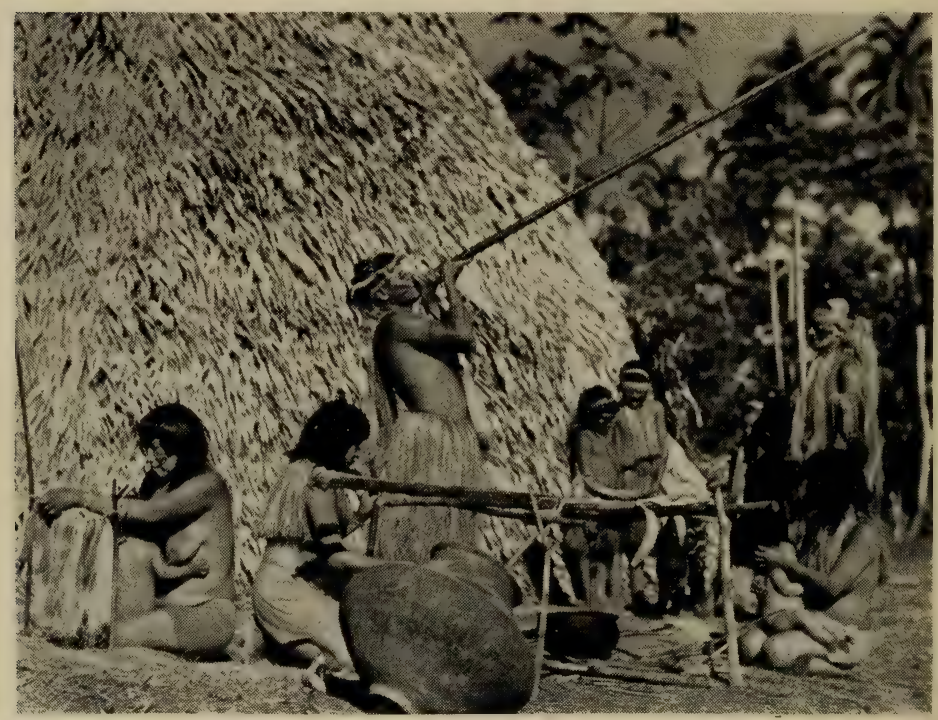

Fig. 6. Yagua scene showing use of blowgun.

Courtesy of Dr. Paul Fejos.

The blowguns were about eight feet long. The standard equipment for the blowgun included a bamboo quiver for the supply of split palm darts; a gourd full of tree cotton to be used as a wadding on one end of the dart; the jaw of a piranha fish, the teeth of which are sharp enough to cut a groove near 
the point of the dart; and a clay jar of curare poison. Only specialists trained in the proper magical ritual were permitted to prepare the curare poison which was an important article of trade. The strychnine element in curare produces a paralyzing effect on the game but does not permanently poison the meat. Traps were also used in hunting and included spring bows, spring nooses, deadfalls, pitfalls, and nets. Dogs, the only domesticated animals, were specially trained for hunting.

The rivers of the tropies abound in fish; these were shot with bow and arrows, harpooned, or speared. Weirs were constructed and many kinds of basketry traps were known and some groups used dip nets. The most widely used technique was to dam a stream and poison the fish. Many varieties of effective poisonous plants were known. Wild plants supplemented the food supply. Over twentytwo plants and edible fruits, of which palm cabbages and nuts were most important, were collected by the women who also gathered honey, birds' eggs, and shellfish where available.

Fish and meat were grilled over the fire, but the basic dish was the pepper pot, a stew of the available meat and vegetables. Some foods were dried or smoked, but in general little attention was paid to preserving for storage, due in part to the scarcity of salt, itsolf an important article of trade. The firedrill and basketry fire fan were part of the standard equipment. Most forest tribes prepared mildly intoxicating drinks from fermented cassava bread or from the local fruits and also used several nareoties. Tobaceo, the most important of these, was rolled into cigars, chewed with lime, taken as snuff, or, in liquid form, snuffed up the nose through tuhes. Most of 
the tobacco was used in connection with ceremonies, particularly those of initiation.

Although the tribes changed locale from time to time, a village might be occupied for two or three years and the houses were correspondingly durable. All houses were constructed of log frames covered with thatch, and, in spite of considerable variation in detail, conformed generally to two types. One, the round house, had an outer circle of upright wall posts connected to a tall center pole by crossbeams. The conical roof thus formed was thatched with grass or palm leaves. This type of house was common south of the Amazon and in the Guianas. The second type, the maloca, had a rectangular groundplan outlined with short wall posts, a central ridgepole, and a gabled roof. The ends might be bowed outward to form an oval groundplan. The roof extended almost to the ground and was closely thatched as a protection against rain and wind. House walls might be left open or filled in with bamboo splints, bark, or poles covered with wattle. In some regions the houses were sealed tight to guard against mosquitoes. The floor was of packed clay. Each house had an entrance at either end, one for the women, one for the men and their guests. Some houses were large, others small, the size depending in part on the type of village. Three main village plans were followed: the barnyard type, consisting of a number of small houses without special alignment; the Guaraní type, with regular streets flanked by large houses; and the upper Amazon type in which the village consisted of one large house. Some of the last-mentioned houses had a groundplan one hundred fifteen by seventy-five feet and a height of thirty feet.

The hammock, a common article of household 
equipment, was made of palm fiber or cotton, either woven on a true loom, or netted. Some tribes of the upper Amazon built platform beds of split palm poles set on a frame raised from the floor. Wooden stools, with either two or four legs, which might be carved in animal form were used everywhere. Other household equipment was part of the craft tradition. Many types of palm leaf baskets were woren, including openwork carrying baskets, telescope storage baskets, work baskets of various shapes, and square baskets with fitted covers. Palm leaves and reeds were also-used in plaiting manioc squeezers and sieves, fire fans, fish traps, and crowns for feather headdresses. Fish nets, net bags, and hair nets were made of bast fibers, twisted on the thigh. Pottery, used everywhere, was either painted in geometric designs or decorated with modeled lugs. The main forms were plates, bowls, cooking pots, big platters, storage jars, and large burial urns. Weaving had a wide distribution although it was not alwars of major importance. Both cotton and palm fibers were spun on a supported spindle or rolled on the thigh. A frame loom was used to weave hammocks, bolts of cloth for clothing, headbands, bags, and similar articles. The techniques were competent, but not unusually complex. In eastern Bolivia and elsewhere, bark cloth was made from the inner bark of certain trees, soaked and pounded with wooden clubs or flat stones. The bark cloth was painted and used for dance masks and ceremonial costumes. Many artifacts, mortars, pestles, stools, drums, clubs, bows, platters, and bowls were made from wood; bark ressels were common; and bones and teeth were used to make a number of imple- 
ments. Stone tools were rare, metals infrequent, and dressed skin work unusual.

The manufacture of many of these articles was usually a village specialty. In a limited area the people in one village made pottery, in another they prepared calabashes, another basketry, another blowguns, another poisons, etc. The finished products were then traded by private informal barter or gift exchange; but this practice did not result in regular markets, middlemen, mediums of exchange, or formal trade. Still, this exchange system provided each village with a reasonably wide selection of craft products. The quality and versatility of craftsmanship was relatively high, but it led neither to the formation of craft guilds nor to any particular emphasis on the individual artist. Likewise, wealth and property concepts remained undeveloped.

Boat building was also a village or tribal specialty. Of course, all groups made simple rafts by lashing logs together, and some authorities consider these the oldest form of water transportation in the area. The log dugouts, the most widespread type of watercraft, required exceptional skill in manufacture, especially those used for ocean travel which were up to sixty feet long and capable of carrying from thirty to sixty men. Large trees were felled by fire and ax, chopped and trimmed to the desired size, and the interior burned out with controlled fire. Both the outer and inner sides were then scraped to the proper thickness and thwarts inserted. The paddles were of wood with a crutch handle and a long thin blade. Bark canoes were also widely used. A large piece of bark was cut from a tree in the shape required. The ends were turned up and the ribs and thwarts inserted. Some bark canoes were forty 
feet long and could hold thirty persons. In contrast, land transportation was of minor importance. Paths were eut through the forest and log or twisted
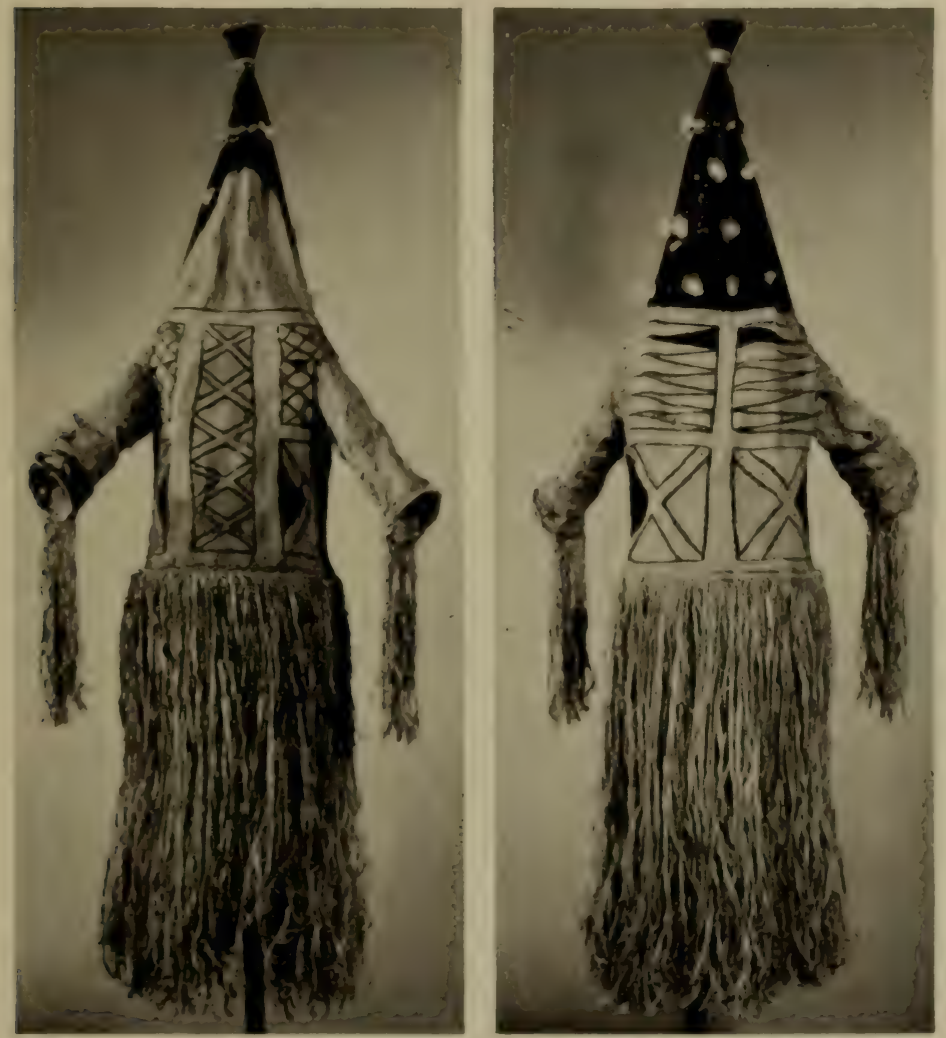

Fig. 7. Ceremonial barkeloth costume from western Mrazil.

cable bridges were built for crossing small streams.

In most parts of the tropies, clothing was restricted to the simplest genital covering. An exception to this rule was found in the upper Amazon 
where, due to Andean influence, loin cloths, belts, and slit neck shirts were worn. Everywhere, however, ceremonial costumes were more elaborate than the ordinary dress (Fig. 7). The use of ornaments and body decoration compensated in part for the paucity of clothing. Ligatures were bound tightly around the upper arms and the ankles, giving a distorted appearance to the limbs. This practice was followed for magical increase of strength rather than for beauty. Heads were deformed by means of tightly wrapped boards in the upper Amazon area. Most groups tattooed their faces and arms, and some filed or blackened their teeth. Lip plugs, earplugs, and noseplugs were made from stone, shell, and wood. Grease paint was used on the body, not only for decoration on ceremonial occasions but also for protection from insects. Each tribe had a distinctive style of hairdress; all used combs made of palm splints bound between two wooden bars. There were many types of feather ornaments. Feathers were attached to basketry hats and sewn on woven bands for back hangings, arm pendants, and aprons. Capes had a net base to which feathers were attached. The Tupí glued feathers on their bodies with honey. Beadwork aprons were common, and necklaces were made of jaguar teeth and claws, stones, shells, seeds, beetle wings, human teeth, and bird bones. Quite apart from their aesthetic value, these ornaments indicated distinctions of sex, age, and position; designated tribal affiliations; and furnished magical protection for the wearers.

Subsistence activities and material culture were more or less uniform throughout. There were, to be sure, some differences in details and emphases, 
but no startling contrasts. The social, religious, and political organization, on the other hand, was far more variahle. The village was the basic social unit, and its members were usually loosely united by kinship ties. The villages varied greatly in population, but the maximum figure was probably around the six hundred reported for the Tupí. It is difficult to establish the minimum because of the common practice of a larger village absorbing one that became too small to function. Most villages were composed of several enlarged families, with relationship traced through either the mother or the father. These enlarged families occupied a single house within which each of the component families had its own fireplace and sleeping quarters. However, many activities, such as house building and group hunting, required the cooperation of all the village members.

Each village had a chief who sometimes acquired considerable power through his ability as a war leader. However, permanent political organization rarely extended beyond the village itself. Even though many members of two villages might be related, kinship did not outlaw internecine fighting. Common language helped to unite a number of villages, but the unity was informal. Several Jivaro villages might unite for a time under a single chief, but they had no name for this larger political group. Everywhere a powerful village might dominate a weaker one, but such fitful unity lasted only until strength was regained by the subject people.

Perhaps as a reflection of the intimacy of the village life and the numerous social and kinship relationships, events in the individual life cycle were treated as public affairs. Birth was an occasion for 
public celebration. The whole village saw to it that the parents observed the proper taboos, particularly the widespread custom of the couvade, in which the father, not the mother, goes into confinement and receives the visits of his neighbors. Soon after birth the child was named, an important event supervised by the magician or medicineman. At puberty, girls were isolated for several days, forced to observe special food taboos, and instructed by the older women. A change in style of hairdress or facial tattooing signified that they had completed the ceremony. Boys were subjected to certain tests before being admitted to full adult tribal status. In one of the more drastic of these ordeals reported for the Guianas, a wickerwork frame which contained many wasps was placed on a boy's bare back. When simultaneously stung by these insects, he was expected to show no sign of pain. Marriage was not celebrated with great ceremony since it was usually prearranged by the parents, according to standard rules of the village. Death, on the other hand, was an occasion of grave concern for all the community since the ghosts might return, a circumstance avoided by abandoning the house, performing wild dances, mutilating the corpse, building fires on the grave, and participating in complex purification rites.

Warfare, one of the curses of Amazonia, played a large role in hampering cultural advancement. Motives for aggression were numerous, including plunder, revenge, and individual prestige for the warrior. Some groups sought trophy heads, others wanted prisoners for their cannibalistic practices. Even the non-aggressive tribes were forced to take measures in their own defense. The weapons for 
warfare and hunting were interchangeable, except for the blowgun, which apparently was ineffective in fighting. Protection was a major consideration. Consequently, many villages were situated well back from the rivers, were approached by hidden paths, and might be further protected with palisades, reinforced outer walls, sentry boxes, and watch towers. Pitfalls withøoisoned stakes and spring traps were placed along the open approaches. In northern Amazonia, log signal drums were used to summon aid and warn friendly neighbors. The war spirit was drilled into the boys from early childhood, not only through specific instruction in fighting, but also through tales of the honor and prestige to be gained by becoming a full-fledged warrior.

As mentioned before, some warfare was inspired by the desire for trophy heads which not only brought great prestige to the taker, but also transferred the ghost power of the victim. Carefully preserved and decorated trophy skulls were commonly collected, but the Jivaro Indian tsantsas, the shrunken heads, are probably the best known trophies (Fig. 8). The Jívaro warrior tried to obtain his enemy's head so that it could later be skinned and shrunk for a trophy. Only heads taken in formal warfare with established enemies were recognized. The residents of neighboring villages who frequently were actually relatives were often the traditional enemies. It was a violation of custom to allow the head of a blood relative to be shrunk, but the killer was permitted to substitute a sloth or monkey hearl. The heads were prepared before the war party returned to its home village. The process took about twenty hours. A slit from the top of the head to the base of the neck facilitated 


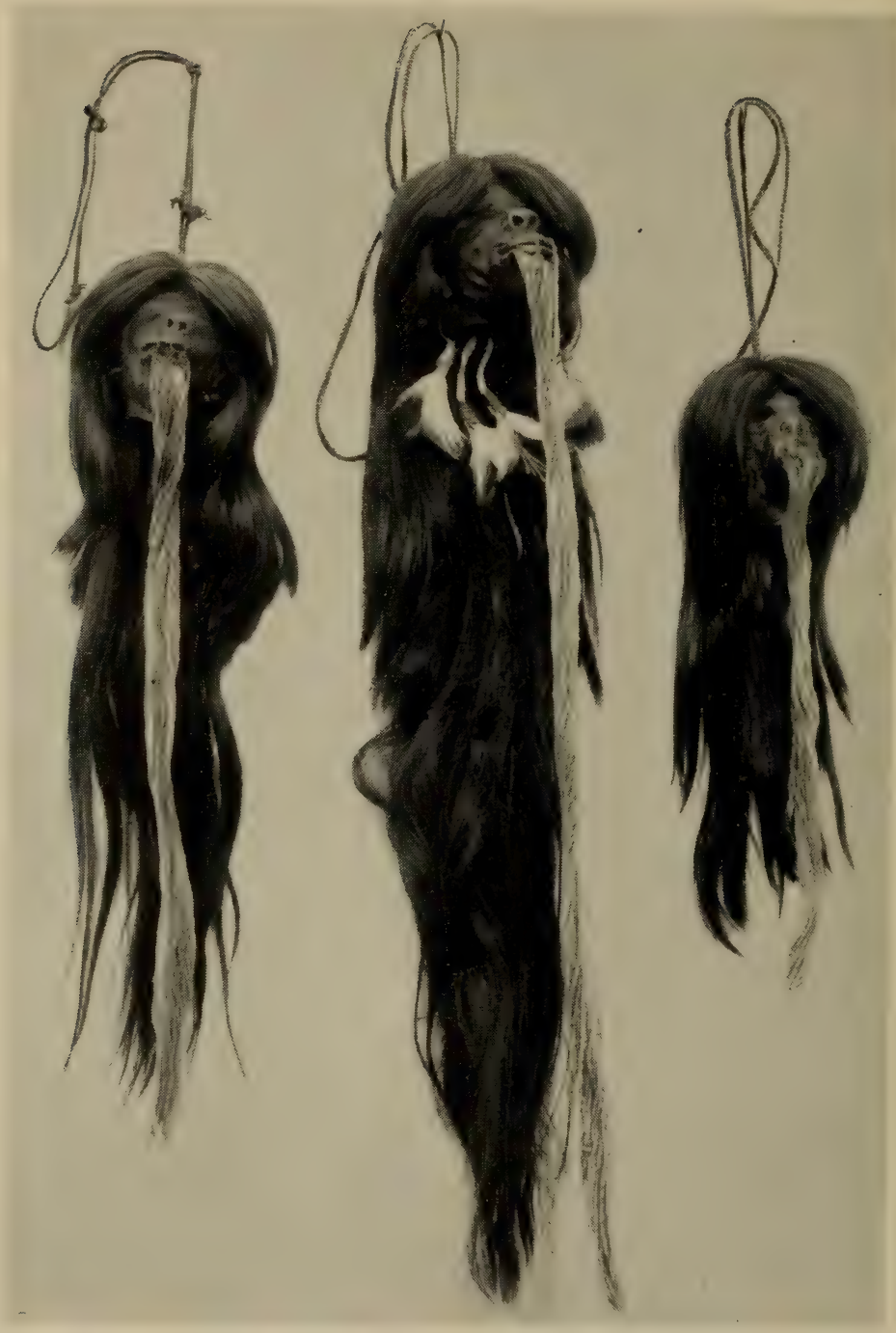

FIG. 8. Shrunken human trophy heads from the Jiraro Indians. 
the removal of the skin from the skull. The slit, the eyes, and the mouth were sewn so that the skin formed a bag which was then simmered but not boiled in a vine juice solution that contained some tamin. Next, round stones were heated and rolled inside the skin bag, and hot sand was poured in at intervals. The outside was ironed with hot stones. This repeated scorching process reduced the skin to about the size of a doubled fist. A ring was then sewn around the neck and a suspension cord inserted through the top. Finally the trophy was smoked over a smudge for final curing. When the warriors returned to their village, they were received in a triumphal entry which was succeeded by elaborate ceremonies, intended to purify the killer and to transfer the power of his trophy head to him. Later, the slayer himself gave a victory feast at which the purification rites were repeated and the transfer of enemy power completed.

Not all tropical forest tribes were cannibals. However, some, like the Witoto and Bora of the upper Amazon and the Tupinamba of the Brazilian coast, were ardent practitioners. Tupinamba cannibalism has been recorded in some detail. In every battle the warriors attempted to take prisoners alive in order to bring them back as slaves until the time arrived for their sacrifice. The prisoners were forced to do menial tasks and were frequently insulted verbally, but otherwise they were well treated and even permitted to intermarry with their captors. Dressed like other Tupinamba, they were distinguished only by a cotton rope around the neck or by a string of heads representing the number of months preceding the day of sacrifice. Prisoners never attempted to escape, even though they were 
not closely guarded, since it would be a great disgrace for them to return to their own villages. A ceremony of several days' duration preceded the execution. The prisoner was painted black, decorated with feathers, and was even forced to escape and be recaptured, thus giving prestige to still another warrior. Finally, the victim was led around the village, secured by a rope around his waist, but otherwise free to repel attacks, until, still fighting, he was killed by a selected executioner. The orgy of eating his barbequed flesh was enjoyed by men, women, and children alike. The skull was cleaned and placed on a pike set on the village stockade. The executioner went through a long period of purification.

The Tropical Agriculturists had numerous ceremonies, but these were not calendrical, reflecting their lack of interest in the agricultural seasons. Instead, ceremonies were coincidental with such irregular occasions as baptism, house-warming, death, or the return of a war party. All such celebrations presented a mixture of social and religious elements, but in general they were gay affairs, involving beer drinking, singing, animated dancing, and distinctive costumes and ornaments. The music was furnished by split log or skin-headed drums, flutes, panpipes, trumpets, and rattles.

As suggested by the social nature of the ceremonies, the religious practices were not very formalized. The Indians were strongly animistic, with a belief in many nature demons, ghosts, and good and evil spirits, but none of these was arranged into a complex hierarchy. Cults were rare although some groups had secret religious societies, but none of these was led by formal priests. The medicine- 
man, however, was prominent both as a curer of sickness and a sorcerer. He was carefully schooled by older members of the profession and taught a kinowledge of herbs, rentriloquism, and the methods of attaining a state of trance. This last ability involved taking strong nareotics, such as tobaceo juice, which induced visions and, according to belief, allowed the spirits to speak through the medium.

Centuries of European contact have changed these tropical forest Indians. Some have been eliminated, others have been driven from their original territory, but none has escaped modification of culture principally through the acquisition of European trade goods. A few have maintained their independent culture patterns by the simple device of retiring still deeper into the vast Amazonian jungle.

\section{Lowland Archaeology}

It is difficult to determine the antiquity of the Tropical Agriculturists' culture pattern because of the paucity of archaeological information. The Lake Valencia region in northern Venezuela and the Orinoco River basin are the best known areas, but even here chronological studies have barely been initiated. The few known sites in Amazonia are widely separated and none has been scientifically excarated. In the southeast, including parts of Brazil and Argentina, there have been minor excavations in sites with simple incised ceramics, but no great antiquity is claimed for these. It seems significant that no pre-agricultural or pre-ceramic sites have yet been reported. Some of the more important ceramic sites are briefly discussed.

In Venezuela, the archarological sites of Farly 
Ronquín and Los Barrancos on the Orinoco River and La Cabrera near Lake Valencia are considered to form a fairly early group. All these are village habitations with burials in pits rather than in urns. Griddles, open bowls, and plates are the most characteristic pottery shapes, although there are also a few narrow-mouthed containers. The ceramics are well made, highly polished, and decorated by monochrome painting in solid color areas, broad line curvilinear incision, red-on-white polychrome design, and modeled, bimorphic ornamental lugs. These vessels are stratigraphically earlier than another group represented by Late Ronquín, Arauquín and Valencia. The ceramics of this second group are more crudely constructed, but shapes are more varied. Polychrome painting is replaced by a monochrome red slip. Incised decoration occurs in narrow lines forming rectilinear patterns. Some pieces have anthropomorphic designs in low relief, but appliqué fillets, both modeled and incised in animal form, are more common. The burials are typically in large clay urns. Numerous mounds are located on the old lake bed around Valencia. The lower occupational levels in these mounds contain evidence of lacustrine dwellers. Later, mounds were artificially built up over these lake-dwelling sites and used as house foundations and for burial. The Venezuelan evidence shows that the Tropical Agriculturists pattern was established well before the European conquest, but there is no indication of extreme antiquity.

Three widely separated archaeological sites along the Amazon have certain common characteristics. On the first of these, on the island of Marajo in the mouth of the Amazon, about one hundred mounds 


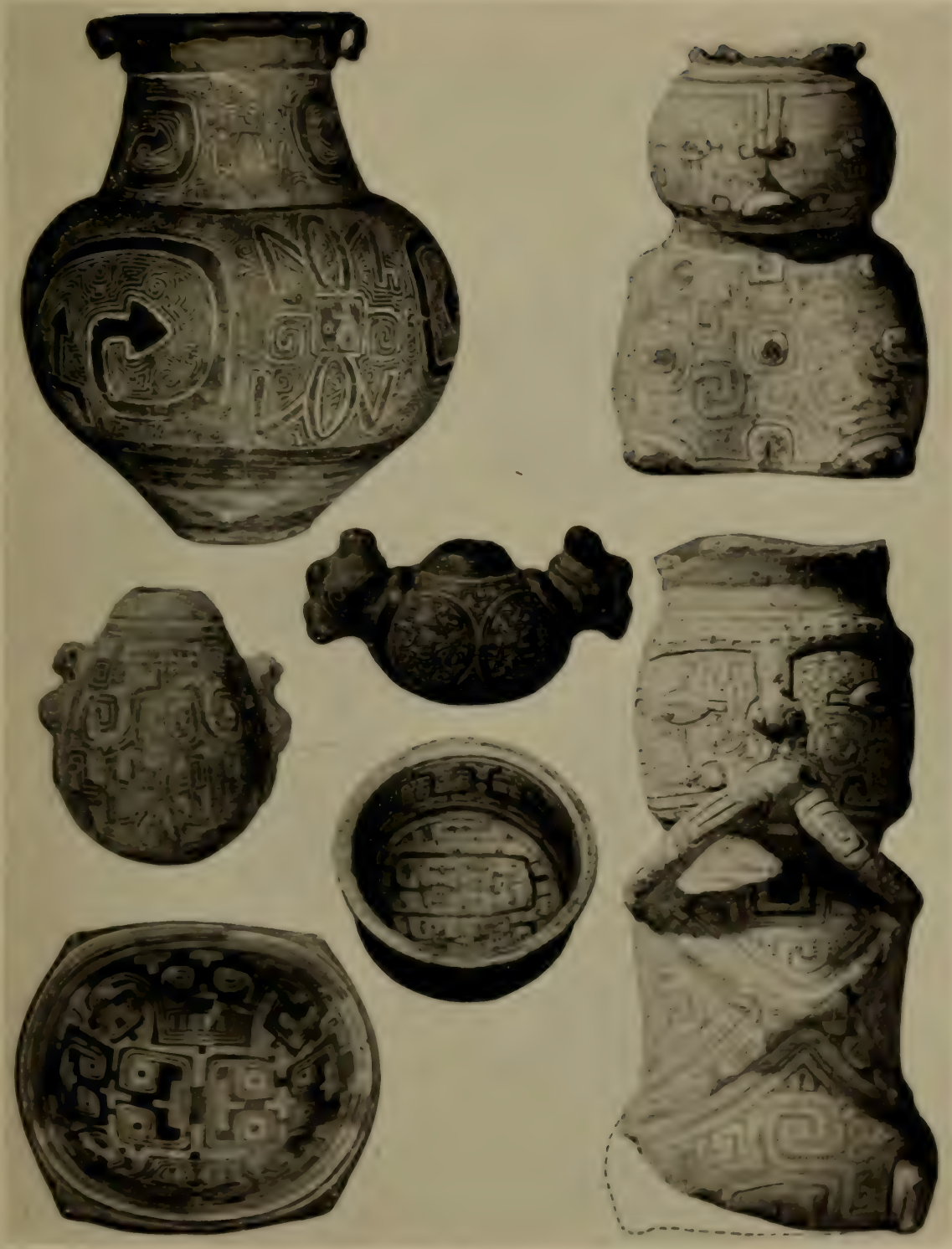

Fig. 9. Maraji pottery showing different types of incising and painting. 
have been reported. These contain urn burials and quantities of broken pottery. The distinctive ceramic shapes are large constricted mouth jars, open

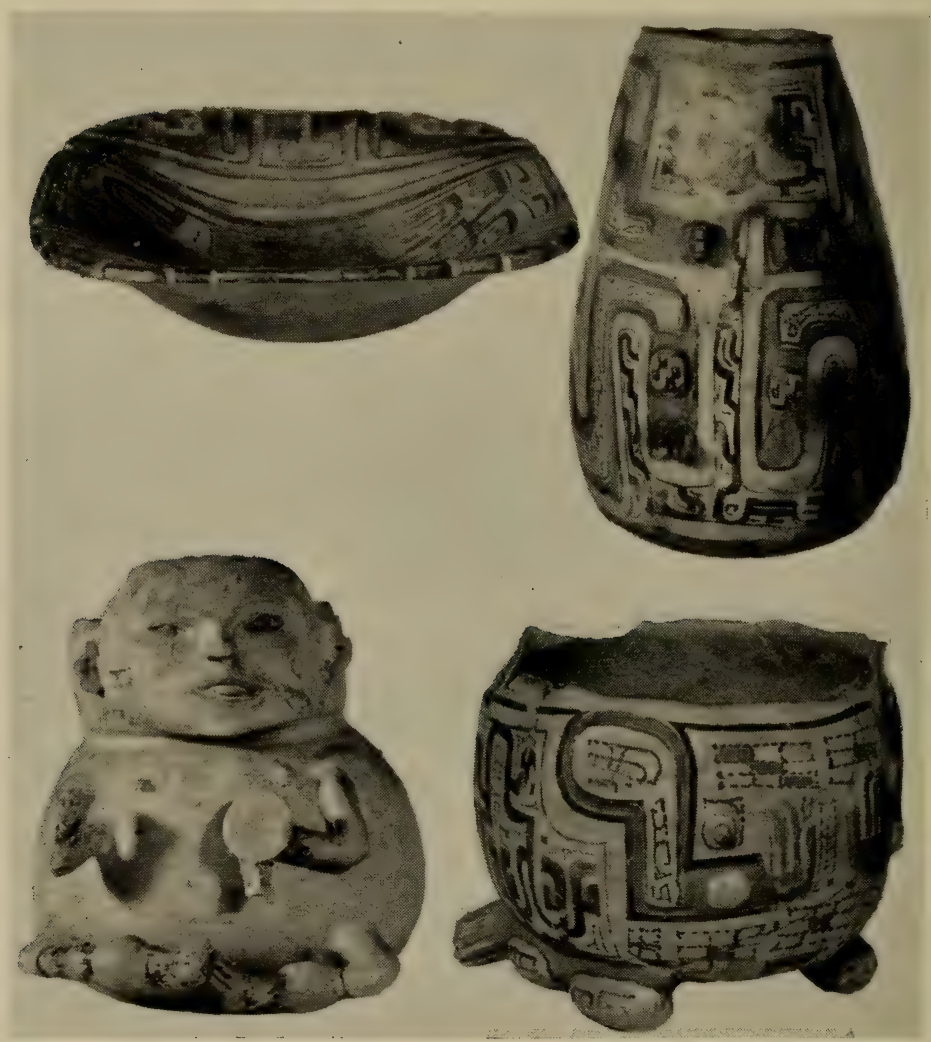

Fig. 10. Río Napo urns and platter.

bowls, bell-shaped jars, platters, and urns (Fig. 9). A broad classification of types of decoration presents seven groups : plainware; plain, incised; incising filled with paint; whiteware with incision; white, 
incised plus red retouch; champleve; and polychrome painted red, brown, and white. All the designs adhere to a pattern of alternating broad and fine lines in which straight and curvilinear elements contrast sharply. Trms have anthropomorphic low relief design. Figurines and decorated whorls are also found. Systematic excavation would undoubtedly permit the chronologieal separation of some of these styles. The second site, Mirakanguéra, is on the middle Amazon at the mouth of the Madeira River. Here bowls and effigy urns have been found. The head of the effigy figure is on the cover of the urn; the limbs are represented in low relief; and the urns are further decorated by incised and painted rectilinear designs. The final site, on the Río Napo in eastern Ecuador, again has bowls and anthropomorphic urns. The urns have relief features, but the limbs are modeled as separate appendages and are banded in a fashion suggesting ligatures (Fig. 10). The decoration combines broad incisions with black, red, and white polychrome painting to form patterns of alternating broad and narrow lines. In brief, these three Amazonian sites all have effigy urns with covers decorated in somewhat similar patterns in relief, modeling, polychrome painting, and broad line incision.

At Santarem, at the junction of the Tapajoz and the Amazon, the style of ceramies is quite different. There are many variations on the basic shapes of open bowls, open mouth jars, and constricted neck vessels. Most ceramies are not painted, but are elaborately ornamented with modeled lugs and other appended elements resulting in one of the most exotic styles yet found in South America (Fig. 11). A few pieces with more realistic modeling are 


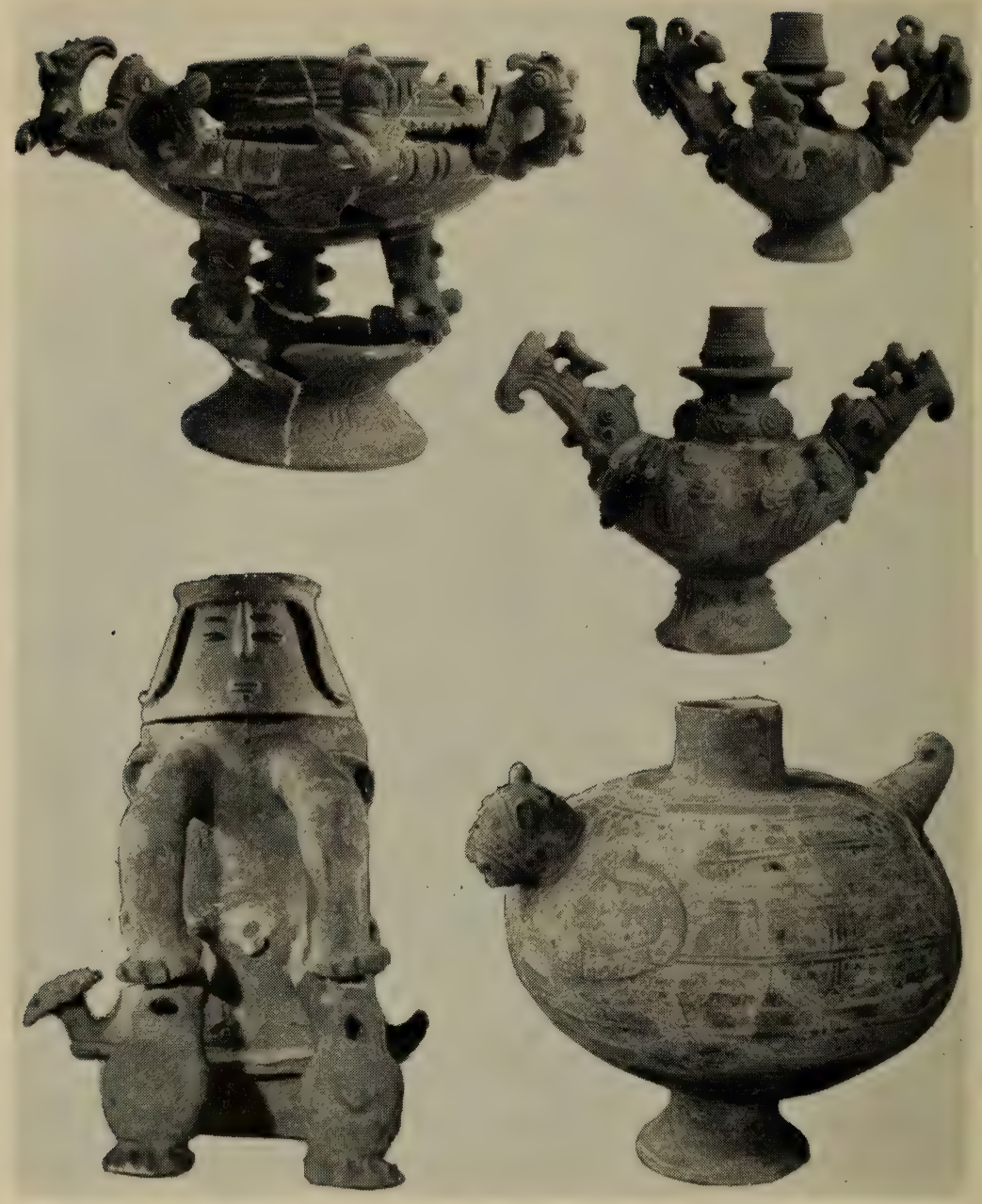

Fig. 11. Santarem vessels and figure urn from Maracá. Courtesy of Belem Museum (Santarem) and Museo Nacional, Rio de Janeiro. 
painted in black, white, and red geometric designs, suggesting the Recuay style of Highland Peru. Although a few pieces may be old, the bulk of the material seems more recent than the Amazon effigy urn group described above. Anthropomorphic urns continued to be made well into the historic period, as illustrated by those found with glass bead bracelets at the site of Maraci in the Brazilian Guianas. At Mojos, in the eastern Bolivian tropies, stratified habitation mounds have been excavated. The earlier levels contain polychrome painted ceramies, but no urns; tripod urns painted in a manner suggestive of the Amazon effigy urn group are found in the later levels.

These few known archaeological sites, although largely uninvestigated by professionals, suggest a reasonable antiquity for the Tropical Agriculturists pattern. The ancient village sites are approximately the same size as the modern ones. The archaeological burial urns and many of the ceramic shapes are similar to the modern forms, though more ornately decorated. The early modeling represents figures seated on wooden benches, with a paucity of clothing, but with the bodies decorated by painting, tattooing, and arm and leg ligatures. Spindle whorls indicate weaving. The spread of certain ceramic styles throughout large sections of the tropies suggests that the mobility pattern of the tribes is an ancient one.

Lowland archaeology will eventually be correlated with the Andean sequence and will then permit comparisons of relative antiquity. For example, the upper levels of Mojos in eastern Bolivia are elsewhere associated with a late Tiahuanaco style, and the three-color resist negative painting on some of the 
Santarem pieces seems distantly related to the Central Andean Recuay style or to the middle periods of Ecuador and Colombia. Thus, an antiquity comparable to that of the so-called "middle" periods of the Andes is implied for the Amazon sites. This would suggest that the Tropical Agriculturists pattern had existed for at least 500 years before the arrival of the Europeans.

\section{Andean Farmers}

The third major South American culture pattern was based on intensive sedentary agriculture. The pattern was distributed throughout most parts of the Andes, or, in terms of modern political divisions, the highlands of Colombia, Ecuador, Peru, and Bolivia; the coast of Ecuador and Peru; northwest Argentina; and north and central Chile. All of this area, except Colombia, formed part of the Inca Empire when it was conquered by the Spaniards in 1532, which accounts for some of the cultural uniformity. However, the Inca held this region only a short time and there is considerable evidence that the basic Andean pattern had prevailed long before. In many countries, the names of outstanding preInca tribes were recorded. The Chibcha, the most advanced tribe in Colombia, were limited in distribution to the Departments of Cundinamarea and Boyacá, roughly around modern Bogotá. Elsewhere the Colombian highlands were occupied by many small tribes, of which the best known were the Tairona of the Santa Marta Mountains and the Quimbaya, Lile, and Coconuco of the Cauca Valley. Each major basin of the Ecuadorian highlands was dominated by a single tribe, named, from north to south, Pasto, Cara, Panzaleo, Puruhá, Cañari, and 
Palta. The Esmeralda, Manta, and Puná oceupied the coastal plains. The pre-Inca cultures in Peru and Bolivia will be discussed in detail, in terms of their archaeological remains, in the second section of this volume. North Chile was held by the Atacameño, while Northwest Argentina was divided between the Humahnaca and the Diaguita. The Araucanians once occupied the whole Central Valley of Chile, but were forced southward by the Inca invaders. The Araucanians deviated considerably from the Andean Farmers pattern and were in many ways equally close to the Squthern Hunters.

The Andean Farmers based their subsistence on intensive agriculture; hunting, fishing, and gathering were definitely secondary activities. Agriculture was both a male and female occupation. The major religious ceremonies and rituals concerned the agricultural cycle. The principal domesticated plants were distributed to their full climatic limits within the area wherever they could possibly be grown. Most important were: maize, beans, squash, potatoes, quinoa, sweet potatoes, manioc, peanuts, cotton, peppers, tobaceo, and coca. The agricultural implements were simple: a digging-stick, with or without a metal point, a hoe, and a club with a stone head for breaking up clods. In spite of these simple tools, technical knowledge of planting and cultivating was well advanced. Fields were systematically irrigated; most groups not only used fertilizers, but understood the virtues of erop rotation and allowing land to lie fallow. Terraces were built to utilize hillsides and to prevent erosion. This agricultural knowledge was shared by the total population and was not the property of a few specialists.

Everywhere food preservation and storage were 
important. Drying and freezing were the principal methods of preservation, and special granaries were built for storage. Foods were prepared by boiling, toasting, roasting, and baking in underground ovens. Corn was fermented for a mild beer called chicha. In areas where the narcotic coca was chewed with lime, tobacco was of secondary importance and was used more like a medicine. Elsewhere it was smoked in pipes or taken through nose tubes as snuff. In the Central Andes, Northwest Argentina, and northern Chile, herding was second only to agriculture in importance. The domesticated llama and alpaca added greatly to the total economy of these people.

The crafts were advanced. The potters made utilitarian cooking jars, bowls, plates, and water jars for daily use, as well as elaborately decorated vessels for ceremonials and burial. Both men and women shared the work of weaving their garments on simple looms. Both cotton and wool were employed. A distinction was maintained between clothing for common wear and the superlative cloth woven for ceremonial and mortuary purposes. Utilitarian tools and fine ornaments were made of gold, silver, copper, and tin as well as in combinations of these metals in a variety of techniques, such as hollow casting, soldering, filigree, and gilding. Other craft skills were devoted to basketry, woodwork, the decoration of calabashes, and the manufacture of numerous artifacts of stone, shell, and bone. In general, each family produced its own utilitarian articles, but more skilled craft work was in the hands of specialists. Villages as well as individuals might specialize and exchange the products of their skills. In some places, fixed markets were established. 
All clothing was loom woven. The standard male costume consisted of a breechelont, belt, slit neck shirt, shawl, and headband. The women wore a wrap-around garment secured at the waist by a belt, a headband, and a shoulder shawl. Woven bags with carrying straps were a constant part of the costume. Hore elaborate costumes were made for religious and ceremonial occasions and for interment. Body painting, tattooing, skull deformation, earplugs, noseplugs, necklaces, and many other types of ornaments were elaborated and often distinguished people of different rank, profession, or tribe.

On the whole, water transportation was only slightly developed. Simple rafts and reed balsas were used on Lake Titicaca and on the coast of Peru; more elaborate rafts were built on the north coast of Ecuador. The Araucanians were exceptions, and made large dugouts and plank canoes. Elsewhere, more attention was paid to land travel, on foot, and with llamas and alpacas as transport animals. The widespread Inca Empire was united by a network of roads, bridges, and wayside inns for the traveler.

Intensive agriculture resulted in a relatively stahilized food economy and the consequent support of large permanent populations. Houses were built accordingly. In the Central Andes the commonest building materials were sunbaked adobe and stone. The tribes of Ecuador and Colombia constructed round frame houses with conical thatched roofs. The side walls were either of stone or clay lined. Plank houses were huilt by the Araucanians in Chile. The village which consisted of a number of houses formed an important social and cooperative 
labor unit and often held title to the real property. Each village had a chief or headman, and usually its own religious cult. The households represented several closely related families who were united as a village by affiliations of residence alone. The Andean Farmers pattern was characterized by political organization of the village units. The complexity of this political superstructure varied: in many places it assumed the form of a confederacy and among the Inca it became a true state or empire. Both within the village and in the political superstructure class distinctions were marked, were based on wealth and leadership, and tended to crystallize into true caste systems.

Warfare was well organized. The military leaders were also political figures, and the warriors constituted a specialized class. The spear-thrower, spear, club, sling, and shield were basic weapons; the bow and arrows and the bolas were of secondary importance. The war tactics involved the use of spies, blockades, storming, and formation fighting. Many villages were fortified and special forts and places of refuge were built.

Events in the life crises of the individual, birth, puberty, and marriage, were usually family affairs with little public ceremony. Death, however, involved considerable public ritual in the preparation of the corpse, the tomb, and the grave equipment. In part this was associated with the widespread practice of ancestor worship. Other public ceremonials were correlated with the calendrical agricultural cycle and were conducted by specialized priests. Medicinemen, as distinguished from priests, confined their practices to individuals and did not participate in the great public cere- 
monials. The priests were the interpreters of the formalized religion and the leaders of specialized cults. Religious centers and temples were constructed. The gods were arranged in a hierarchy and surrounded with specific ceremonies. The Araucanians were the exception to this formalized religious pattern; among them animistic beliefs, sorcerers, and medicinemen were of paramount importance.

This basic pattern existed throughout the Andean area, although in varying degrees of elaboration, since its intensity depended in large part on the availability of large areas suitable for wide scale agriculture. The European conquest initiated profound changes, eliminating, displacing, or absorbing some groups, radically modifying the cultures of all others. The modern Indian population, judged culturally as well as physically, is concentrated in certain areas. The Quechua-speaking Indians, descendants of the Inca, live in the highlands of Ecuador, Peru, and eastern Bolivia. Around Lake Titicaca are the Aymara, who successfully resisted both Inca and Spanish absorption. The Araucanians survive in the extreme southern part of the Central Chile Valley. Elsewhere the Indian cultures have been largely eliminated, although a few small groups of minor significance are still extant. The Indian of the past is rapidly becoming the Mestizo of today, mixed both in blood and in culture.

The Andean Farmers pattern is demonstrably old in the Central Andes, where sufficient archaeological work has been done to furnish the data for an historical reconstruction of development from its earliest beginnings to its culmination in the Inca Empire. Ontside of the Central Andes the evidence 
for antiquity is less satisfactory, due in part to the limited amount of recorded excavation. The Central Andean cultures seem to have been united for many centuries. Elsewhere, there was apparently greater cultural diversity. This may be clarified in a brief review of the outstanding archaeological finds beyond the boundaries of the Central Andean region. These archaeological finds are presented in terms of the major geographical divisions: the Northern Andes, which covers Colombia and Ecuador; and the Southern Andes, which includes Northwest Argentina and Chile.

\section{Northern Andean Archaeology}

COLOMBIA

Although the western mountainous section of $\mathrm{Co}$ lombia is extensive, it contains only a few regions suitable for the intensive development of the Andean Farmers pattern. The best terrain with cultivable soil and adequate rainfall is the high platean of the Departments of Cundinamarca and Boyacá where the Chibcha achieved their significant cultural development. Elsewhere appropriate flat lands and intermont basins are relatively small, with the exception of the Cauca Valley flats which in early times were too swampy or too grass-covered to be utilized by Indian farmers. The archaeological records demonstrate that the full Andean pattern crystallized late and principally in the Chibcha region. The small mountain areas developed local cultures which were comparatively isolated and had little influence on each other. At least we have no evidence for widespread organization or for any great cultural overlap from one region to another. 
The Colombian cultures are in some ways similar to those of the Tropical Agriculturists. Slash and burn clearing was practised; the circular houses were of frame construction; secondary burial in effigy urns was widespread; leg ligatures were worn; and four-legged wooden stools were used. However, the Colombian cultures are distinguishable from those of the Amazon in their great emphasis on agriculture and in their craft skills in metallurgy, ceramies, and wearing (Fig. 12). Moreover, in view of the extremely limited amount of scientific archaeological work, it is premature to draw conclusions. Many areas have never been investigated and others are known only through undocumented collections. Consequently, the archaeology must still be described in terms of the major geographic zones which present distinctive local styles. The evidence for arranging these zones and styles in any chronological order is largely conjectural.

The Chibcha civilization, in its adranced development, is frequently classified with the Inca and Aztec. Its builders occupied the most favorable plateau in Colombia. It is in this area, then, that one would anticipate discovering the most elaborate archaeological remains and the best evidence for the antiquity of the pattern. As yet, however, the archaeology is disappointing. Large village sites have not been discovered, although there are some circles of upright stones outlining the foundations of conical houses. Chibcha burials are in simple pits, either with or without stone slab covers, or in dry caves. The ceramics are not very well made. The principal shapes are ollas, pedestal bowls, and jars with either short or tall collars decorated with painted or relief faces and figures. How- 

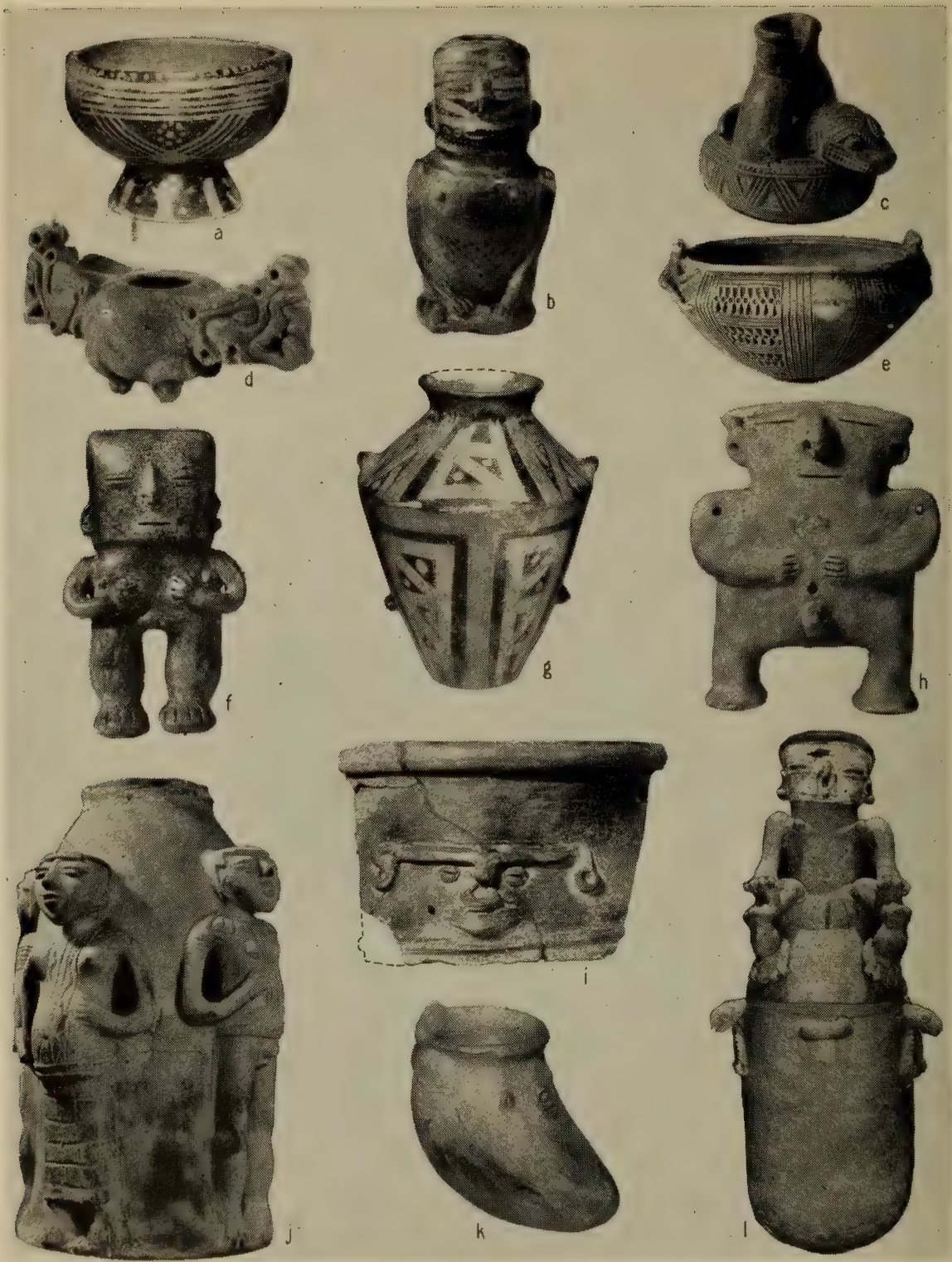

Fig, 12. Prehistoric ceramics from Colombia. a, b, e-h, Quimbaya; c, i, k, Santa Marta; j, Sinu; 1, Mosquito effigy urn; d, unknown. 
ever, most of the ressels are decorated with simple geometric designs executed by painting, incision, punch, appliqué, and, more rarely, relief. There are also elaborately decorated clay figurines, incised whorls, effigy ocarinas, clay pipes, and carved stamps. The spindle whorls and the figurine designs imply weaving. A few pieces of large rectangular cotton shawls with painted geometric designs have been preserved in the dry caves. The gold work demonstrates the control of many techniques, such as hollow and solid casting, gilding, and repoussé, although the objects themselves are not very artistic. Openwork eut-ont figures, with features and limbs made of gold wire, are characteristic. ('ut-out work was also used for diadems, crowns, and bangles. The collections also contain many utilitarian artifacts, such as stone axes, celts, and grindstones as well as wooden stools, lances, and spear-throwers. Although all of this material is pre-Spanish, it does not imply any great antiquity for the Chibcha culture.

The isolated mountain range of Santa Marta in northeastern Colombia was the center of the Tairona culture. This region is the best known scientifically, but the large collections have not been temporally subdivided although they are all believed to be pre-Spanish. Some of the Tairona sites are large villages with a great deal of above-ground stone construction. The stone masonry includes both rough stone and carefully dressed and fitted blocks. Ring house platforms lined with single or double rows of stone are typical. The houses have two entrances approached by stone slab steps. Other stone building features are faced terraces, long stairways, paved roads, slab bridges, and lined 
reservoir pits. A village consists of a number of ring houses surrounded by paths, terraces, stairs, and reservoirs. Most burials were in simple pits or in large urns, but a few were in stone-lined boxes or in dressed stone burial vaults. There are two major types of ceramics; thick redware plates, bowls, and jars with appliquéd design; thin incised blackware annular base open bowls, cups, double spout vessels, tetrapod jars, stirrup spouts, and modeled effigy vessels. Tall cylindrical "treasure" jars with fitted clay covers are also characteristic. Rarely do these have polychrome painted designs. Tairona collections abound in small artifacts. These include clay toys, rattles, cylindrical stamps, ocarinas, whistles, and small modeled figures, but, interestingly, no spindle whorls. Among the numerous stone artifacts are utilitarian metates, manos, mortars, and pestles, as well as better finished polished axes, incised batons, winged pendants, and many types of beads. Jade was used to some extent. Incised and carved objects of bone and shell are also characteristic. Beads, rings, and pendants were also made of gold, copper, and tumbaga. The Tairona culture had certainly achieved a reasonable complexity, but again evidence for antiquity is lacking.

The hills on both sides of the Upper Cauca Valley, roughly between Cali and Popayán, are dotted with small scattered house sites, again dated as preSpanish. The house platforms are simple cut-out earth terraces with a thin refuse deposit, indicating: only a brief occupation. Graves are found in or near the houses. A typical grave has a square or round shaft about one meter in diameter and some two meters deep, and a hollow side chamber en- 
tered through a slab-covered window door. Several extended burials and as many as two hundred pots may be found in a single grave. The pots, mainly open bowls, pedestal jars, ollas, and constricted mouth ressels with conical bases, seem to have been made especially for burial. They have a red slip, but no painted designs. Decoration is by incision, punch, crude scoring, and simple appliqué. Other associated artifacts are clay spindle whorls and gold noseplugs.

The ('hibcha and Tairona cultures present some evidence of complexity. Other Late period sites are similar to those of the Upper Canca, without evidence of concentrated population, large settlements, or great complexity. Because of certain stylistic analogies with Ecuador and Peru, the Nariño and Quimbaya cultures seem to be slightly earlier in time than the Late period cultures described above. In gross comparative terms these cultures may be classed as Middle period in Colombia.

The Nariño sites are in the Nariño Department along the Ecuadorian border at the headwaters of the C'auca River. No surface ruins are known, but there are both short and deep shaft graves that contain both direct and erude urn burials. The main ceramic shapes are variants of ollas, plates, and annular base bowls, all decorated in two-color positive, or in two to three-color resist negative painting. Positive designs are applied directly. Negative designs are first applied in dye resisting wax ; the vessel dipped in black dye; the wax fired off, leaving a design of the base clay color, rimmed with black. Most designs are carelessly applied broad line geometric figures, but there are some animal motifs. Among the typical associated artifacts are clay oca- 
rinas, spindle whorls, and whistles; stone chisels, celts, T-shaped axes, pounders, and grindstones; and some simple gold dises and plaques.

The Quimbaya sites are located in the Departments of Antioquia and Caldas in the Central Cauca Valley. The large Quimbaya ceramic collections include a great variety of materials which may eventually be temporally subdivided. The most typical pottery shapes are double jars, modeled containers, double spout vessels, whistling jars, tripod and tetrapod vessels, annular base bowls, tall shoulder jars, and many open bowls and ollas. These vessels are decorated in red and white positive painting, both two and three-color resist negative painting, modeling, incision, and champlevé in which the background is cut away to produce a relief design. The designs are generally simple geometric patterns. Seated and standing clay figurines, incised whorls, and a variety of decorated clay stamps are also common. Stonework is abundantly represented by celts, T-shaped axes, beads, and grindstones. The Quimbaya culture is best known for its metal work in gold and tumbaga, a combination of gold and copper. The objects demonstrate great technical skill in solid and hollow casting, cast filigree, cutouts, and repoussé. Most of the gold was worked into ornaments, such as nose rings, breast plates, bells, and bracelets, but this metal was also fashioned into hollow jars, bottles, and figurines (Fig. 13). There are gold masks for burials, and solid scepters, decorated by bands of metal of different composition. Although distinctive in many details, both the Quimbaya and Nariño cultures share such features as deep shaft and chamber graves, annular base vessels, and particularly two and three-color 

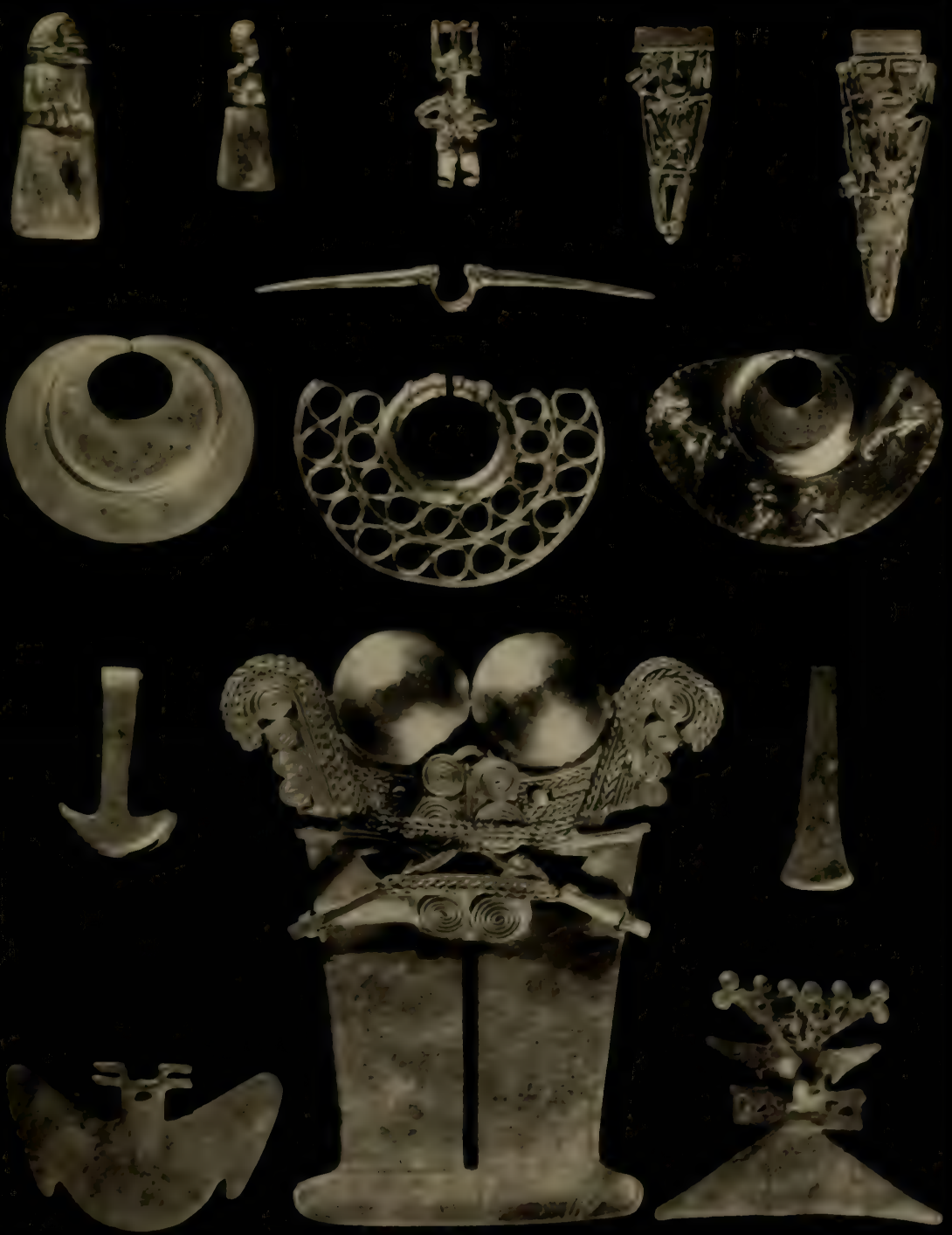

Fig. 13. Chilecha and Quimhnya goldwork from colombin. 
resist negative painting. These features also serve to link them with the middle periods of Ecuador.

Between the Upper Cauca and Magdalena rivers lie sites of the Tierradentro culture which is also classed with the Middle periods, although it may be slightly earlier than the Quimbaya and Nariño. Tierradentro culture is distinguished by elaborate painted subterranean tombs excavated directly into the soft rock of the area. A spiral stairway enters the main arched chamber which may have one or more central columns and a series of cut-out side niches. The walls and ceiling are decorated with high relief figures and with an over-all black, white, red painted geometric design. Broken pottery covers the floors but, nevertheless, the chambers seem to have been intended for burial rather than habitation. The ceramic fragments represent several styles : blackware, black-on-red painted, and incised red. Most distinctive, however, are fragments of large vessels with relief serpentine bands decorated with deep incised lines and punctations filled with a white paste. Some of these serpent-like bands end in high relief snake heads. Two crude statues were found in one of these tombs; otherwise the stone artifacts are limited to polished axes, chisels, grindstones, and beads. Gold is the only metal yet found.

The rolling forest-covered hills at the headwaters of the Magdalena River do not appear to be a favorable region either for the support of a large population or for the development of an advanced culture. Yet here are found the San Agustín stone carvings and temples that represent the earliest known remains in Colombia. San Agustín is a general designation for a series of sites in this 
rather extensive area. These are not villages nor, for that matter, even true habitation sites, but some of the sites consist of large artificial mounds containing stone-lined and covered temples and carved idols. The slabs are not well dressed, but some are painted in geometric design. Other sites are isolated, slab-lined tombs, some of which contain monolithic coffins. In other words, all of the construction work seems to have been of a religious nature. San Agustín is particularly famed for its stone carvings of which over three hundred have been found. These include bas reliefs on large boulders,

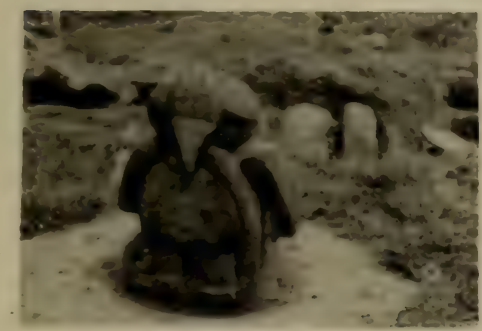

Fig. 14. San Agustín stone earvings. The face on the right is eight or nine feet high.

cylindrical stones with sculptured heads, carved animal figures, elaborately carved base rock in stream heds, and many statues, some human and some anthropomorphic (Fig. 14). The carved figures are depicted as wearing headbands, ornaments, simple clothing, and holding some object in the hands. The sculpture is well executed and highly varied, especially in details. As mentioned, some of these carvings are found in the temples, but others in isolated spots were possibly intended as grave markers. Grave accompaniment is limited. The ceram- 
ics are simple clay bowls, plates, pedestal jars, and tripod vessels, all characterized by body angularity and great rim variation. Most vessels are monochrome, but on a few, geometric designs are executed in two-color positive or negative painting, incision, and punch. Other artifacts include plain spindle whorls, simple gold ornaments, stone axes, mortars, pestles, and stone cutting tools. By analogy with the stone sculpture of Peru and Central America, San Agustín falls into the Early period in Colombia.

In spite of the impressive San Agustín carvings, there is scant archaeological evidence in Colombia for any great elaboration of the Andean Farmers pattern until relatively late times. Instead, the local cultures of each region show little relationship to those of neighboring regions. The general impression is that there was no widespread cultural unity in prehistoric Colombia.

\section{ECUADOR}

Ecuador has been investigated more thoroughly than Colombia, although there are still many untouched areas. The evidence thus far assembled indicates that the Andean Farmers pattern was well established in both the highlands and the coast and also that it has a respectable antiquity in some sections. The highlands are dominated by two parallel mountain ranges, between which lie ten large intermont basins with sufficiently rich soils and adequate rainfall for the support of intensive agriculture. The coastal plains vary from tropies in the north to desert in the south, but all sections present remains of higher civilization, at least from the immediate pre-Spanish periods. However, significant period names have not been established, except in 
a few places, and it is still impossible to set up comparable sequences for the whole country. Consequently, a review must follow the major geographic divisions. (Fig. 15.)

A Far North Highlands unit is represented in the basin of Tulcán in Carchi Province, actually the southern extension of Nariño, Colombia. Most of the archaeological finds are virtually identical with those previously described for the Nariño culture, although some Inca materials are known in this basin. The similarities occur in ceramic shapes and design, in gold work, and even in the deep shaft type of tomb. In Ecuador, as in Colombia, there is no evidence of any great antiquity for these finds. Apart from the graves and their contents, there are also circular house foundations with thick earth walls, arranged in village clusters. The roofs were probably of the conical frame and thatch type.

The basins of Ibarra and Quito in the provinces of Imbabura and Pichincha are closely united physically and culturally as a North Highlands unit distinguished by large earthen mounds. Some of these were for burials, others were foundations for houses or temples. The three commonest shapes are circular, elliptical, and squared pyramidal. The mounds contain pottery and fragments in considerable quantity, but none is particularly distinctive. Local archaeologists recognize three major culture periods: the first with burial mounds; the second lacking mounds, but with burial in direct pits; and the third with habitation and temple mounds.

The Central Highlands unit includes the basins of Riobamba and Alausí in the provinces of Chimborazo, Tungurahua, and Alausí. Here seven periods have been established, the longest known 
sequence for Ecuador. The Early period, which includes Proto-Panzaleo I and II, has house foundations built of rough stones set in mud, circular pit graves, and simple bowls, jars, pedestal base and tripod ressels. Ceramic designs are geometric and executed by incision, red and black positive, and two-color negative painting. A knowledge of agriculture is demonstrated by finds of maize, stone metates and manos. Llama bones are also associated. The Middle period, called Tuncahuán, is characterized by pedestal bowls and other shapes decorated in three-color negative painting similar to the Far North Highlands and Nariño in Colombia. The Late periods, called collectively, Puruhá, have three subdivisions, namely Guano, Elen Pata, and Huavalac, and are again associated with stone house foundations. The ceramies continue the traditions of the Early period, particularly the emphasis on incision and two-color negative painting. Applique design, however, is far more common in this period. Large face collar jars with textile-like patterns in two-color negative are characteristic. Metal work in gold and copper is found. Finally, the Inca Period terminates the sequence. This Central Highland chronology is a key series for Fenador. With the exception of the Tuncahuan interruption, it seems to represent a continuous derelopment, although possibly not of too extensive a time duration.

The large Cuenca basin covers the provinees of Cañar and Azuay and forms the South Highland unit. All the important surface ruins have been assigned to the Inca Period. An earlier occupation is, however, represented by many small habitation sites, and some remarkable grave finds with 
hammered gold plaques and ceremonial weapons, not clearly assignable to any period. The pre-Inca habitation refuse represents two major periods, Early and Late Cerro Narrío, and it seems likely that both of these will be subdivided when additional data are available. The Early Cerro Narrío is characterized by red-on-buff painted wares and by polished redwares with engraving and low relief. The late period is, in part, a continuation of the early period, but is associated with various intrusive styles, including painted clay drums. Again, great antiquity has not been established for this sequence.

Although Esmeraldas Province on the tropical north coast of Ecuador does not seem environmentally favorable to higher cultures, numerous earth mounds containing ceremonial artifacts have been reported. No time sequence has been established, nor ean the materials be accurately placed in any comparative chronology. Treasure hunters have systematically looted the mounds, searching for the amazingly fine and technically varied miniature gold objects. Copper dises or gongs with high relief, socketed axes, and hollow bells have also been found. Esmeraldas is noted for its small beautifully modeled figurines with detailed appliqué and incised designs and elaborate headdresses. Also common are clay roller stamps with carved curvilinear designs. No stone statues were made, but many axes, ring stones, polishers, and grinders have been found. The ceramic shapes include many types of ollas, wide-mouthed open bowls, and a variety of miniature vessels. Some are plain; others are covered with red slips or decorated by incision, modeling, 
and applieque. One modeled vessed represents a frame house with a sway-backed thatched roof.

Manabi Province marks the coastal transition zone between tropies and desert. Surface ruins of

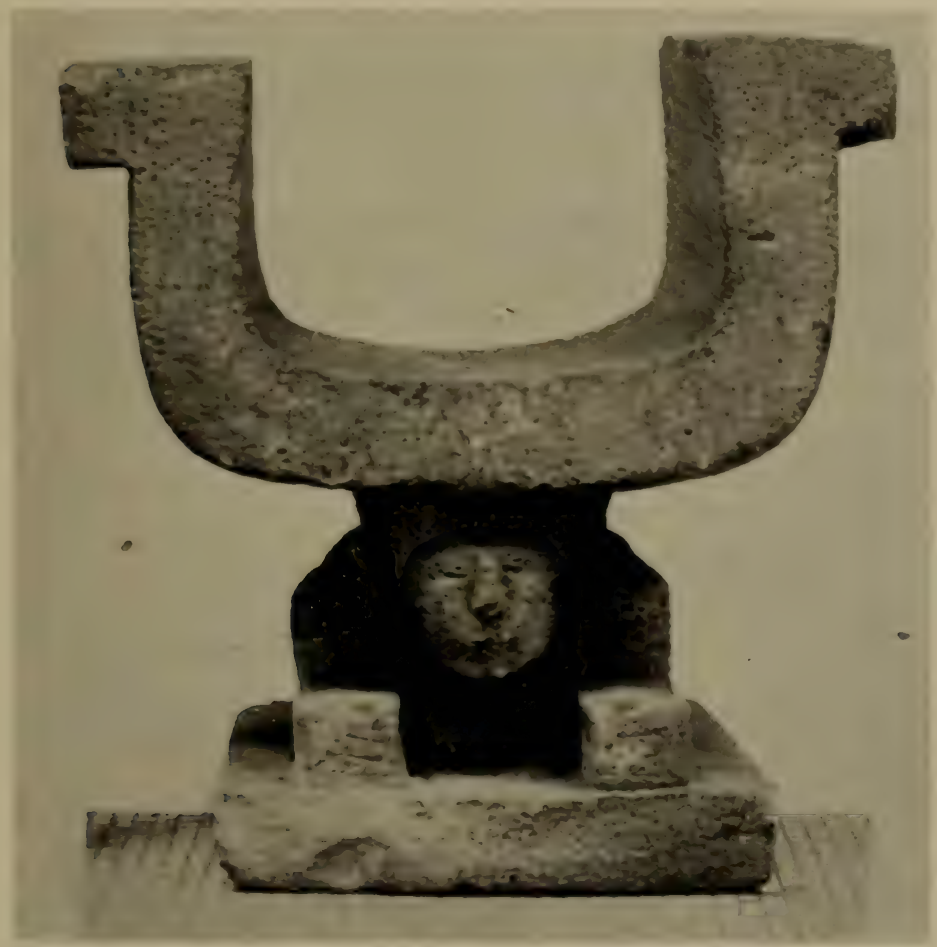

Fig. 16. Stone seat from Manabi, Eeuador.

stone-faced platform mounds and clusters of house walls are numerous. However, Manabi is most - samerl for its stonework, including unique U-shaped stone seats (Fig. 16) which rest on crouching hunan or animal figures, flat slabs with low relief, 
stone columns, and crude stone statues. Urn burial is also a feature. The ceramic forms comprise ollas, open bowls with annular bases, tripod vessels, double-spout jars, and many others. The designs are varied, ranging from rough and fine line geometric incision, two and three-color negative painting, red-on-buff positive painting, threecolor polychrome, appliqué, to modeled lugs. Clay figurines are numerous and beautifully modeled. Flat carved stamps and incised whorls are also common. The varied ceramic collection suggests more than one time period, but, as yet, significant subdivisions have not been established.

Archaeological work elsewhere in Ecuador is in its infancy. The total picture is one of local complexities and certain antiquity, but still quite distinct from the Central Andes. Some pre-Inca influences from Peru can be traced, but these are generalized rather than specific; there are an equal number of parallels with Colombia. Considered in its entirety the archaeology of Ecuador appears diversified rather than unified; on the basis of present evidence an over-all developmental sequence cannot be established.

\section{Southern Andean Archaeology}

The Southern Andes include Northwest Argentina on the east and Chile on the west. That this area, like Ecuador in the north, was ultimately incorporated in the expanding Inca Empire is readily confirmed by numerous archaeological remains. Two main branches of the Inca road system are known, one through Northwest Argentina, the other along the Pacific coast. In Argentina the roads are outlined by rows of stones, and, at regular intervals, 
clusters of small stone rooms and corrals represent the old rest houses which served the traveler. Large forts are identified as Inca through the associated ceramies. The fortified sites have rough stone room divisions with such typical Inca features as corbeled arches and wall niches. More frequent are mixed sites, such as La Paya in Salta Province, in which local styles are combined with Inca derived designs. Other common Inca artifacts are lacquered wooden keros, bronze knives, stellate stone maces, and slit bells. Many finds of the pre-Inca periods parallel, in a sense, the derelopments in the Central Andes, but with a distinctive orientation. Again, in spite of the extensive archaeological investigation, a great antiquity has not been established.

\section{NORTHWEST ARGENTINA}

Many sites in the Argentine Department of Jujuy reveal Inca influence; as many again are slightly pre-Inea. Among the former, particularly in the high puna which marks the Chilean border, the Inca, and even Colonial materials, are associated with a complex of wooden artifacts identified as the residue of the Atacameño culture. Characteristic types are wooden bells, toggles, knives, whorls, bows, arrows, tubes, and carved snuff tablets. However, the remains of an extensive pre-Inca culture, the Humahuaca, are found in the larger basins and valleys. Stone-faced agricultural terraces are numerous; villages are large and often dominated by fortresses on the higher peaks. The houses are rectangular, with stone walls but without niches. The roofs were made of perishable materials. There are also carefully built subterranean granaries. The burials in unlined pits or in stone-lined tombs contain pre- 
pared trophy skulls as well as many artifacts. Ceramies are represented by open bowls, goblets, cups, and ollas painted in black-on-red geometric designs. A few vessels have slight modeling or appliqué features. Gold, copper, and wooden artifacts are also common. The remains of the Humahuaca culture are widespread in this area, but do not extend farther south, nor, for that matter, are there any remains of the southern Calchaquí culture in Jujuy. A few finds seem to antedate Humahuaca somewhat, but none of these is sufficiently well identified to be designated as a separate period.

The other inhabitable basins of Northwest Argentina are found in the Departments of Salta, Tucumán, Catamarca, La Rioja, and San Juan. Here the first major pre-Inca period, called Calchaquí (or Diaguita), presents remains of large populations, extensive irrigation systems, stone-lined agricultural terraces, and sizable villages. The building's have rough stone walls, rectangular or circular groundplans, and roofs of perishable materials. Clusters of such rooms are arranged irregularly along narrow streets. Some rooms contain geometrically carved stone columns, which, although not statues, seem to mark religious centers. A fort is generally found on some high point near the village.

The Calchaquí adult burials are in oval or round stone-lined and covered graves, but infants and children are more generally buried in urns. In fact, child urn cemeteries are a characteristic feature of this culture. Large painted urns are the most typical ceramic form. The commonest is in the Santa María style, so named after the type site. It has a short body with two horizontal handles, a wide neck, and a flaring rim. The exterior is painted in black 
and red on a white or yellowish slip base. The collar is decorated with a face, arms are painted on the body, and the rest of the vessel is covered with geometric steps, scrolls, or serrated lines, or with designs of ostriches, toads, jaguars, birds, and snakes. Several variants of this Santa María urn type, such as the Belém and San José types, have a different geographical distribution sugesesting local cultures. Additional Calchaquí ceramic shapes are shoe-shaped vessels, ollas, and open bowls, called pucos. These ressels may be plain or painted in the animal or geometric designs found on the urns. Copper, bronze, and gold are represented by decorated breast plates, relief plaques, curved knives, daggers, and knuckle dusters. The stone artifacts are not very numerous; the few preserved wooden pieces resemble the Atacameño examples.

The Calchaquí culture seems to correspond roughly to the Tiahuanaco time horizon in the Central Andes. Several earlier cultures have been found in Northwest Argentina; of these, Barreales is outstanding. In this culture, houses are built of adobe or of rough stone and the burials are in unlined pit graves. The associated ceramics present two contrasting styles: a black or brown monochrome incised series of one-handled cups, pitchers, and rases, decorated with geometric, human, and animal figures; and a polychrome group in black, maroon, and violet, in which semi-globular vessels, goblets, and cups are decorated with a stylized curvilinear jaguar. The name "I)raconian" given this style refers to the jaguar or dragon. Other distinetive artifacts of the Barreales culture are stone arrowpoints, mortars, pestles, and particularly carved stone bowls; clay pipes with relief modeled faces 
and hollow clay figurines; gold and copper objects; and bone flutes, spatulas, and whorls. The Barreales culture is found largely in the Departments of Catamarca, La Rioja, and San Juan. North of this area it is replaced by La Candelaria culture, which is thus far represented by large, conical plain urns, a few polychrome pots, and some black incised vessels not very different from the Barreales style. Although the Northwest Argentine cultures have often been compared with those of Peru, the parallels are general, not specific. At present it is advisable to consider Northwest Argentina as a distinct culture area which reflects the Central Andean development, but is not a part of it.

\section{CHILE}

On the western slopes of the Andes, Chile can also be culturally separated into a northern and central region. The northern region, the Atacama desert, one of the driest in the world, has always had a limited occupation. Small fishing groups existed on the coast, but in the interior the only sizable habitable oasis is Calama on the Río Loa. This oasis was the center of the Atacameño culture which is characterized by simplicity and by an emphasis on llama herding as a supplement to agriculture. The villages consisted of clusters of rough stone rectangular houses arranged along irregular streets. Mummies are well preserved in this dry climate and are found in cylindrical crypts. The ceramics are characterized by open bowls, shoe-shaped vessels, ollas, one-handled pitchers, and containers with truncated conical bases, constricted necks, and two side handles. Most of the vessels are plain, but some are painted in black-on-red, or black, red-on-white sim- 
ple geometric designs. Wooden artifacts are abundant. The inventory includes carved tubes and tablets for snuff (Fig. 17), crude wooden knives, shovels, bells, whorls, boxes, toggles, spoons, and goblets.

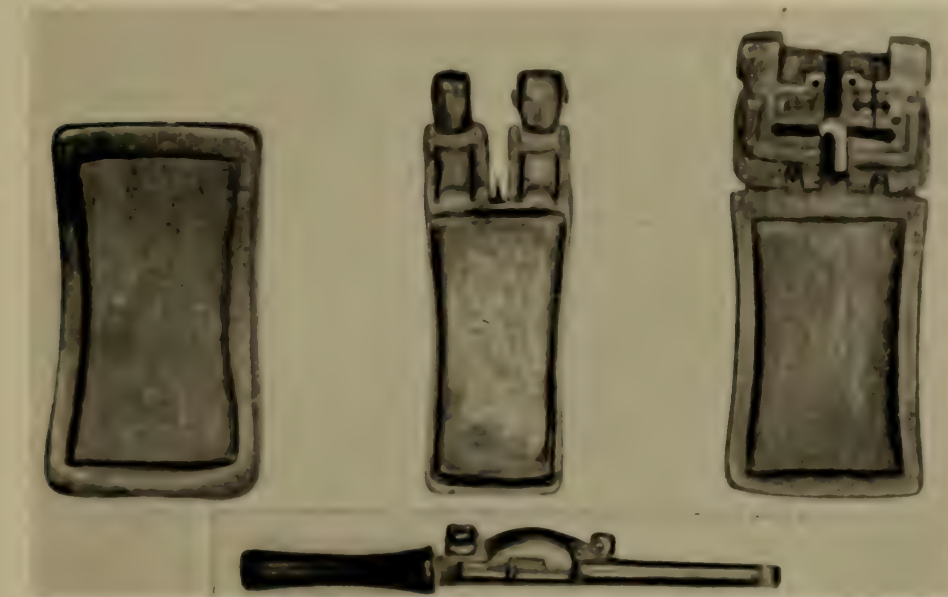

Fig. 17. Tablets and tube for mixing and inhaling snuff, Atacameño, North Chile.

Leather was used for making bags and armor. There are also coiled baskets, decorated calabashes, rather good weaving, and copper and gold objects. The Atacameño culture compares favorably with the Central Andean development, but its extreme simplicity, as well as the absence of scientific reports, makes it difficult to identify precise parallels. Furthermore, not only its subdivisions but the time range of A tacameño culture is yet to be established. For example, Tiahuanaco type burials have been found in Calama, but whether these represent a distinct cultural occupation or whether they are con- 
temporary with or earlier than Atacameño has not yet been determined.

At Pichalo on the North Coast, a pre-Atacameño culture has been isolated. It is characterized by simple, thick rim open bowls in monochrome black, brown, or red. Coiled baskets, rush mats, feather fans, and a variety of textiles are also associated. Many of the artifacts, such as stone scrapers, drills, sinkers, bone harpoons, and spear-throwers, are survivals of the earlier fishing pattern, but domesticated plants are also present. The burials are flexed, wrapped in mats, and placed in direct graves. The similarity of Pichalo to the Early Farmer cultures in the Central Andes is noticeable, but it lacks the definitive Chavín style and a truly comparable chronological position. The two pre-ceramic fishing cultures of the north Chilean coast have already been mentioned in the discussion of Early Migrants. Certainly this area has a considerable cultural antiquity as well as a long range of cultural development, the importance of which still needs amplification by additional archaeological work.

Farther south, around Coquimbo, are the remnants of the Chilean-Diaguita culture, a local parallel to the Calchaquí of Argentina. The ceramics are superior to those of Argentina and the vessels are generally smaller. This culture is too little known to permit a lengthy discussion. Still farther south, in the Central Chile Valley, the Inca expansion encountered the Araucanians, but it seems likely that these peoples had adopted many of the basic features of the Andean cultural pattern long before this time. The archaeological work which would confirm or deny this is yet to be done.

The Central Andean pattern seems, in many ways, 
more closely allied to that of the Southern than to that of the Northern Andes. This in part reflects the closer affinity of northern patterns to the Amazonian cultures, an alternative source of influence not available in the south.

This general picture of the South American setting shows that the central Andean area forms a distinct unit, distinguishable geographically and eulturally from the rest of the continent. This seems more than a mere reflection of differential quantity of archaeological work. The Central Andean pattern is old and its gross history of development is well outlined. A detailed examination of this history is next in order and forms the content of the following section. 


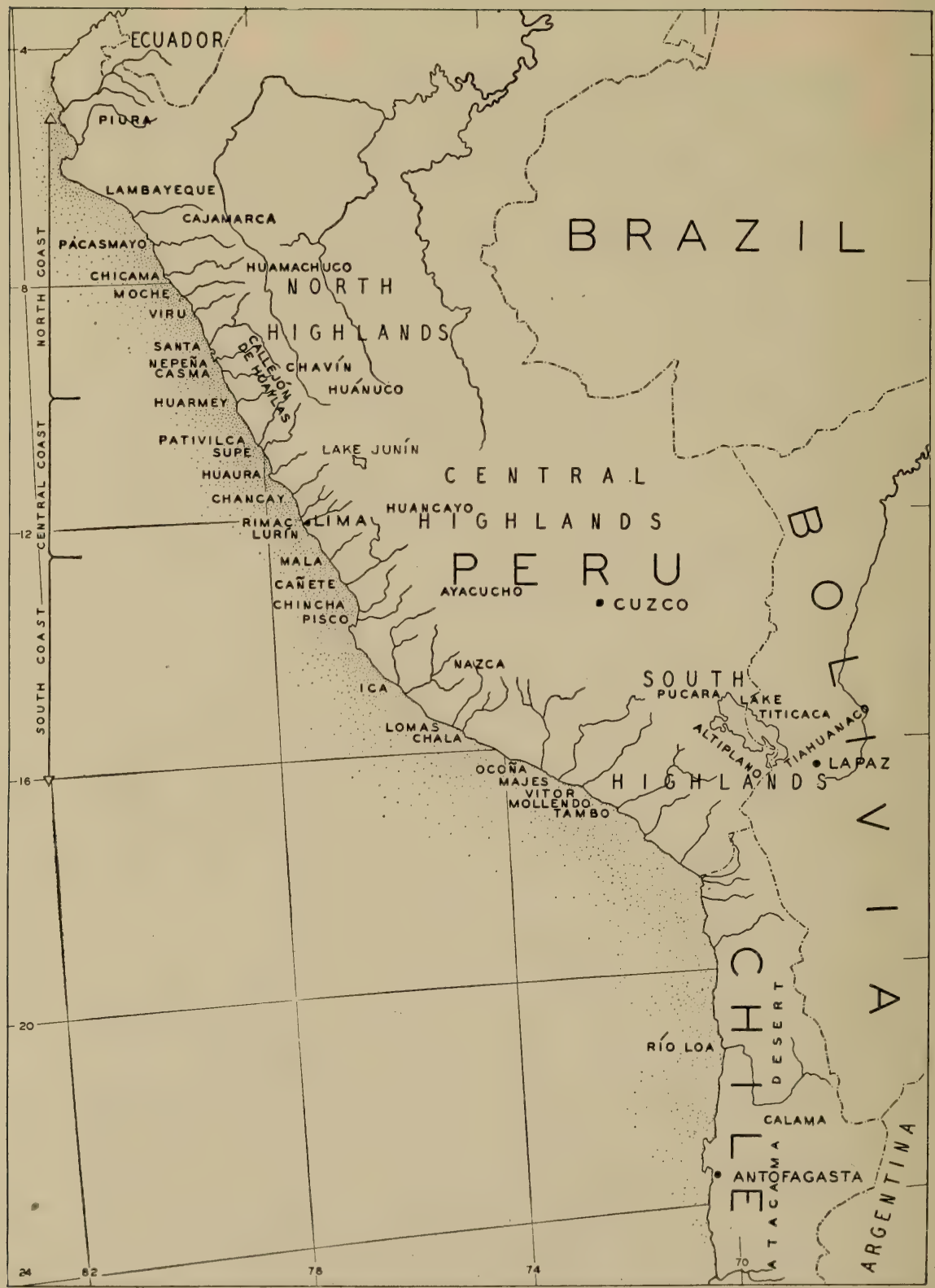

Fig. 18. Principal valleys and major cultural divisions of the Central Andes. 


\section{Part 2}

\section{THE CENTRAL ANDES}

\section{Divisions}

The term Central Andes is here used to include the mountains and desert coast of Peru and the mountains of Bolivia. In the first part of this account it was demonstrated that this area can be isolated as a cultural and geographical unit. The Central Andean culture pattern contrasts markedly with that of the Southern Hunters and the Tropical Agriculturists. While it is not so sharply distinguishable from the Northern and Southern Andes, the differences are sufficiently marked to justify separate treatment. The Central Andes also presents an environmental unity when compared with other areas of South America. At first glance, the contrast between the desert Pacific Coast and the formidable highlands seems marked, but when considered in cultural terms the differences diminish in significance. For maximum development, a subsistence economy based on intensive agriculture with simple digging-stick cultivation requires rich soils, a genial climate, an adequate water supply, and an absence of regetal coverage such as forest or deeprooted grass which are difficult to eradicate. In this sense the Peruvian coastal valleys and mountain basins have much in common. Except for certain altitude limitations, there were no major physical barriers to the spread of the basic eultural pattern throughout all the large basins and valleys of the Central Andes. Its extension was sharply curtailed, however, by the eastern tropies where the 
dense forest coverage presented a serious obstacle to highland agricultural techniques. Cultural expansion into the Northern Andes was blocked by a shift in the rainfall pattern which made it difficult to graze the llamas and alpacas, the basic animals in the Central Andean economy. The Southern Andes are separated from the Central by a desert strip; but the principal barrier to great cultural interchange seems to have been gross distance rather than environment.

The Central Andes, despite certain over-all cultural unity, includes numerous regional subdivisions that are not only isolated geographically, but also have local cultural traditions. Considering the size of the area, its inhabited parts are decidedly limited. An examination of these requires more geographical detail. An airplane view of the Peruvian coast reveals a long strip of desert cut across at irregular intervals by mountain streams which drain into the Pacific. Some twenty-five principal rivers are separated not only by barren areas but by sharp mountain spurs. In the past communication between these valleys was always so difficult that major intervals between them usually mark significant cultural divisions. The close relation between cultural development and river valleys, while obvious, cannot be overstressed. Although small fishing groups can have existed along the coast, no major advancement of culture was possible until the valley flats were utilized. With the domestication of plants and controlled irrigation, the fertile flats became important agricultural centers capable of supporting large populations. Their size depended, in large part, on the size of the valley itself. It is interesting to observe that the most extensive valleys and those with 
the most permanent streams are on the North Coast. More intensive desert conditions prevail in the South Coast valleys, and the flats are restricted in area by a low mountain range that skirts the Pacific shore line. It is not surprising, then, that as technology advanced, the northern valleys became the more important centers of cultural development.

In the mountains, surrounded by high snow-covered peaks, are puna grasslands, some plateaus and intermont basins, and numerous rivers, most of which eut their way into the Amazon. Although many small pockets along the rivers can support some population, only six areas are of sufficient size for any elaboration of pre-Columbian development. From north to south these are: the large basins around Cajamarca; the Callejón de Huaylas along the upper Santa River; the basins along the Río Mantaro; the various valleys and flats around Cuzco; the basin of Puno in southern Peru; and the Bolivian plateau south of Lake Titicaca. All these areas have extensive regions of well-watered fertile soils and are surrounded by high punas ideal for grazing. Each of these six areas was a major cultural center in the past, isolated from its neighbors both by distance and by mountains, but not to the extent of blocking some intercommunication.

Each major highland basin and each coastal valley might be treated as a distinct cultural unit, but there is insufficient archaeological evidence to support such consideration even if it were practical. In spite of the numerous archaeological investigations in the Central Andes, perhaps more than in any other part of South America, much still remains to be accomplished and many sections are still unknown. Only a few of the many investigators have 
been trained archaeologists and only a small percentage of the numerous publications are scientific reports on excavations. Other accounts, some of great merit, have been written by travelers, by artists, or by folklorists interested in interpreting symbolism in design. Even the professional excavators have rarely done more than sample the numerous sites. For practical purposes of presentation, then, the valleys and basins are arranged in six groups, three on the coast and three in the highlands. Each of these groups corresponds to a major geographical division, each has been subjected to a reasonable amount of scientific investigation, and each, as will be explained below, seems to have some historical validity. The groups, with simple geographic designations, are:

1. North Coast. Geographically, the North Coast includes all the valleys from Piura to Casma. Four subdivisions are suggested by the archaeological finds, namely, Piura in the north; Lambayeque; Chicama, Moche, and Viru; and Santa, Chimbote, Nepeña, and Casma. Adequate archaeological data, however, are available only for the third subdivision, Chicama, Moche, and Viru; consequently all references to the North Coast will be so limited unless otherwise stated.

2. Central Coast. The Central Coast extends from Huarmey to Lurín. All of these valleys seem to present a fairly compact unit with the exception of Huarmey which is well isolated geographically and probably forms a subdivision in itself. Since the best information is limited to the valleys of Chancay, Supe, Ancón, Rimac, and Lurín, these are here considered typical of the group. 
3. South Coast. In total, the South Coast extends from the Río Mala to the Río Lomas, but it has some major subdivisions, such as Cañete and Chincha in contrast to Ica and Nazca. On the basis of our present knowledge only Pisco, Ica, and Río Grande (Nazca) can he considered here. A series of small valleys in extreme southern Peru are as yet not well enough known to be included in this over-all account.

4. North Highlands. This division extends from Huinuco to the Ecuadorian border, but archaeological records are available only for the Callejón de Huaylas, Chavín de Huántar, and Huamachuco.

5. Central Highlands. The central zone is the extensive stretch from Huánuco to Cuzco. The Inca remains of Cuzco are well known. Flsewhere there are only scattered accounts for important sites in the Río Mantaro basin, east of Lima.

6. South Highlands. Southern Peru and Bolivia are grouped together because of an extensive plateau, the altiplano, which includes Lake Titicaca. Archaeological exploration has largely been limited to sites around the lake. The eastern cordillera of Bolivia is excluded not only because of lack of information but because it is effectively beyond the limits of the Central Andean culture area.

These regional subdivisions are not mere conveniences for describing a region as extensive as the Central Andes, but actually represent significant segments of cultural development. The valleys that are grouped together present similar archaeological materials and sequences. Furthermore, each major division is characterized by certain cultural traditions which persist thronghout many of the cultural 
time periods and stylistic changes. For example, the North Coast ceramics over a long and varied span of cultural history are still united by an emphasis on incised decoration, modeling, pictorial style, mold-made vessels, and the stirrup-spout. The design styles change, but these features persist. The South Coast is distinguished by polychrome ceramic painting and elaboration of weaving. Exceptional climatic conditions have favored the preservation of textiles on the South Coast, but other evidence indicates that so much emphasis was placed on weaving that other aspects of culture were not equally elaborated. In the North Highlands there is a traditional emphasis on stone carving. Likewise the buildings are constructed of rough or dressed stones and commonly utilize such features as galleries, multi-storied floors, and subterranean chambers. Quite apart from these long persisting traditions, the cultural development in each major area was sufficiently distinct to differentiate it from the others at any particular point in the chronological history. In one area that has been intensively studied there is every indication of a basic population continuum through many cultural and political changes. This would account for the regional traditions.

Although the regional subdivisions are important, the Central Andes as a whole was closely united throughout most of its cultural history. Certainly at the time of the Spanish conquest, the Central Andes was a cultural area, that is, a region in which the component tribes shared a significant percentage of their cultural traits. There is also considerable evidence for the antiquity of this common cultural pattern. Some of its distinguishing features are 
intensive agriculture, based on such plants as maize, beans, squash, potatoes, manioc, oca, and others; digging-stick cultivation; techniques of irrigation, fertilizers, and terracing; the use of nareotic coca instead of tobacco; domesticated cotton ; and domesticated llamas and alpacas. Buildings were constructed with adobe, stone and other durable materials. Weaving, metallurgy, basketry, ceramics, and other crafts were highly developed; furthermore, many specific techniques and designs in these crafts were widely employed. A social and political superstructure controlled the village units, and there were distinctions of rank, class, specialized priests, and craftsmen long before the Inca formulated their political empire. In brief, the archaeological record demonstrates that the cultural pattern established at an early date in the Central Andes persisted with more or less uniform modifications to the time of the Spanish conquest.

The concept of a Central Andean cultural block with considerable time depth has been recognized by most archaeologists. This concept not only permits the consideration of the Central Andes as a unit, but also a comparison of its cultural developments and achievements with those of other parts of the world. Moreover, it makes feasible a generalized descriptive account of the cultural development in a chronological sequence. One of the basic assumptions in such an approach is that a major invention or advancement in one part of the Central Andes would soon spread to all the area. In so large a territory with so many well-isolated subdivisions, there is always the possibility that the cultural development in one region might lag seriously behind the others, but it is significant that 
thus far archaeological investigation has failed to reveal such a lag. This does not signify that the Central Andean culture was everywhere uniform. By definition, a culture area does not imply such uniformity. In fact, it is possible to demonstrate for any specific time horizon that the cultural pattern of each subdivision differed in many respects.

The Central Andes presents, then, a basic cultural pattern established at an early date, and one which advanced everywhere at a more or less uniform rate. This makes feasible a history of the Central Andes which starts at the earliest known beginnings and traces the development through major periods to a culmination in the Inca Empire. This procedure is followed in the succeeding chapter. For each major time period, the general characteristics of the total Central Andes will first be considered, followed by a discussion of local variants, specialized developments, and significant regional differences.

This approach, although valid historically, has certain limitations. For example, the same conditions of preservation do not prevail in all sections. On the coast preservation is generally excellent, even for the most delicate textiles, but the South Coast is more favorable than the North. In the highlands the heavy rains prevent the preservation of all but the most durable materials. Another limitation has its source in the nature of most of the archaeological work. The excavators, primarily interested in establishing time sequence, have directed their techniques towards this end. Thus the greatest emphasis is placed on ceramics, not only because pots and sherds are valuable cultural diagnostics, but also because they are preserved everywhere in house sites, refuse heaps, and other positions favor- 
able for sequence interpretations. Consequently, many field reports include excellent interpretations of the time relations of ceramic styles, but add little or no information on the total cultural content of a period. Finally, an historical approach of this kind demands more than an inventory of the materials preserved for each period. Social implications based on archaeological material are somewhat hazardous even under the best of conditions. Many suggestions are to be found in the realistically painted ceramic designs, the house trpes, the size and construction patterns of buildings, the extent of territory occupied, and the like, but their interpretation is always in the nature of inferences without final factual proof. All of these , limitations are recognized in this history and every attempt has been made to keep the inferences as sound as possible.

In this introductory section the major regional and cultural subdivisions of the Central Andes have been sketched. Before initiating the descriptive historical account, the time divisions must be considered. It seems pertinent to mention briefly the dating techniques employed, the resulting relative chronology, and the major time periods here selected to present the history of cultural development of the Central Andes.

\section{Chronology}

The Central Andes was occupied by sedentary agriculturists for many generations, so that the archaeologist has an enormous quantity of materials to consider. For example, during recent work in Viru, one of the smaller valleys on the North Coast, the Institute of Andean Research mapped the lo- 
cation of over three hundred sites which were estimated to be about a one-quarter sample. Furthermore, the units designated as sites varied from simple house refuse accumulations to mammoth ceremonial village constructions. Few valleys have been as thoroughly explored, but there is every indication that an enormous number of sites will be found in each valley investigated in the same detail. Several major categories of materials are available for classification and study. The first may be termed "surface ruins." These include habitation refuse, houses, villages, cities, temples, forts, irrigation systems, agricultural terraces, and other constructions. The second, "cemeteries," includes

- graves of many types, varying from simple pits to stone-lined burial vaults. The graves may include only a skeleton or two, but more frequently they contain cloth-wrapped mummy bundles and a reasonable quantity of grave furniture. The "stone carvings," such as decorated lintels, sculptured heads, and statues, are here treated as a third category although they are technically a subdivision of the first. The utilitarian and ceremonial artifacts found in the habitation sites and in the graves are classified, on the basis of the material employed, as ceramics, cloth, metallurgy, basketry, calabash work, woodwork, stonework, and shellwork.

The first problem for the Andean archaeologist is to arrange this great variety of materials into periods and their chronological sequence. Which materials belong to the same culture? Is that culture earlier, contemporaneous with, or later than others in the same area? To accomplish both of these tasks the archaeologist is dependent almost exclusively on his special techniques. The Spanish 
conquerors described the Inca culture and recorded certain oral accounts of the traditional history. These furnish a few, though not very reliable, dates for the relatively recent times. Neither a form of phonetic writing nor a recorded calendar was known in the Central Andes in pre-European times, in spite of the fact that the early agriculturists must have had some calendrical knowledge. The dating technique based on the annual ring growth of trees, so successfully used in the United States Southwest, has so far not been applicable to the Central Andean woods. Consequently, all so-called dating in the Central Andean region is relative, not absolute, and, moreover, is based entirely on the excavations and their interpretation. The archaeologist endeavors first to establish relative sequences at the specific sites excarated and then extends these to the ralley or basin in which the sites are located, then to adjacent valleys or basins, and finally, on broader comparative grounds, to the entire area.

The dating techniques employed are relatively simple and standardized. Stratigraphy, the superimposition of one type of material over another, is the most reliable and has been the most extensively used. Stratigraphy may refer to various periods of building in a single structure; to one type of building which overlies another; to a building over a grave; or, in reverse, to a grave intrusive in a building. It may also refer to the superimposition of one habitation room over another or to the relative position of graves. The determination of the latter is particularly difficult, since it is the mouth of the grave which is important and not its absolute depth. By far the best stratigraphic rec- 
ords are found at sites where successive inhabitants have built up refuse accumulations. Such sites are common on the coast of Peru; some are as much as nine meters deep. The archáeologist cuts through these, level by level, in order to obtain a crosssectional picture of the history of occupation. In all cases, superimposition is meaningless unless the occupational remains change from one level to the next. The important sites are those with materials from several periods since their stratigraphic positions furnish the basis for relative dating.

Surface sampling is another common technique. Unselected sample collections, usually potsherds, are made from the surfaces of many sites, classified, and arranged in a hypothetical sequence which may ultimately be verified by stratigraphic excavation. Sampling pits, instead of surface collections, may be excavated in a number of sites and the excavated materials classified and compared. Unit sites, that is, those occupied during a single period only, are important for isolating the styles and content of that period, but their relative dating depends on other types of evidence. Grave collections can be analyzed if a record is kept of every piece found in each grave. On the assumption that all materials found in a grave are contemporaneous and that graves of transitional time periods will contain mixed materials, a sequence can be built up by isolation and association of styles. The direction of such a sequence can be fixed only when one end is identified, as for example, by the presence of known Inca material. Seriation might be mentioned as still another technique in which art sequences, technological devel- 
opments, and similar trends serve as a basis for relative chronological dating.

The valley and inter-valley chronologies depend on the interrelationships of the site sequences. The materials from two adjacent valleys are occasionally so closely identical that there is no question of their common period classification. For example, it is almost impossible to distinguish the Nazca materials in Ica from those in Nazea itself, or the Mochica materials from Chicama, Moche, and Viru valleys. Trade pieces are also important in linking areas. When a typical North Highland negativepainted ressel is found in the top levels of a Gallinazo site in Viru Valley, the sequences in these two regions can be adjusted to each other.

The establishment of a relative chronology for the total Central Andes is a further extension of this matching process. The procedure is aided by the presence of a number of so-called "horizon", styles, each widely distributed. Some of these horizon styles consist of a distinctive design element; others are based on a technique, such as positive or negative painting; still others are combinations of several traits and might better be designated as horizon complexes. To be most usable, the diagnostic elements of the horizon style should be clearly definable and readily identified. Its relative position in the local series must be known. In other words, the horizons are established by relative dating techniques, but once confirmed they are useful for dating new finds and interrelating regions. The particular cultures linked in time by the horizon style may he quite diverse, that is, the horizon style itself may be the result of simple diffusion, a dominating religion, or political conquest. However, the 
presence of a number of horizon styles in the Central Andes furnishes additional evidence of its cultural unity over a long time period.

At present six important horizon styles are recognized in the Central Andes, although most of them do not extend over the entire area. These are briefly defined below and may be found on the chronological charts in their relative time positions. The order is arranged from the earliest to the latest.

1. Chavín Horizon. The Chavín horizon is characterized by a highly stylized feline design. The full figure feline is represented in profile, or the head alone is presented in front view, top view, or profile, the latter position having the widest distribution. The profile head has a wide U-shaped mouth band that curves outward at the corners, two crossed fangs, and squared teeth. The nose is a circle surmounted by a scroll; the banded eye is oval with a cut-out circle at the top. Other appendages and details are equally distinctive so that the Chavín feline is recognizable by its claws, tail, and other details. The design is executed in a carved technique in curvilinear style. The feline motif is most highly elaborated in the flat stone carving at the highland site of Chavín de Huántar. Elsewhere it appears as a dominant design element in stonework, bonework, ceramics, textiles, and metal work. The Chavín horizon, the earliest known horizon in the Central Andes, is found in the North Highlands and on the South, Central, and North Coasts.

2. White-on-Red Horizon. The White-on-Red horizon is basically a technique of positive brush painting of ceramics in white on a red clay base. The clumsily executed white designs are composed 
of simple elements such as bands, plain lines, wary lines, and triangles filled with dots. This horizon style is difficult to identify because of its simplicity. Some ceramic shapes may be associated, but these associations are not sufficiently varied to constitute a complex. It is distributed on the Central and North Coasts, and in the North Highlands. In time position the White-on-Red always succeeds Chavín and precedes Tiahuanaco.

3. Negative Horizon. The Negative horizon is likewise a technique of ceramic decoration by resist negative painting. A design is first applied on the ressel with some dye-resisting substance such as wax or clay pellets. The whole ressel is then dipped in the dye. When the resist elements are removed, the design appears in the base clay color, surrounded by a dyed field. In this horizon, brown to black dyes are applied on an orange or buff clay. The design elements are simple lines, wavy lines, and dots. The style is found on the South, Central, and North Coasts and in the North Highlands. The negative horizon is more recent in time than the White-on-Red. Some confusion arises from the fact that resist negative painting continues into much later periods as a tradition, particularly in the North Highlands.

4. Tiahuanaco Horizon. The previous horizons are characterized by single styles or techniques, but the Tiahuanaco horizon is composed of a number of elements which form a complex. The dominant style is best represented by the relief carved "Gateway of the Sun" at Tiahuanaco in Bolivia. One design is the profile ruming figure. Another is a front view figure with stiffy outlined body, rectilinear head, squared eyes with tear bands, and a 
mouth with squared teeth, but no crossed fangs. Other typical designs are stylized puma, condor, and snake heads. These designs occur in stone carving, tapestry, weaving, wood carving, ceramic painting, and other media. In addition to the characteristic style, the horizon complex is distinguished by polychrome ceramic painting in black, white, yellow, and gray, on a red base; by well executed textiles, particularly tapestries; and by two common vessel shapes, namely, a tall goblet and a flaring-sided squat cup. The Tiahuanaco horizon is truly pan-Central Andean.

5. Black-White-Red Horizon. On the Coast of Peru the Tiahuanaco horizon is followed by a breakdown into a black-white-red geometric style of ceramic painting with design units consisting of small steps, squares, checkerwork, and dots. A flask shape as well as other forms and ceramic details are usually associated. The horizon is present on all the coast and in the North Highlands.

6. Inca Horizon. Like the Tiahuanaco, the Inca horizon is a complex, not a single style. The ceramic design style is called the Cuzco Polychrome after the type site. It is characterized by well applied polychrome designs composed of small geometric elements. The typical and distinctive vessel shapes are a conical base aryballoid, a shallow plate with a bird handle, a pedestal beaker, and a pitcher with a wide ribbon loop handle. Many other features are associated in this horizon complex, but these can best be described in a later chapter. The Inca horizon has a pan-Central Andean distribution corresponding to the total extent of the Inca Empire at the time of the Conquest.

The accompanying chart presents a graphic pic- 
ture of the distribution and relative time position of these six horizons. These are presented as true horizontals, implying that the styles appeared in the different regions at the same relative time. In historical reality, each style must first have existed in a particular region and spread out from it. Thus, a style which originated on the South Coast would reach the North Highlands somewhat later so that the graph should show an ascending curve rather than a horizontal line. This diffusion process undoubtedly occurred, but the refinements of comparative chronology are not adequate enough to determine it. The gross picture is, however, consistent. Wherever a series of these horizons occurs, they are always in the same sequence and are separated by approximately the same intervals. In one sense this results from aligning one region with another on the basis of horizons; however, it is significant that none falls seriously out of place.

The chart (Fig. 19) presents the major periods for each region in the Central Andes on the basis of present evidence. The terminology for the various periods and subperiods is still somewhat eomplex. It is a common practice among archaeologists to name new styles and periods after local sites. This has the advantage of being specific, but presents difficulties in preparing a chart for the entire area. Some simplification is attained by considering the six horizons as period markers, but ultimately a detailed discussion reverts to the local terminology. A broad picture shows the earliest periods united by the Chavin horizon, in spite of many differences in detail. The next phase is one of experimentation and development of local styles, although these are united by techniques of the 


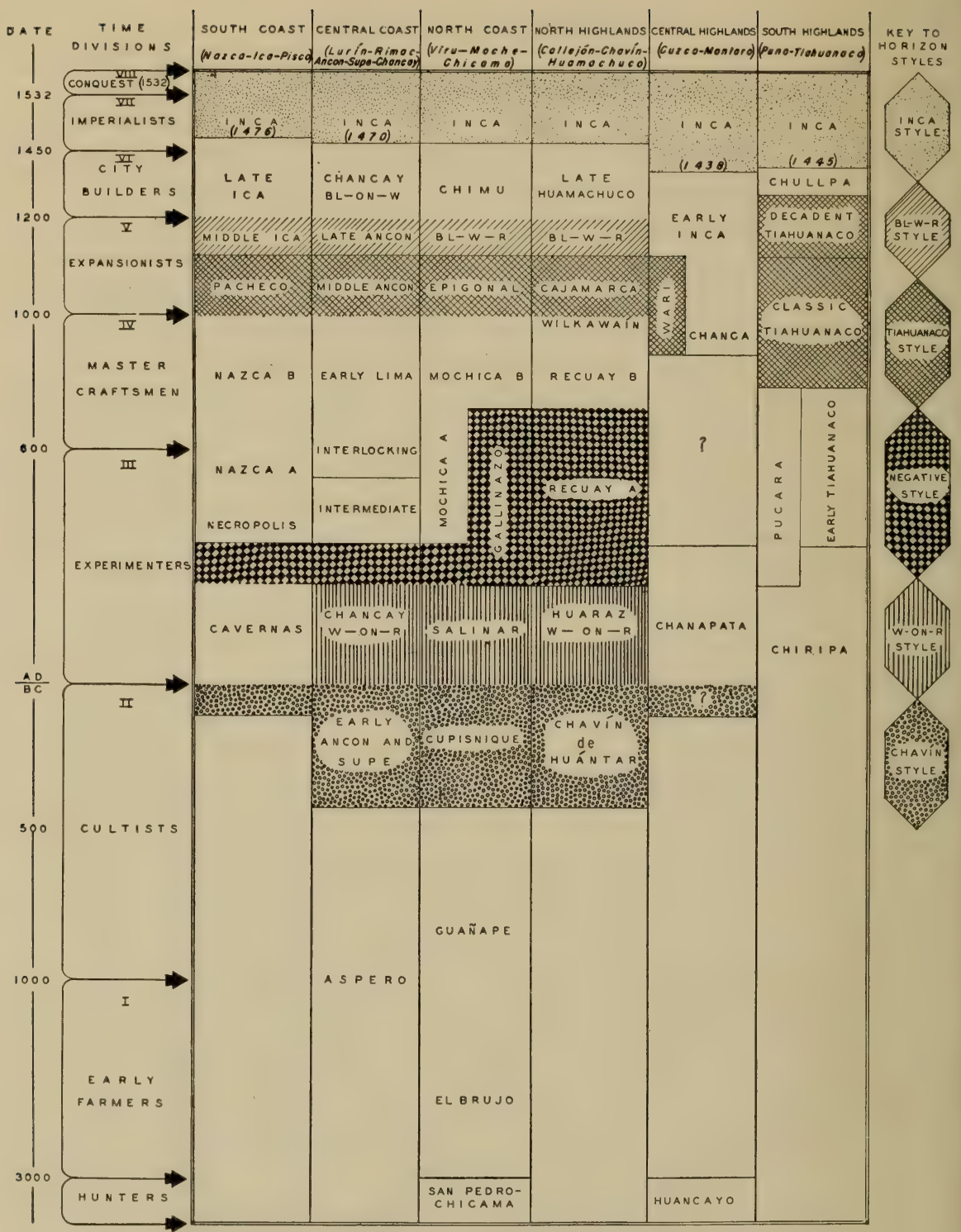

Fig. 19. Chronological chart for the Central Andes. 
White-on-Red and Negative horizons. The widespread Tiahuanaco and Black-White-Red horizon complexes again unite the Central Andean cultures, even though these are soon followed by a reemergence of local developments. The Inea horizon complex marks the final unification into a single empire.

For the present account which deals with the Central Andes as a whole, the total chronology is divided into seven major time periods. These are indicated on the chart so as to show their relationship to the local periods and to the six horizons. The divisions between the seven major periods are somewhat arbitrary, but this is inevitable. Each time period is selected to represent a significant step in the historical development of the Central Andean culture. The descriptive names indicate the outstanding characteristics or trend for the period as a whole. The presentation follows the order of early to recent.

A word of explanation is needed for the series of guess-dates included on the chart. It has already been indicated that the chronology is relative, not absolute. Howerer, guess-dates are useful for general orientation. Those used here conform in general to the opinions of most of the archacologists who have worked in the region. Dr. John H. Rowe has made the best analysis of the Colonial Spanish documents which refer to Inea chronology and has suggested a series of dates for the Inca and other late periods. These are indicated in parentheses in the charts. A gross scale for some guess-dates is based on the depth of the refuse deposits in each period. For example, Inca sites excavated at Cuzco and in Bolivia have about one-half meter of refuse 
corresponding to an historically derived period of about one hundred years. For the coast, the scale should be doubled, namely, one meter of refuse equals about one hundred years. This argument takes into consideration the facts that the coastal peoples had greater opportunity for concentrated settlement and made extensive use of adobe in buildings. Also, because of the aridity, there would be a greater accumulation of wind-blown sand and dust on the coast than in the highlands. Actual excavations demonstrate that the highland refuse sites are far more compact than those on the coast. The Inca deposits at Pachacamac on the coast are twice as deep as those at Cuzco and, likewise, a twometer deep deposit at the highland site of Chavín de Huántar corresponds roughly to about four meters of Chavín period refuse on the coast at Ancón. Without placing too much reliance on the accuracy of this time scale, some general comparisons are possible. Dr. George Kubler has studied all accounts of specimens found at different depths on the guano islands, and has correlated them with the supposed rate of deposit of the guano. He arrives at a ninth century date for certain Mochica culture pieces. Mr. Junius Bird has studied the total soil profile of Viru Valley and matched this to refuse deposits. He concludes that agriculture on the north coast might well have been introduced by 3000 B. C. and ceramics by 1000 B. C. The present chart is based on these estimates, although it must always be remembered that these are at best good guesses only. 


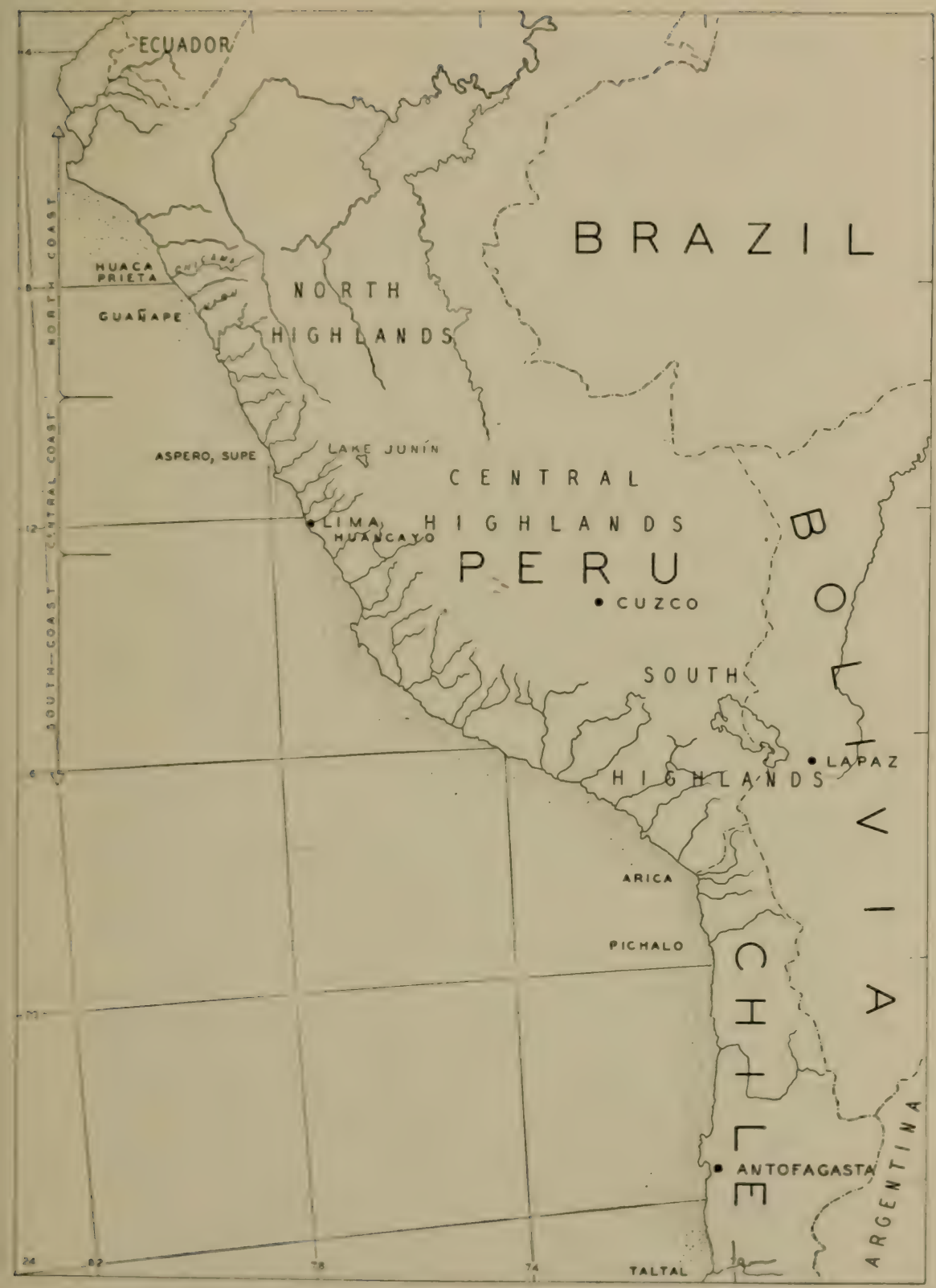

Fig. 20. Principal Early Farmer Period sites. 


\section{EARLy Farmers}

\section{(ca. 3000-1000 B. C.)}

The ultimate origins and even the earliest manifestations of culture in the Central Andes are still shrouded in mystery. Some sites represent a simple cultural level with no ceramics, but these are located on the Pacific Coast and were quite possibly marginal to the true centers of development. The early and widespread Cultist Period sites present evidence of a sophisticated and complex culture but the simple coastal cultures, although known to be older, do not seem sufficient in themselves to account for such a development. Future work in the highlands may uncover important centers of early development, but it is equally possible, and in some ways probable, that the initial centers lie outside of the Central Andes, perhaps in the tropies, perhaps in other parts of the Andes.

The evidence for early migrations into South America has previously been presented. On the basis of this evidence it seems logical that man first entered South America via the Isthmus of Panama and moved southward through the Andes. These earliest migrants were hunters and gatherers with relatively simple cultural equipment. In the Central Andes they probably found the highland basins more attractive than the coastal valleys. Presumably snow line was then at a lower elevation resulting in a larger precipitation zone, more vegetation and more game. The known sites for this hunting period are few in number: a series of rock-shelters near Huancayo in the Central Highlands and some isolated workshops between Chi- 
cama and Pacasmayo. It is not yet known whether these early hunting peoples remained in the Central Andes or moved on to the south, but in any case, it seems unlikely that they were directly responsible for the higher civilizations which developed later. This is strongly supported by the fact that the technique of pressure flaking stone artifacts was commonly used by the hunters but was not used at all by the pre-ceramic farmers.

The coast, in spite of its limitations for hunters, might well have been attractive to early fishermen. Campsites of ancient fishing groups have been found in North Chile as described in Part One. Similar sites may ultimately be found in Peru, but, so far, the known pre-ceramic cultures all seem to fall generally within the agricultural horizon and, in point of time, may be contemporaneous with ceramic periods elsewhere. This does not negate the importance of fishing, which was part of the basic subsistence pattern for many centuries.

There is as yet no agreement on the localities in which the various plants were first domesticated. Geneticists after an exhaustive study of cotton have recently proposed a part Asiatic ancestry for the linted American cotton. Their research indicates northern Peru as the center of dispersal of cultirated cottons in the New World, and it is a curious coincidence that the most ancient evidence of agriculture found in America is in the same region and that cotton was one of the plants grown. With it is found the bottle gourd, also thought to be of Old World origin.

A similar study of corn, which appears long after cotton and gourds on the north coast, points to some region east of the Andes, possibly along the 
southern margin of the tropical forest as its area of domestication. This is not supported by cultural and archaeological evidence. In fact, one ethnological study is quite in opposition to this and points to Colombia as the more likely region.

Other plants because of their ecological distribution must have been domesticated up in the highlands. But until much more work has been done, we cannot consider any of the present theories as conclusively settled. All we can be sure of is that agriculture without corn was established on the north coast long before the introduction of ceramics.

So far five pre-ceramic coast sites are known: Puemape near Pacasmayo, Milagro and Huaca Prieta in Chicama, Cerro Prieto in Viru, and Aspero in Supe. All present deep deposits, from two to twelve meters, and probably antedate the Christian era. Five sites are admittedly inadequate for sound generalization, and besides, in none of these is an abundance of materials available. In fact, a comparison of the artifacts from the five sites shows that few are distinctive-a situation unlike that in Chile where widely separated fishing sites contain many characteristic artifacts in common.

Huaca Prieta at the mouth of Chicama Valley presents the best picture of life in these early times (Fig. 21). The valley itself was probably quite different before its settlement by intensive agriculturists. The river probably meandered back and forth more freely than at present, forming lagoons and swamps, and supported a dense undergrowth. On the other hand, game birds, wild plants and animals were undoubtedly more abundant. Subsistence depended heavily on shellfish and seafood, 


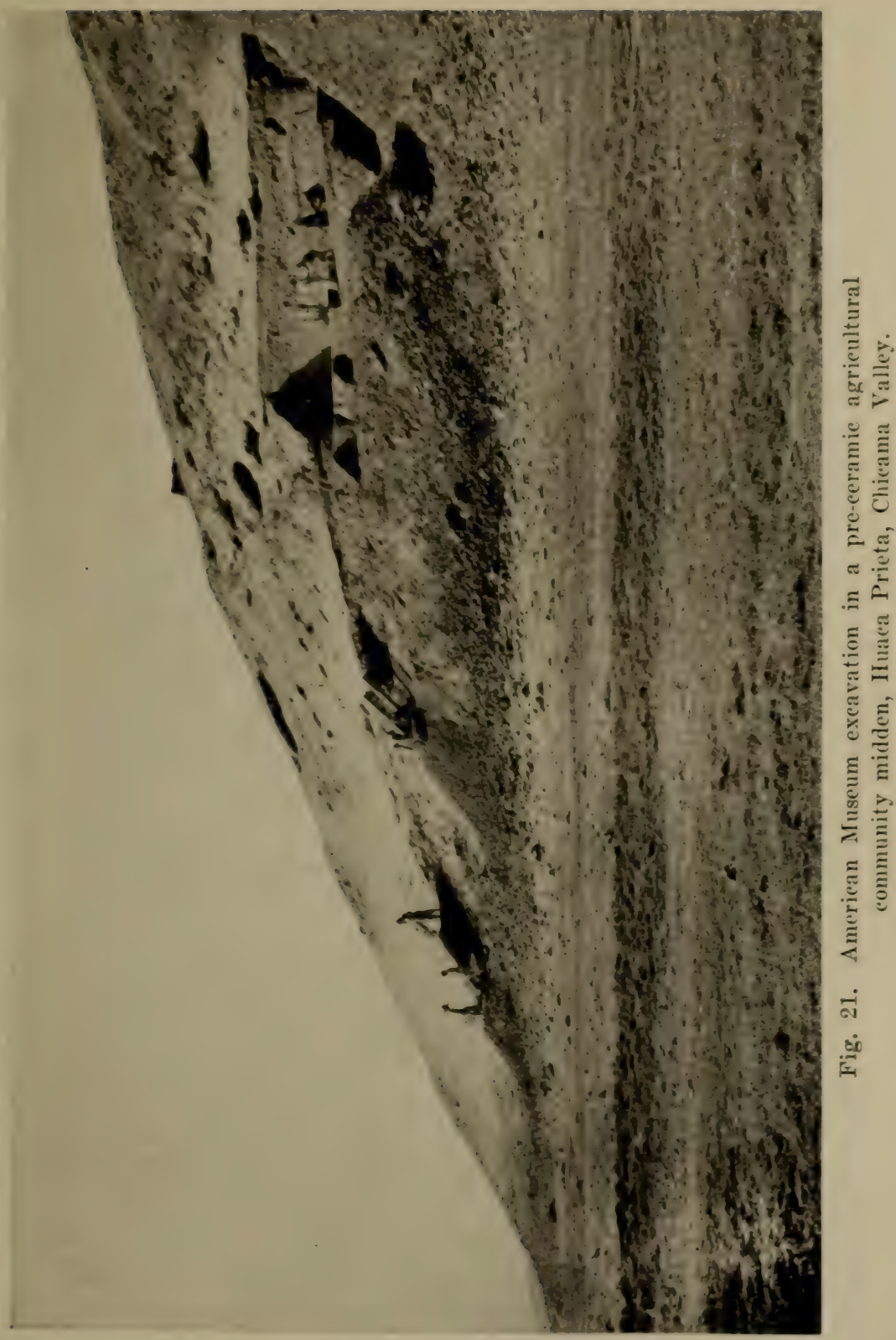


but this is considered to have been insufficient to support the estimated population. However, there is surprisingly little evidence for the practice of hunting. Bones of land animals are not present in the midden and, though there are a few of sealion and porpoise, hunting weapons are lacking. A large part of the cooking was done with hot stones probably by roasting. The hot stones may also have been used for boiling by putting them with food and water in gourd containers which were abundant. Ceramics were completely unknown. The seafood diet was supplemented by gathering and by a few cultivated plants, such as achira, squash, gourds, beans, chile peppers, a fruit called lúcuma, the tubers of a reed called papas de junco, and roots of cat-tails. Cotton, presumably domesticated, was also known. The fibers were twisted into string without the use of spindle whorls. True weaving is rare, with twined fabrics, looped and knotted pouches, and fishing nets more common. Twined baskets and reed mats were made. There are also pieces of pounded barkcloth, a surprising occurrence because this is generally more characteristic of the upper Amazon than the Andes. The simple utilitarian objects include percussion flaked scrapers and stone flake knives ; perforated net weights ; bone needles; and perhaps stone bowls. Noteworthy is the complete absence of the technique of chipping stone artifacts by pressure in the early agricultural horizon. The earliest burials are found in unprepared pits, but slightly later graves are constructed, like vaulted tombs, of waterworn boulders. The houses, like the graves, are semi-subterranean and lined with boulders. Similar semi-subterranean rooms, 
faced with rectangular adohes, have been uncovered in Viru.

This simple culture pattern, with some local developments, overlaps the earliest coastal ceramic period. For example, at Huaca Prieta the use of hot stones in cooking continues into the ceramic period, twined fabries are found in association with true weaving, and semi-subterranean constructions continue to be used along with constructions of cylindrical and conical adobes. The use of cylindrical and small biscuit-like adobes occurs with the first ceramic containers. These are simple olla cooking pots, irregularly colored from dull red to dark brown and black, showing lack of oxygen control in firing. The only decorative elements are applique ridges or ribs made irregular by pinching or notching. Pottery roller and plain stamps and figurines were also made. Jet mirrors, shell and bone beads, bone wearing tools and ornaments give further reason for believing that a population movement rather than a spread of ideas was responsible for the items new to the region. The only burials identified with this time contain a few simple artifacts as grave offerings. Bodies were either seated with legs extended in front or fully extended with arms at sides. At Aspero in Supe there is a structure which may represent an altar or religious site of this period. A large room, about four meters square, is connected by doors to two adjacent small rooms. The floor is of packed clay. The walls of uncut stone, crudely coursed and held together with mud plaster, are less than a meter high and abrout forty centimeters wide. A platform, 1.50 meters square and 50 centimeters high, in the center of the main room is built with uncut boulders set on 


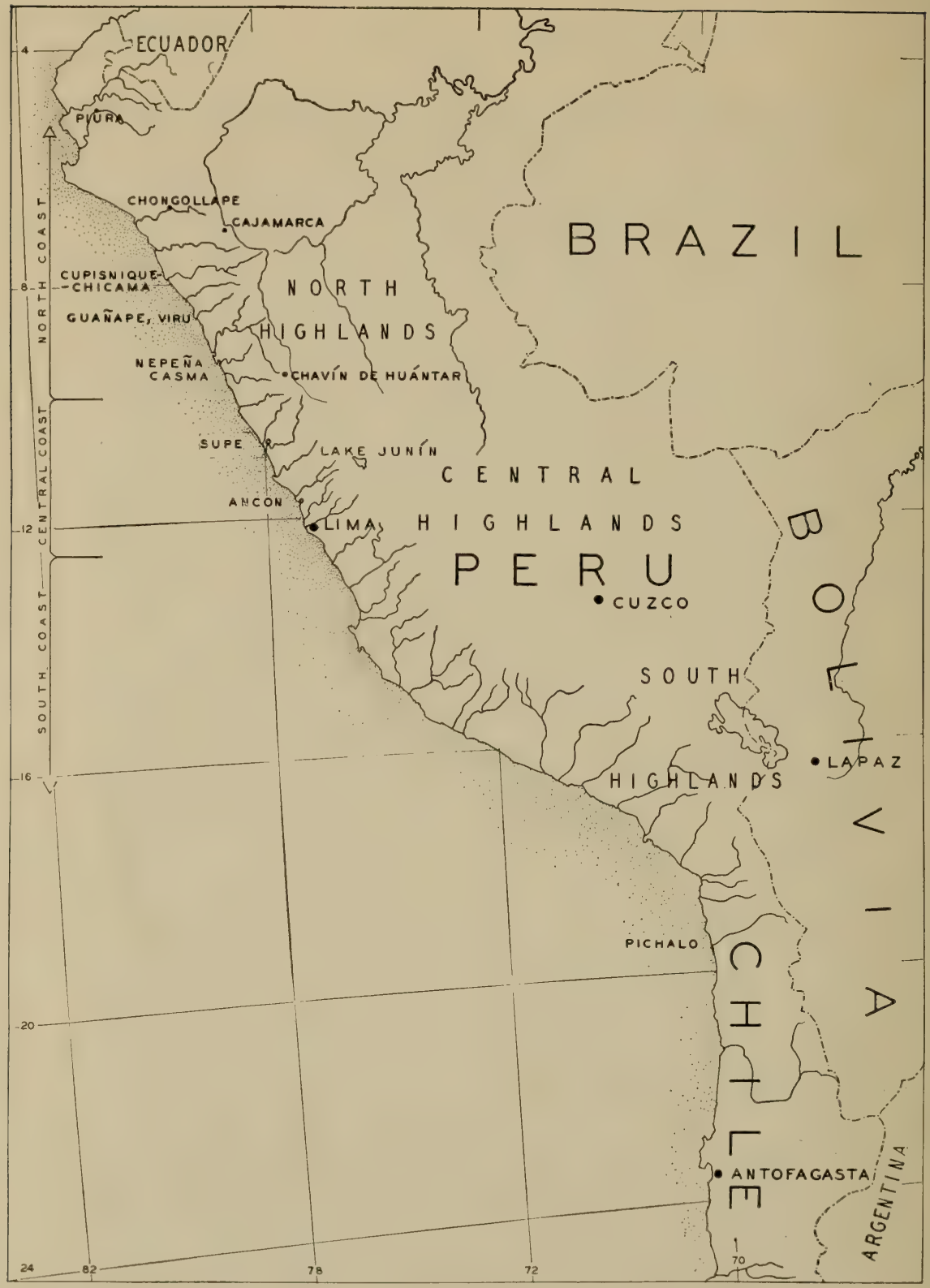

Fig. 22. Principal Cultist Period sites. 
end, with small stones filling the interstices. This base is covered with a clay plaster. Actually, pottery was not found with this structure, but discoveries of a lance point of chipped stone, llama bones, and maze serve to place it in the carly ceramic period.

In many ways these coast sites apparently present a developmental sequence from the pre-ceramic into the ceramic, but it is doubtful that this is a true picture of the origin of higher civilization in the Central Andes. It is more likely that these coastal sites merely reflect the important cultural developments that had oceurred in the highlands. This becomes more apparent in the following discussion of the Cultist Period in which the Chavin style first appears. In art, architecture, and other aspects of culture, the contrast is great. It seems unlikely that so marked a change should suddenly emerge from such humble beginnings as presented by the Farly Farmer sites. Nonetheless, all evidence points to a long period in time for these preceramic cultures.

\section{Cultist Period \\ (ca. 1000 B. C.-0)}

Following the humble and modest beginnings represented by the coastal pre-ceramic sites, the flowering of culture in the Cultist Period seems sudden and abrupt. Despite certain technological limitations, the ceramies are varied and well made. Judging by the few known samples, weaving is adranced. There is evidence of versatile craftsmanship and considerable sophistication in art and architecture. Subsistence is no longer dependent on fishing, gath- 
ering, hunting, and limited agriculture, but rather on true agriculture with a good range of plants. In some regions the population shows a marked increase. A stylized feline design is common to most cultures in this period. The manifestations of this design suggest a strong religious cult, as will be pointed out. For this reason, the term "cultist"' is used as a name for the period.

The Cultist Period includes many local cultures and sites which, in spite of their wide distribution, are linked by the Chavín style horizon. Some of the outstanding sites are: Chavín de Huántar in the North Highlands; the extensive shell-heaps at Ancón and Supe; various building units, such as Moxeke, Pallka, Sechín Alto, and perhaps Cerro Sechín itself, in Casma Valley; Pungurí and Cerro Blanco temples in Nepeña Valley; Guañape and related sites in Viru Valley; all of the Cupisnique culture sites in Chicama Valley; Chongoyape in Lambayeque Valley; and miscellaneous isolated finds in Piura, Cajamarca, and the Lima region. More extensive exploration will undoubtedly reveal a much wider distribution of the Chavín horizon and perhaps permit the inclusion of additional sites that are apparently ancient but lack the Chavín design, such as Pichalo on the North Coast of Chile.

There is abundant evidence for the relative antiquity of the Cultist Period. In Viru and Chicama valleys, the cultural remains follow immediately after the Early Farmer period and precede the Salinar and Mochica cultures. Likewise, the sites are stratigraphically older than the White-onRed culture in the North Highlands and the Interlocking culture at Ancón. In general, Cultist materials are not mixed with other known styles, and 
have technological limitations which are not found later. The total period was one of long duration, perhaps one thousand years. Of this range, the characteristic Chavín horizon cultures are estimated as between four and five hundred years by the guessdates used here. These estimates are based on the exceptionally thick refuse deposits which range from 4.5 to 8.5 meters in Viru and Ancón. Within this long time range, many cultural advancements were achieved, but the archaeological evidence is still insufficient to permit the establishment of reliable subdivisions.

In this type of historical approach all cultures and sites that fall into the same relative time bracket, on the basis of stratigraphic evidence, are included in the period under consideration. In the Cultist Period the component cultures are somewhat uniform. All share the feline design of the Chavin horizon. Other similarities are due to technological limitations, to trade and diffusion, and perhaps to a common background and tradition. In spite of all this, each region presents local independence and variations which cannot be dismissed even when the period is considered as a unit. The significant regional differences will be emphasized in the subsequent cultural description of the period.

Cultist sites on the coast are generally located close to the shore or along the margins of the valleys, even in quebradas which are now dry and stone covered. The highland sites likewise are in the small valleys rather than in the large basins. These marginal locations imply that the complete control of irrigation and agriculture had not yet been achieved. The flats of the coastal valleys were probably still brush-covered and swampy so that 
unskilled farmers could utilize only their boundaries. Furthermore, some of the regions which are now so arid were probably less so before the total flow of the rivers was channeled into irrigation systems. The sites are refuse deposits, cemeteries, and temples or other religious structures. Some of the latter are of considerable size, but there is still no convincing evidence for huge concentrations of people.

The large middens near the ocean shore prove that seafoods were still important in this period. They also provide us with the best data on the perishable items of this epoch which show a major development in agriculture. From middens near the Huaca Prieta comes evidence which indicates that maize was introduced into this part of Peru at the same time as the Cupisnique ceramics. With maize came several other new plants: peanuts, warty squash, pacai, and avocados. Other evidence suggests that manioc was also known. With these additions to the plants previously cultivated we have an impressive list.

Data on domesticated animals are less conclusive. They may have had the dog though the evidence is not too positive. Certainly there is no trace of it earlier. The llama also may have been domesticated at this time, but, if so, its wool had not yet become important in textiles.

The Cultist used bone and stone extensively for tools. However, only stone mortars and pestles, plain and decorated stone bowls, and bone spatulas are found throughout the whole area. Adding the bone and stone implements from local sites, gives an inventory of grooved stones, hammerstones, long: lance heads, both four-pointed and four-flanged club 

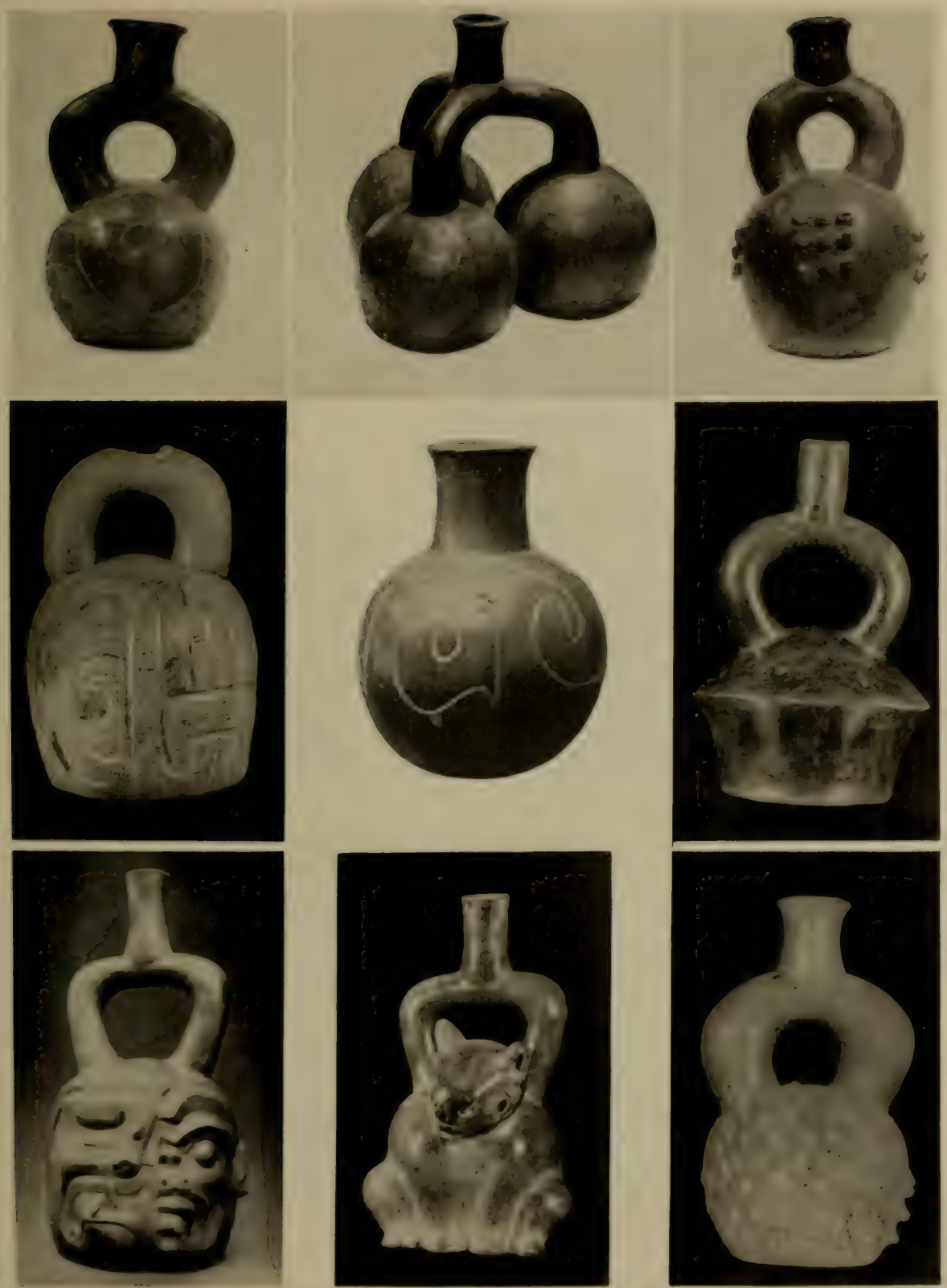

Fig. 23. Cultist period ceramic types. Courlesy of Rafacl Larco IIoyle, exccpt top center. 

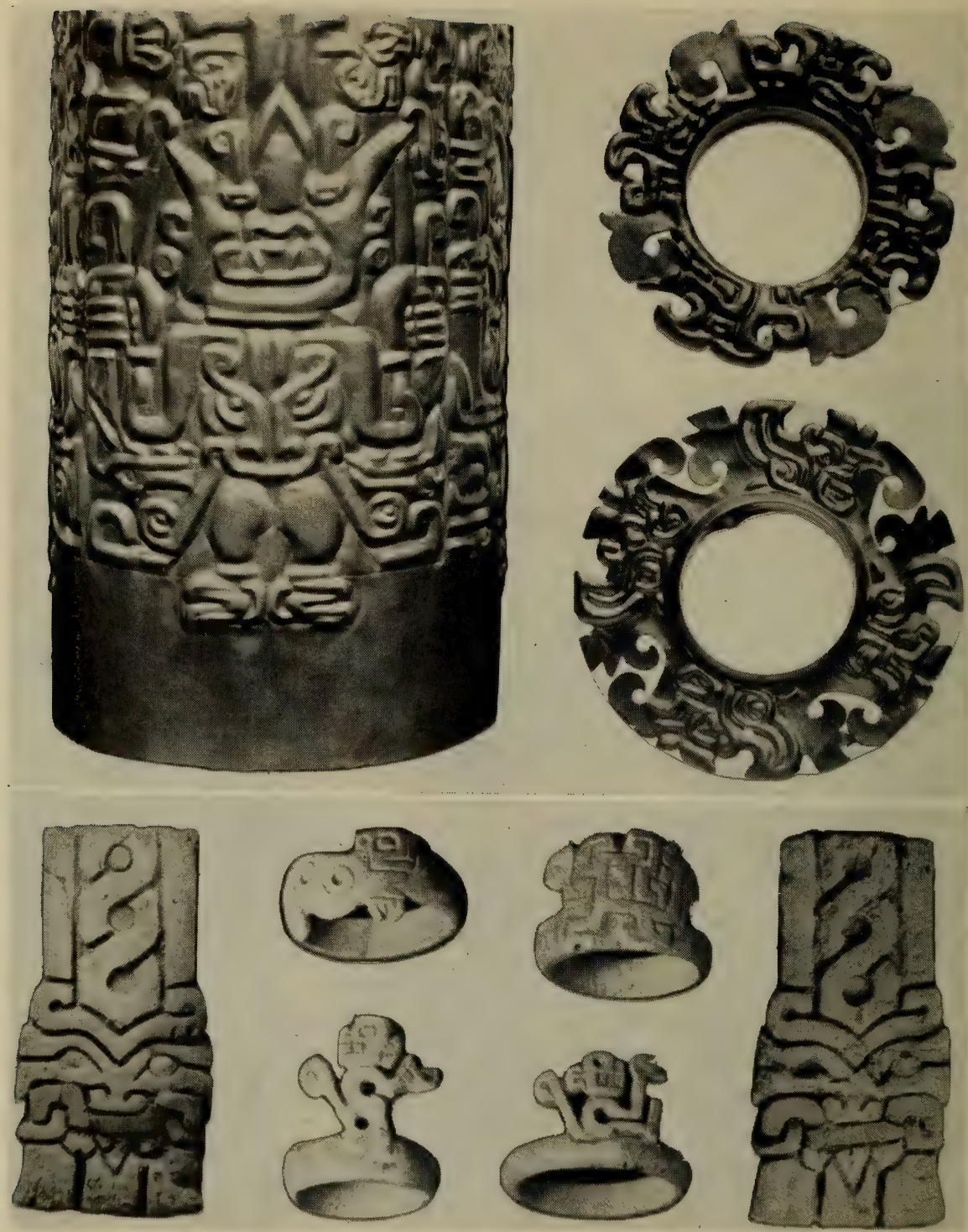

Fig. 24. Cultist Period goldwork from Chongoyape and bone artifacts from Chicama. Courtesy of Museum of the American Indian, Heye Foundation; Bone, Courtesy of Rafael Larco Hoyle. 
heads, stone boxes, and bone awls, needles, dagerers, spear-throwers, and spoons. A long chonta palm bow was found at Ancon, but the spear-thrower was probably the more characteristic weapon.

Ceramics are now a constant association and these present certain similarities due largely to technological limitations. Vessels are basically monochrome, black, brown, or red, with thick walls and coarse tempering. The dark colors show that firing was in a reducing temperature, usually in the form of a smudge, but that control of oxidation was still limited. Brush painting was still unknown, but a number of characteristic decorative techniques appear, namely, modeling, relief, incision, stamp, appliqué, punch, scratch, and area polishing. The commonest ressel shapes are open bowls with thickened rims, bottles, collar jars, and stirrup-spouts (Fig. 23). The designs consist largely of geometric elements like circles and dots, cross-hatch, and curvilinear lines, but the Charín feline is also important. On the basis of the ceramics two major regional divisions are recognizable: one, the North Coast, the second, the Central Coast and the North Highlands. The North Coast may be characterized by its emphasis on modeling, mold-made pottery, thick stirrup spouts, and the feline design. In the Central Coast and the North Highlands open bowls with thickened rims and the simple geometric designs are emphasized.

In this early period textiles are poorly preserved, but spindle whorls and rare cloth fragments illustrate a knowledge of true loom weaving. The fragments are virtually all made of cotton and demonstrate that the weaving techniques were competent although not as varied as in later times. 
Plain weaves, some with creped threads, are the most frequent and there are also monochrome tapestries, weft stripes, fringes, tassels, and embroideries. A more elaborate piece, found in a shellheap at Supe, has a woven design depicting the Chavín feline.

From the textiles, the ceramic modeling, and the stone carving, it is clear that the typical Central Andean costume was not used. The figures are depicted without skirts, shirts, or footgear, and as wearing only belts, breechcloths, and some form of head covering, plus snoods. Feather headdresses have been found at Supe and some of the stone carving designs represent feather capes. On the North Coast the meagerness of clothing at Cupisnique was compensated for by an elaboration of body ornament. The graves contain stamps for body painting; cylindrical and pendent earplugs; bracelets; rings; many types of necklaces; wristlets; crowns; etc. The ornaments are made of many materials such as bird bone, turquoise, quartz, lapis lazuli, shell, bone, stone, and gold. All of these are well constructed and illustrate the artistic expression of the period. Pyrites or jet mirrors are found in all sites. Artificial skull deformation is also typical.

Metalwork is limited in materials and techniques. Gold was the only metal used and even this is not found everywhere. Thin hammered sheet gold occurs at Supe and pressed relief objects have been found in Viru and at Chongoyape (Fig. 24) in Lambayeque Valley where the goldwork is more elaborate than at other sites and may be somewhat more recent. Gold cuffs, ear discs, and other ob- 
jects are made by welding and soldering and decorated in relief with the Chavin foline motifs.

More perishable artifacts have been found in the middens and graves at Supe and Ancon. These include carrying nets, fish nets, netted hags, twined baskets, and totora mats, carved gourd containers, wooden boxes, and knobby sticks.

Most graves are simple pits containing flexed or extended burials. Variants, namely a simple stone lined and a shaft and chamber grave, are known only from Cupisnique where the skeletons are covered with red paint. Grave offerings are usually limited. Food is rarely included. Ceramics are either absent or limited to a few vessels. Other grave accompaniments are equally simple except at Cupisnique where personal ornaments are found in considerable quantity.

The domestic architecture is generally extremely simple, with circular or rectangular stone house foundations and stone-faced terraces for house platforms. One modeled Cupisnique ressel depicts a house with a gabled roof, straw thatch, and a thickened foundation wall. A structure near Huaca Prieta indicates that the walls were of adobe. Perhaps, when excavated, the site of Pallka in Casma, with its aggregate of many rough stone rooms, may prove to be an exception to this simple domestic architecture. The religious architecture is on the other hand quite elaborate. The buildings identified as temples are quite large, well plamned, and extensively decorated. The coast temples are constructed of rough stones set in mortar, or of conical adohes, which vary greatly in size, but are always laid so that the flat bases form the surface of the wall. Several buildings in Viru and Chicama on 
the North Coast are constructed of conical adobes. These probably belong to this period, but so far they have not been excavated. On the Central Coast no buildings of any magnitude can be assigned to this period. The best examples are found in Casma and Nepeña valleys where the sites of Cerro Blanco, Pungurí, and Moxeke are outstanding. All these buildings are constructed of rough stones and conical adobes. Each has such features as platforms, steps, rooms, clay columns, and decorated walls. The decorations are in polychrome fresco, in incised clay, and in high relief clay carving. The predominant design element is the ubiquitous Chavín feline.

The site of Chavín de Huántar, located in the North Highlands on a small tributary of the Marañón River, is the most elaborate construction of this period. The narrow valley in which Chavín is located certainly could not have supported a very large population, but the massive construction which covers a large area must have required many laborers. The several building units have a roughly symmetrical arrangement around a large sunken court, about forty-eight meters square, flanked on the north and south by raised platforms. The river has cut away the end of one of these platforms revealing a rubble construction with a few poorly constructed interior galleries. The exterior is faced with rough stones. Behind a raised terrace to the west of the courtyard is the "Castillo," the principal building, roughly seventy-five meters square and over thirteen meters high at the southeast corner. In order to maintain this height, the walls are inclined inward and are also set back in narrow terraces near the top. The exterior walls are finished with carefully dressed stones. The building was once en- 
circled by a decorated cornice beneath which was a row of carved heads, each with its tenon for insertion in the wall. The interior of the Castillo has three floors, each with an elaborate series of stonelined and covered galleries and rooms, as well as a special system of rentilating shafts which are found throughout the construction. The galleries are about one meter wide and 1.8 meters high. The rooms vary from two to four meters on a side. Ramps and stairwars lead from one floor to another. One gallery still contains a carved prismatic stone known as the "Lanzon.".

Many smaller buildings form part of this group, ret the site does not have the appearance of a village. Some habitation refuse is found near the structures, but actual house sites are few. Several house foundation walls on top of the Castillo are made of carefully dressed stone. The interior galleries and rooms contain no refuse nor other evidence that they functioned as dwellings. The symmetrical layout, the careful construction, and the carved wall decorations suggest a religious structure. Certainly, a unit like the Castillo must have been built according to plan. The first floor vents, galleries, and rooms were first constructed of stone, the spaces between the walls filled in with rubble, and the outside walls finished with dressed stones laid in horizontal rows of alternating thick and thin slabs. The second floor was added, following a similar pattern of galleries, rooms, and vents. Actually, massed man power would have been essential only to assemble the materials. The construction could have been completed over a period of time by a small group of skilled masons. 

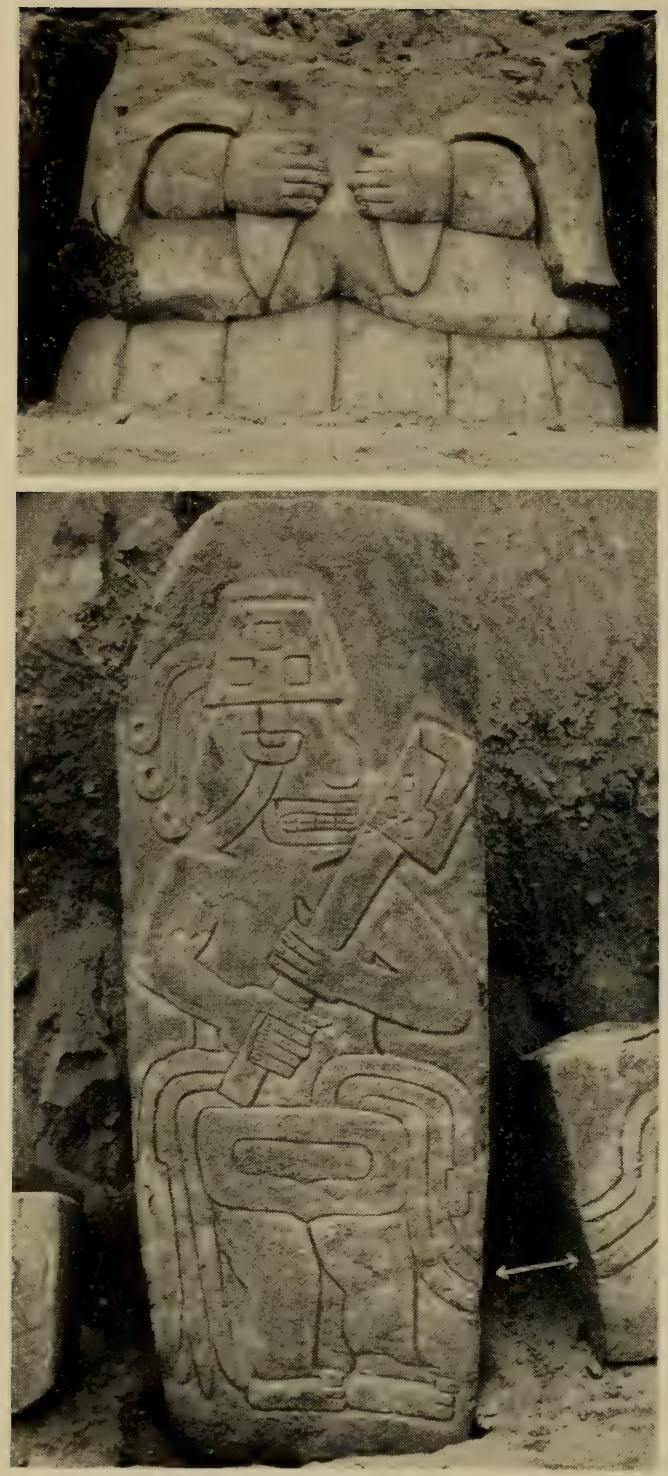
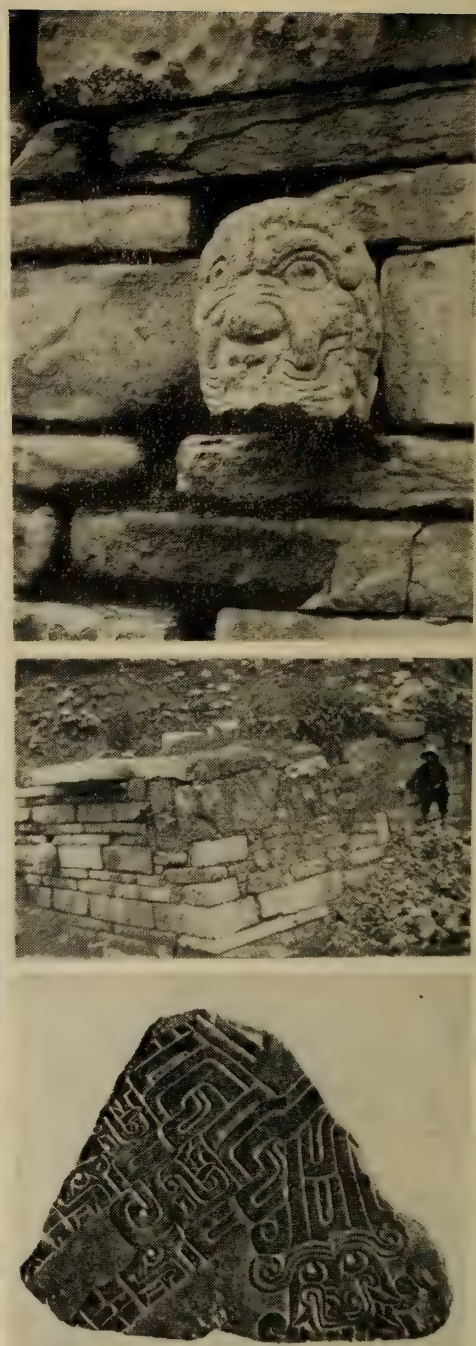

FIg. 25. Building and carving of the Cultist Period. Upper left, modeled clay, Moxeke, Courtesy of Donald Collier; lower left, Cerro Sechín; others, Chavín de Huántar. 
Although carving is reasonably abundant at Chavin de Huantar and at some other highland sites, it is not characteristic of the entire period (Fig. 25). The carvings include human and feline heads in the round, with tenons for wall insertion, flat slabs for cornices and lintels, but no true statues. The flat carving is accomplished by incision and champlévé rather than by high relief. The style is dominated by the feline motif represented in profile or in front view. The basic feline figure may be anthropomorphized or appendages may be added to identify it as a condor or a fish. Almost every detail of the design portrays another stylized representation of the feline head. Technically, this style is not very consistent for stonework, but suggests a repoussé metal technique applied to stone. In fact some authors see a stylistic technological sequence within the Cultist Period from the metal relief work of Chongoyape, through the clay relief of Nepeña and Casma, to the stone carving of highland Chavín.

Stone carving of any kind is rarely found on the coast of Peru; the outstanding exception is at Cerro Sechin in Casma Valley. This is a large construction composed of two principal terraces. The lower terrace has a central stairway flanked on either side by a series of earved monoliths between which are smaller stones, each with a face carved on one side. This carring style is unique in Peru. The designs are based on the human figure, and there is no suggestion of the Chavin feline. If, as present evidence suggests, this construction belongs in the Cultist Period, it must antedate the spread of the Chavin horizon. 
In spite of certain features and similarities which characterize the Cultist Period as a whole, there is no evidence of over-all political unity. Instead, the social organization appears to have been based on family units grouped into small villages. It is not even demonstrable that the villages in a single valley were united politically. The general impression is that of a society which still devoted considerable effort to subsistence activities and directed its excess energy and limited leisure time towards art expression and religious practices. The art work, particularly the ornaments, seems individualistic in spite of the restrictions of techniques and the conventions of the Chavín horizon style. The religious practices find their major expression in the construction of temples, both local and regional. The religious importance of the feline concept is obvious. However, if the quantity of grave goods is significant, ancestor worship had not yet reached the prominence which it gained in later periods.

Large constructions like those at Chavín de Huántar do not in themselves imply enormous concentrations of population. As has been suggested, such building's could have been erected by a small number of skilled masons and workers, once the necessary materials had been assembled. A religious pilgrimage pattern is implied, in which large numbers congregate during certain ceremonial periods in the year, contribute their labor service, and return to their respective settlements. The pilgrimage pattern still exists. For example, at Copacabana in Bolivia thousands assemble every August for religious celebration. At the time of the Conquest, Pachacamac, near Lima, was renowned as a 
pilgrimage center, and much of the archacological evidence suggests the antiquity of this pattern.

A reconstructed picture follows. During one or more weeks in the year many people made the pilgrimage to a center like Chavín de Huántar for religious celebration. While great numbers were assembled, the building materials would be brought in, stones dressed, and some of the larger slabs put in place. When the ceremony ended and the pilgrims returned to their distant homes, specialized architects carried on the construction with a few local laborers. During the time of assembly, ideas and perhaps goods would be exchanged. At a minimum, the feline design, the primary symbol of the religion, would be widely distributed, without the implication of political unity.

As technology improved and as irrigation and agriculture became more firmly established, more attention was devoted to the local region. Populations increased and political organization adranced. Regionalism became marked and the pilgrimage pattern was abandoned. In each local area experiments in many types of controls were undertaken. The Experimenter Period lacked over-all unity. This tendency towards local development continued for a long time; in fact, until the Tiahuanaco horizon complex again represents, in appearance at least, a pan-Central Andean unity.

\section{Experimenter Period}

$$
\text { (ca. 0-600 A. D.) }
$$

The Chavin horizon, characterized by the stylized foline design, gives a definite unity to the Cultist Period. The exact origin of this style is unknown; 


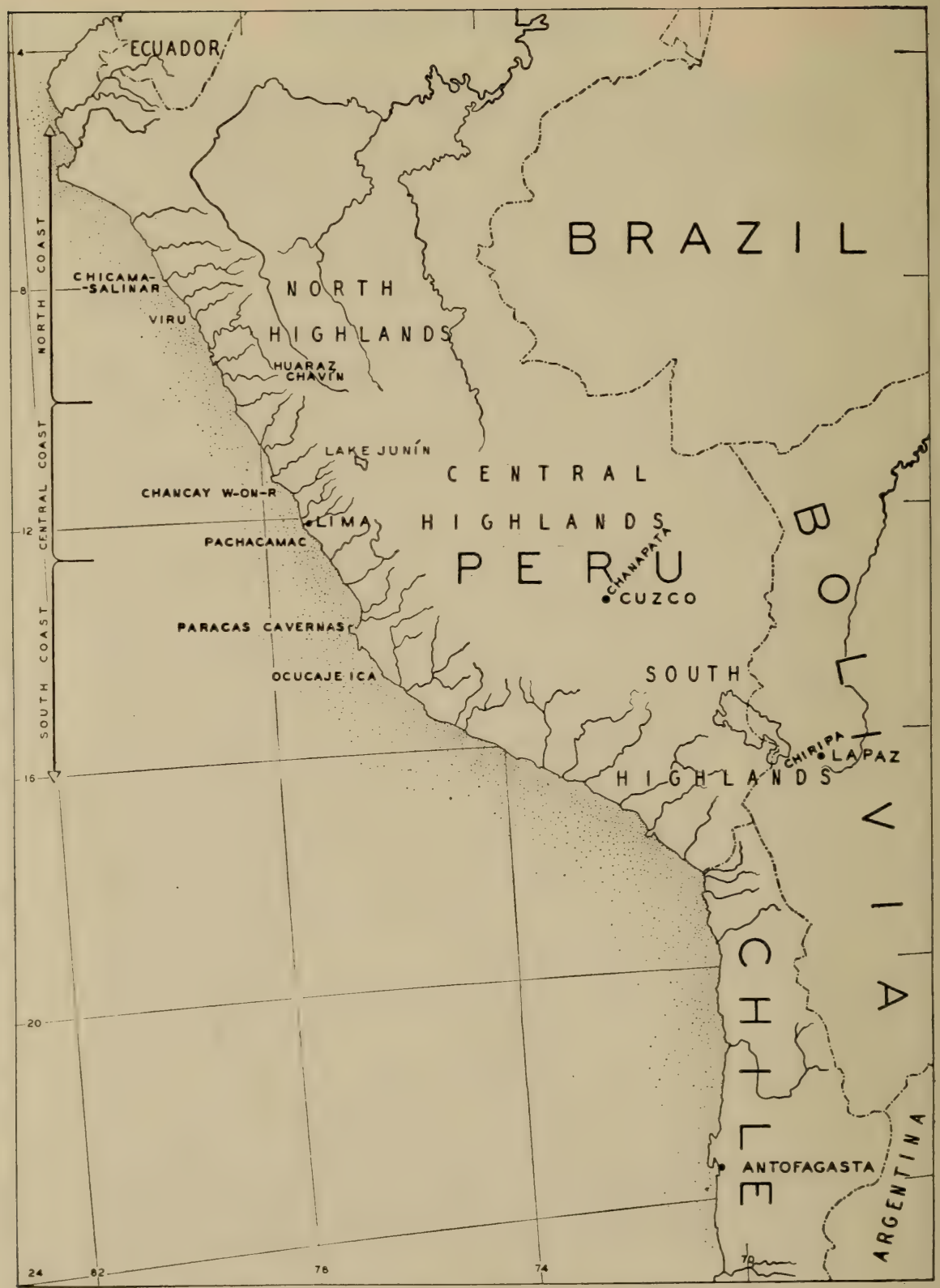

Fig. 26. Prineipal sites of the Experimenter Period. 
in most regions it disappears as rapidly and mysteriously as it appeared. However, the Chavin feline reappears as a design element in the much later Mochica culture, so that presumably it continued to dominate the artistic expression in some marginal area of the Central Andes. The most likely section for such a surviral is the Far North Coast, namely, in Lambayeque and Piura valleys where, unfortunately, full archaeological sequences have not been established. Elsewhere, the gap between the Cultist and Experimenter Periods is a sharp one, in spite of the fact that the undecorated utilitarian ceramics demonstrate a population continuum.

The Experimenter Period includes many local cultures, grouped together basically because they can be assigned to the same relative chronological position. However, they are also linked by some general characteristics as well as two horizon styles, namely, the White-on-Red and the Negative. The principal cultures and sites of this period are the following: the Salinar culture sites in Chicama Valley and the closely related Puerto Moorin culture sites in Viru Valley; Cerro de Trinidad and Baños de Boza, type sites of the Chancay White-on-Red style; the North Highland White-on-Red style sites near Huaraz and at Chavín de Huántar; the Carernas culture, represented at Paracas near Pisco Valley and at Ocncaje in Ica Valley; sites of the Chanapata culture near Cuzco; and the Chiripa culture site on the Bolivian side of Lake Titicaca. There is good evidence for placing these local cultures and styles in a time position between the Cultist and the Mastereraftsman Periods. A cultural sequence of Cupisnique, Salinar, Mochica has been 
established in Chicama Valley by grave stratigraphy. In Viru this is confirmed by refuse stratigraphy which places Puerto Moorin as post-Cupisnique and pre-Gallinazo. In the Chancay sites, the Whiteon-Red style gradually fades into the later Interlocking style-a sequence duplicated at Pachacamac. White-on-Red style graves are intrusive at the Chavín de Huántar ruins. At Paracas on the South Coast, the refuse of the Cavernas culture is older than the Necropolis culture graves. The Chanapata sites are known only to be stratigraphically pre-Inca, but the Chiripa culture can be shown to antedate both Early and Decadent Tiahuanaco.

Deep refuse deposits in Viru, Chancay, Paracas, and Chiripa point to a relatively long duration for the Experimenter Period, some six hundred fifty years in the guess-dates employed here. This estimate is complicated by the uncertainty of the beginning and the termination of the period. The lower limit is unsatisfactory because of the apparent abruptness of the break with the Cultist Period. Only a few Salinar bone spatulas and some rare incised Cavernas ceramics indicate any carry-over of the Chavín feline design, and even in these it is an atypical variant. It is even more difficult to fix the upper limit because of the gradual transition into the technological controls and mastery of crafts that mark the next period. The specific changes differ in each region and undoubtedly occurred at different times. On the North Coast the Salinar culture soon divides into the Gallinazo and the Early Mochica. On the Central Coast a gradual transition is traceable from the Chancay White-on-Red to the Interlocking. The South Coast situation is not very clear, although the Cavernas culture contains 
the basic elements of both Necropolis and Nazca. The Chiripa culture in the South Highlands apparently develops into Pucara and Early Tiahnanaco. There is, then, no sharp cleavage between the Experimenter and the Mastereraftsman Periods. Rather, the first represents the begimning and the second the culmination of the same sequence.

The Experimenter Period sites are found in every major region of the Central Andes, which was not true of the Cultist Period. In all probability this may be due to differences in archaeological information and does not imply any sudden expansion of occupation. The sites include cemeteries, villages, habitation refuse deposits, and, more dubiously, hilltop fortresses and shrines.

On the whole, this period is characterized by experimentation in new techniques and new controls. This can be best observed in the technological achievements, in the crafts, in building, and in the agricultural methods. Similar experiments on the socio-political level are not so clear and probably were not of major importance until the technological controls were well crystallized. Superficially, some of the materials seem inferior to those of the Cultist Period, but a detailed examination proves these to be superior in technique, even though less artistic. Some artifacts have a reasonably wide distribution, but in general the period is marked by local developments, so that description of the periorl as a whole is difficult. The Cultist Period achieved unity through a religious pilgrimage pattern, but even this seems now to have disappeared. The two horizon styles that transcend the regional houndaries are both based solely on techniques. The White-on-Red horizon is little more than a tech- 
nique of positive brush painting on ceramics that spread throughout the North and Central Coasts and the North Highlands. The slightly later Negative horizon is likewise a ceramic technique of resist painting that spread all along the Coast and into the North Highlands. In some areas these techniques were further improved and retained for a considerable length of time. Elsewhere they were tried and abandoned.

On the coast, the sites of this period are located on the valley margins and along the shore. The latter show a marked dependence on seafood, but there is now no doubt that irrigation was practised, particularly in the upper narrows of the river valleys. The highland sites, like Chanapata and Chiripa, are associated with stone-faced terraces which are probably part of the cultivation system. Stone hoes are common. Several new plants and fruits can be added to those known previously: the frijol bean, quinoa, cañahua, and pepino, a sterile hybrid which can be propagated only by cuttings. Llamas are now common and one modeled clay animal at Chancay resembles a guinea pig. Coca, the important narcotic, has been found in a Cavernas tomb, as well as pots containing the dregs of some liquid like the corn beer, chicha. Dried meat found in coastal graves and a bin which contained quinoa at Chiripa suggest that methods of food preservation and storage were now known. In brief, the Experimenter Period is marked by greater dependence on agricultural subsistence, new techniques of cultivation employing terraces and irrigation, experiments with new plants, and the preservation of food. 

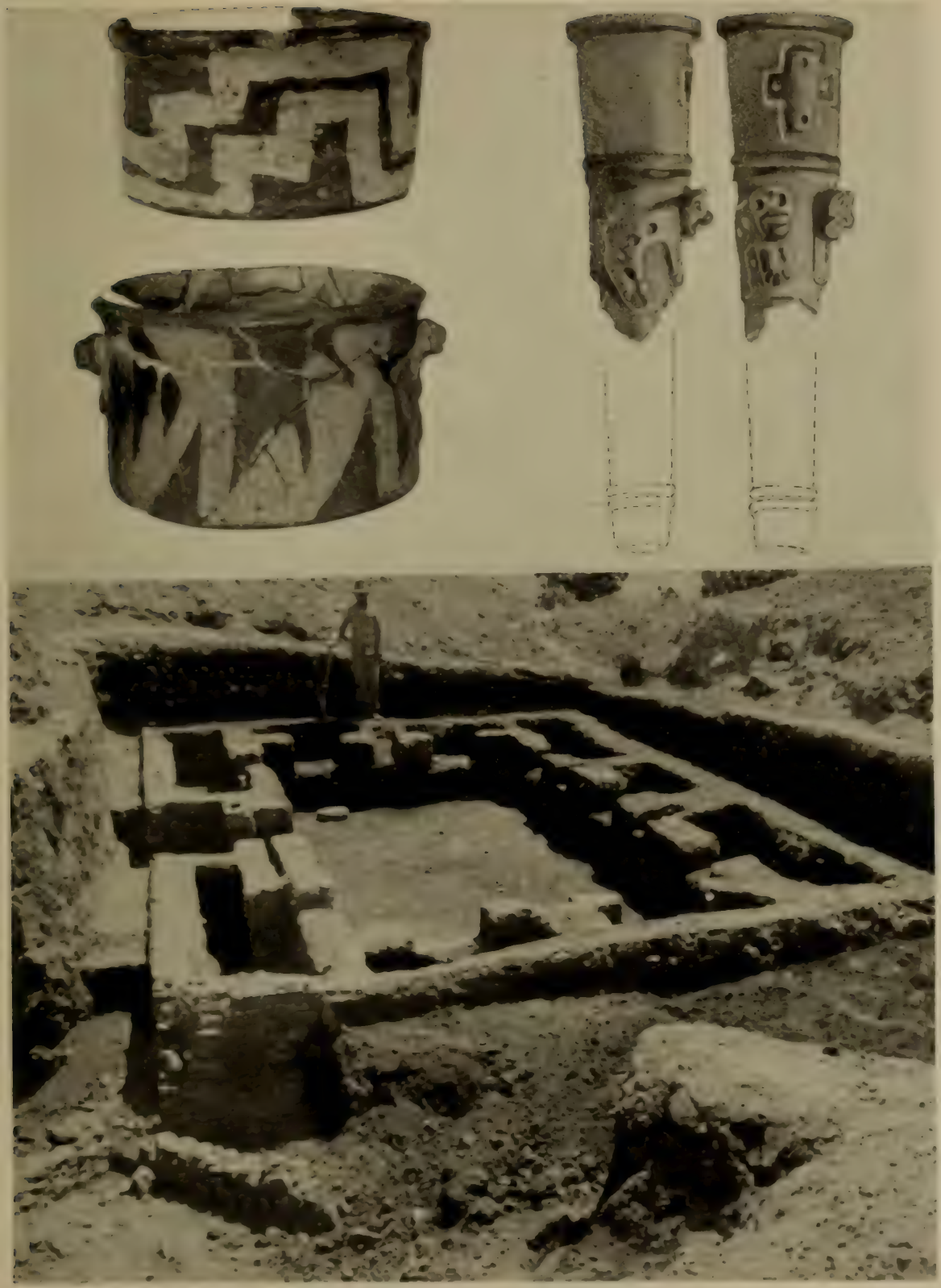

Fig. 27. Chiripa ceramirs and house site, Experimenter P'eriod. 


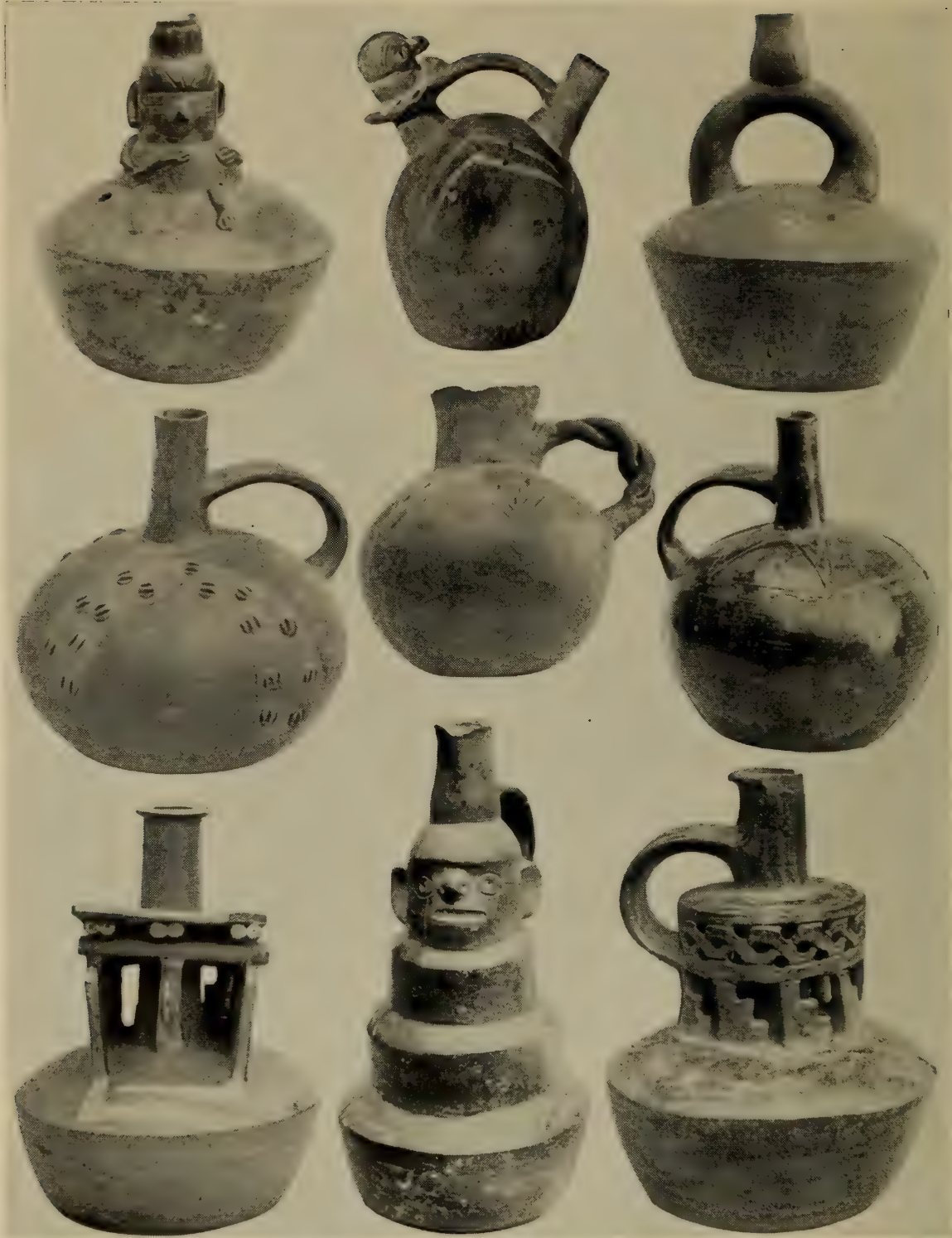

Fig. 28. Salinar ceramies of the Experimenter Period. Courtesy of Rafael Larco Hoyle, except top center. 
Rough stone continues as a common building material, but, in addition, various types of hand-made adobes were used on the coast. These are conical or odontiform on the North Coast, dome-shaped on the Central Coast and blunt-conical on the South Coast. Modeled Salinar ceramics represent two house types; one, circular, with a flat roof supported by step-shaped side pillars; the other, rectangular, with an open front and a pent roof supported by cross beams and a central pillar. In Viru Valley there are small villages composed of clusters of three to five stone house foundations. It is also possible that honeycomb clusters of subterranean or semi-subterranean rooms were built of tapia and ball-like adobes. At least, these are the earliest types found in the succeeding Gallinazo culture. Underground dwellings are also found at Cavernas, Huaraz, and perhaps Chanapata. A unique type of village is found at Chiripa on the Bolivian shore of Lake Titicaca. It consists of fourteen rectangular houses arranged in a circle around a central court. The foundation walls, which are intact, are about one meter high and are built of small stones packed in clay. The upper walls were constructed of rectangular adobes and the roof of sticks and grass thatch. The side walls are double; their hollow interiors were used as storage bins, access to which was by means of inside rectangular windows. Deep vertical slots in the door jambs were for sliding wooden door panels (Fig. $2 \overline{7}$ ).

Technological advancement in ceramic manufacture and decoration is evident, although some of the earlier techniques, such as incision, punch, appliqué, and relief continue. A major improvement has been achieved in firing in open ovens with full oxidation, 
resulting in hard, red-orange ware. The ceramics are thinner than in the preceding period. Another advance is the use of a brush for painting. Color is usually limited to white. Painted designs are restricted to panels or simple geometric elements. They are never figural and are usually secondary to the decorative features. Negative painting likewise is employed only in the execution of simple designs. In spite of the technological similarities and the widespread horizons, each region has an easily distinguishable local ceramic style.

Salinar presents a great range of vessel shapes, of which the most typical are stirrup-spout containers, jars with a spout and a bridge to a modeled figure, bottles with cylindrical necks and flat handles, and ollas (Fig. 28). Modeling is an outstanding characteristic. The small figures which are almost caricatures are noted for their detail of facial expression. The modeled vessels portray birds, animals, and human figures in peculiar positions. All are disproportionate in detail, particularly in the treatment of the eyes. Incision, appliqué, punch, and white-on-red brush painting are also employed. The white paint is applied directly to the base clay. The designs are simple lines or triangles. Paint is also used to augment the modeled features of the vessels.

The Central Coast ceramics, best known from the Chancay sites, consist mainly of bowls with flaring lips, mammiform jars, flaring-sided cups, and plain jars. Incision is rare and modeling is limited to simple lugs. Some negative painting is found, but positive painting, either white zoned, or white-onred, simple geometric designs, is the more characteristic decoration. 
The Cavernas ceramies are also varied in shape, including open bowls, containers with a spout and bridge to a modeled figure, and globular ressels with two spouts. Modeling is common; the figures resemble those of Salinar, except that they are not so well portrayed. Many ressels are decorated by incision and some of the designs display the influence of the Chavin feline motif. Negative painting is employed rarely. However, the most distinctive style is a combination of incision and painting resembling cloisonné (Fig. 29). The paint, applied after firing, is in bright colors, such as canary yellow, green, red, and black. Again paint is used to fill in areas, not to produce the major designs.

The Chanapata ceramics are predominantly monochrome blackware: ollas with strap handles, open bowls with flaring sides, bottles, and plates. The major decorative techniques are incision, punctation, and appliqué. A simple cat, unlike the Chavín motif, is the characteristic design. Some positive painting presents both a red-on-white and a whiteon-red combination, although it is not related to the Chancay style.

The typical Chiripa ressel is a flat-bottom open bowl, with perpendicular sides, and a thickened rim edge. Simple geometric designs are executed in a thick yellow paint on a red slip base (Fig. 27). The color areas may be outlined by incision. A cat figure in appliqué relief, like Chanapata, is also common. This style, plus black paint and more emplasis on the modeled relief, forms the basis for the Pucara style.

Certain cultural traditions are either continued or established during this period. On the North Coast, the ceramic traditions of modeling, stirrup-spout, 


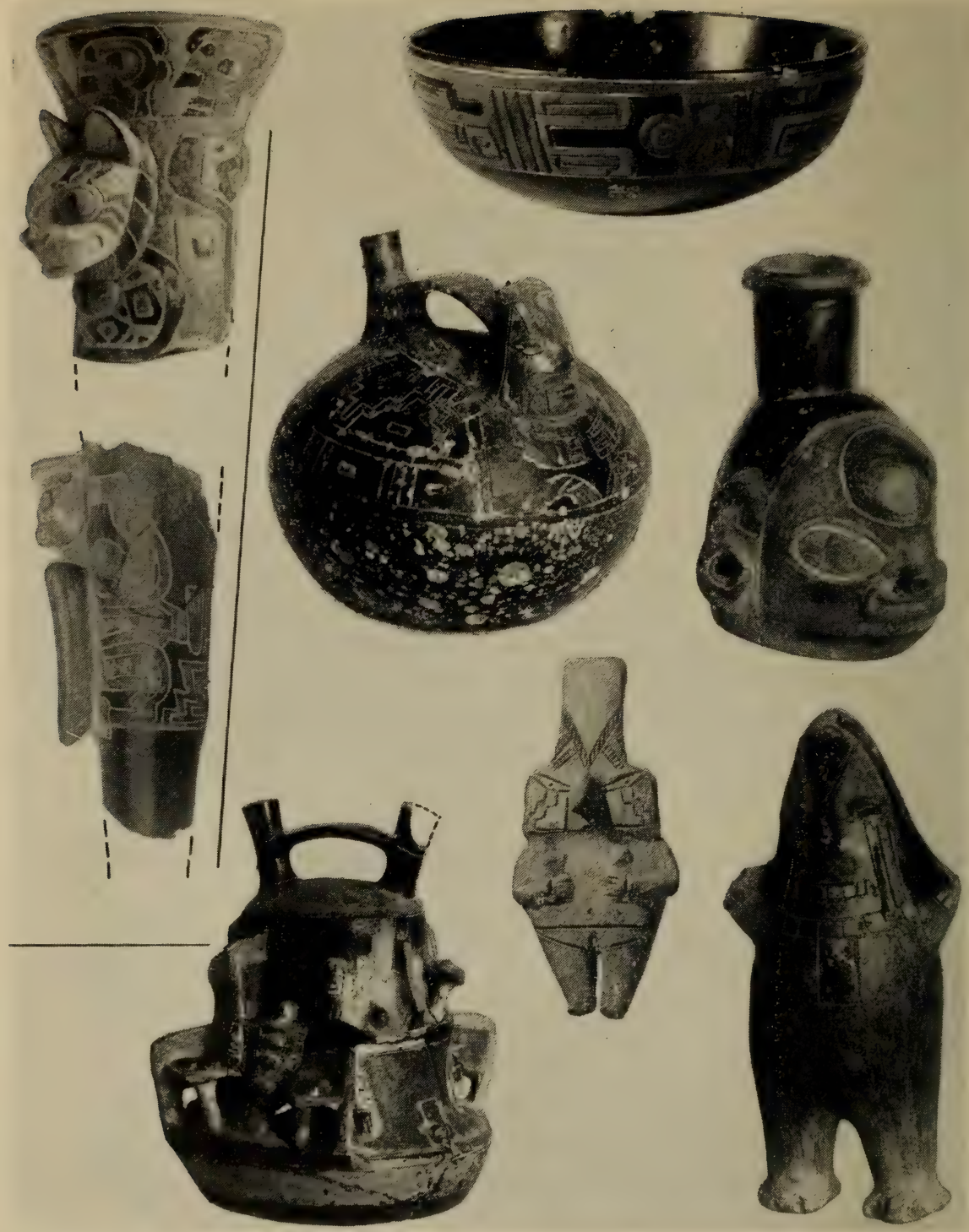

Fig. 29. Paracas Cavernas ceramic style of the Experimenter Period. The tube at left is Pucara culture showing same technical treatment. Courtesy of Museo Nacional de Antropología y Arqueología de Peru, except for bowl at top and small figurine. 
and mold manufacture are continued and the bichrome painting tradition is established. All of these persisted into the later Mochica culture. On the South Coast, the Cavernas culture initiates the polychrome painting ceramic tradition.

Loom weaving is associated with all the cultures of this period, but the greatest advance occurs at Cavernas. Elsewhere plain cotton cloth is present, as well as such basic spinning and weaving equipment as plain and incised clay whorls, bone and thorn needles, and spindle shafts. The Cavernas weaving presents advanced techniques and utilizes cotton, wool, maguey fiber, and human hair. Great emphasis is placed on the single element techniques of netting, knotting, knitting, twining, and plaiting, for making fish nets, carrying nets, and headband nets. Fine ganzes are particularly distinctive. Other common techniques are brocade, single-faced weft pattern, embroidery, and painted cloth.

Among the woven fabrics at Cavernas are a variety of turbans and headbands, shirts, shawls, breechcloths, waist bands, and bags with straps. This is the basic Central Andean clothing pattern. It is reasonable to assume that the highland inhabitants possessed adequate clothing, although no actual specimens are preserved. The modeled ceramics on the North Coast present little evidence for the clothing except for the use of a knee length shirt. However, the head coverings represent skull caps, headhands made of layers of cloth, conical caps, and mitre-like square caps with visors. Perhaps good conditions for preservation alone account for the distinct leadership of Caremas in weaving, but it seems more likely that the eulture placed great ('mphasis on this craft. The greater variety of 
fibers, techniques, and woven garments all bear this out. The South Coast also continues to be a versatile weaving center in later periods.

With greater attention given to elothing, there is less emphasis on personal ornaments than in the preceding period. Skull deformation is practised in both Cavernas and Salinar. Some of the modeled clay figures depict tattooing, but face painting is not very common. Shell, bone, and stone beads are found everywhere. At Salinar circular and tubular earplugs, finger rings, and nose rings are added to the range of ornaments.

Metalwork, although still not very advanced, demonstrates some experimentation with new techniques and alloys. Simple hammered and cut-out gold objects are found in practically all of the sites. At both Chancay and Salinar a gold-copper alloy is used and pure copper makes its first appearance at Cavernas and Chiripa.

The sling and the spear-thrower are the most common weapons. Bone daggers are found in several sites, a wooden spear in one, and, at Chiripa, the bolas is still in use. The Experimenters made a great variety of bone and stone tools. The greatest range is to be found at Chiripa, but all sites have many of the standard implements. The bone inventory includes spatulas, needles, awls, daggers, spear-throwers, hooks, chisels, polishers, knives, and scrapers, some with serrated edges. Only Salinar has decorated spatulas. The stone artifacts consist of such utilitarian types as mortars, hammers, polishers, grinders, and scrapers. Shell seems to have been used only for beads. The Cavernas sites preserve certain of the more perishable artifacts: nets, calabashes decorated by pyrogravure, totora 
baskets and mats, painted leather containers, a circular strainer attached to a handle, and a five-stop flute. Clay panpipes are found both at Chancay and Cavernas.

There is still no evidence for stone carving in this period, although presumably the art carried over from the Cultist Period since it reappears in the Pucara and Tiahuanaco cultures in the South Highlands and in the Recuay culture in the North Highlands. Actually many carved stones in the highlands camnot ret be assigned to any specific period. Some of these may some day be identified as belonging to the Experimenter Period.

Direct pit burial was characteristic of the preceding period and is still a common type. However, there is now evidence of greater attention to the preparation of tombs. Some type of covering is usual. In Salinar, the elliptical graves are covered with inclined slabs. At Chancay the graves are covered with poles or rough stone vaults. Stonelined box graves are commonly found underneath the house floor at Chiripa. Cavernas has more elaborate tombs cut into the soft rock. A typical tomb has a stone-walled upper chamber, 1.5 meters in diameter and about two meters deep. A passage cut through the soft rock extends some three meters below this before it broadens out into a lower chamber which serves as the burial vault. Some Cavernas tombs contain many bundle burials and artifacts. Elsewhere the grave accompaniments are relatively poor: one to three vessels and perhaps a few other artifacts.

It is extremely difficult to reconstruct the type of social organization in this period. Some of the Cavernas tombs appear to have been family vaults; 
these contain burials of both the rich and the poor, judging by the quantity and quality of the cloth wrappings. However, in general, there is little archaeological evidence of any sharp class distinctions. The arrangement of the house clusters, however, suggests an extended family pattern in which each unit was more or less equivalent.

Religion, too, seems to have been of no great importance. The feline cult of the Cultist Period disappeared and no new religious cult replaced it. The paucity of ruins which can be identified as temples or shrines, the relatively meager attention paid to grave construction and accompaniment, and the absence of symbolic design in the ceramics and other arts all confirm the impression of a poorly organized religion. Graves at Ocucaje in Ica Valley contain skulls cut in two halves, a practice which may imply either a religious custom or the preservation of war trophies. A medicineman kneeling beside his patient is represented on one Salinar vessel.

Each local region can be distinguished on the basis of its ceramic styles, but there are no marked contrasts in development except at Cavernas which is clearly more advanced in weaving techniques. Even with this exception, the regional culture patterns are not markedly different. Instead, the picture everywhere is one of relatively small populations, divided into family or extended family groups, which directed their major energies towards the development of agricultural methods, and towards the control of a variety of new techniques. The concentration of attention was therefore on the local region. Techniques developed outside its limits were rapidly accepted and applied locally, but there seems 
to have been no great pressure for widespread political or religious unity.

As experiments proved successful, the technologieal controls improved, and the population increased. When this happened, the geographical differences in size and fertility of regions became an important factor. Increased populations also created new problems in social and political controls. These new problems were solved in different ways in each local region, so that by the succeeding period, which marks the acme of technology and craftsmanship, each region has a distinctive pattern of orientation. As previously mentioned, it is not possible to determine precisely when this transition from experiment to mastery occurred. Doubtless it varied from region to region. However, there comes a point when it is clear that techniques have been mastered in all parts of the Central Andes and a new period has begun.

\section{Mastercraftsman Period \\ (ca. 600-1000 A. D.)}

The long period of experimentation eventually culminated in the complete mastery of many techniques, particularly those relating to aqricultural subsistence and the crafts. Since, as pointed out in the preceding chapter, similar experimentation was carried out in all parts of the Central Andes, it is impossible to determine exactly when the controls were finally achieved, but the quantity of artifacts of good quality suggest a substantial time duration for the Mastereraftsman Period. In the guess-dates used in this volume four hundred years are allowed for this period, but the time span might 


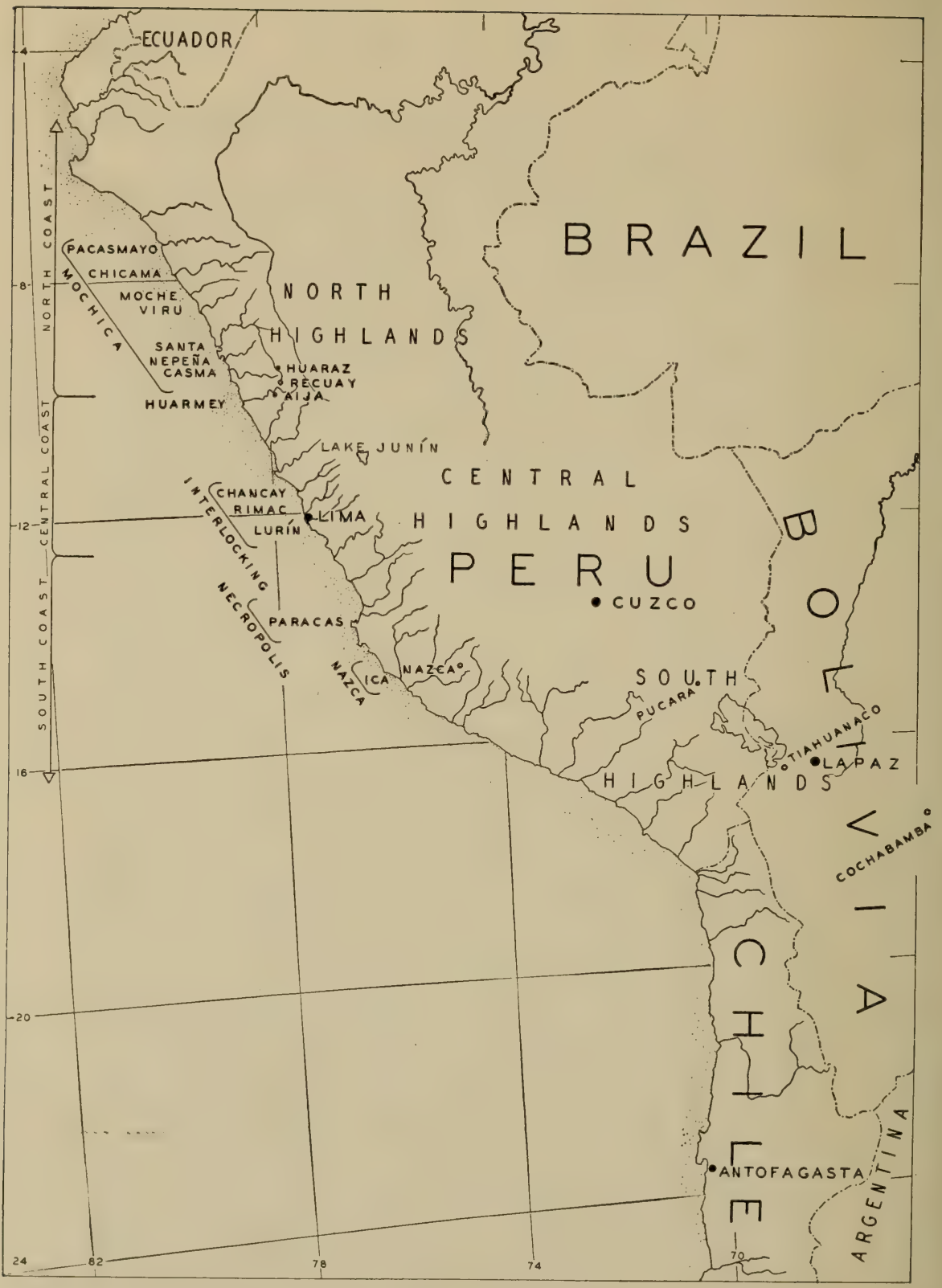

Fig. 30. Principal cultural divisions in the Mastercraftsman Period. 
easily be larger or smaller. The upper time limit is reasonably well established by the widely distributed Tiahuanaco horizon which is so uniform that it serves as a convenient time marker. Everywhere Tiahuanaco is either intermingled with or replaces the local culture of the Mastereraftsman Period, as has been demonstrated many times by stratigraphic excavation and by the analyses of the resultant collections.

In both the highlands and the coast the Mastercraftsman Period is characterized by the mastery of agricultural techniques, by ambitious monumental architecture, by skilled craftsmanship in ceramics, wearing, and metallurgy, and by a florescence of art styles. Despite this apparent unity on the technological level, regional differences are marked. Each sub-area may be distinguished by its distinctive local patterns which were apparently strong enough to absorb alien influences and mold them into the dominant styles without interrupting the basic trends. Some design motifs, such as the feline, snake, sea-otter, and ray fish, are widely distributed, but their specific portrayal is in terms of the local style. In fact, regionalism is so strong that there are no horizon styles in this period. The diffusion, which certainly resulted from the ever-increasing contacts between peoples of the different regions, must have taken the form of a direct exchange of ideas rather than wholesale borrowing. In brief, the differentiation between regions is now of such magnitude that it is no longer merely marked by a contrast of local styles of manufacture and design, but, rather, by distinct patterns of orientation based on the same trechnological elements. Fach local cul- 
ture had a large inventory of techniques and controls at its command and these were selected and developed in terms of the particular regional pattern. For example, the absence of massive temple construction in the Nazca culture cannot be attributed to a lack of knowledge of building methods, but rather to a pattern which directed mass energy into other channels. At the close of this chapter two of the most distinctive patterns are described in some detail because they are important in the later history of the Central Andes.

The Mastercraftsman Period is represented by hundreds of sites and by extensive collections of artifacts. Since this period attained the peak of perfection in craftsmanship, the ceramics, textiles, and other art objects have been avidly collected by both amateurs and professionals, and are abundantly represented in museums throughout the world. It is not practical to list specific sites for this period since each major culture covers a rather extensive area. The Mochica culture is found in the North Coast valleys of Pacasmayo, Chicama, Moche, Viru, Santa, Nepeña, and Casma. The closely related Gallinazo culture is also present in some of these valleys. The Interlocking and Early Lima cultures dominate the Central Coast, particularly in the Chancay, Rimac, and Lurín valleys. On the South Coast, the Necropolis culture at Paracas, near Pisco Valley, is closely related to the Nazca culture of the Ica and Nazca valleys. The Recuay culture is found throughout the Callejon de Huaylas and in other parts of the North Highlands. The South Highlands are the center of the Pucara and Early Tiahuanaco cultures. The distinctive Tiahuanaco culture undoubtedly had its origins in the 
period, but it will be described with the next period which it so clearly dominates. Only the Central Highlands, later so prominent as the center of the Inca Empire, have no known cultural remains of this period.

So vast is the quantity and variety of cultural material that detailed treatment of each culture is impractical. By and large the Nazca and Nochica cultures are the best known; consequently, these are treated in greater detail, particularly in respect to their contrasting cultural patterns. The other cultures are included wherever possible. The technological achierements are presented first as the basis for subsequent analysis of the regional patterns of orientation.

In the Mastercraftsman Period subsistence is based almost entirely on agriculture and there is every indication that the coastal valleys were completely conquered with respect to cultivation. In Viru, for example, hundreds of sites of this period are found in all parts of the valley, with the principal sites concentrated on the valley flats. Some of these are small habitation mounds; others are reasonably large villages. Irrigation systems are intricate and suggest over-all planning. In Chicama Valley one irrigation canal is over seventy-five miles long; another, at Ascope, is conducted across the wide mouth of a quebrada by means of an artificially constructed aqueduct, fourteen hundred meters long, fifteen meters high, and estimated to contain over 785,000 cubic meters of earth. Likewise many of the complicated arrangements of agricultural terraces in the South Highlands are assigned to this period. 
In preceding periods the range of domesticated plants included maize, squash, beans, cotton, peppers, peanuts, manioc, coca, quinoa, cañahua, achira ; and various fruits: pepino, pacai, lúcuma, and avocado. Additional plants and fruits were grown by the Mastercraftsmen: sweet potato, potato, oca, mashua, ulluco, jíquima, yacón, and lupines; tuna, granadilla, chirimoya, guanábana, tumbo, papaya, and pineapple. To be sure, some of these plants and fruits were undoubtedly known previously, but the evidence is now definite. In other words, the total range of Central Andean domesticated plants is now established, and no new plants are added until the Spaniards arrived. Likewise, the standard agricultural techniques include the digging-stick, the hoe, guano fertilizer, and probably every other method known in the Central Andes at any time. The psychological importance of agricultural subsistence is indicated by the common representations of domesticated plants in the art work, the frequent association of plants and religious symbols, and the pictures of ceremonies related to agricultural activities. Domesticated llamas, alpacas, and guinea pigs are numerous, and herding plays an important role in the subsistence. The gathering of wild foods no longer seems important, but fishing, with hooks, nets, and harpoons, is still a standard supplement to the food supply. Hunting, judging by the scenes on Mochica pottery, has now become a sport for the privileged upper class. The hunting scenes depict the use of deer nets and traps, spear-throwers and darts, clubs for sea-lions, and blowguns for birds.

The advanced agricultural techniques and the size and number of habitation sites all suggest a large population. However, population pressure cannot 
have been very severe since many regions and valleys of considerable fertility were apparently only slightly utilized. It is of course possible that future archacological work will prove that these were equally well populated by peoples with different cultures.

Permanent materials, such as stone or adobe, are used everywhere in house building, with the possible exception of Nazca, where village remains have not ret been identified. However, the closely related Necropolis culture at Paracas has subterranean rooms lined with stone and hard-baked, hand-made adobes. An antechamber at the surface has a shaft with a stairway leading down to the lower room. Subterranean dwellings are also associated with the Recuay culture in the North Highlands. Some are long narrow galleries, lined and covered with stone slabs, and entered by a shaft at one end. Others have a central chamber surrounded by a number of small niche-like rooms. These are constructed of large and small stones, carefully chinked, plastered, and often painted. Still others have two floors underground, or a combination of a surface room and a basement-like chamber. Subterranean houses are also found in the South Highlands, but most villages consist of a number of rough stone surface dwellings. The North Coast Mochica ceramies portray houses built on terraces around open patios and with small rectangular rooms. The roofs are gabled and apparently thatched with straw or mats. The excavated ruins reveal clusters of rectangular rooms around some of the large temples. The walls are usually composed of mold-made rectangular adobes. 
Villages of this period are not laid out according to a specific plan. An open scatter pattern is the most typical arrangement of house units. An exception is found in the North Coast honeycomb pattern of which the Gallinazo group in Viru Valley is a good illustration. This group consists of six artificial platform mounds, the largest of which is roughly two hundred by four hundred meters, and over five meters high. Its surface is covered with small rectangular rooms constructed of plain or cane-marked adobes. The rooms average about ten meters square, so that they number several thousand on this one platform. The layout is haphazard; new units were added in amorphous fashion from time to time. It does not follow that all the rooms were occupied simultaneously nor that each room represents the home of a single family unit. However, the group as a whole must have housed a sizable population.

The Mastercraftsman Period is generally characterized by the construction of large public works, usually identified as temples and forts. Again, the chief exception is on the South Coast where, so far, no large buildings have been associated with the Nazca culture. On the Central Coast, although time association for the many large pyramids and building units is not very satisfactory, some of the large pyramids and building units, like Pachacamac and Cajamarquilla, were certainly initiated during this period. For example, some thick walls built of hand-molded adobe and stone are decorated with frescoes with typical Interlocking designs of fish painted in white, yellow, red, and black. In the North Highlands some of the two and three-story 
temples with interior rooms, stone walls, and slah roof's, undoubtedly are assignable to the Recuay culture, although final confirmation of this identification is lacking. Consequently, our best knowledge of large scale public building is from the North Coast and the South Highlands.

The most outstanding Mochica constructions on the North Coast are found at Moche, not far from Trujillo. At the base of a rocky hill, called Cerro Blaneo, are two large buildings separated by a flat plain, once the site of a village. The first building, the "Huaca de la Luna," is a step-sided platform, eighty by sixty meters, terraced against the side of the hill. Graves with Mochica style pottery were uncovered at the base of this platform and some of the room walls on top are decorated with a freseo in black, white, red, yellow, light blue, pink, and brown. The design, in Mochica style, portrays shields, maces, darts, and the like, represented as if in revolt against human control. The second building, the "Huaca del Sol," is one of the largest single structures on the Coast of Peru. The base is a step-sided platform, two hundred twenty-eight by one hundred thirty-six meters and eighteen meters high; it is approached by a causeway six meters wide and ninety meters long. A step-sided pyramid, one hundred three meters square and twentythree meters high, caps the south end of the platform. The Moche River has eut into this building, revealing a solid mass of rectangular mold-made adobes. In fact, the whole mit is composed of columns of adohes, piled up with little attention to binding, implying that it was constructed by organized groups of unskilled workers. 
The Moche ruins are the most impressive, but there are many other examples of large isolated architectural units on the North Coast. Some are step-sided pyramids built on the village flats; others are platforms approached by a ramp. Still others cap natural rocky outcrops and thus augment the impression of massiveness. Rough stones are used in the foundations and algarrobo logs may be inserted as binders, but the greater part of the construction is always of mold-made rectangular adobes. The outer walls are plastered and some are painted or decorated with cut-out arabesques. The decorated walls and the constant association of cemeteries imply that these structures were temples. However, some of the constructions surmounting the high peaks may have served as forts.

In the South Highlands the architecture is more skilled and complex than the simple massive North Coast constructions. The temple at Pucara in southern Peru serves as an illustration. The basic materials are dressed sandstone and basalt blocks, although some adobe is also used. The over-all plan is somewhat complex. An inner court, about fifteen meters square, contains two subterranean burial vaults built of carefully dressed blocks and slabs. The vaults are entered through a doorway and a series of steps. This central court is at a lower level than the surrounding constructions which consist of a series of walls forming a horseshoe-shaped enclosure and contain small compartments with the doors facing the inner court. Each compartment contains one or two slab altars. The stone masonry is consistently of good quality, although the joining techniques so characteristic of the somewhat later Tiahuanaco are not employed. 
The identification of this Pucara building as a temple seems obrious. The North Coast building seems to represent mass labor, but Pucara gives the impression of being the work of skilled professional masons.

Stone carving is associated with all highland cultures of this period. In the North Highlands, carved statues and lintels are characteristic of the Recuay culture. The statues (Fig. 31) represent
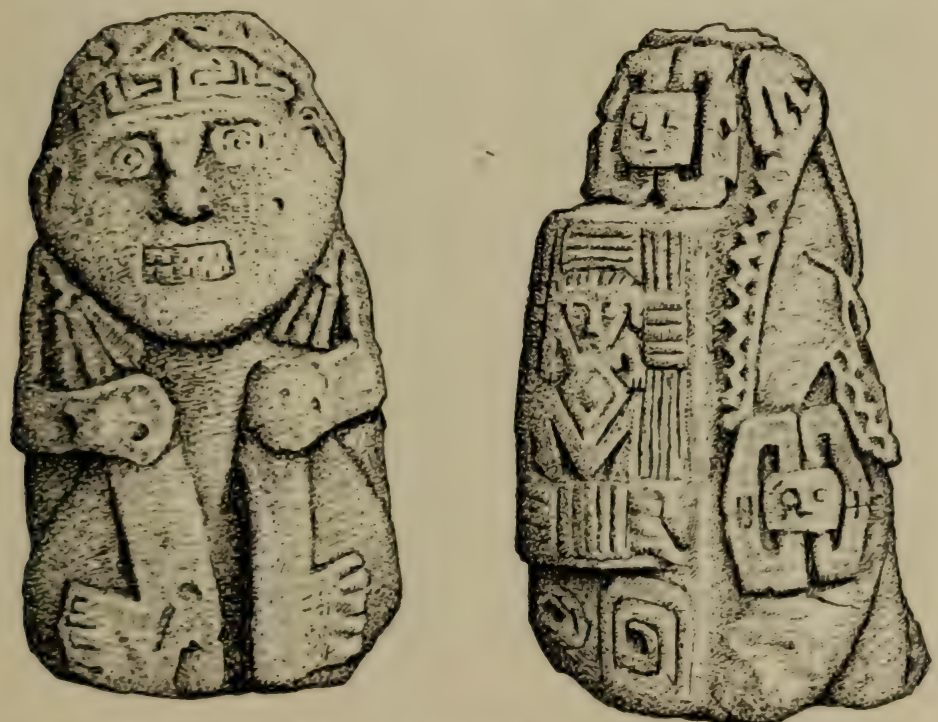

Fig. 31. Recuay style stone statues of the Mastercraftsman I'eriod. Statues in the Huaraz Museum.

seated females and stylized warriors who carry clubs and shields. The figures are further decorated with finely incised designs in Reculay motifs. The Pucara sculptors carved human figures, animals, stelae, and slabs (Fig. 32). The carving is 
competent and displays some attempts at realism, although it is not remarkable as sculpture. The stelae and slabs are usually decorated with frankly geometric designs. The few statues in Bolivia which are assigned to the Early Tiahuanaco culture have certain stylistic resemblances to those of Pucara. Again the statues are somewhat realistic and represented in kneeling or seated positions.
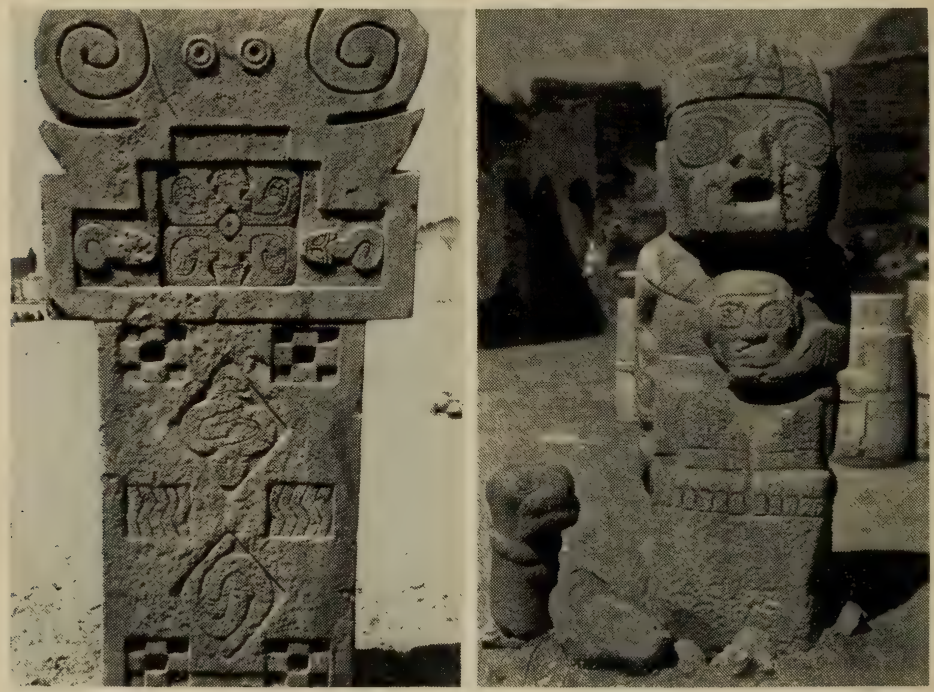

Fig. 32. Pucara style stone carving of the Mastereraftsman Period. Courtesy of Museo Nacional, Lima.

Throughout the Central Andes, the graves of this period, although differing in detail, are always carefully constructed and usually contain a large number of offerings. To be sure, all burials are not equally elaborate even in the same culture, since by this time there are marked distinctions in the importance of individuals. The materials placed in 
the graves are definitely ceremonial. For example, in both ceramies and weaving there is a sharp ('ontrast between the utilitarian pieces and the ceremonial objects intended for interment. The deceased everywhere are buried in definite cemeteries; some are located in isolated spots, others in close proximity to the temples.

The typical Mochica grave is a rectangular box made of adobes. Niches may be built in its walls to hold grave offerings. The roofs are constructed of poles, a combination of poles and adobes, or rarely, of adobes arranged in the form of a true arch. The single or multiple burials are in an extended position and the grave accompaniments are usually numerous. The South Coast Nazca graves are pot-shaped, with a square or round shaft, which may be lined with poles or rough stones, leading to an enlarged chamber below. The burials are flexed and cloth wrapped. Burials of the Necropolis culture at Paracas were in stone-lined subterranean vaults similar to their houses. Some of these vaults contain forty or more elaborately wrapped mummy bundles. The Recuay graves in the North Highlands are either subterranean stone-lined boxes or underground galleries. The dressed stone burial vaults of Pucara in the South Highlands have already been mentioned.

Most museum collections of this period are from graves that have been systematically looted for years, and consequently, contain largely ceremonial objects. In general, knowledge of the utilitarian manufactures is decidedly limited. However, the Mastereraftsman Period is particularly noted for its skilled craftsmanship in ceramics, wearing, and metallurgy. There is no outstanding regional dif- 
ference in technical abilities, so that the distinctions found represent local styles and preference. Each of the major crafts is described, then, in terms of its generalized technical achievement and its specific regional styles.

The ceramics are the best made and most competently decorated of those found at any time in the Central Andes. The pastes are fine and made from selected clays; the firing is done in open ovens with complete control of oxidation; and the thickness or thinness of the ware is entirely under the regulation of the manufacturer. Most vessels are covered with an over-all slip before the design is applied. Modeling, incision, appliqué, and pressed relief are universally known decorative techniques, but the principal distinguishing trait is brush work painted design. Polychrome painting is equally characteristic, although the number of colors varies regionally. In general, the ceramic design is depictive in that the modeling and painting is intended to portray actual objects, animals, birds, and figures. Occasionally the design approaches true realism; sometimes, the basic naturalistic figure is modified or stylized. Each major area has its distinctive series of shapes and designs which are readily distinguishable.

The major diagnostics of the Mochica ceramics are the stirrup-spout, the depictive linear brush design, bichrome painting in white and red, and skilful naturalistic modeling' (Fig. 33). While the number of vessel shape categories is limited, the variations within each are enormous. Roughly, sixty per cent of the vessels in museum collections have stirrup-spouts, that is, two arched tubes which meet in a single cylindrical spout. The stirrup-spout is 

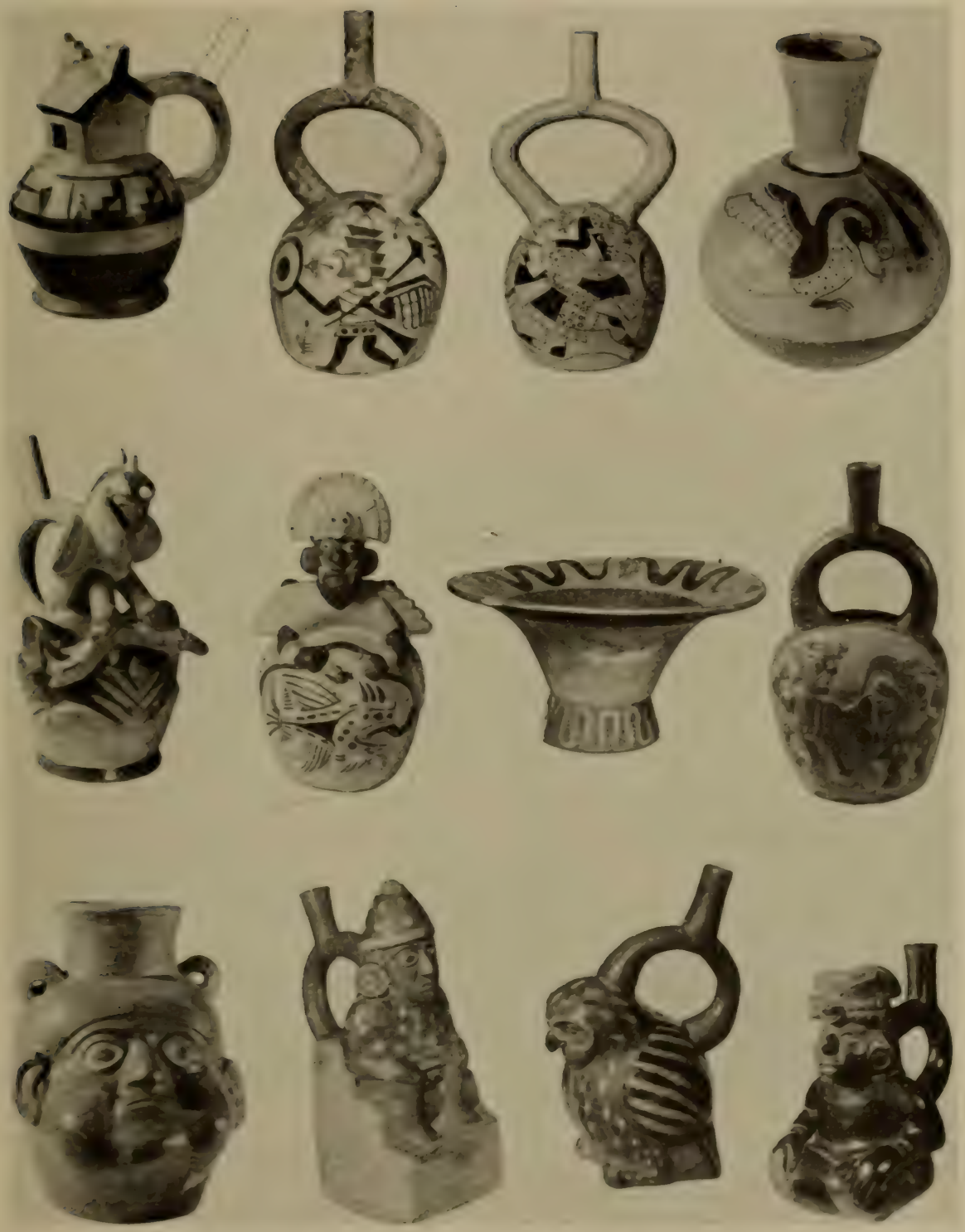

Fig. 23. Tarieties of Mochiea pottery of the Mastereraftsman J'eriond. 
one of the North Coast ceramic traditions, but it is distinguishable in Mochica because of its consistent thinness and regularity of dimension. It is found on globular containers, or, less frequently, on angular-bodied, squat, cylindrical and square vessels. It is also commonly found on modeled containers which portray human heads, human figures, animals, birds, houses, fruits, plants, etc. Other prominent ceramic shapes are head bowls without stirrupspouts, containers with a spout and an arched handle, double bowls, dippers with conical handles, flaring-sided (flower) vases, collar jars, and bowls. Although virtually all vessels are made in molds, true duplication is unusual. Painting, modeling, and relief are used singly or in any combination of the three techniques. The bichrome painting is depictive, some designs showing single figures; others, scenes. Three dimensional effects are achieved in the modeling. Nochica design is basically realistic, portraying many details of the life of the times: fishing and hunting scenes, ceremonies, punishments, battles, modeled portraits of distinguished individuals, house types, animals, birds so carefully modeled that the species can often be identified, and representations of the gods and religious concepts. All these realistic representations permit considerable reconstruction of the Mochica culture. Further references to these designs will be made in discussing other aspects of culture.

On the Central Coast the ceramics have little variety. The predominant shape of the Interlocking culture is a beaker with out-flaring or ontslanting sides, painted in black, white and bright red on a reddish base slip. The characteristic design, after which the culture is named, is an inter- 

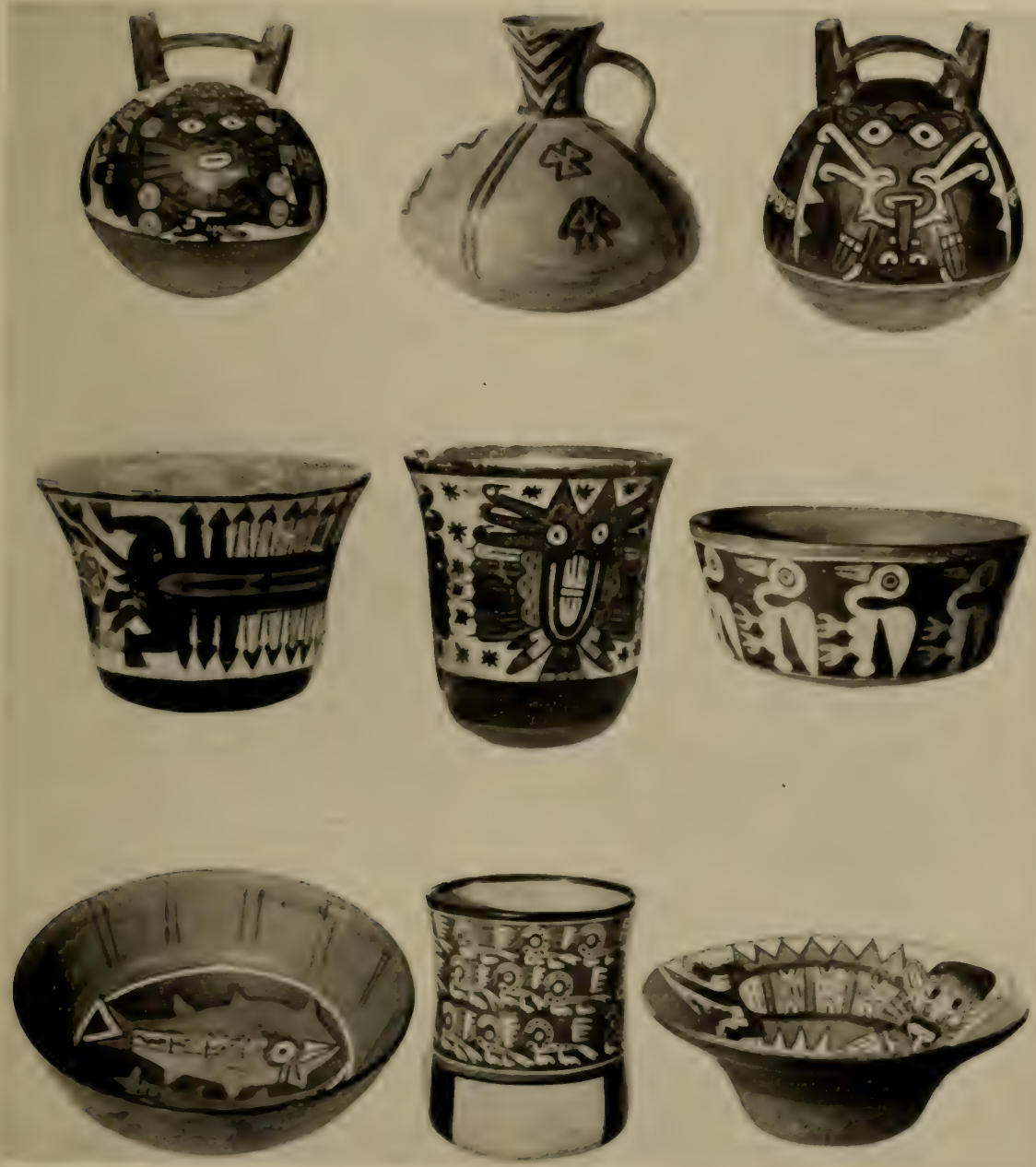

Fig. 34. Interlocking and Nazea style ceramies of the Mastercraftsman Period. Top center, interlocking style. 
locking fish, undoubtedly derived from a textile pattern. Other associated shapes are mammiform jars, double-spout vessels, constricted collar jars, and spout and handle jars. The Early Lima culture has few distinctive ceramic elements, but has, rather, a combination of features from both the North and South Coasts.

The Nazca ceramics (Fig. 34) are characterized by globular containers with two short spouts and a flat connecting bridge, variants on tall, graceful goblets, complex stylized design, and polychrome painting in from one to eight colors on a background slip. There are twenty-five basic shapes; most of them are variants on shallow open bowls, tall goblets, double-spout jars, and a spout and bridge to modeled figure jars. Polychrome painting is outstanding, while modeling is decidedly secondary and not particularly distinctive. The commonest colors are various shades of red, yellow, gray, brown, violet, black, and white. The designs may be termed naturalistic in that they represent fish, fruit, birds, and other identifiable figures. Each design unit is usually outlined in black and filled in with other colors. The more elaborate designs include trophy heads, centipede-like figures, a human figure with a jagged staff and, most distinctive of all, an anthropomorphized feline with a mask. Nazca ceramics are excellently made, highly polished, and brilliant in color.

In the North Highlands, the Recuay ceramics are characterized by three-color negative painting in black, white, and red on a pure white clav, and a stylized jaguar design with outlined angular body and a large head comb. The variety of shapes is so great that it is difficult to isolate the most typical 
ones. There are open bowls, conical-handled dippers, goblets, tripod bowls, jars with high flaring collars, jars with disc-like rims, containers with short collars and abhreviated hridges to modeled heads, double jars, and flat-topped jars with small modeled figures on them. Though inferior in quality to that of Mochica, the modeling is competent and has a wide range of subject matter. Besides the characteristic jaguar design and three-color negative painting, there are geometric, condor, and serpent designs painted in positive red, white, and black.

The Pucara ceramies in the South Highlands are distinguished by flat-bottom open bowls with diverging sicles, a full cat figure design with profile body and front view face, and painting in thick black and rellow on a red slip with the color areas outlined by incisions. Large goblets and jars and some smaller ressels are also associated; additional designs are composed of rows of profile human heads, ruming human figures with elaborate headdresses, men leading llamas, and anthropomorphized figures. The Pucara pottery is affiliated with the earlier Chiripa and the somewhat later Tiahuanaco cultures. Its relationship to the Early Tiahuanaco is not very close, although these two seem to be contemporaneous. Instead, the Early Tiahuanaco is characterized by long-necked decanters, flat-bottom spittoon-shaped bowls, and a fretted rim incense bowl with modeled puma heads. The designs, peculiar animals, birds and geometric patterns, are painted in a polychrome on buff, employing glossy, burnished white, black, red, brown, orange, and yellow. 
Although cloth is preserved only in certain favorable sections, there is considerable indirect evidence of competent weaving everywhere in the Mastercraftsman Period. For example, though no fabries are preserved in the highlands, weave daggers and spindle whorls are numerous, and the incised designs on many stone statues represent complex textile patterns. Cloth is best preserved on the South Coast which, consequently, furnishes the fullest evidence for the textile arts. Quite aside from preservation, fine weaving seems to have been a tradition in the south. On the North Coast, the few known Mochica textiles are largely plain weaves of cotton. The threads, from one to fourteen ply, are hard spun and have a characteristic crepe. Colored threads are rare, possibly due to the scarcity of wool fibers. There are, however, examples of tapestry, gingham, embroidery, brocade and twills. The ceramic designs represent well clothed figures but do not suggest elaborate weaving designs.

The textile art reaches its highest development on the South Coast. Both cotton and wool fibers are extensively employed. Since the Central and South Highlands are more favorable environments for the breeding and herding of llamas and alpacas than the North Highlands, the South Coast peoples always had an abundant source of wool for weaving, a circumstance which may account for some of the emphasis on this craft. In their totality, the textiles of Nazca and the Necropolis cultures present almost every weaving technique known in the Central Andes at any time. Over-all embroidery is the most characteristic decorative technique, but brocade, warp and weft stripe, gauze, lace, double cloth, and tapestry are all common. There are also 
many types of braiding and three dimensional needle knitting. Polychrome design is the rule and as many as one hundred ninety hues in seven color ranges have been identified. Most designs are complex, but the embroidered figures are particularly elaborate, resembling the polychrome painted designs on Nazca pottery in many details. In fact, the textiles of the South Coast represent one of the greatest artistic achievements of the Central Andes. The demonstrated skills in spinning, dyeing, and weaving techniques rank these textiles among the great arts of the world. The known quantity of woven fabrics is almost unbelievable. Furthermore, many of the garments were woven exclusively for the mummy bundles, rather than for the use of the living.

The woren parts of clothing include breechclouts, belts, slit neck shirts, wrap-around skirts, large shawls, rectangular pieces folded and wrapped as turbans, woven headbands, and other forms of headdress. The Nochica ceramic designs depict a similar clothing pattern for the North Coast, with, if possible, even greater emphasis on the elaboration of headdress. Indirect evidence from other areas confirms the conclusion that by the Mastercraftsman Period, the basic Andean pattern of male and female costume was established throughout the Central Andes. Closely related to costume are personal ornaments which show elaboration and variety. Ornaments and details of dress seem to mark individuals of different rank and importance and also to identify local groups and specialists. The variety of headdresses has already been mentioned as characteristic. These include plain bands, turbans, skull caps, animal and bird skin caps, and 
some attachments like feather fans and metal crests. The Mochica ceramics suggest that the headdress symbolized messengers, wise men, fishermen, agriculturists, priests, warriors, and rulers. Face and body painting is a common practice; again it seems that the design detail served to distinguish rank and association. Some of the South Coast mummies are tattooed. Elsewhere the ceramic designs represent facial incisions and punctations which probably signify tattooing. Artificial skull deformation is a widespread custom. It has been suggested that this was a mark of rank, but actually, undeformed skulls are so rare that the practice seems to have been fairly universal. Earplugs, noseplugs, and lip plugs are found in every region. Other types of ornaments such as beads, necklaces, anklets, rings, feather plumes, collars, and tweezers for depilation are also widely distributed. Ceremonial or burial masks of clay, cloth, or metal are also associated with every culture of this period.

The metallurgists worked with silver, copper, and gold, and made alloys of copper and gold, copper and silver, and silver and gold (Fig. 35). It is noteworthy that bronze, the alloy of copper and tin, is still unknown. The range of techniques includes soldering, hammering, embossing, casting, gilding, and annealing. Some regions, particularly the South Coast, were not as advanced as others in metalwork. In general, metal objects were used only for ornaments. The Mochica are exceptions, since they used copper for spear points, diggingstick points, battle axes, and some other tools.

Many minor crafts were undoubtedly advanced, although archaeologists have not devoted much attention to them so that our knowledge is somewhat 
restricted. The Mochica tombs contain incised clay whorls, figurines, whistles, trumpets, and panpipes; coremonial stone axes and club heads; intricate examples of inlaid shell mosaic; incised and carved

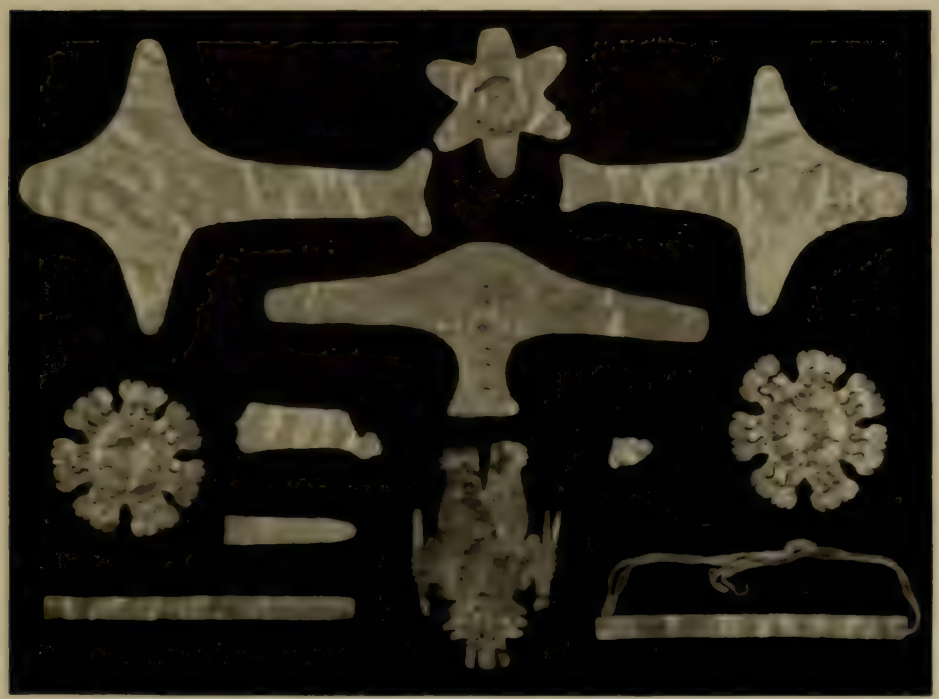

Fig. 35. Gold objects from a Paraeas mummy bundle of the Mastereraftsman Period.

lone tubes; and some carved wooden staff heads and other objects. Other sites preserve decorated calahashos and a varicty of baskets which, although competently made, are not very elaborate in technique.

There is also evidence of advancement of knowlalge in other fields. The Mochica seem to have had an ideongaphic type of writing. Varionsly decorated beans in the ceramic designs are ascociated with specialized messenger figures who carry small 
bags. Other scenes represent important individuals who seem to interpret the significance of the decorated beans brought in by these messengers. Somewhat similar decorated beans appear as design elements in the Necropolis culture of the South Coast and in the Tiahuanaco culture of the South Highlands. Many skulls from the South Coast and the North Highlands have pieces of bone cut out, and since the edges of the cuts show subsequent growth of the bone, this trephining operation was obviously successfully controlled. The Mochica ceramics record other surgical practices, namely, bone setting, limb amputation, and circumcision. The artists also depicted many types of diseases and their cures, some, apparently, with medicinal plants. The ceramics also display medicinemen curing patients by means of massage and by sucking out disease objects.

The designs on stone carving and ceramics and, in some places, the actual specimens, show that feather capes, masks, and other special costumes were worn in ceremonial dances. Many of the ceremonies are directed by priest-like figures and are accompanied by musicians. These designs and the preserved artifacts present a fair inventory of musical instruments, including drums of various types, tamborines, and flutes, panpipes of both clay and reeds, gongs, clappers, rattles, shell trumpets, and both straight and coiled clay trumpets (Fig. 51).

Religion is highly developed and organized in the Mastercraftsman Period, as witnessed by the ceremonial paraphernalia, the elaborate grave equipment, the temple constructions, and the depiction of priests and anthropomorphic divinities. The feline is the most universal religious figure represented, 
but many others depicted in the modeling, painting, and carving seem to suggest a hierarchy of gods. Nature worship is certainly prominent in the religion and the elaborateness of burial indicates an equal importance for ancestor worship. The Mochica ceramies represent many sacrifices of prisoners and the widespread distribution of the trophy head design suggests that the taking of trophy heads was part of the religious practice.

A marked increase in population occurred in the Mastereraftsman Period, but the organization and control of agricultural subsistence was adequate to produce an excess supply which permitted leisuretime activities. In other words, when technology had advanced to a satisfactory level in terms of the local economy, attention was shifted to socio-political organization and the utilization of leisure time. Many different patterns for such organization are theoretically possible and each major area may well have had its own distinctive type. On the basis of existing evidence three emerge clearly, namely, the Nochica pattern on the North Coast, the NazcaNecropolis pattern on the South Coast, and the Tiahuanaco pattern in the South Highlands. The characteristies of the first two patterns are presented here; the third, the Tiahuanaco, is reserved for the next section, since it forms the basis for the subsequent pan-fentral Andean horizon.

The Mochica socio-political organization and leisure-time superstructure emerged as a sharply divided class system in which a small upper group directed the labor of the masses. The ceramic designs suggest many specialized groups, such as rulers, wise men, messengers, warriors, priests, weavers, potters, fishermen, musicians, doctors, and 
prisoners or slaves. Certain symbols are regularly associated with some of these groups. A combination symbol composed of shield, mace, and darts identifies the warriors. The messengers are represented by centipedes, birds, and dragon-flies. A fox or a cat-like mask usually distinguishes the learned men, and a jaguar is commonly the symbol of authority. Specialized groups in themselves do not necessarily imply a strong class system, but in this case there is additional evidence for rather marked differences in the ranking of the groups. The costumes of important individuals are definitely more elaborate than those of the commoners. Furthermore, the "rulers" often combine the attributes of political, religious, and military authority. The leaders are pictured as seated on raised daises under special sun shelters, as carried in litters, or as seated on rafts which are towed through the water by menial swimmers. Guests of inferior rank dine at a lower level than the important chiefs. Servants are often depicted as lizards. Both the rulers and the gods are approached with an attitude of reverence-the hands clasped as if in prayer, the head inclined towards the ground. The chiefs occupy prominent positions as leaders of ceremonies and as supervisors of hunting and fishing parties. The graves of such important individuals are markedly richer and more elaborate than others in the same cemetery.

The Mochica erected immense public buildings and temples which display only limited architectural skill, but certainly suggest well organized mass labor. The adobes were made in molds and piled up in columns. One vessel shows a group of weavers working under the direction of a super- 
visor, but in general, the Mochica preferred ceramics which could be produced in quantity with a minimum of time consumption, rather than textiles which require many man hours of labor. The ceramic painting and modeling reflect a great interest in mundane affairs. Even the anthropomorphized deity engages in agriculture, fishing, and hunting, and fights with demons as a symbol of the "good.", Since the chicf is portrayed as both a political and religious leader, many of the ceremonies and religious beliefs served to bolster the upper class authority. Many scenes represent systematic and severe punishments, including mutilation, stoning, exposure, and execution or sacrifice. Nude prisoners are pictured with ropes around their necks, but even here the more important individuals are carried in litters. The Mochica women occupy a definitely subordinate position. They are never represented in social or ceremonial scenes, but are portrayed as engaged in the menial tasks of weaving, domestic work, and burden bearing. The warrior group, on the other hand, is particularly prominent. The warriors have distinctive headdress and garments and carry copper battle axes, maces, darts, shields, and spear-throwers. Battle scenes are common and illustrate the Mochica aggressive tendencies.

The Nazca-Necropolis pattern on the South Coast presents a sharp contrast to the Mochica. The social organization and the leisure-time activities appear to have been directed essentially towards the preparation of special grave materials in an elaboration of ancestor worship. There are no large seale buildings and the simple structures use handmade rather than mold-made arlobes. The greatest 
emphasis is placed on textile weaving, a craft which requires an enormous expenditure of time, particularly for the more elaborate pieces. Increased production in hand weaving can be achieved only by increasing the number of weavers, so that the vast quantity of Nazca-Necropolis fabrics suggests that a large part of the population was involved. Although artistic and technical standards of weaving are exceptionally high, almost every fabric achieves them, which again implies numerous highly skilled weavers. Most of the fabrics were woven especially for interment, rather than for utilitarian purposes. The grave garments reveal no signs of wear and, furthermore, many are made to fit the enlarged size of a cloth-padded mummy bundle rather than the living.

Both textile and ceramic designs are essentially religious rather than worldly in nature. Furthermore, the designs offer no suggestion of rigid class distinctions. The subterranean burial chambers of the Necropolis culture at Paracas look like family burial vaults, and burial bundles vary in the elaborateness of wrapping. These differences, however, suggest greater prestige for the honored head of a family rather than class distinctions; it is significant that women are as frequently honored as men. Each mummy bundle shows several stages of wrapping, probably done at different times, which again suggests a pattern of ancestor worship.

The reality of these two patterns is confirmed in part by an examination of their later history. The Nazca-Necropolis pattern did not expand, but rather was confined to the three South Coast valleys of Pisco, Ica, and Nazca. The expanding Tiahuanaco horizon complex, whatever its nature, mingled read- 
ily with the Nazea style to produce new types of textiles and new combinations of ceramic shapes and designs. In fact, Tiahuanaco completely absorbed the Nazca-Necropolis culture so that it never reemerged. The Ilochica, on the other hand, became aggressive at the end. They spread their culture by military conquest from the original center of the Chicama and Moche valleys until they controlled the North Coast from Pacasmayo to Casma. The Mochica culture mixed very little with the Tiahuanaco. In fact, the meeting of the two cultures appears to have resulted in a struggle for survival in which the Mochica were temporarily eclipsed or, more likely, withdrew to such northern valleys as Lambayeque and Piura. At least the Mochica style and the Mochica pattern soon re-emerged in the modified form of the Chimu culture which persisted up to the time of the Inca conquest.

The Mastercraftsman Period in general marks the culmination of technological advancement. A successful formula for subsistence and crafts had been achieved, and attention was shifted to the control of man units rather than development of additional techniques. The remaining cultural history of the Central Andes is, then, that of different types of political and social organizations. The next period is marked by confusion and political expansion out of which the Tiahuanaco formula becomes panCentral Andean in scope. This is not based on any radical change in technology, but is rather a new form of social, political, or religious organization. 


\section{Expansionist Period \\ (ca. 1000-1200 A. D.)}

The shift from technological advancement to manipulation of man-hour units and political organization had begun even before the close of the Mastercraftsman Period. With this change in emphasis, expansion in the form of conquests of new regions became profitable. This general tendency for expansion and aggression is not limited to one region, but, except for the Nazea culture, seems to be general throughout the Central Andes. As previously mentioned, the Mochica had occupied five of the major North Coast valleys. Still farther north, the local cultures of Lambayeque were spreading their influence to neighboring regions. In the North Highlands, both the Recuay and Cajamarca cultures were increasing their territory to the extent of strong influence and, in some cases, actual penetration on the coast of Peru. The several Central Coast valleys were united stylistically, if not politically, by the Interlocking culture. This widespread expansion resulted in considerable conflict and confusion. In some regions the irrigation systems seem to have broken down and the populations diminished and scattered. In fact, the peoples of the Central Andes apparently became engaged in serious internecine warfare.

The Tiahuanaco culture, presumably developed in the Central and Southern Andes, starts the spread of its influence which characterizes the whole Expansionist Period. The exact nature of this expansion cannot be finally determined, but the archaeological materials include the diagnostics of the Tia- 


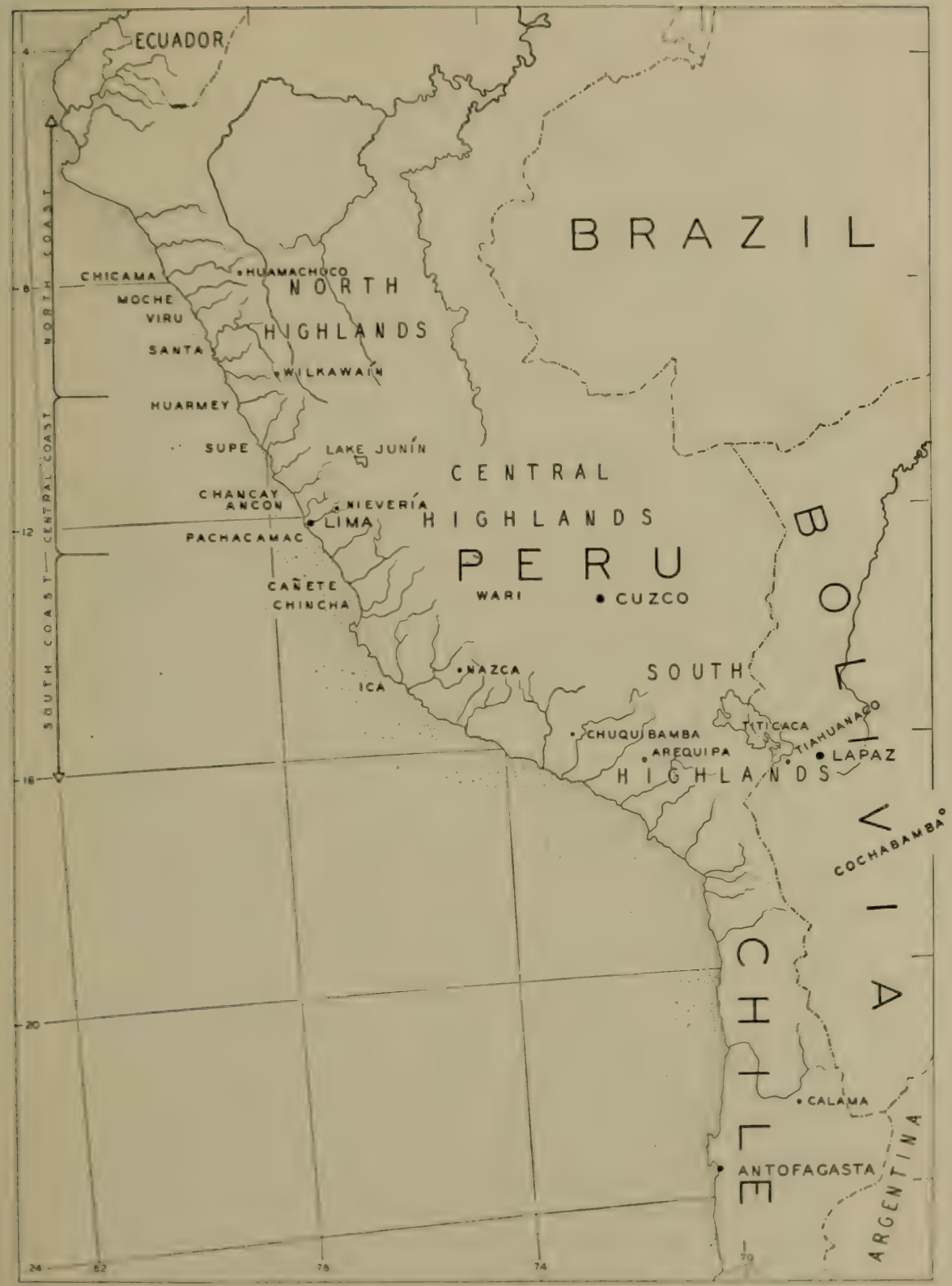

Fig. 36. P'rincipal centers of the Explansionist P'eriod. 
huanaco horizon complex in all six of the major areas of the Central Andes. The problem of interpreting the nature of this expansion is complicated by the fact that by the close of the Mastercraftsman Period, each region had a well-established local culture represented by a sizable population. Irrespective then of the type of Tiahuanaco expansion, a merger with each of the local cultures would be anticipated and this is precisely what occurred. However, the Tiahuanaco horizon presents a complex, not merely a single style, and the fact that the various components are so readily recognized in such widely separated areas certainly suggests some form of political expansion, even though the integration was religious and priest controlled. Considering the type of cultural development everywhere in the Central Andes, this wide distribution in all probability was effected over a relatively short span of time, nor is there any indication that the unity, political or otherwise, endured for any great length of time. Instead, the local cultures were so strong that they soon re-emerged as independent organizations. The assignment here of two hundred years for the duration of the Expansionist Period is largely guesswork; it might have flourished for a longer or even shorter time.

In order to present an adequate picture of the long recognized pan-Central Andean Tiahuanaco horizon, the highland Bolivian site of the same name must first be described. The ruins of Tiahuanaco have long been considered as the type site for the culture, partly because they have been extensively covered in the literature, partly because the culture here is well isolated. It seems highly improbable now that Bolivia was the center of distribution for 
this horizon. The bleak altiplano near Lake Titicaca has an altitude of almost fourteen thousand feet, which is too high for the cultivation of many plants, although quinoa, potatoes, and oca can be grown, and there is pasturage for llamas and alpacas. Today, the region supports a scattered, although reasonably large Indian population; presumably the situation was not very different in the past. However, the Tiahuanaco site appears to have been a major ceremonial center, rather than a city or large village. This would enhance its importance even though it was not the political or distributional center. In most regions, the Tiahuanaco elements are intermingled with local styles, but the Bolivian site is an exception, and thus offers the best illustrations of the basic culture. Chiripa, Early Tiahuanaco, and Pucara cultures all antedate Tiahuanaco in the South Highlands and contribute, in part, to its final formulation. This must have been initiated at least in the Mastercraftsman Period since some designs are shared in common with the Mochica and Nazea cultures. However, Tiahuanaco as a whole belongs in the Expansionist Period which it so thoroughly dominates.

The ruins of Tiahuanaco, located about twelve miles south of Lake Titicaca in Bolivia, are composed of four major structural units and numerous minor ones scattered over a large area. The largest unit, called Acapana, is a natural mound, about fifteen meters high, which was re-shaped into a stepsided pyramid and faced with stone. The over-all groundplan measures two hundred ten by two hundred ten meters and has the appearance of a stepsided triangle. House foundations rest on top of the mound and there is also a large artificial reser- 
voir, with an overflow canal built of dressed and fitted blocks. The unit appears to have been a fortress which served as a place of refuge in time of siege.

Immediately to the north of the fortress is a large rectangular unit, one hundred thirty-five by one hundred thirty meters, called Calasasaya (Fig. 37). This was at one time a raised earth platform or terreplein faced with a dressed stone wall of slab uprights and smaller filling blocks. Today most of the smaller stones have been removed and the earth fill has eroded so that the ruin has the appearance of an inclosure of upright pillars. An inner court, sixty by forty meters, is still discernible and is approached from the east by a megalithic stairway consisting of six slabs. The best preserved wall on the west side of the unit may possibly have been added at a slightly later time. Several stone statues and a decorated monolithic gateway, the "Gateway of the Sun," are associated with this unit.

A smaller inclosure, sixty by fifty-five meters, west of Calasasaya, is called the Palacio. It contains many dressed and fitted stone blocks, as well as a painted stairway. The fourth major unit, Puma Puncu, another platform structure, lies some distance southwest of the others. It is built of great slabs and stone blocks, some weighing over one hundred tons. Although badly destroyed, remains of cut-out seats, decorated blocks, and broken monolithic gateways are still identifiable. The nearest source of the sandstone used in this construction is over five kilometers distant. Organization and skill were needed to transport and place these immense stones in precise positions. 

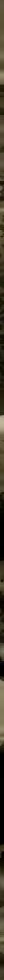

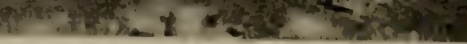
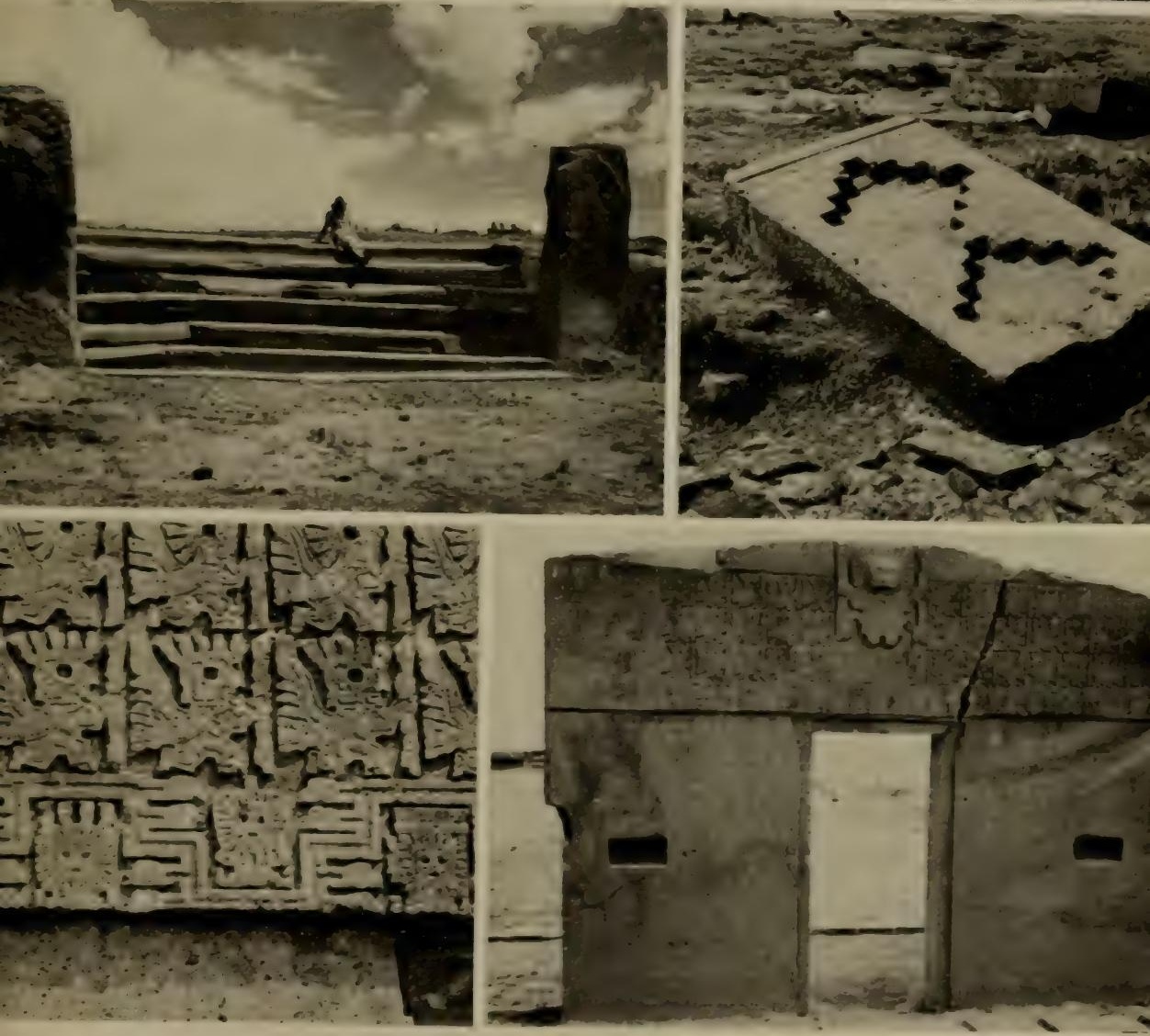

Fig. 37. Tiahnanaco ruins and decorated gateway. l'anorama, taken in 1896, Courtesy of Inicerstly Mustum, Philaulphia; others, Courtesy of Harry Tschopih, Jr. 
The major construction units are in themselves symmetrical, but their relationship to each other is not. The units appear planned, the over-all arrangement haphazard. The architecture is massive as illustrated by the solid raised platforms and the stone-faced pyramids. Both basalt and sandstone slabs and blocks are ground down to a smooth dressed finish. Stones are fitted by means of notches, joints, and copper cramps placed in cutout T and I-shaped grooves (Fig. 38). Not only is stone sculpture associated, but it is also one of the architectural features. Other Tiahuanaco specialties are decorated monolithic gateways, megalithic steps, cut-out step-sided wall niches, and decorative blocks arranged in mosaic patterns. Both surface conduits and underground drainage canals are found in the vicinity of the buildings, and some subterranean rooms are lined with dressed stone and entered by stairways. On the whole, this Tiahuanaco masonry is the most skilled and complex found in the Central Andes.

The stone carving' at Tiahuanaco includes pillarlike statues, relief slabs and blocks, decorative friezes on gateways, and both animal and human heads with tenons or blocks for wall insertion. The statues are stiff and conventionalized and little attention has been given to sculpture in the round (Fig. 39). The figure is usually in a standing position with the hands placed on the chest. The squared head has a raised headband, T-shaped evebrows and nose, and eyes with wings or tear bands. Fine incised designs on the body and waist bands represent woven garments. These incised designs and the low relief friezes on the gateways illustrate the style which is commonly considered as typical of 

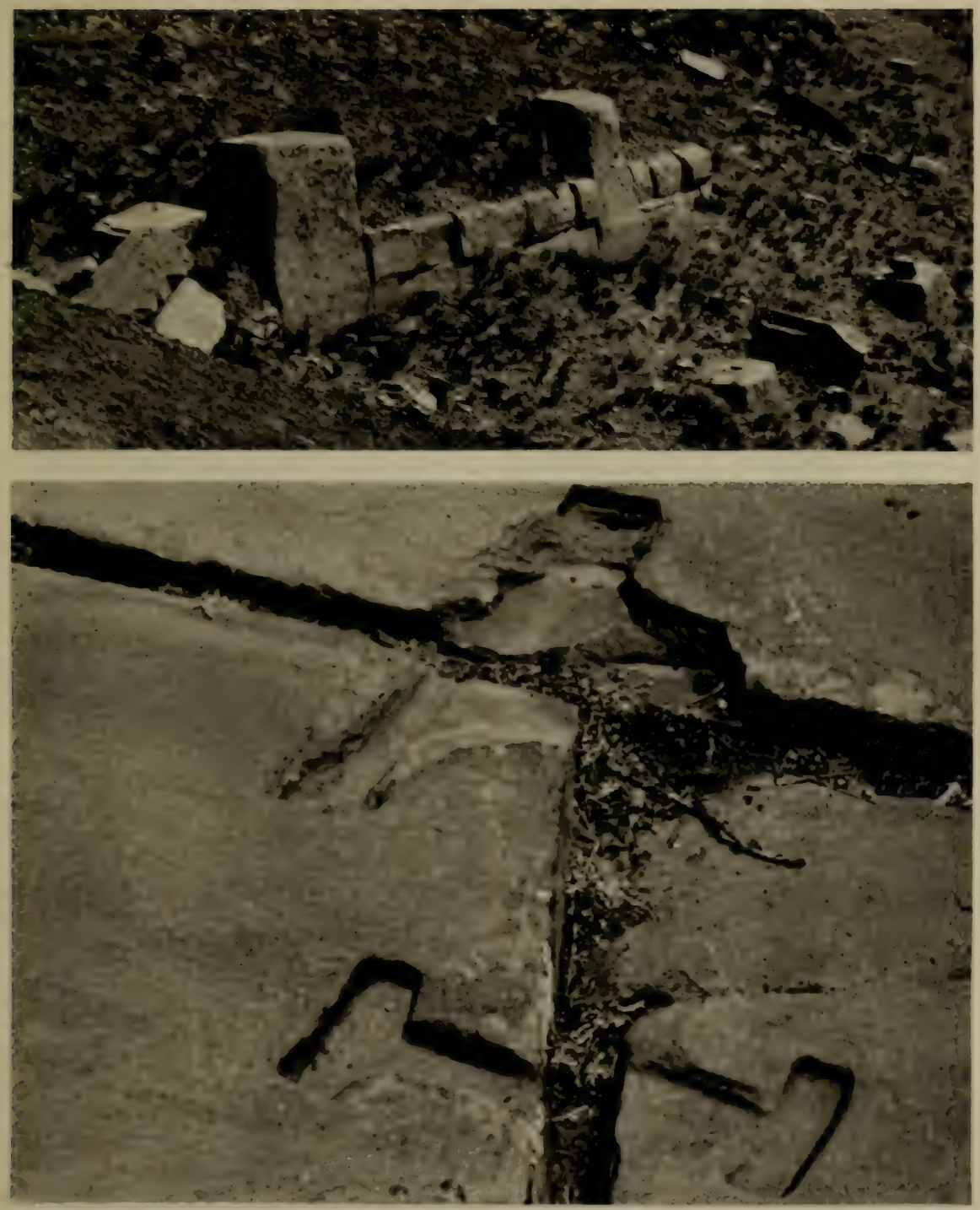

Frg. 38. Typical wall construction and detail of sockets for cast copper cramps or tie boltg in stone paving at Tiahuanaco. 

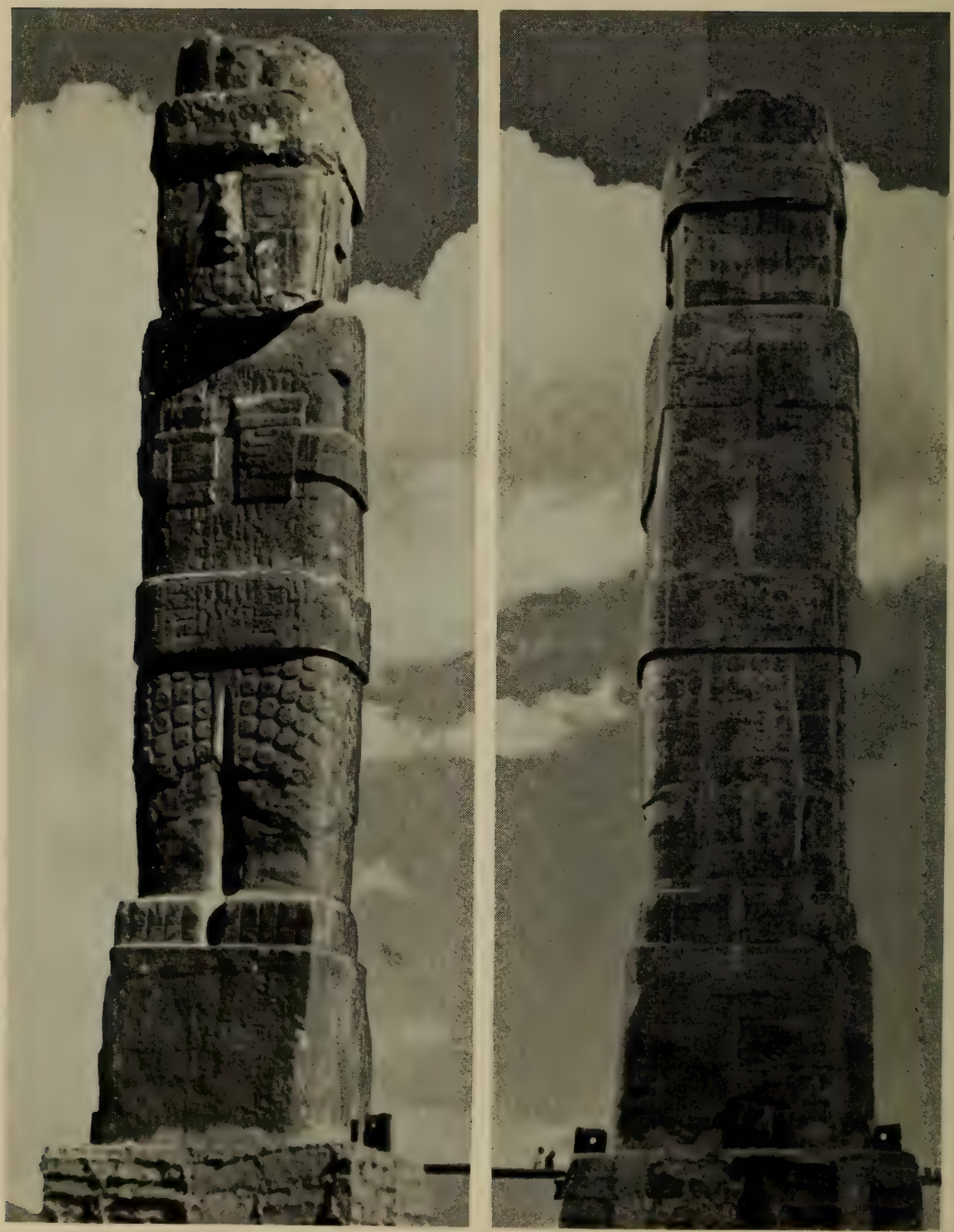

Fig. 39. Monolithic statue from Tiahuanaco. Discovered by Wendell C. Bennett. 
Tiahnanaco because of its wide spread. The designs include front view human figures with a staff in each hand, profile rumning figures with masks and flowing capes, profile puma and condor figures, and a series of characteristic appendages composed of puma, condor, or fish heads. That these designs áre basically derived from textile patterns is confirmed by the tapestries of this period. It is of interest that at the Tiahuanaco site, the ceramic designs are usually distinguishable from the stone series incised with textile patterns, and more local in distribution. Other styles of stone carring, such as realistic human figures and geometric relief slabs, are also found at Tiahuanaco, but are not definitely associated with this time period.

There have been only a few systematic excavations at Tiahuanaco. The graves described are simple pits containing a few pieces of pottery, but more elaborate graves undoubtedly existed and perhaps some of the subterranean rooms served as burial vaults. However, fairly large private collections of grave pottery have been assembled. The ceramics are characterized by flaring-sided goblets, squat, open bowls, annular base libation bowls, modeled puma and llama vessels, tall vases, and open bowls with wide flaring rims (Fig. 40). The ceramics are well fired and highly polished. All vessels are covered with a red slip and painted in polychrome designs of two to eight colors, although black, whiteon-red are the basic combinations. The designs are usually outlined in black, or black and white, and other colors are addled to fill in the figure. In contrast to the stone incised patterns, the ceramic designs are simple: profile pumas, human heads, and condors, or combinations of these elements. 

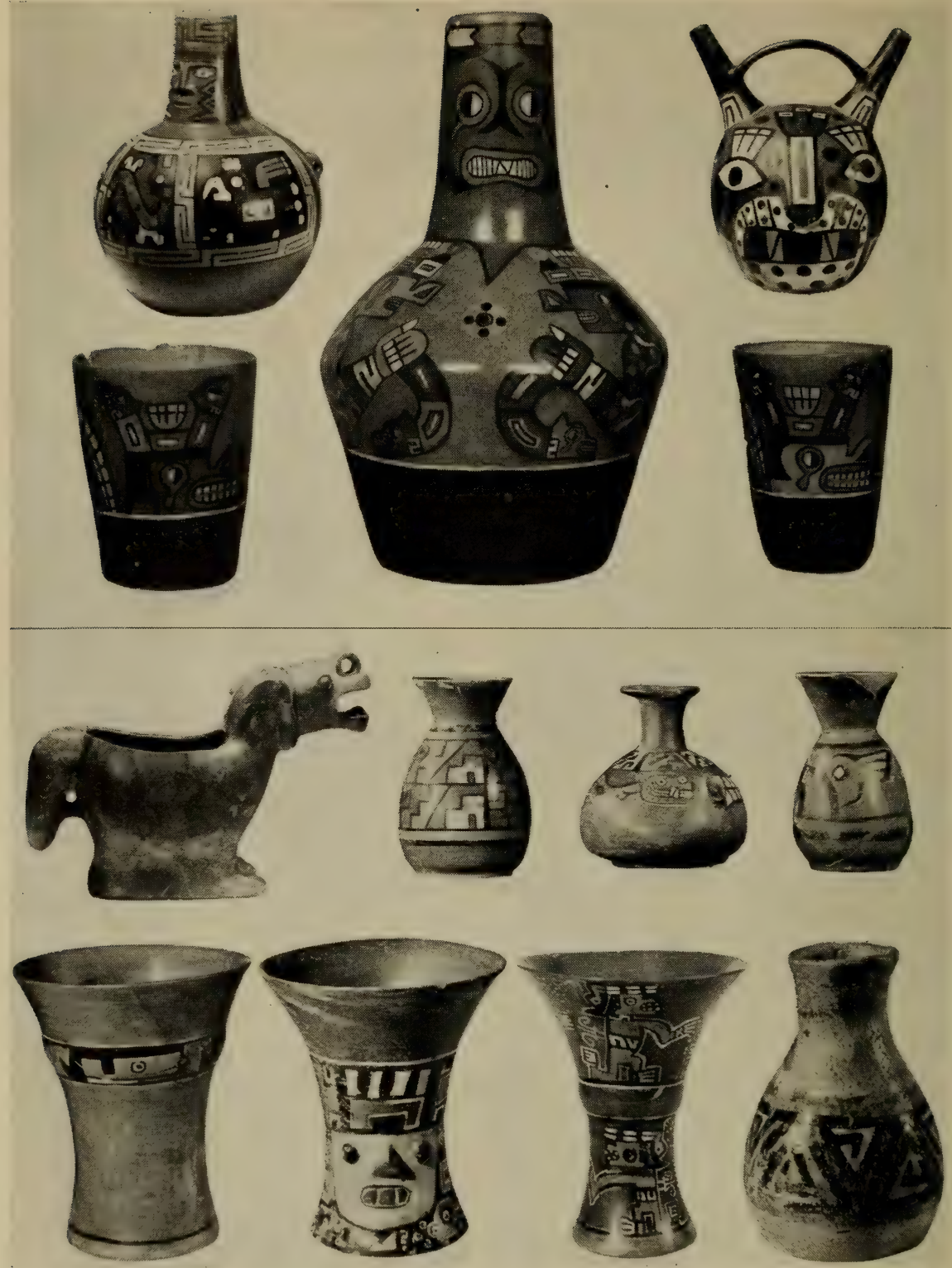

Fig. 40. Coast and Highland Tiahuanaco vessels. Upper half, Coast Tiahuanaco; Lower half, Bolivian Highland sites. Central jar and two side cups, Courtesy of John Wise. 
Textiles are not preserved in the rainy altiplano, but, as mentioned, the stone carring designs are evidence that this craft was advanced. The metallurgists employed gold, silver, and copper with competence and skill. It is possible that bronze first appeared at Tiahuanaco, since Bolivia is about the only source of tin in South America, but thus far the analyses show only pure copper artifacts, even for the cramps used in fitting the stone. Decorated stone bowls, incised snuff tablets, clubs, pounders, polishers, and axes are all common. Bone and shell objects are numerous, but all the more perishable types of artifacts are not preserved.

The cultural pattern implied by the archaeological remains at Bolivian Tiahuanaco is that of a well integrated and powerfully controlled religious organization. The large construction units required organized mass labor, careful advanced planning, and skilled masons. The site has every appearance of a ceremonial center, so that it is logical to assume a religious direction. There are many indications that Tiahuanaco was built at intervals and that much of it was never completed. This suggests once more the religious pilgrimage pattern, in which great masses of people assembled at certain times of the year and contributed the labor of hauling, dressing, and placing the large stones. In the interim periods, skilled masons worked on the fitting, joining, and carving. The Tiahuanaco art style, represented by stone carving and ceramic painting, is highly conventionalized, little varied, and rigidly limited. Chavín style was limited in motifs, Tiahuanaco is limited by conventions. The designs are doubtless symbolic but they are also impersonal. 
They confirm the impression of a formalized and well organized religious control.

The type site of Tiahuanaco presents a unique combination of masonry, stone carving, and ceramics, but there is good evidence for the spread of some Tiahuanaco diagnostics, both in the highlands and on the coast. Other sites have been found on the islands and shores of Lake Titicaca. Lucurmata, on the Bolivian shore, presents a terraced platform and a small temple built of dressed and fitted blocks. Cemeteries near Cochabamba prove that Tiahuanaco expanded into the eastern cordillera of Bolivia. In the Calama oasis of North Chile, Tiahuanaco is represented by textiles, polychrome ceramics, and incised wooden snuff tablets. Likewise, Tiahuanaco style ceramics have been found near Arequipa and Chuquibamba in southern Peru.

The recently discovered site of Wari, near Ayacucho in the Central Highlands, may well prove to be one of the most important Tiahuanaco centers. Preliminary reports describe Wari as an enormous area covered with rough stone walls, some of which are still twenty feet high. Dressed stone tombs, simple upright statues, and thick polychrome pottery with elaborate Tiahuanaco designs are also associated. The central location of Wari, plus its apparent size and complexity, makes it a favored candidate for the true center of expansion, particularly for the coast region. Materials pertaining to the Tiahuanaco horizon complex are found in quantity in all the coastal valleys from southern Nazca to northern Chicama. Pacheco in Nazca and Pachacamac and Ancón on the Central Coast are outstanding sites, but it is impractical to list all the others. In the North Highlands, many sites, like 
Wilkawaín, near Huaraz, contain Tiahuanaco horizon materials. It is interesting that their stylistic affiliations are with the coast rather than with other parts of the highlands.

The highland sites of this period are represented by building units, stone sculptures, and cemeteries, but the coast sites thus far known are largely limited to cemeteries. This situation is due in part to the lack of adequate archaeological work, but it may also reflect the nature of the Tiahuanaco expansion. This whole period seems to have been one of great confusion, and it is unlikely that the unification represented by the Tiahuanaco horizon was a well organized political one. Somewhat later, the Inca perfected the techniques of conquest and incorporation, but at this point political organization was still experimental. Consequently, ambitious building projects would not be expected, but instead, the existing constructions would be re-utilized. If the expansion were truly religious, the priest leaders would probably try to maintain the authority of the recognized highland ceremonial centers rather than establish new ones. This is, of course, speculation; but, as ret, major buildings on the coast have not been assigned to this period and there is ample evidence that earlier constructions were re-used. The recent work in Viru Valley adds to the general picture of conditions at this time. Though sites are numerous, they are located on the margins of the valley. This may indicate that the valley flats were under total cultivation, but it is more likely the result of a temporary breakdown in the main irrigation system. Other evidence suggests a marked decline in population. Reorganization at the end of the period is demonstrated by finds of some villages composed of 
clusters of forty by sixty meter rectangular enclosures which contain interior subdivisions.

Numerous coast and highland sites of the Expansionist Period are united by the Tiahuanaco horizon complex, as well as by stratigraphic evidence which places them in the same relative time span. For example, at Moche on the North Coast an Expansionist Period cemetery is found on a platform of the Huaca del Sol constructed by the earlier Mochica. A Wilkawaín-Tiahuanaco building in the North Highlands is superimposed on a Recuay culture subterranean gallery. On the South Coast, Tiahuanaco mixes with the Nazca-B style which marks the end of the Nazca sequence. Much more data on the chronological placement of the various sites are also available.

The diagnostics of the Tiahuanaco horizon complex have previously been briefly mentioned, but deserve more detailed treatment. Ceramic traits are obviously the best criteria since pottery looms large in the collections and is universally preserved. All sites of the Tiahuanaco horizon have some ceramics with the characteristic shapes of the flaringsided goblet and the squat flaring-sided cup; a red slip over-all base; common black and white painted design, and some use of four or more colors; the black outlining technique for design figures with other colors used as fill; and a high polished finish. Equally widespread are distinctive design elements derived largely from the stone incision style at Tiahuanaco, such as the front view figure with a staff in each hand; the running profile figure, with cape and bird mask; the puma and condor figures; the step design, scroll, and trident; and appendages of animal and bird heads. Furthermore, wherever 
textiles are preserved, there are some samples of tapestry with distinctive Tiahuanaco designs. On the coast, other non-Highland ceramic shapes, decorated with Tiahnanaco designs, have a wide distribution: a spout and round-handled jar; thick U-shaped urns; face bowls; modeled animal bowls, although not like the Highland types; collar jars with and without relief faces; double jars; and containers with double spouts and connecting flat bridge. In spite of the numerous horizon components, local styles are equally prominent at most sites. For example, an incised redware is abundant at Ancón on the central coast; two-color negative ware at Wilkawaín-in the North Highlands; and pressed relief blackware on the North Coast.

The architectural features of the Central and South Highlands have already been described. It has been pointed out that large scale building on the coast is not yet associated with this period, even though some of the constructions at Pachacamac on the Central Coast and at Chanchan on the North Coast were probably initiated in this period. In the North Highlands, however, this period presents many one-room above-ground house sites with walls of rough stone and roofs of large slabs. At Wilkawaín a three-story temple was once ornamented with a projecting cornice and a row of carved stone puma heads. Each floor of the temple has half a dozen rooms and a ventilation shaft. The walls are made of split stone laid horizontally in alternating thick and thin rows. The slab roof is gabled. The construction in general follows the North Highland stone building tradition which was initiated with the Chavín culture. 
The graves and burial types vary locally. On the Central Coast direct pit graves contain mummy bundles with false heads adorned with masks of metal, wood, and clay. Urn burials are found on the South Coast, but there are also log-covered subterranean chambers hung with tapestries. At Wari in the Central Highlands, subterranean boxes lined and covered with dressed stone slabs served as graves. Similar boxes lined with rough stone are found in the North Highlands.

On the coast the admirably preserved textiles illustrate skill in most of the known techniques, but the tapestries are most characteristic and among the finest made in the Central Andes. Other commonly employed techniques are brocade, warp pattern, double cloth, painted cloth, square and flat braiding, velvet-like pile knot, particularly for decorating square caps, interlocking warp, knitting, and tie-die patchwork. Both wool and cotton fibers are used. Some colors are quite brilliant, but tans, browns, light oranges, and pale blues are more typical. Many of the tapestry designs are so similar to the incised stone motifs at Tiahuanaco, that they might easily have been used as the models for these.

Many other artifacts found present a great variety of wood, shell, bone, and stonework (Fig. 41). Metallurgical techniques carry over from the previous period, but silverplating is added as well as two new alloys : a silver-copper on the South Coast, and a copper-arsenic on the North Coast.

The over-all unity represented by the Tiahuanaco horizon is soon interrupted and derived local styles appear. However, the coast is somewhat reunited towards the close of the period by the spread of the Black-White-Red horizon, represented by a geomet- 


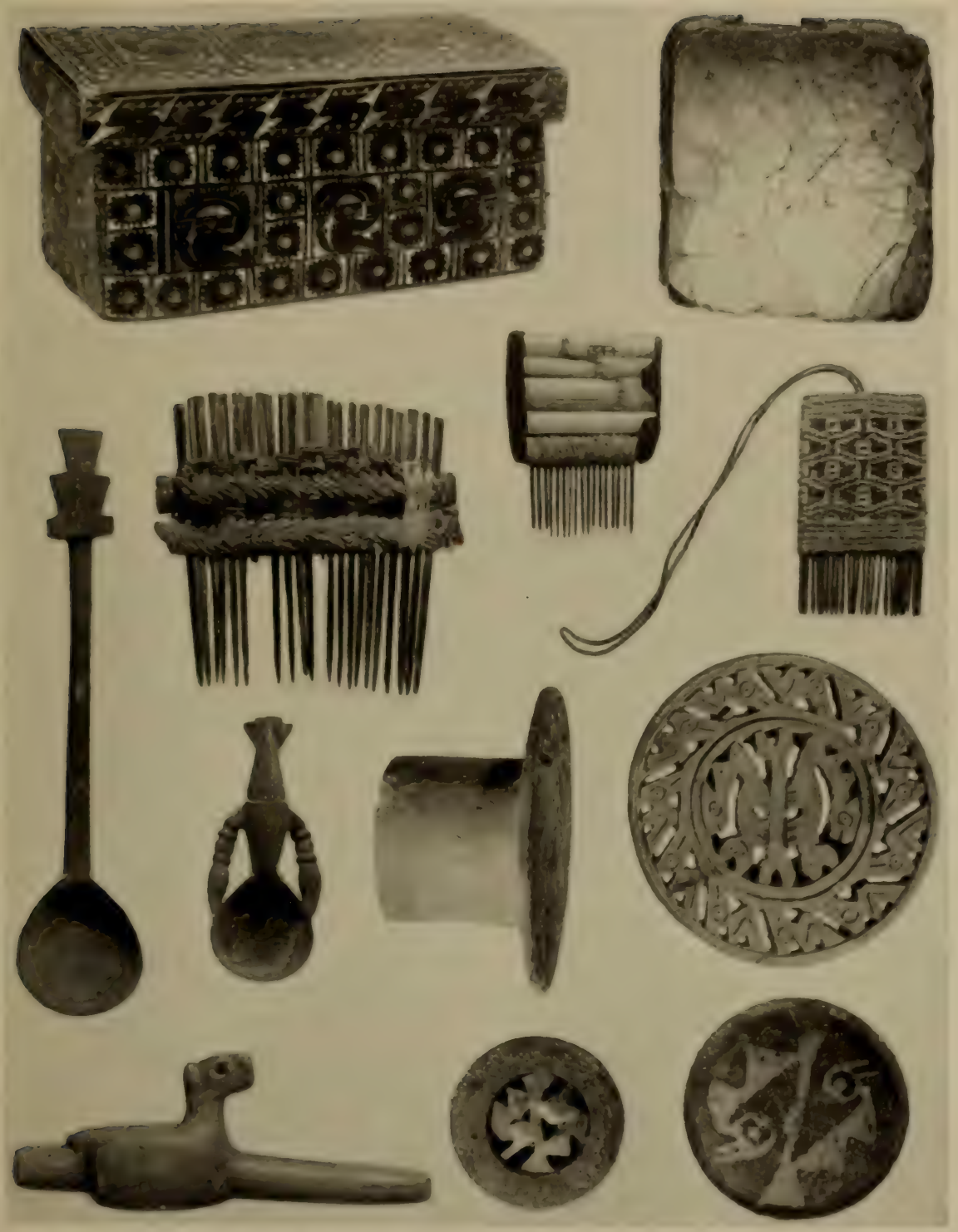

Fig. 41. Miscellaneous prehistorie l'eruvian artifacts; carved and painted box, pyrites mirror, comls, spoons, ear spouls, and snuff tube. 
ric painting style for ceramics and a few characteristic shapes, such as the flask, and the container with spout and bridge to modeled figure. This horizon style forms a minor element in the ceramic collections throughout the coast and in the North Highlands, but its components no longer even suggest any form of political unity.

The Expansionist Period is then distinguished by the widespread Tiahuanaco horizon complex, which certainly reflects a dominant, formalized religious impact, and suggests a loose political unity as well. Some have used the phrase Tiahuanaco Empire, but it is doubtful that the unity and duration were of sufficient magnitude to justify such a designation, in spite of the fact that the unification is greater than at any earlier time. The Tiahuanaco horizon, while widespread, is not all inclusive. The far North Coast valleys of Lambayeque and Piura were not affected, but continued to develop locally, perhaps inspired by the residue of Mochica culture. Cajamarea and Huamachuco in the far North Highlands were also out of the range, and in this same time period their inhabitants constructed sizable buildings and developed a distinctive ceramic style. It is of even greater interest that in spite of the proximity of Wari the Cuzco region of the Central Highlands remained totally independent of Tiahuanaco influence. This suggests that the local Early Inca culture was already sufficiently advanced to resist even such strong outside influences.

Whether political, religious, or merely stylistic in basis, the unity of the Tiahuanaco horizon was relatively short-lived. The local culture of each region had not been entirely eradicated and reformulation soon begins again. This was not achieved 
immediately, but only after a period of some struggle. The new culture is not a pure reemergence of the old, but rather a mixture. None of the technological techniques is lost and the reorganization continues on social and political lines. In some parts this takes the form of large concentrated populations which in many ways reflect a city pattern.

\section{City Builder Period \\ (ca. 1200-1450 A. D.)}

Following the Tiahuanaco dominated Expansionist Period, local cultures reemerge in the six main geographic divisions of the Central Andes (Fig. 42). The disintegration of whatever type of unity the Expansionists had imposed was succeeded by new struggles for power so that the formulation of local cultures did not follow immediately. This is illustrated by the fact that the styles which finally appear are more than simple derivatives of the Tiahuanaco horizon. For example, the Chimu ceramics on the North Coast present a fusion of a number of styles: some from the earlier Mochica, some from the Expansionist Period, some from more local styles of the far North Highlands and the far North Coast. Despite its diversity of origins, the Chimu style which ultimately crystallizes is unified and distinctive.

Throughout Peru this new regional formulation is based on political organization rather than technology. There is now evidence for large, well organized populations living in planned building units in a pattern which can be designated as urban, even though large cities are not found everywhere. The 


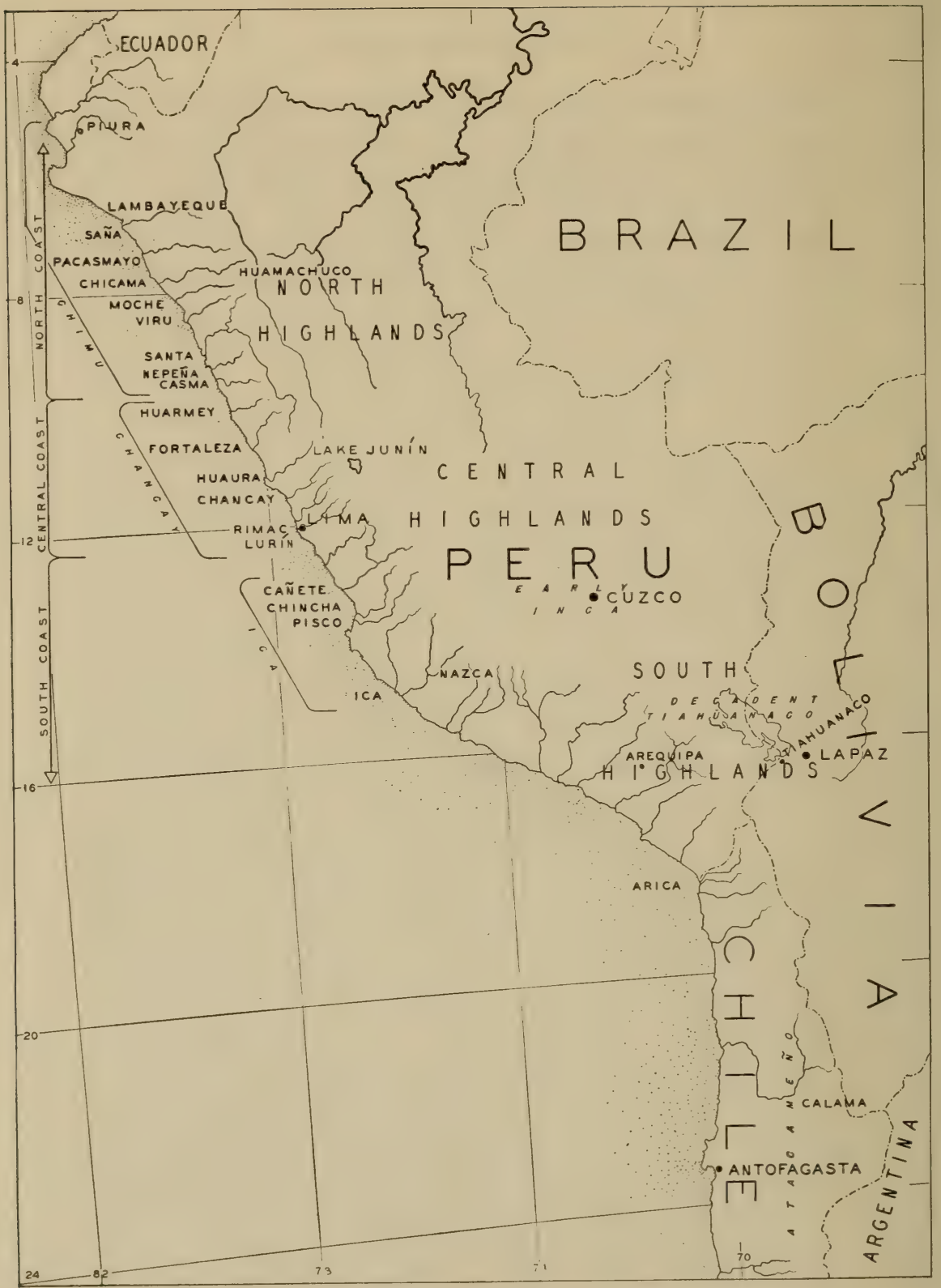

Fig. 42. Principal centers of the City Builder period. 
established subsistence techniques were extended so that a more expanded terrain was irrigated and cultivated than erer before. The population may have reached a new peak, but the shift from rural to urban habitation makes this difficult to verify. Since all cultures now possess adequate technologry and all are concentrating on political controls, the balance of power depends largely on the extent of territory. ('onsequently, it is not surprising that the North ('oast cultures become stronger than those of the c'entral and South ('oasts, since the northerm valleys are larger and have a more permanent water supply.

For the ('ity Builder Period, it is no longer practical to list individual sites, since a single culture dominates and is extensively represented in every major area. The archaeological evidence for the cultures and their distribution is partially verifial)le from the records of the Spanish chroniclers who list the names and locations of the tribes conquered by the Inca in their expansion. The Chimu who dominated the North Coast had their political center at the large city of Chanchan in the Moche Valley. Archaeolonical remains demonstrate that Chimu culture extended over a vast area from at least Piura in the north to Paramonga in the south (Fig. 4:3). The Central Coast valleys of Chancay, Ancón, and Rimac formed the Cuismaneu Empire, which, in archacological terms, is the area of distribution of the Chancay culture characterized by its Black-on- White ceramics. According to the chroniclers, the Mala, Chilea, and Cañete valleys were part of the Chuquimancu Empire, but this is not yet confirmed archaeologically. Inowerer, the Chincha Fimpire in the four Somth ('oast valleys of ( 'hin- 
cha, Pisco, Ica, and Nazca is substantiated archaeologically as the area of the Ica culture. Regional cultures in the highlands are less well known although there are many large stone constructed villages, like Narca Huamachuco in the North High-

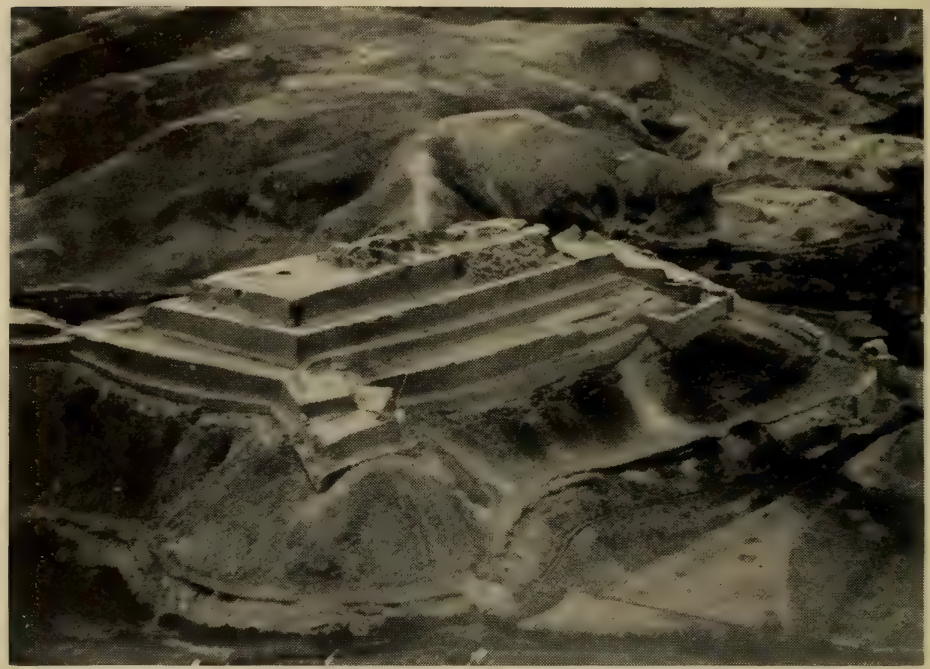

Fig. 43. A fortress of the City Builder period at Paramonga, constructed of clay bricks. Courtesy of $W$. R. Grace and Company.

lands, which are pre-Inca but which lack distinctive styles. An Early Inca culture has recently been isolated in the Central Highlands, although it is still not well known. Presumably evidence for the antecedents of the Inca Empire will eventually be clarified in this region. In the South Highlands, particularly around Lake Titicaca, the Tiahuanaco culture was not seriously interrupted, but continued as a local development, although there are no longer indications of strong organization. Around Arequipa 
and in North Chile are the remains of the Atacameno culture. These regions were not capable of supporting very large populations, but the general cultural development is similar to that in other parts of the Central Andes. The extensive flats of the coastal valleys were the most suitable for large concentrated populations. The highlands, on the other hand, might support equally large populations, but not in the same concentration. Consequently, the city pattern reaches its highest development on the coast.

The City Builder Period cultures and sites fall into the same relative time bracket, as verified by stratigraphy and other dating evidence. For example, their late position is well demonstrated by the fact that the local styles ultimately $\mathrm{mix}$ with the Incaic. On the North Coast typical Inca aryballoid jars are made in the Chimu blackware as are many Chancay and Ica ressels. Whether such mixture occurred prior to the Inca expansion or as a result of the Inca conquest does not affect the relative sequence. The duration of this period is another matter. In this account, a guess-date duration of two hundred fifty years is assigned to the City Builders. The numerous massive structures which pertain to this period might suggest a longer duration, but, on the grounds that man-unit labor was now well organized and that the architecture is not particularly complex, the buildings might well have been completed in a relatively short time.

The period is designated City Builder because of the enormous ruins of planned villages. Perhaps the largest and certainly the best known of these cities is Chanchan near Trujillo on the north coast. These ruins cover about six square miles and contain 
ten distinct units, some as large as four hundred eighty by three hundred serenty-five meters. Between these units, which are not symmetrically arranged, are irrigated areas, cemeteries, numerous small structures and totora reed marshes. The ten major units differ in detail, but each contains approximately the same features. From one to three high walls, some still nine meters high, surround each unit. Within the inclosures are symmetrically arranged streets, houses with gabled roofs, large pyramids, small cells, cemeteries, gardens, and stone-lined reservoirs. Some insist that Chanchan was a ceremonial center rather than a city, but irrespective of its function, there must have been a large number of fairly permanent residents.

Chanchan is the largest of the Chimu cities. There are many others of great size, such as Pacatnamú or La Barranca in Pacasmayo Valley and El Purgatorio in Lambayeque Valley. All of these share such features as symmetrical planning; rows of houses, streets, pyramids, terraces, decorated walls (Fig. 44), steps, ramps, and reservoirs. On the Central Coast other cities, like Pachacamac and Cajamarquilla in the Lurín and Rimac valleys, are comparable in size and plan to those of the north. The smaller valleys of the South Coast did not support such large cities, but centers like La Centinela in Chincha Valley and Tambo Colorado in Pisco Valley resemble the North Coast towns in general plan and combination of features.

From north to south, all of the coast cities, although differing in size, are similar in the plamning, the general rectangularity, and the combination of pyramids, stairways, terraces, and courts. Building materials are everywhere identical. The rec- 


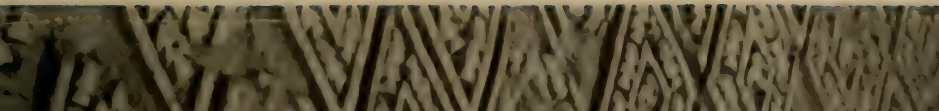 \\ G.

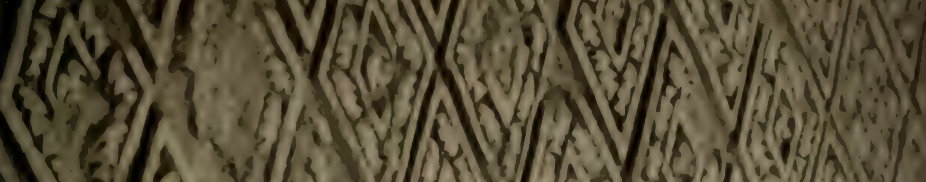 \\ a) \\ V. 30 (2) \\ (c) $)(60)(1) \times(a)$ \\ Vif 1 (a)

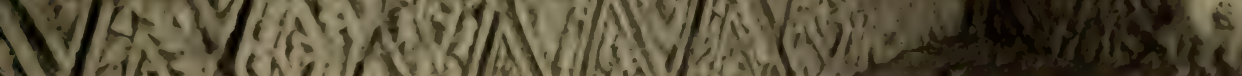

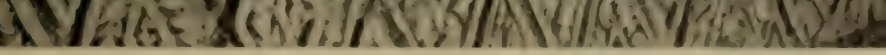
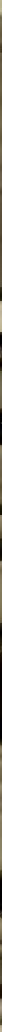

Fig. 4t. Clay arahesque wall decorations at the ruins of chanchan. Many walls were so decorated, hat most of this deeoration has been destroyed by rains. 
tangular mold-made adobes are small and square on the South Coast, large and flat on the North Coast, but identical in technique of manufacture. Tapia walls, in which the clay is tamped into large blocks between plank forms, are commonly used for inclosures and terraces, and algarroba logs are used as lintels and wall binders. The techniques of wall decoration are widespread. Ornamental niches are cut out of the walls and mosaic arrangements of rectangular adobes form decorative frets. Walls may be painted in solid color or with designs. Most characteristic are clay arabesques in which intricate small unit designs are cut out of a thick clay plaster. The small geometric designs, typically birds and fish, are arranged in textile-like patterns. The most famous arabesques are found at Chanchan, but there are equally good examples from the Central and South Coasts.

In this period the elaborateness of the graves reflects the importance of the deceased. Many graves are simply excavated pits, usually marked by an upright stick or paddle. Others are subterranean chambers roofed with poles. These contain more elaborate burials and greater quantities of grave goods. The burials are in seated flexed positions, wrapped with cloth to form a bundle, on top of which is a stuffed false head adorned with a painted face or with a mask of clay, wood, or metal.

Craftsmanship is still at a high level of competence, but lacks individual artistry. Instead, attention seems to have turned more and more to quantity production at the expense of quality. In ceramics, for example, the colors are reduced in number to monochrome on the North Coast and to black, white, and red on the South Coast. Shapes also 
have a more limited range. The design style is generally geometric; a widespread characteristic is the application of textile derived patterns. This decrease of attention to expressive individual art may have been due to the stultifying effects of the Tiahuanaco conventionalizations. In other ways it represents a shift of emphasis from the artist as a craftsman to the artist as a technical worker. In spite of these generalizations about craftsmanship throughout the Central Andes, each region has distinctive local styles.

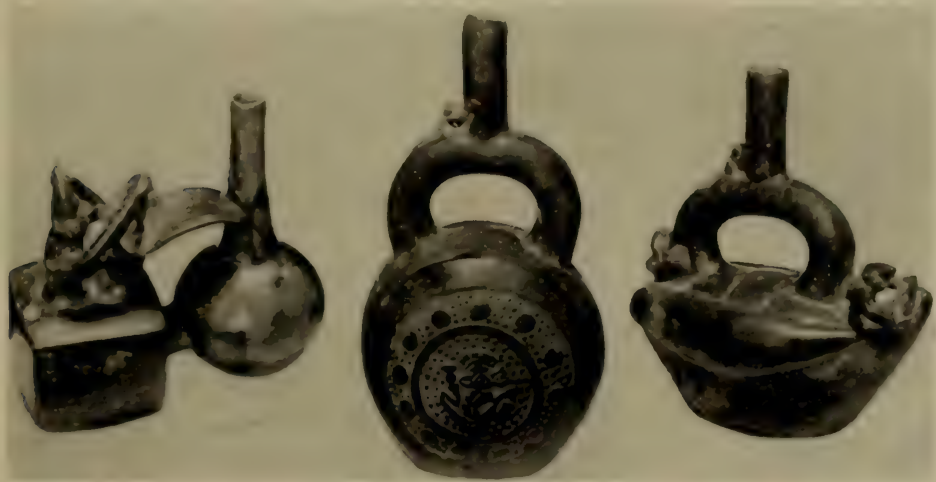

Fig. 45. Chimu blackware water jars. At left, two men boxing; center, an example of mold-pressed decoration; at right, two men on a balsa raft.

The Chimu ceramies, although varied in detail, can be classified under a few basic shape categories: the stirrup-spout, now squared in cross-section, with a small modeled animal at the spout base; a doublewhistling jar; a globular container with taper spout and flat handle; a vessel with spout and a bridge to a modeled figure; ollas; and plates (Fig. 45). Some of these shapes, like the stirrup-spout, are carry- 
overs from the Mochica culture; others, like the spout and bridge, are introductions from the Expansionist Period. The Chimu ceramics are commonly mold made and typically polished redware or smoked blackware. Painting is rare, but decoration is achieved by modeling, pressed relief, stipple, appliqué, incision, champlevé, and paddle marking: The modeling is still somewhat depictive, but the skills of the Mochica culture are no longer present.

The Chancay ceramics on the Central Coast are made of a thin porous red or orange clay which is coated with a scaley white slip over which textile derived patterns are painted in black or dark brown. The typical shapes are straight-sided goblets and face collar jars with flat side handles. The commonest design elements are bands, stripes, dots, wavy lines, cross hatch, serrated, diagonals, and small birds and animals. On the South Coast, Ica ceramics are generally painted in black, white, and red. Open bowls with angular bodies, round bottoms, and beveled rims are the most typical shape, but also common are constricted flaring collar jars and globular vessels with long tubular collars ending in slightly flaring rims. The designs are either geometric units or small birds and fish arranged in diagonals or panels in imitation of textile patterns (Fig. 46).

The ceramics attributed to the Atacameño in Peru and North Chile are characterized by constricted collar jars with two body handles, and one-handled pitchers. Again, the designs are geometric combinations of triangles, diamonds, scrolls, and steps, painted in black and white on a red base. The Atacameño ceramic style has sometimes been considered as a forerunner of that of the Inca. How- 

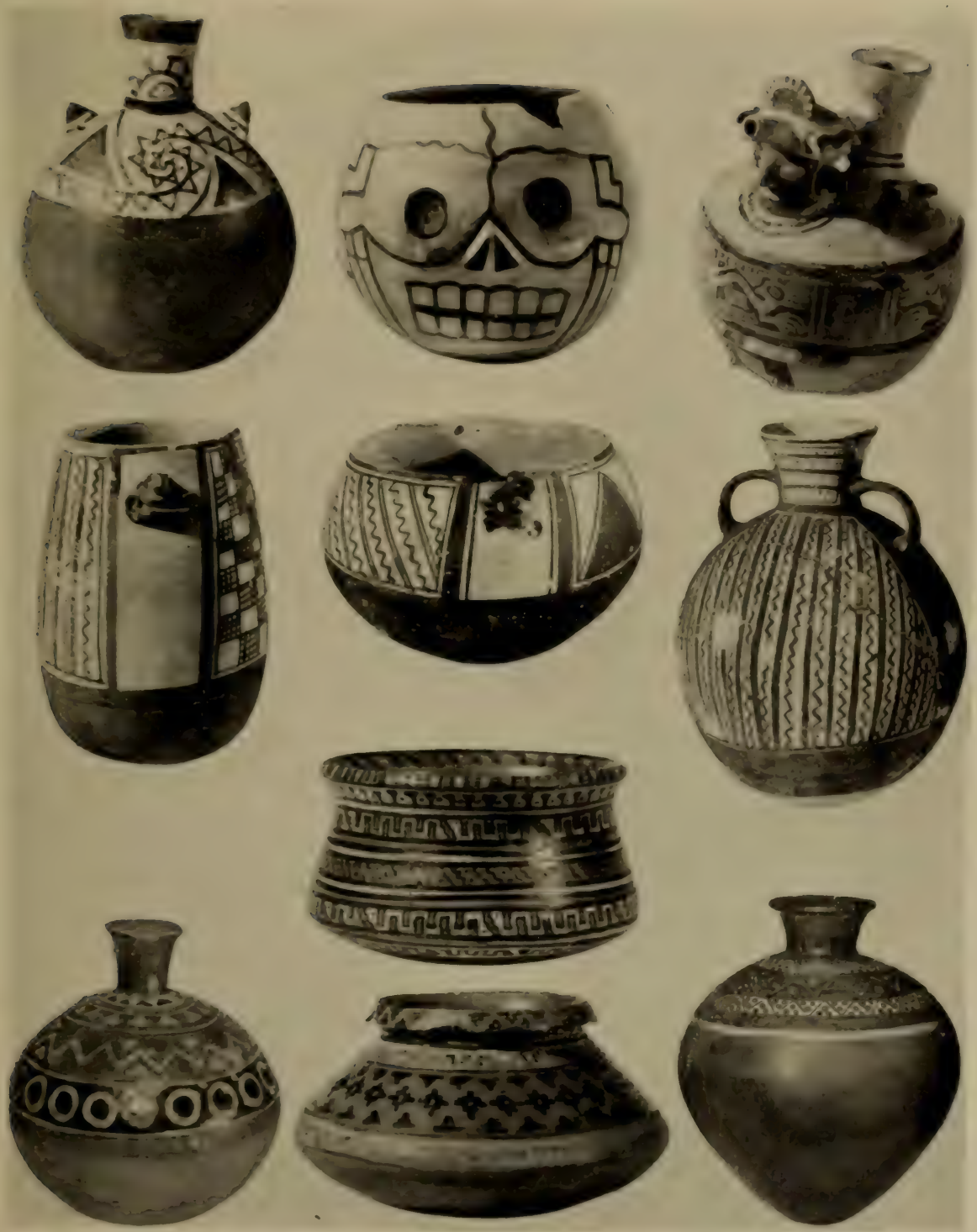

Fig. 46. City Juilder ceramic styles from the cintral and South roast. Top row, right, Negative painted Reenay vessel of the Mastereraftsman Perionl, others, Two late vessels from Parliacamac: secend row, Three vessels of cliancay IBlack-onWhite style; loottom row. Four vessicls of Ieat style. 
ever, many of the pieces considered Atacameño are most common outside the Atacama area and are found unassociated with plainware types used in that area. This indicates incomplete data so until Atacameño sites are systematically excavated, we must avoid theories about their culture. Elsewhere in the highlands, the ceramic styles are not particularly distinctive, as previously mentioned.

Woven fabrics are now produced in quantity, but the ambitious, elaborate weaves are less frequent than in some of the previous periods. The coast regions are united by their great use of all cotton weaves and by the quantity of painted, tie-die, and double cloth. Embroidery is still common, but is now applied to limited areas or to figure outline. Border fringes are typical although needle knitting: is no longer practised. Tapestry is used to finish borders and for small inserts in the centers or in the corners of the cotton pieces. Gauzes, brocades, and pattern weaves are abundant. The textile designs are everywhere similar in the conventionalization of small bird, fish, and geometric figures, and in the arrangement of units in horizontal bands, diagonal rows, and within squares, diamonds, lozenges, and frets. Over-all coast similarities are striking, although detailed studies permit the diferentiation of textiles from the North, Central, and South Coasts. Featherwork is also typical of this period on the coast. The feathers are sewn on a base cloth and designs are produced by arrangement of different colored feathers, sometimes resulting in mosaic-like patterns.

Metalwork is more abundant than in previous periods and some new techniques are added to the earlier inventory. Bronze, or the alloy of tin and 
copper, is now known, and the casting of copper became widespread for the first time. Gold, silver, (opper, and bronze are all used in making such ornaments as masks, earrings, beads, crowns, and breastplates. The Chimu earplugs are long cylindrical tubes of gold, decorated with fine incised designs. At one end is a circular dise with hammered relief figures augmented by attached bangles. Goblets, howls, and plates are made of silver and gold. There are also a great many utilitarian artifacts of copper and bronze, illustrated by points for diggingsticks, club heads, knives, and needles. Many other artifacts are made of shell, bone, stone, and wood. Basketry is common. Decorated calabashes are particularly typical, some ornamented by pyrogravure, others by mosaic insets of beads and seeds.

The existence of an urban pattern in itself suggests a strong social and political organization. The maintenance of a city must have been difficult under conditions in which it was necessary to transport all food by llama or by individuals on foot and in which markets, monetary units, or formal exchange patterns were apparently unknown. The erection of prramids composed of billions of adobes and of cities covering many square miles required organized labor. Certain sections of the cities seem to have been religious centers, others the headquarters of administrative units. Definite class distinctions are indicated by striking differences between dwellings in the same site, by marked contrasts in the quantity and quality of grave goods, by variations in clothing, and by the fow records left by the Spanish chroniclers. The serparated walled-in units of Chanchan and other sites sugerest that social 
groups, of ayllu or clan type, persisted within the political superstructure. The wide distributions of these regional cultures and the high degree of similarity of materials within a region imply over-all political unity. The exact nature of this unity is still unknown. Some have suggested a confederacy pattern, others a type of feudal control in which subject people furnished tribute to the rulers. There is also evidence for formalized religious organization, although in general this seems secondary to the political organization.

Rivalry and conflict would be the inevitable result of a series of expanding local political organizations. Although the City Builders of the coast seem far stronger than their Highland neighbors, subsequent history proves otherwise. In the next period the Highland Inca not only conquered and incorporated all parts of the Central Andes, but extended their political empire well beyond its borders. There is remarkably little archaeological evidence for the development of the Inca organization in the Central Highlands. The Early Inca culture, recently isolated, is estimated to cover the time period of 1200 to $1438 \mathrm{~A}$. D. The few known sites of this culture contain carelessly executed ceramics with simple designs, rough stone walls, beehive-shaped tombs with crude corbeled vaults, and a limited inventory of metal, bone, and stone tools. Future archaeological work will certainly enlarge this picture. There is still no knowledge of cultural development around Cuzco in the Mastercraftsman Period, although it was presumably of sufficient strength to resist the Tiahuanaco influence in the Expansionist Period and to continue through the City Builder Period until it became the center of the Inca Empire. 


\section{Imperialist Period}

\section{(ca. 1450-1532 A. D.)}

The Inea Empire marks the final formulation of Central Andean culture which persisted up to the time of the Spanish conquest (Fig. 47). The political system in previous periods may have been a

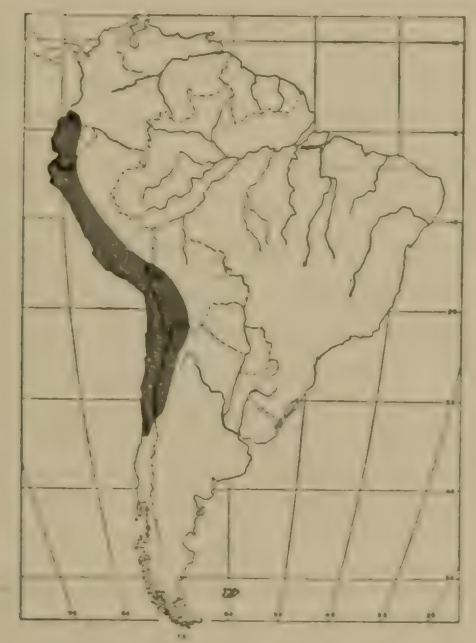

Fig. 47. Maximum expansion in the Imperialist Period.

confederacy, a feudal state, or a military band organization. However, the Inca had a true political empire which united the enormous territory from northern Ecuador to the Río Maule in Chile uncler a single ruler, thus encompassing not only the Central Andes, but much of the Northern and Southern Andes as well. As mentioned before, little is known about the specific origins of the Inca culture. The Early Inca culture in the Cuzco region is not very impressive and is not the only stem for the develop- 
ment which followed. Inca mythology contains several accounts of their origin, but while these are interesting, they have little historical reliability. Actually, the question of precise origin is only of academic interest since the basic roots of Inca civilization are found in the archaeological past of the Central Andes, as demonstrated in the previous chapters. The complete gamut of Inca technology had been developed and the shift of emphasis to political organization had occurred in earlier periods. The Inca contribution was little more than a reformulation of the political pattern into an empire building system.

The archaeological remains of the Imperialist Period preserve a record of the material culture, the construction, the types of towns, the modes of burial, and the standard implications about social and political organization. However, the reconstruction of Inca culture is no longer based exclusively on archaeological evidence. The historical, documentary records present the accounts of the first Spanish conquerors, the early travelers, Catholic priests, and even of prominent Indians who were European educated. On the basis of these documents, it is possible to reconstruct a fairly detailed picture of Inca culture. However, even without such records, it would still be feasible to verify the extent and magnitude of the Inca Empire. Like the Tiahuanaco, the Inca horizon is a complex composed of a number of distinctive artifacts and styles. The chief diagnostics are the ceramic type, the building style, certain techniques and designs in textiles, typical metal artifacts, and specialized stone objects. This complex is found throughout the extent of the Inca Empire. Furthermore, the concentration of 
unmixed Inea materials at ('uzeo implies that it was the center of this vast cultural diffusion.

Although the geographical extent of the Inca Empire is well known, the size of its pre-Spanish population is dubious, as shown by the estimates which range from three to sixteen million. The Inca themselves undoubtedly kept census records, but none was transmitted to the Spaniards. Since the Empire was organized in a decimal system and since the ideal province had forty thousand workers representing about two hundred thousand inhabitants, the population could be easily computed if the number of provinces contained in the Empire were known. The first Spanish census, taken in about 1571, gives a total of about 1,500,000 Indians for the Central Andes. Since this census was taken some time after the Spanish conquest, it raises the question of the rate of reduction of Indian population during the years of struggle. Two estimates have been made in the 1946 "Handbook of South American Indians." George Kubler favors a two to one reduction ratio, based on comparisons with Mexico and the absence of serious epidemics, and thus arrives at a total pre-Spanish native population of three million. John H. Rowe prefers a four to one reduction ratio, based on records of specific provinces, and arrives at a figure of six million. Adding in other parts of the Empire, it would not seem unreasonable, then, that the population was not less than three and a half million nor more than seven million. Some authors have claimed that the populations were larger in the pre-Inca periods but there is no archaeological confirmation of this, nor is it likely since the Inca had the same technical and agrieultural knowledge as their predecessors. 
The early Spaniards recorded the traditional lists of Inca rulers, together with miscellaneous information on the reign and conquests of each. John H. Rowe has made a study of these documents and arrived at the following list of Inca rulers with their dates of reign:

\section{Manco Capac}

2. Sinchi Roca

3. Lloqui Yupanqui

4. Mayta Capac

5. Capae Yupanqui

6. Inea Roca

7. Yahuar Huaca

8. Viracocha

9. Pachacuti Inea Yupanqui (1438-1471)

10. Topa Inea Yupanqui (1471-1493)

11. Huayna Capac (1493-1525)

12. Huascar and Atahualpa (1525-1532)

The information about the first eight rulers is hazy and inconsistent. Rowe considers the year 1250 a reasonable date for the first ruler and believes that the first eight represent a local Cuzco development corresponding archaeologically to the Early Inca culture. The true Inca Empire was thus created between the time of the ninth ruler, Pachacuti Inca Yupanqui, and the Spanish conquest, that is, in less than one hundred years. Undoubtedly there had been raids outside of the Cuzco region in earlier times, but the first territorial conquest was the Lake Titicaca region campaign in 1445 . The incorporation of most of the other areas occurred after 1470.

When the Inca began this expansion, many of the coast cultures were well united politically, and the Highland groups, while less concentrated, were organized into protective confederacies. The Inca 
military conquest eneountered varying degrees of resistance. Many years of fighting were repuired to conquer the Highland tribes and even then garrisons had to be constantly maintained to prevent reliellion. Other groups were less resistant and some of the largest, like the Chimu on the North coast, were incorporated by passive persuasion. Many of the marginal groups, like the Chiriguano in the east and the Araucanians in Central Chile, were never actually conquered.

The Inea conquests were not inspired by population pressure, but rather by a desire for economic gain in the form of new administrative posts, new produce, new labor supply, and more soldiers, and by the necessity of strengthening the position of the ruling class. The conquests were carefully planned. A propaganda campaign usually preceded the military aggression. Official emissaries endeavored to point out the benefits of Inca control and missionaries attempted to make converts for the official sun worship. If these were unsuecessful, the army entered in mass formations of eight to ten thousand soldiers and effected the conquest by siege, cutting off the food supplies, building forts, and pitched battles. The army was well organized and discipline was severe. All officers were from the upper class, but the soldiers were commoners. All able-bodied men were subject to the draft, and it is estimated that one-tenth of the adult male population was in the services. The families of the draftees were supported by the state. Military instruction was given in the use of all weapons: bronze battle axes, slings, bows and arrows, spear throwers, lances, hard wooden (dnbs, and clulse with stone or bronze heads. Metal helmets, thick jackets, 
and shields were used for protection. All of the weapons had been used for many years throughout the Central Andes, so that success of the Inca is not ascribable to superiority in weapons, but rather to superior military organization.

The captured province was systematically incorporated into the Empire system. A census was taken and a rough relief map of the terrain was modeled in clay. Villages were frequently shifted and new towns were built. The administrative officers were usually members of the Inca caste, but every effort was made to continue the previous local rulers in office. To assure their loyalty, their sons were taken as hostages to Cuzco where they received the formal, upper class education. The Inca imposed their sun-worship religion on the new subjects, made the Quechua language the official one, and required Inca style dress, although local distinctions were permitted. If the conquered peoples continued to be rebellious, the Inca resorted to the system of mitimaes whereby whole villages were transplanted to another district and replaced by pacified populations. As each new district was conquered, the network of roadways was extended to include it, so that ultimately the whole Empire was linked by connecting roads. Some of the roads were paved, some hewn out of the bed rock, and some merely indicated by markers. Rivers and gorges were crossed by means of suspension, pontoon, and cable bridges. Inns for the travelers were maintained at intervals along the road. Widespread communication was effected by means of professional runners, the chasquis, who covered as much as one hundred fifty miles a day by running in relays. However, the Inca Empire did not endure 
long enough to provide a true test of the effectiveness of this system of pacification and incorporation.

In the Imperialist Period, subsistence was based on intensive agriculture, which by this time had passed through the stages of exploitation and conservation and reached that of restoration. No new plants were domesticated, but all those known previonsly were still grown. Likewise, irrigation, terraces and other techniques were little changed, although the digging-stick was slightly improved by the addition of a foot bar and a handle. The importance of agriculture was recognized and intimately linked with other aspects of culture. A great proportion of the laborers were so engaged; the work was done in groups rather than individually. For example, the planting season was determined by solar observations; the priests fasted to insure good crops; public religious ceremony accompanied the first planting and the harvest. The ruling Inca and members of the upper caste made agriculture a symbol of honorable labor by breaking: the first ground themselves. The Inca used personal service as a form of taxation and agricultural work became the economic basis of the system. Fach family cultivated not only its own plot of land, but also worked on the fields assigned to the church and the state, the produce from which supported the political superstructure.

The common foods prepared in Inca times are still used by the contemporary Indians and had undoubtedly long been known. Llama meat was eut into strips and dried as charqui. Potatoes in the high altitudes were frozen into chuño, which could be preserved for long periods of time. The basic dish, ealled chupe, was a corn or potato soup with 
other foods added to form a stew. Corn was toasted, popped, roasted, and used in many other ways. For example, t'anta was a cornbread, huminta a sweet cornbread, and cancu a cornbread mixed with blood for ceremonial occasions. A corn beer, chicha, was also prepared for religious and secular celebrations. Tobacco was utilized only in the form of snuff for medicinal purposes, but the narcotic coca was of great importance. Coca chewing among the Inca was a restricted upper class privilege; the commoners were permitted to use it only on special occasions.

In the Imperialist Period, each district produced more than was needed to support the local population and this surplus was stored in state granaries throughout the Empire. Careful records were kept of production and storage since the surplus was used to support the aristocracy, the priests, and the special artisans, and the army and all laborers who were working on public projects or in the mines. The surplus also provided social security on the occasions when a district was stricken with famine because of crop failure.

All cultivable land was divided into three parts. The first, and usually the smallest area, was assigned to the support of the priests and the temples. The second was the property of the state, acquired by confiscation or as the result of new irrigation projects. The third, and usually the largest portion, pertained to the local villages for their own support. The village land was divided into strips of equal size, each considered large enough to support only one couple, so that additional assignments were made for each child. Since the village lands were controlled collectively, only a house and per- 
haps a garden plot belonged exclusively to the family.

There was no monetary srstem. Local markets allowed simple exchange of goods on a barter basis, but even this practice was not very extensive. To be sure, great quantities of produce were transferred from one region to another, but this was state property and state controlled business. Foreign trade likewise was a state monopoly.

The herding of llamas and alpacas continued to be an important subsistence activity. Here again, a distinction was made between indiridually owned animals and state flocks, the tending of which was another form of tax parment. Along the coast and around Lake Titicaca fishing was a common addition to the subsistence, but hunting ererywhere had beeome a sport restricted to the upper caste.

Extensive building activities are characteristic of the Imperialist Period. These range from irrigation systems, agricultural terraces, roads, and bridges through various types of habitations to large public centers, temples, and forts. The dwellings of single families were generally one-story rectangular buildings, with walls of rough stone or adobe, floors of trodden earth, and gahled roofs with grass thatch. Such houses had narrow doorways, and niches and pegs in the walls, but no windows. The house furnishings were very meager, consisting of a single platform bed and such utilitarian objects as grindstones, clay braziers, animal skins, and rush mats. A compound of several such houses was oceupied by the extended family, and a village consisted of a scattered group of such compounds. In general, the Imperialists were not urban dwellers, although some of the religious and 
administrative centers reached respectable sizes, and were planned and constructed by special architects. One of the best known town centers is Machu Picchu (Fig. 48), built on a high ridge near Cuzco. The ruins present a conglomeration of terraces, house compounds, courts, stairs, terraces, and temples. Most of the construction is done with rough stone, but some of the important units are built of carefully dressed and fitted stone. The best houses have windows, carefully built niches, stone wall pegs, and narrow doorways capped with stone lintels.

The large public buildings for religious or administrative purposes are quite ambitious affairs, but even so all of those better known can be assigned to the one hundred year period of Empire expansion. In the Coast buildings, large rectangular adobes were used, but in the Highlands stonework of many types was utilized. In Cuzco alone there is a megalithic style with large slabs and blocks of irregular sizes and shapes carefully fitted together; a similar style but with smaller stones; walls built of unit blocks, either dressed smoothly on all sides or left slightly rounded on the outer face (Fig. 49). These different building styles do not imply a sequence since their employment seems to have been functionally determined by the purpose of the construction, whether it was intended to support a heavy superweight, to be a free standing wall, or to have some other function. The architects planned the buildings by making clay models. In viewing the finished structures it is worth bearing in mind that they were produced without benefit of any iron or steel tools; that the available bronze was of little or no use in stone cutting. Quarrying 


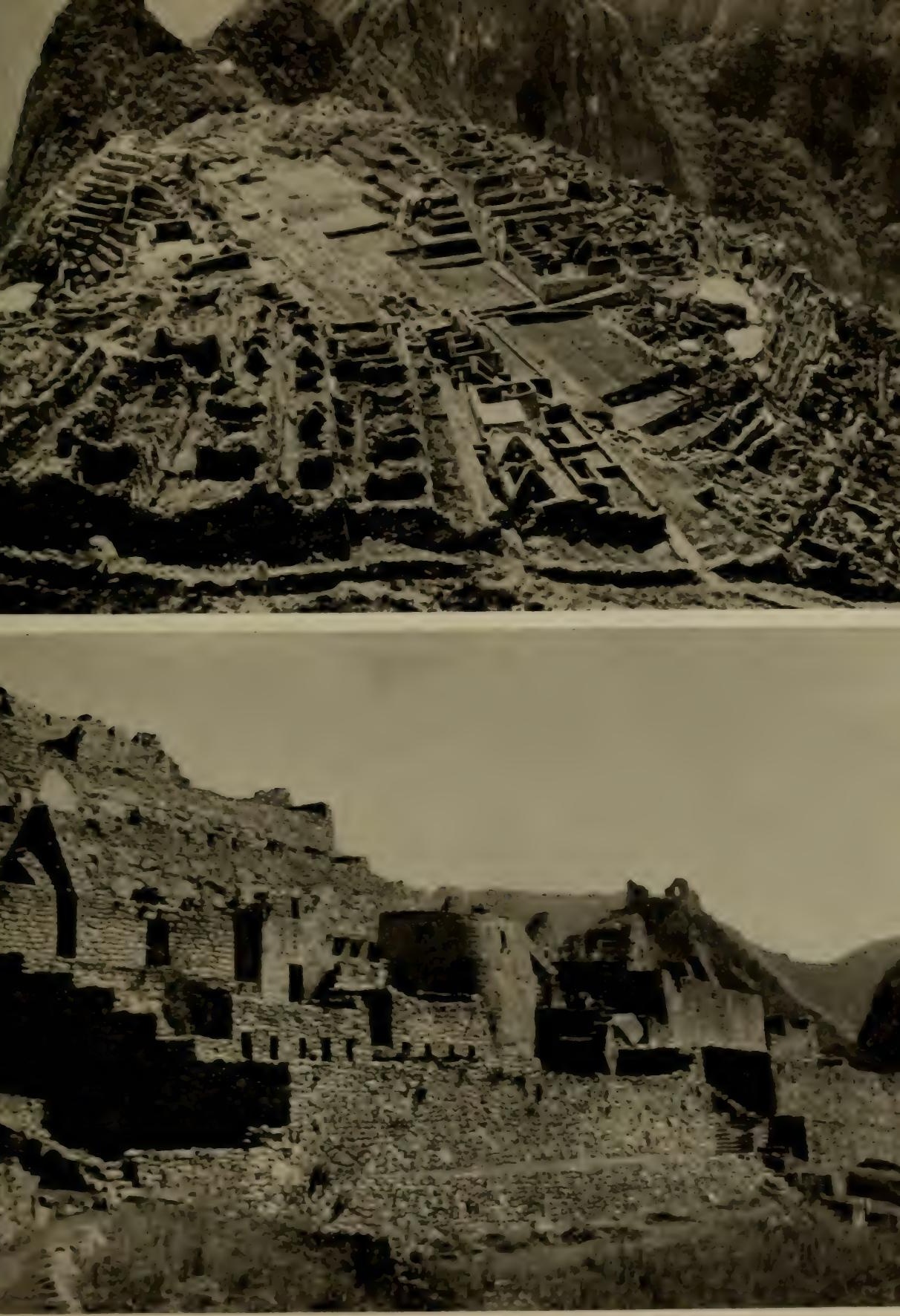

Fig. 48. The famous Inca citadel of Machu Piechu. 
was a laborious process of pecking and hammering store against stone until the desired block was so nearly free that the final cleavage was simple. Most of the dressing and fitting was obviously done at the last moment at the construction site. Many of these walls have stood for over four hundred years, testifying to the skill exercised in their construction. The quality of the masonry is a remarkable achievement, although it does not surpass that of some of the earlier periods.

Craftsmanship was still at a high level of competence, but the artistic quality does not match the earlier achievements. Each family among the commoners made the pottery, textiles, and other artifacts necessary for its own use. Selected specialists produced the finer work for upper class and ceremonial uses. These specialists were supported by the state, but were not organized into craft guilds, nor, so far as can be judged, was their position particularly favored in the social system. The art style of this period is distinctive and is identifiable in every craft.

The ceramics are well made, highly polished, and polychrome painted with black, white, red, yellow, and orange. Except for small, stylized butterflies, bees, and animals, the design is frankly geometric, consisting of serrations, bands, diamonds, checkers, triangles, cross hatch, circles, and dots. The vessel shapes are standardized. Most characteristic is the aryballoid jar with its conical pointed base, vertical, flat side handles, tall flaring collar, and animal head body nubbin (Fig. 50). Shallow, bird handle plates, straight-sided goblets, pedestal base beakers, one and two-handled pitchers, and bottles are also com- 


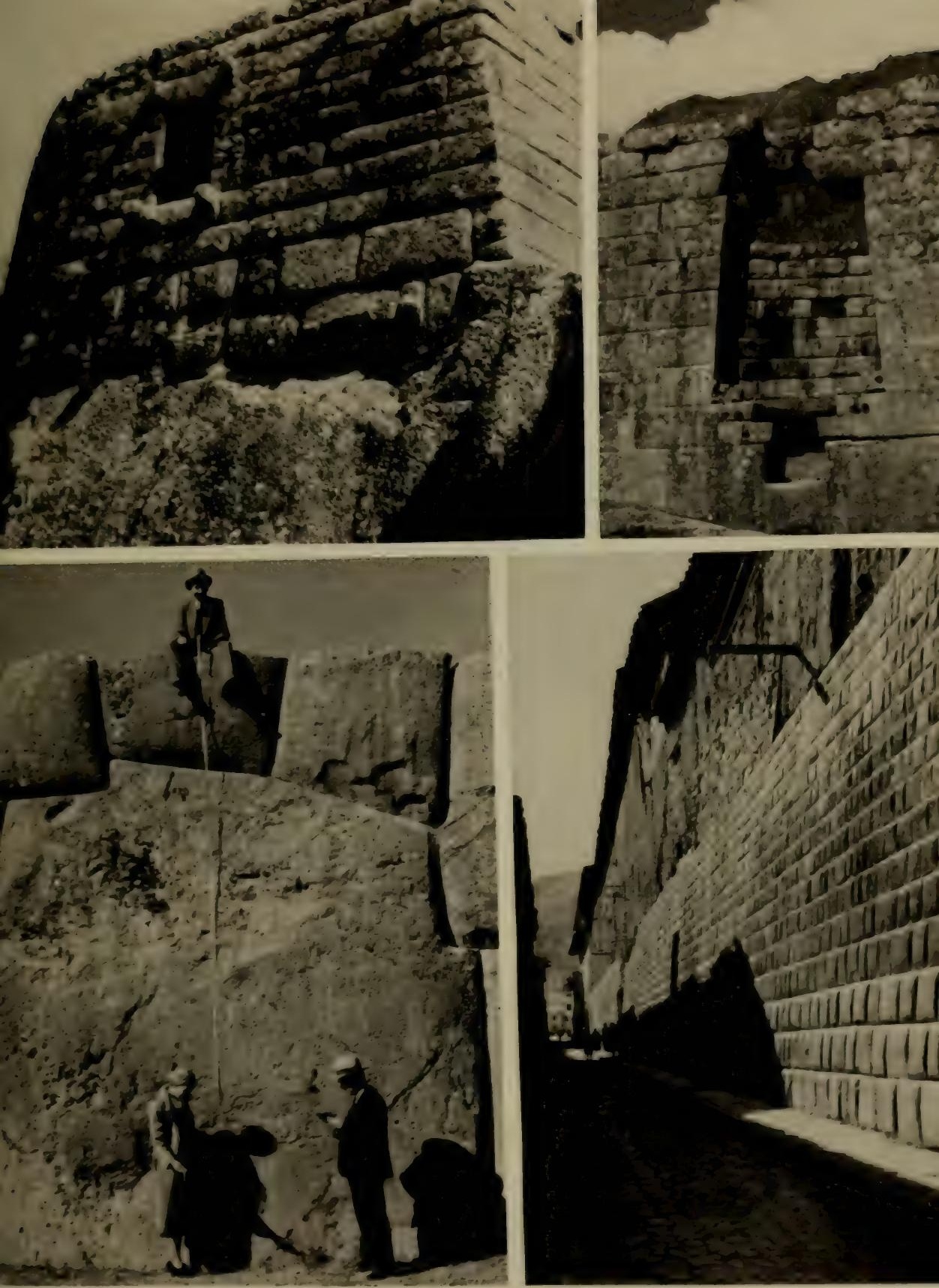

Fig. 49. Types of Inca masonry. Top, Machu Piceluu; lower left, Fortress of Sacsahuamán; lower right, a street in Cuzco. 


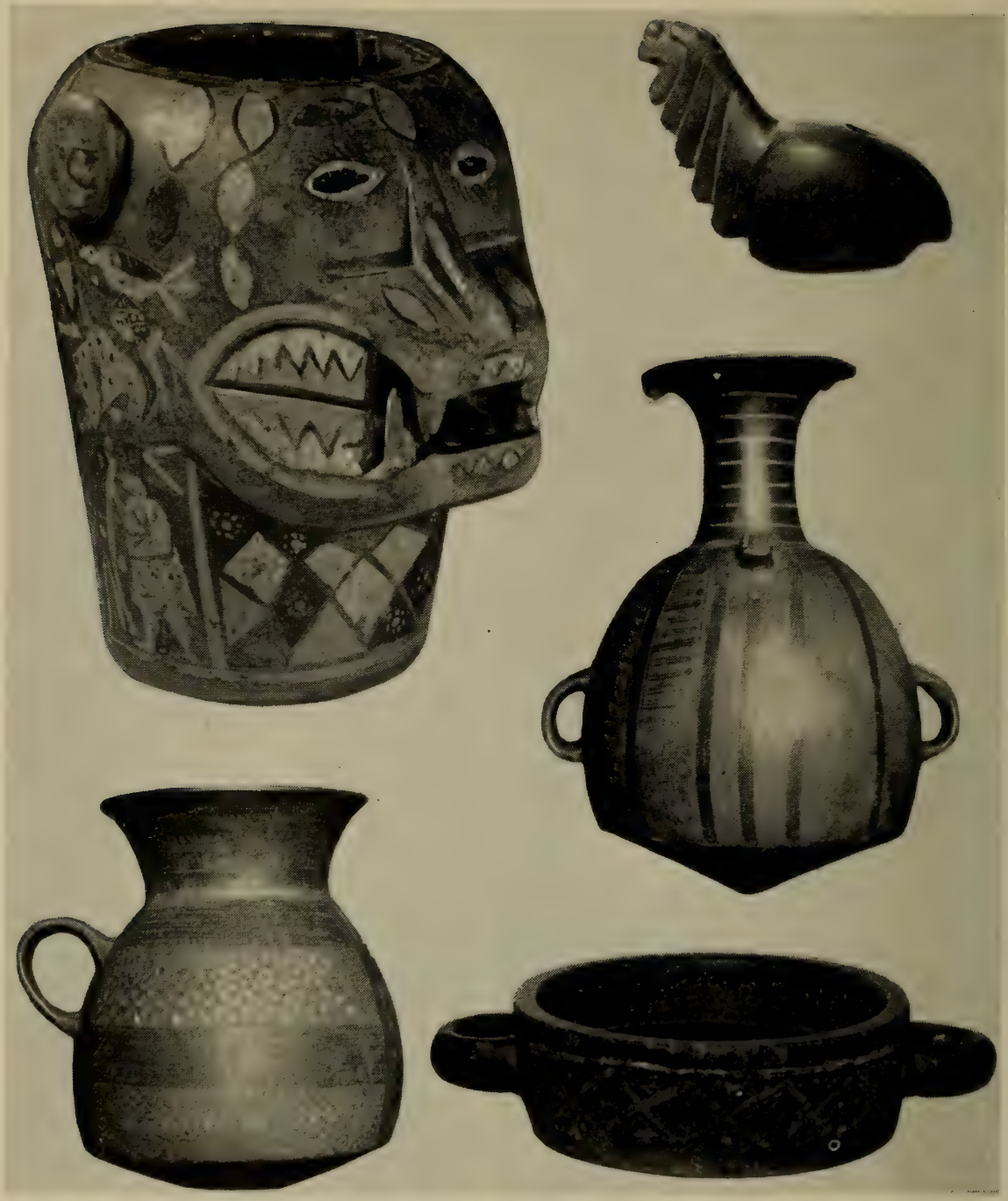

Fig. 50. Inca artifacts: lacquered wooden kero, ceremonial stone llama form container and bowl, two very typical pottery containers, a pitcher and aryballoid water or beer jar. 
mon. This typical Inca ceramic style is found throughout the widespread Empire.

The weaving is competent; control of all earlier techniques is demonstrated, but the number of truly fine pieces is limited. Among the best examples of the weavers' craftsmanship are ambitious tapestry ponchos decorated with small design units. Warp patterns and repps are very common. The clothing pattern previously established is continued and details of dress, particularly in headgear, distinguish class, special occupation, and regional residence. The woren articles include breechclouts, mantles, waistbands, headbands, poncho shirts, rough blankets, belts, bags, and slings.

Metallurgy is now equally important for utilitarian artifacts and ornaments. The collections of gold ornaments demonstrate great skill in workmanship and this is rerified by the early Spanish descriptions. The utilitarian objects are now commonly made of bronze and include club heads, digging-stick points, tweezers, chisels, flat-headed pins, dises, and needles. New methods of gilding and casting are added to the techniques previously known. Stone carving is not associated with this period, but stone artifacts are numerous. The most distinctive are bowls, club heads, stellate-shaped mace heads, and small carved llamas with holes in their backs for offerings. Wood is also used extensively. The wooden kero, or goblet, decorated by lacquer inlay, is a most characteristic container.

The Imperialist Period placed great emphasis on social and political organization. Actually, the system developed was little more than a formalization of tendencies already initiated in the Central Andes. The family and extended family were still basic 
units. Several extended families were united by a local village group, or ayllu, which theoretically controlled the real property. The ayllu is sometimes called a clan, but actually it lacks the kinship unity and other characteristics of this unit of social organization. Instead, the extended patrilineal family within the ayllu was the most important kinship group, and also cooperated in labor, controlled the education and marriage of the children, and supported local religious cults. The entire village, however, also had certain social and religious functions which increased in importance when the Inca formalized them. For example, the Inca made marriage within the village compulsory. Furthermore, the village was made an economically independent unit of sufficient strength so that it has survived up to the present day.

The economic system was based on the organization of man-power labor units. The population was classified into twelve age grades to facilitate the maintenance of a labor census. Those classed in the able-bodied age grade were taxed by being assigned a specific quantity of labor service such as agricultural work on the state and church fields, army service, herding, or work on a public building project. Records were kept of each individual's contribution. The assignments were made in terms of quantity rather than time, so the man who could use the assistance of his children finished sooner than the others. The system also encouraged exchange of labor on a cooperative basis, particularly in the form of individual arrangements for substitute laborers. In most cases this made little difference since the work was performed in groups, and the tasks demanded little skill. In fact, much of 
the planning consisted in reducing the work units to the unskilled level.

The political system, usually described as pyramidal, was based on the labor unit. Ten laborers formed a work group under the supervision of a foreman. In the ideal pattern work groups corresponded to the village or allyu, under the direction of a head man. In turn, ten village units formed a tribe, under the supervision of a high-ranking official. Such pyramiding continued until large units corresponding to the four quarters of the Empire were attained. The ruling Inca formed the apex. In the functioning of this system each administrator reported to his immediately superior official, and so on up to the Inca. In reverse, the Inca's orders filtered down to the laborers. Administrative officers of the same magnitude were not organized in any way. Instead this vertical political organization was cut across by the sharp class distinctions which had by this period assumed the rigidity of a true caste system.

The upper caste contained two classes: the Inca aristocracy, the original conquerors and their families and the nobles, composed largely of the previous rulers in the local districts seized. The lower caste included all the commoners, the basic mass of the labor population. The outstanding distinction between these castes was in the privileges accorded them. The upper easte had finer garments, more permanent houses, gold and silver service; but food was abundant for all, and coarse clothing, adobe houses, and ceramic vessels do not imply poverty. The differences in privilege, however, were numerous. Not only were travel, dress, marriage, and celebrations regulated for the commoners but they 
were forced to perform all the manual labor. The upper caste controlled all of the higher administrative and religious posts, were permitted several wives, performed no labor, and were treated with extreme reverence and homage. Formal education was limited to the upper group. Little mobility was allowed in the system so that it was virtually impossible for a commoner ever to enter the upper caste. Even those selected as specialists in weaving or metallurgy remained in the lower caste. The ruling Inca himself had absolute authority and was considered divine. His symbols of authority were a special mace, a feather headdress, and other distinctive insignia. Most of the Inca rulers, judged by achievement, were outstanding men. The caste system had become so dominant that in reference to any aspect of the Imperialist Period, distinction must be made between upper versus lower class.

Archaeological information about customs and ceremonies of the life cycle is at best meager and conjectural, and even with the addition of the Spanish records the data are still limited. It is known that children were considered an economic asset and, therefore, desired. The mothers observed certain prenatal taboos, but there was no special ceremony at the birth of a child. The infants were kept in cradles until old enough to walk, and weaned at about two years of age. At this time a special naming ceremony was performed by the family and close relatives. The infant's hair was tied into bunches which were cut off singly by the participants who contributed gifts and selected a name. Most of the names were those of animals, natural objects, places, or particular qualities. In the upper caste, special titles of rank were added. Chil- 
dren played with tops and balls, and competed in footraces. Education for the commoners consisted of practical home training in those crafts and techniques necessary for self support. In the upper caste, education was formalized under the supervision of special wise men who taught regular courses in history, mathematies, religion, and language. The twelve age grades, previously mentioned, were not recognized in local custom. However, the transition from youth to adulthood was an occasion for rigorous tests in the upper caste. Among the commoners marriage was a family affair arranged by the parents within the village unit. The families concerned held simple home ceremonies; once or twice a year the marriages were officially recognized by the Inca overlord at a public ceremony. Death and burial were family affairs among the commoners but the occasion for elaborate public ceremonies among the upper caste. Pits, caves, and bottleshaped graves were used for burial; important individuals were buried in a seated position, wrapped with fine cloth, and accompanied by many offerings.

The Inca calendar was based on the solar year and the lunar phases, but was not recorded. In contrast to the Maya, however, their observations and calculations were not elaborate. Althongh lacking any form of writing, numerical records were kept of the quantity of crops raised, the size of the herds, the population totals in terms of age-grades, and many others. The exact system of calculation is not known although it had a decimal basis. Boards with various box-like divisions have been found which were probably used as a form of abacus for calculation with beans or pebbles. Whatever the system of counting, the totals were recorded 
on the quipus This consisted of a base cord with a series of attached strings on which half-hitch knots represent decimal units. The numbers from one to nine were recorded at the extreme tip of the string, and the tens, the hundreds, and sometimes the thousands were proportionately closer to the base cord. Strings of different colors represented specific categories of objects. On some quipus the total for a group of four or more strings was recorded on another on the opposite side of the base cord.

In examining the religious beliefs and practices of the Imperialist Period, a distinction must be made between the local village cults, maintained by the commoners, and the formal state religion directed by the priests of the upper caste. The distinction is an elaboration and formalization rather than in the basic beliefs which are, in both cases, concerned with the agricultural cycle, nature worship, and especially ancestor worship. The gods in the official state religion were arranged in a hierarchy. Viracocha, the leader, was considered to be the creator of the world and to reside in heaven. The Sun, second in importance, was the protector of the crops. He was represented by a golden dise with a hammered relief face. Thunder followed as the god of weather and warfare, appropriately represented by a club and a shield. The Moon, as the wife of the Sun, held an important position. Many stars were identified as lesser gods and some constellations, like the Pleiades and Lira, had special functions. The Earth and the Sea had apparently been important gods in earlier periods and continued to be prominent. There were many ghosts and spirits, both good and evil, but these were outside of the formalized hierarchy. 
The state religion was in the hands of a priest group, arranged in a pyramidal system in which the upper caste occupied the top positions. The priests as well as the religious temples and shrines were supported by the commoners. The principal ceremonies were calendrical, at least one for each month, and more important ones for the new year and the solstices. Other ceremonies were held on irregular occasions such as the death of the ruler, the inauguration of his successor, and the initiation of warfare. The public ceremonies were elaborate, several day affairs organized by the priests for the benefit of the commoners. East and west were the most important ceremonial directions. The gods were approached with special attitudes of worship in which the priest faced the image, bowed, and stretched out his arms. Fasting and confession were regular duties of the priests. Offerings and sacrifice were important in the ceremonial. Prisoners captured in warfare were sacrificed or children were offered by their parents for this purpose, but this practice was not carried to extremes. More common was the sacrifice of llamas and alpacas selected for their particular color or markings. Food, coca, clothing, gold and silver objects, and other things were burned on the altars as sacrificial offerings. The ceremonies also included the consumption of special ceremonial foods, chicha drinking, and coca chewing.

The most elaborate ceremonies were held in Cuzco and involved many participants. The priests and privileged members of the upper caste conducted parts of the ritual within the temples. The commoners were restricted to special sections of the city where they observed only the public phases of 
each ceremony. Groups of warriors in full regalia engaged in violent activities in order to drive off evil spirits. There were parades, games, and dances at every performance, and sometimes the mummies of the important deceased were removed from their burial vaults and carried in the parades. The ceremonies started at sunrise and closed at

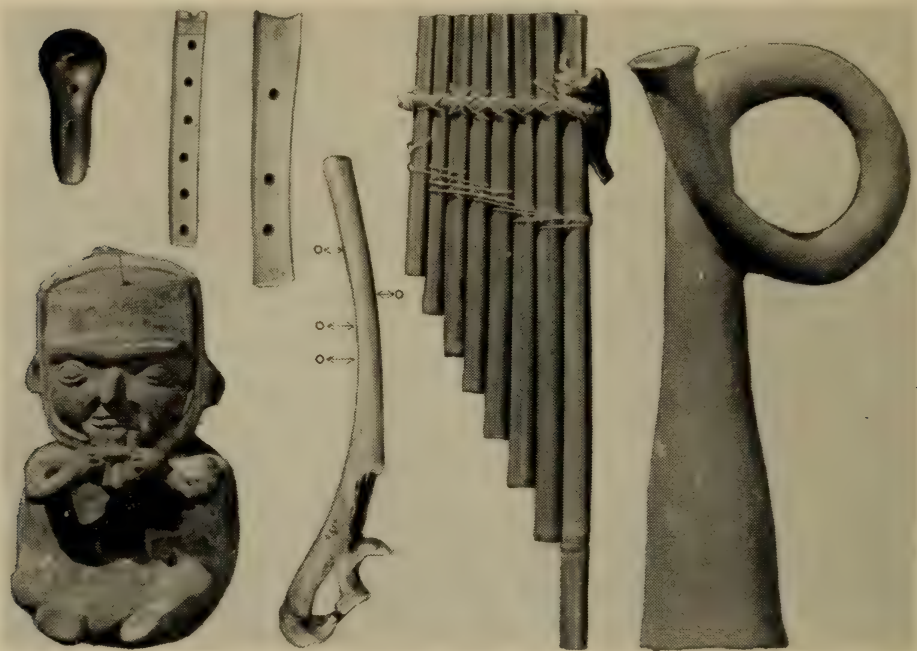

Fig. 51. Musical instruments, panpipes, flutes, whistles, and a horn.

sundown with a ritual bath for all the performers. Special chants and song's were composed for the dancers who were specially trained groups with elaborate masks and costumes of skins or feathers. The music, all in the pentatonic scale, was provided by skin drums, bronze gong's, copper bells, bone flutes, panpipes, trumpets, and whistles (Fig. 51).

Apart from the hierarchy of priests in the state religion many lesser priests presided at local 
shrines. These were actually medicinemen or soothsayers who, under the influence of liquor and narcotics, went into trances and then uttered oracles which revealed the wishes of their controlled spirits. Some became very famous and pilgrims traveled many miles to consult them. Other medicinemen also practised divination with llama lungs, coca leaves, and dream interpretations, or effected magical cures; still others specialized in herb cures.

Among the commoners, the village and the extended families conducted their own local ceremonies for curing the fields, curing the sick, calling the winds, before beating and wimnowing quinoa, increasing fertility and the ritual occasions surrounding birth, naming, marriage, and death. These ceremonies were not led by priests, but by members of the village. Each extended family built a local cult around the founding ancestor and kept special household fetishes, such as bundles of cornstalks or small stone llamas. Finally, each individual had his own guardian spirit.

The Imperialist Period is a natural outgrowth of the earlier Central Andean patterns. The techniques of agriculture and eraftsmanship had long since been perfected to the point where large populations could be supported and their fundamental needs successfully met. Likewise, the shift of emphasis from technology to manipulation of labor units had passed through a reasonable period of experimentation. The Imperialist pattern was only one of the possible formulations, but certainly a logical one. An objective evaluation of the Imperialist system is difficult. It consisted basically of a sharp dual division between a large lower caste of workers and a small privileged upper caste. The 
commoners were organized around the ayllu or village which became a self-sufficient unit for the support of its members, the production of the necessary housing, clothing and other artifacts, the maintenance of local government and of local cults. National government, economic security, and protection were under the control of the upper caste. The gap between these castes was ever increasing, until no equality was admitted. Knowledge and education as well as the skilled productions in the arts and crafts were controlled by the upper caste. When the Spaniards replaced the upper caste, following the conquest, there was naturally a rapid breakdown in craftsmanship and education.

The Inca Empire had existed less than one hundred years before the conquest, which probably furnished insufficient experience to perfect final controls. Had it been uninterrupted by the Europeans, modification might well have occurred and the size of the Empire unit might easily have been reduced. However, it is doubtful that the fundamental pattern would have changed greatly since it had been maintained for several centuries. There were, to be sure, signs of weakness in the Inca political system itself. The pyramidal structure, while efficient, failed to provide esprit de corps or communication between officers of the same rank. The regimentation in the Empire was excessive in spite of the guarantee of security. It certainly appears that the commoners' loyalty to the upper caste was not very great. A final weakness was the failure to establish a fixed rule for succession in the rulership so that immediately prior to the conquest there were two contenders who had already divided the Empire. The Spanish conquest has always seemed 
amazingly rapid, reflecting, in part, some of the fundamental weaknesses of the Imperialist system.

\section{Aftermath}

The year 1532, when Francisco Pizarro and his followers initiated the conquest of Peru, marks the end of the archaeological and the beginning of the historical epoch. The more dramatic incidents of the conquest are well known: the bold seizure of the Inca ruler, Atahualpa; the golden ransom paid for his release; the assassination of the Inca; and the collapse of the Inca Empire. Although amazingly rapid, the conquest was not as simple as this historical condensation implies. The initial shock was followed by forty years of active resistance during which the balance of power was often delicate. However, the Europeans eventually won and the four hundred years since the conquest have made many profound changes in the Indian culture.

One of the immediate effects of the conquest was a marked reduction of the actual numbers of Indians, whether one selects the estimate of three and a half million or seven million for the maximum population of the Inca Empire. In fact, the census records, such as they are, show unrelieved loss up to 1796 when an all-time low of under seven hundred thousand was reached. Following the wars of independence, however, the situation was reversed and the Indian population increased at a rapid rate so that today there are some six million in the area once included in the Inca Empire. The vast majority of these, roughly five and a half million, are the Quechua-speaking peoples in the highlands of Ecuador, Peru, and eastern Bolivia. In the Lake Titicaca basin, there are five hundred thousand Aymara 
speakers, and along the Desaguadero River, which drains the lake, are still a few remnants of Uro speakers. Today these Indian populations form an integral part of the several countries. After four hundred years of European influence, the contemporary Indian cultures obviously do not represent a direct survival from the past. Rather, these cultures are distinctive blends of elements from the ancient times, from the Colonial Spanish and from the recent Republican period. Although it is not the intent to present any detailed picture of this long historical period and the modern scene, some of the major changes and survivals may be briefly described.

The Spanish superimposed a new culture, a different language, and a contrasting physical type on the indigenous inhabitants of the Central Andes. The European conquerors became a new ruling caste, with economic, political and religious controls. The sharp caste differences which had divided the Indian populations were eradicated and a long leveling process was inaugurated ultimately reducing all Indians to a single lower class. In the Imperialist Period, travel for the commoners had been limited by law to strictly Empire business. Such restrictions were not maintained after the conquest, resulting in great mobility of the Indian population. This was motivated both by the desires of the Indians to escape tax payments and too great Spanish influence, and by the Spaniards' need for miners in the mountains. In time, there was considerable displacement of the Indian population, particularly since the coastal valleys were the most suitable for European commercial crops and for urban settlements. Today, the coastal region has a 
Spanish and Mestizo population, while the Indians are concentrated in the highland sections. The Europeans also introduced many new techniques and new methods of power control which effected the Indian culture, such as the principle and use of the wheel, ocean travel, firearms, the true arch, writing, iron and steel, frame looms, and new domesticated animals. Of equal importance was the systematic imposition of a new religion on the Indians. The suceess of the church was amazing, since by 1650 the Indians were pronounced to be Christianized and no longer a field for intensive missionary activity.

A comparison of the Imperialist Period culture pattern with that of the contemporary Indians reveals other specific changes and survivals. Relatively few changes have occurred in the subsistence pattern. The Central Andean domesticated plants were well adapted to the different environments and knowledge of their cultivation was deeply ingrained in the Indian population. The Spaniards brought few practical substitutes for such high altitude plants as potatoes, oca, and quinoa. Barley, alfalfa, and a few other cereals have been introduced, but on the whole, the modern Indians still raise most of the old plants. Since food habits are generally conservative, there has likewise been little change in the preparation of the standard foods. The old agricultural tools were simple, inexpensive to make, and effective, and consequently they are still in use. For example, nothing has replaced the digging-stick for cultivating the fields on the steep mountain slopes. Old methods of terracing and irrigation are still practised. For Indian agriculture, the chief innoration has been the introduction of the wooden plough and oxen as draft animals. On the other 
hand, European domesticated animals, including the pig, chicken, burro, horse, cattle, sheep, and goats, were vastly superior to any known in the New World. The Indians have accepted most of the new animals, but have not abandoned the llamas and alpacas.

The construction of temples, public buildings, and similar major projects was taken over by Spanish architects, although the Indians still furnished unskilled labor. The Indians continue to build their own houses, however, much as in the past. The simple rectangular room with frame and thatch roof is now made of adobes, and several such units are arranged in compounds for the extended family. The scatter village pattern is still common.

One of the major changes in craftsmanship has been due to the fact that ceremonial objects are no longer manufactured. Most utilitarian artifacts are, however, still made by each family. The ceramics are coarse and poorly decorated, but made in the old techniques. There are also some professional groups who now use the potter's wheel. Everywhere some weaving is still done on the old types of girdle-back and belt looms, although the European foot treadle loom is also common. Sheep wool is now used as extensively as llama wool. For the most part, the weaving is limited to coarse homespuns. Practically all native metalwork has now disappeared, but wooden bowls and other artifacts, decorated calabash containers, baskets, and mats are still commonly made. There have been many changes in the clothing pattern, but the breechelout, shirt, headdress, and carrying bag are still standard parts of the Indian costume. 
The Indians of today, as in the past, are largely engaged in farming. Some are independent farmers, living in small isolated communities. Others are peon farm laborers on the haciendas. The residence pattern and the social organization is reminiscent of the old ayllu village group. The village consists of a number of seattered house compounds and the residents recognize definite territorial claims. Individual ownership of land is now the common practice, but the group as a whole assumes the responsibility for the defense of its territory. Marriage within the village is still the rule, so that the members are united by many kinship ties, as well as local cult practices. The village is a selfsufficient unit and any form of inter-village unity is decidedly weak.

Indian languages have persisted with amazing tenacity. Many groups speak only their native language, although the number of bi-lingual individuals increases every year. Mythology too has survived along with this linguistic persistence. Catholicism was accepted as the official religion long ago, but local superstitions and rituals have survived with only slight modifications. The Indians still decorate llamas and march them around the fields in a euring ceremony. Children receive names at a simple ceremony in which the infant's hair is tied in bunches which are cut off by relatives who leave small gifts. The threshing of quinoa is initiated by a medicineman who calls the proper winds. There are many medicinemen who specialize in medicinal herbs, predict future events with coca leaves, and perform magical cures. Such practices do not constitute a formalized religion. 
The Indian population of Ecuador, Peru, and Bolivia maintains a distinctive culture, even though modified by many years of European influence. One of the major problems faced by the contemporary Andean countries is the incorporation of the Indian population into the national scene. The cultural past of these Indians is characterized by its high achievements. There is every reason to believe that their future achievements can be even higher. 


\section{Part 3}

\section{TECHNIQUES}

One measure of the cultural development of a people is their technical skill. This does not imply that culture and technology are synonymous or that we can take something like the metallurgical knowledge of a group and use it to calibrate a scale for measuring their culture. It will, however, if we have sufficient information, indicate whether the group has adapted itself to its environment and available natural resources, whether it has been receptive to cultural suggestion, or whether the members of the group were themselves inventive and ingenious. For better comprehension we must sometimes compare the technological development not only according to contemporary standards but in terms of the total record of human achievement. A technical comparison will often furnish the key to understanding and appreciation; hence, this short resume of three of the crafts. As our knowledge is still far from complete, the section on each craft should have been prepared by a specialist who could evaluate the published data and point out where further work is needed. In a limited way this has been attempted and if the following comments stimulate interest, they will be justified.

The statements on ceramics and metallurgy are based largely on published material. Only in the textile section have the results of some original research been included.

\section{Ceramics}

Most of the coastal valleys and the highland basins of Peru contain deposits of exceptionally good 
clays for making pottery. These clays are of fine quality, easily worked, and varied in color, and include the white kaolin now used in making porcelain. The composition of some varieties of clays is such that they are usable without further modification, but most of them require the addition of a temper to render them more plastic and less liable to crack in the firing. Crushed rock or grit temper was used for thick-walled cooking jars, but clays intended for thinner-walled vessels were mixed with fine sand, ground potsherds, or, rarely, ground shell. In the mountains where the clays are naturally sandy, mica temper was added to increase their plasticity. Sometimes in valleys where good clay was rare or absent, material of poor quality was used for the local wares. This, rather than lack of skill or interest, may explain the seemingly inferior ceramics of some Central Coast sites as A. O. Shepard suggests after examining a sherd series from Pachacamac.

The processes of ceramic manufacture have been reconstructed from an examination of the archaeological specimens and from our knowledge of the methods of modern Andean Indians. The clays were soaked in water, kneaded, and pounded until they attained the correct consistency and pliancy for shaping. Vessels were shaped in several ways. The coil method, so widely employed throughout the Americas, was also common in Peru, although any marks of the coils was rarely left on a completed vessel. In coil technique, the base of the vessel is first modeled by hand and placed on a flat plate, often only a large potsherd. A lump of clay is then rolled between the palms into a long cylindrical strip which is used to build up the sides of the vessel, either row by row or spirally. The coil marks are smoothed 
out with a damp cloth, a scraper, a stone polisher, or a paddle and anvil. The latter consists of a wooden paddle and a stone or clay anvil. The anvil is held inside the ressel and the paddle blows are applied on the outside. Another technique is known as direct shaping. A prepared lump of clay was modeled and expanded into bowl shape by hand pressure and paddle and anvil. Although the potter's wheel was unknown in the Americas, the sherd or plate base on which a ressel was constructed was placed on a smooth surface so that it could be easily turned. In some cases this must have been fairly rapid for the scratches and tool marks on the surface of unpolished pieces closely resemble those on coarse wheel-turned products. The symmetry of many of the finer pieces suggests the same conclusion.

Mold-made pottery is particularly characteristic of the north coast of Peru. Unfortunately, all too few molds have been collected, so we must rely mostly on the finished products for information about them. It is obrious that actual casts of fruits and regetables, as well as modeled cores, were reproduced in piece molds generally of two parts. More complex piece molds were used where details or under-cut parts of the original object made them necessary. The molds are of clay, apparently the same mixture as employed in the ceramics, and these were fired so they could be used repeatedly (Fig. 52). We do not know what was most commonly used as a separator, the coating or substance applied to the mold parts to prevent the casts from sticking, unless it may have been animal fat. Broken vessels show that the halves or sections were joined after removal from the molds and the seams smoothed down. 
Spouts, handles and such details were made separately instead of being incorporated on the original model.

Once shaped, the outer surface was finished by smoothing, scraping, and polishing. Many vessels
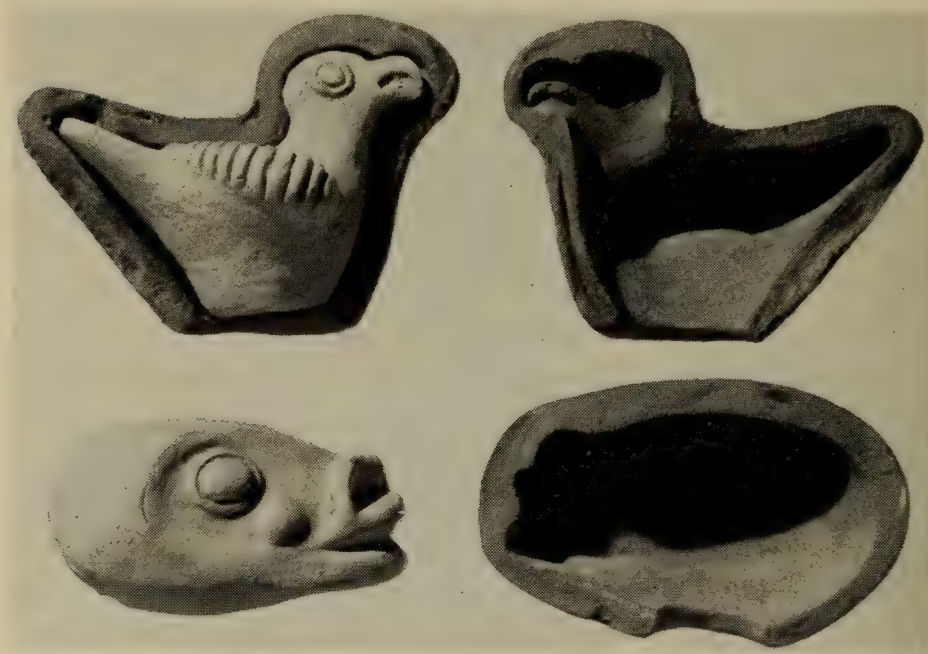

FIG. 52. Molds for ceramic manufacture.

were then coated with a thin clay wash, called a slip, which served as a base for painted designs. Decoration might be added before or after firing. The ancient methods of firing are not definitely known, although the finished products demonstrate that controls were good and that high temperatures were achieved. Some vessels were fired in a reducing atmosphere which restricted the circulation of oxygen and produced a black or dark colored clay. Others were fired in an oxidizing atmosphere in which the air was circulated by a forced draft, thus burning off the carbon and producing a light colored 
clay ranging from creamy white to red. As in the bucehero ware, vessels might be deliberately smoked black and later polished. Most firing was probably accomplished in the open, but there is some evidence for firing in pits and in built-up ovens. Some of the finer vessels may have been fired inside coarser ones.

The Peruvian pottery familiar to most people is that with the finest and most elaborate decoration. Some of this may have been intended for "ceremonial" use, in the sense that it could have been made intentionally as grave equipment. If so, it follows the types actually in daily use, for one finds sherds of the finer wares mixed in the community refuse.

The cooking pots were usually plain, but great attention was paid to the decoration of other containers. Modification of the surface of a vessel was achieved in various ways: by incision with dull or sharp instruments; by punctation with pointed sticks or the ends of reeds; by stamping with the thumb nail, with notched shells, or with a decorated die or paddle; with rocker stamps; by adding clay strips or fillets; by scratching with various instruments; and by cutting away the background around a design. Painting, in which from one to ten colors were used, was also common. Positive painting is most frequent, but resist negative painting was also known. In this a design was applied with some resist material such as wax or clay strips. The whole ressel was then dipped in a black dye and the resist elements removed. The result was a design in the base clay color rimmed with black against a black field. The same process produced three-color negative painting but the third color was added, either 
by repeating the negative process, or by positive painting.

Peruvian ceramics have an enormous range of shapes. Some of the basic forms are ollas, open bowls, plates, vases, goblets, pitchers and jugs, all of which can be easily identified from the illustrations. Many kinds of modeled vessels are included. Some special shapes are the stirrup-spout jar, which has a spout composed of two arched tubes which meet in a single cylindrical one; the double-spout jar, which has two cylindrical or conical spouts connected by a flat bridge; the spout-and-head and the spout-and-figure jars, in which one spout is replaced by a modeled head or figure which often contains a whistle; the double-jar composed of two connected chambers, one venting through the whistle which emits a plus or minus low note when water forces the air past it.

As yet no one has published a detailed survey of the sequence of ceramic technical development. The skilful modeling and massive stirrup spouts of the oldest Cupisnique water jars must have a longer background of technical development than has been found in Peru. Later Cupisnique jars show the use of paint applied to parts of incised designs or figures. This treatment is also found on Paracas Cavernas and Pucara pottery in distinctive forms. Even if considerable difference in age exists in these three, they may mark the diffusion of a technique which may have a common origin with the incisedpainted old wares of Mexico. This is mentioned only to point out the wide distribution of a simple technical device which might yield important data if fully explored. 


\section{Metallurgy}

The conquering Spaniards were amazed at the quantity and quality of the Peruvian metal objects. Almost everything of value they could appropriate was melted down and shipped back to Spain. Such examples as have survived show that high skills were developed in this craft. Gold, silver, and copper were the principal metals used; and minor use was made of tin, mereury, and, rarely, lead and platinum. Some of these metals are found in a relatively pure state; others have local impurities. The art of refining both copper and gold ores was practised.

Some gold was found in surface outerops which were worked with shallow mines, but most of it was obtained by panning the river gravels. Stone riffles built across stream beds impounded the gold-bearing detritus during flood seasons and, where necessary, water was carried in sluices to undereut or wash down the valley walls. Copper ores were obtained from open pit mines or shallow shafts, none over twenty feet in depth. The copper was in the form of atacamite, a blue to green sand, easily reduced. This was crushed with stone hammers and scraped into bags or baskets. One unfortunate miner in North ('hile was caught by a cave-in which covered him with atacamite, with the result that in time he was impregnated with copper. This "Copper Man", is displayed at the Museum together with his simple mining tools. Pure free silver is rare and the ores are difficult to smelt, yet it was rather widely used. Mercury was extracted from cinnabar or recovered in metallic form in underground pockets.

Clay furnaces, which burned wood, coal, or charcoal, were used for smelting. A draft was produced 
either by blowing through copper tubes, or by placing the furnaces on hill slopes where advantage could be taken of the prevailing winds. Since the same furnaces might be used for different metals some accidental alloys undoubtedly resulted, but a number of artificial alloys were also known. Goldsilver is a common one, in which the silver content ranges from 35 to 50 per cent. Gold-copper and gold-silver-copper alloys, often called guanin or tumbaga, are also found. A silver-copper combination contains over 20 per cent of the latter metal. Copper was mixed with silver, tin, lead, and possibly arsenic. The copper-tin alloy, or true bronze, does not have a very high tin content. The copperarsenic combination seems intentional although the arsenic is rarely above five per cent. Even this quantity would reduce the melting point of the metal and increase its hardness. Copper was also hardened by the simple process of cold hammering which will actually make it harder than soft iron.

Analysis of specimens which have been preserved proves that many metal-working techniques were skilfully handled. Gold was cold hammered into sheets which were annealed by the application of heat to render them less brittle. Objects of varied shapes were cut out of these sheets, and decorated by embossing, in which the design is pressed out with a bone tool on a leather anvil; repoussé, in which the sheet is hammered over a carved mold; or engraving, in which the designs are incised. Two pieces of metal were fastened together by clinching, that is, folding and fitting the edges together and hammering; welding, namely, hammering and heating; and by soldering. Mercury soldering was probably unknown. Instead, a gum was mixed with 
a powdered copper salt and applied to the surfaces to be soldered. A slow heat was applied until the gum charred and reduced the copper salt to metallic copper which combined with the gold to form a lower melting alloy, and made a strong, ahmost invisible joint.

Casting was well developed. Small rough cast copper discs have been found which appear to be ingots made at the smelter. Although these were sometimes hammered out into various objects their original shape had little or no connection with the final product. Such items as the heavy points for digging-sticks found in the north coast valleys were cast in molds only approximating the final form. A lot of hammering and probably annealing was necessary before they were shaped for use. This increased the hardness of the product and seems to have been intentional for other mold-made objects of copper show good control of the process and required very little subsequent finishing. Gold and silver were cast in both open and closed molds. In hollow casting, called a ci cire perdue process, a core of fine clay is mixed with charcoal and carved into the desired shape. The core is coated with wax, worked into its final shape, and placed in an outer clay mold, with vents at top and bottom. The hot metal poured in at the top replaces the wax which is drained out at the bottom. Some pieces are cast in two different metals. A collar in the American Museum of Natural History has alternating strips of light and dark gold. Analysis shows the dark strips to be 80 per cent gold, 13 per cent silver, 7 per cent copper, and the light strips 47 per cent gold, 44 per cent silver, and 8.5 per cent copper.

Several methods of gilding may have been known. 
One is a form of amalgam plating in which powdered gold is mixed with mercury and spread on a copper or silver object etched with acid. The mercury is driven off with heat, thus depositing the gold. Another method was to line a mold with gold leaf before the copper was poured. A third method, called mise en couleur, is with an alloy of copper and gold. Surface application of an acid eats away the copper and floats the gold. The same alloy was also heat fused to the surface in some cases. Wooden objects and stones were sheathed with thin gold leaf, and metals were inset in other materials. Silver or gold vessels were also inlaid with shell and semi-precious stones.

In parts of Ecuador, where gold was used even for fishhooks, platinum was recovered from the same gravel deposits. Platinum has a higher melting point than can be obtained by any primitive methods, yet they successfully worked it. This was done by a process known as sintering, in which a little gold was mixed and fused with the platinum, producing an alloy used for making small ornaments and for plating gold. This was a remarkable achievement for it was not until the nineteenth century that Europeans first developed a method of utilizing platinum and only very recently has sintering been employed in modern metallurgy.

Metals were used for tools and ornaments, but never coined. Copper and its combinations were made into points for digging-sticks and spears, knives, club heads, battle axes, pins, needles, chisels, whorls, and pincers for plucking the beard (Fig. 53). The ornaments are too varied and numerous to list in total, although rings, earplugs, noseplugs, and 


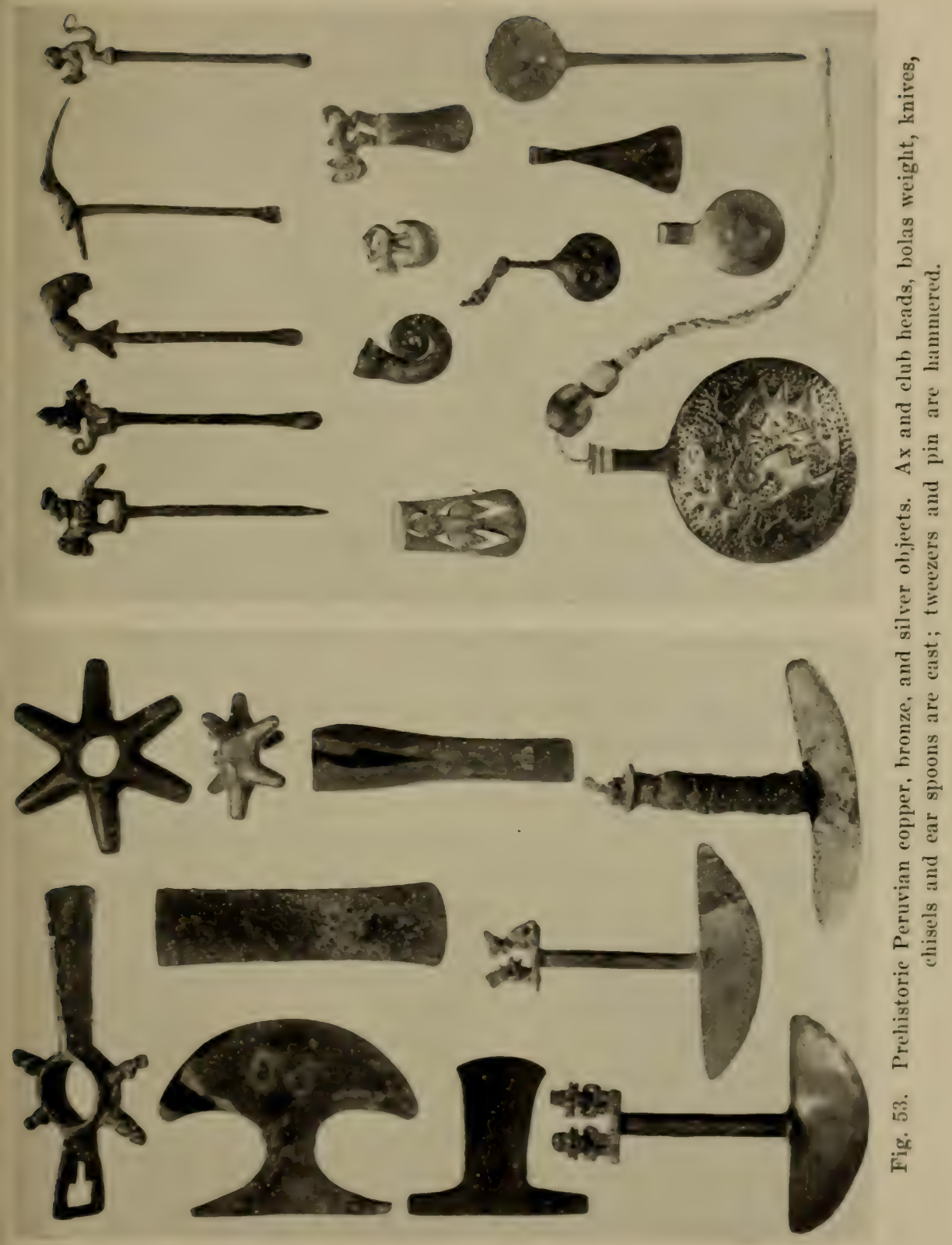


face masks for mummy bundles are outstanding. Luxury items include metal plates, goblets, and pitchers.

\section{Textiles}

Of all the known products of prehistoric Peru, the textiles are, without a doubt, the most fascinating. In our modern culture, conditioned as it is by the use of machinery, we are so divorced from the ancient tradition of hand spinning and weaving, that relatively few people have the necessary background to appreciate not only the skill, but the pride in accomplishment and the effort that these textiles represent. The fact that some of them rank high among the finest fabrics ever produced should lead us, in all humility, to seek not only a knowledge of their origin and development, but also a better understanding of what they actually represent in terms of human accomplishment.

If we review the existing literature on the subject, it is immediately apparent that proper investigation has only covered a fraction of the subject and that an intriguing amount of research still lies ahead. It is certain that there will be an abundance of material to study, for the quantity of textiles preserved by the extreme aridity of many Peruvian sites is probably greater than has survived in any other dry region in the world. The accident of survival accounts for the existence of the evidence and not for its creation, which can be seen as the result of a fortunate combination of at least three factors.

The first was the basic essential, the fibers. In this respect the Peruvians were more fortunate than were most ancient weavers for, of the principal natural fiber groups, cotton, wool, bast, and silk, they 
lacked only the silk. To this choice of excellent fibers can be added another factor, the climate. This provided a stimulus for their use; although clothing is not essential to life in the Peruvian valleys, it is desirable. A third important factor for the production of textiles was an abundance of leisure; fine fabrics camnot be created in haste. As leisure is closely dependent on food supply, the local economy must be mentioned. Once maize and various other domesticated plants were introduced, the fertile valleys yielded an abundance of food throughout the rear. Thus with this combination of three favorable elements, fibers, climate, and leisure, it is not surprising that textile creation became a major interest, a medium for the expression of artistic urges and a competition in ingenuity.

The bulk of the existing collections of fabrics has been gathered from grares, most of them without data on the associated ceramics. As the ceramics are the present basis for chronological determination, the result is a marked lack of organized knowledge of the derelopment of the wearing craft. As long as material from graves is the source of our information this will remain so, for in the older graves most of the perishable items have mingled with the dust of their owners. Recent excavation, however, has uncovered many textile fragments even in the midden debris of the pre-ceramic period, so it is certain that, in time, a uniquely complete record of textile development can be recovered and will he a valuable contribution to our knowledge of human cultural achievements.

In terms of modern technology the old Peruvian fabrics are outstanding for several reasons. Almost every known technique of modern wearing was 
nsed as well as a number which are either impossible or impractical for mechanical looms. The spinning ranks among the finest known in the world and the large range of colors is evidence of exceptional skill in dyeing. Obviously, technical developments of this order were based on a great pride in weaving and a widespread appreciation of quality, as shown by the frequency with which examples of excellent workmanship occur in the collections. The following notes are intended only as a brief outline of our present knowledge and do not cover the subject fully. A real appreciation of their technical and artistic merits can only stem from first-hand experience with the textiles themselves.

\section{FIBERS}

Recent studies of the contents of the strata of refuse dumps in widely separated localities have yielded basic data on the occurrence and utilization of the different fibers. In the Viru and Chicama valleys, in the great deposits of debris left by an early farming group who knew neither maize nor pottery, cotton seems to have been the only fiber used. Some bast or twisted sedge was used in making open mesh coiled pouches but, with the exception of matting, not for fabrics. On this evidence alone, it is clear that the Peruvian textile craft is based on the use of cotton and not on wool or any other fiber.

This explains the cotton-wool ratios in the analyses of other series of Peruvian textiles for which chronological data are available. One set of these from northern Chile, covering the entire period from the introduction of weaving to the sixteenth century, shows proportionately much more cotton than wool in the oldest fabrics than in the more recent. This 
is also true of the Paracas textiles checked by ()'Neale; the older series from the Cavernas graves contained more cotton than wool as compared with the later Necropolis material. Still older mummy wrappings from Ancón and Supe are all of cotton, except for a single piece in which a little wool is used. The latter may be contemporary with the Cupisnique textiles from the Chicama Valley, among which no wool has as yet been found. Considered in terms of the still older pre-ceramic fabries, all this evidence clearly establishes cotton as the oldest textile fiber.

Modern Peruvian spinners are said to distinguish by name six naturally colored varieties of cotton, ranging from light tan to reddish brown and gray. At least several of these have been known from the Cultist Period, as examples occur among the Supe and Chicama finds. Used with white cotton in patterns and designs they have been and still are important to the weavers for they eliminate the necessity of dyeing in those shades.

To a people possessing the tradition of cotton spinning and weaving the value of wool would be obvious once they moved into the habitat of the animals producing it, namely, the Peruvian highlands southward from the Fcuadorean border. We know nothing of the wild forms of the llama and alpaca, but the wool from their wild cousins, the ricuna and guanaco, is very soft and fine. Parts of their coats are pure white and as white wool is much more easily dyed than cotton, the utilization of wool may have stimulated the use of dyes.

Wool from the vicuna was secured by great roundups of these animals. It was so highly prized for its fineness that its use in Inea times was reputedly lim- 
ited to the nobility. Because of this tradition many of the finer fabrics have automatically been classed as vicuña without proper verification. Recent research by Mr. Truman Bailey leads him to believe that many of the prehistoric fabrics formerly classed as vicuna are of selected alpaca wool. He also reports that it is more difficult to hand spin vicuna wool than alpaca; in explanation, the spinners say that this is so because "the vicuna is a very active, playful animal," and that its wool retains these characteristics.

Guanaco wool is found in textiles from north Chile, but we do not know how it was secured. Young guanaco are easy to tame, but they never seem to have been domesticated. Was this because their habitat is largely marginal to the area of intensive farming and weaving? If the young of the wild llama and alpaca, living within that area, were as easily tamed, it is quite possible that a growing interest in wool was the major incentive for the domestication of these animals.

Domestication ultimately increased the yield of white wool and extended the range of the animals beyond their natural habitat. It may be impossible ever to date the beginnings of domestication, but such finds as the sacrificed llama burials beside a Cupisnique period structure in the Viru Valley show that some animals were being brought down to the coast during that period. It would be interesting to know if there was a simultaneous spread of weaving into the highlands, where no other fibers were available and warm clothes were needed.

Human hair was at times employed in twisted and braided cordage but is so completely lacking in some periods as to suggest that some groups may have had 
taboos against its use. Sedges and reeds, and bast fibers from maguey leaves were employed to some extent in all periods, mainly for cord and rope. Their use, in part, antedates the textiles, for fishlines of unidentified bast have been found with the remains of a non-agricultural pre-ceramic fishing culture in north Chile.

\section{DYES}

The variety of colors which were ultimately used in the fabries testifies to the skill achieved in dyeing, a skill so advanced that it is tragic that so few data on the subject were recorded after the conquest. O'Neale, comparing Paracas Necropolis dyed yarns with the Maerz and Paul color charts, distinguished one hundred ninety hues. Uneven fading undoubtedly accounts for some shades, but the record is nonetheless impressive. Truman Bailey, gathering surviving information and experimenting with native plants, has prepared two hundred fifty color formulae which may well duplicate most of the ancient ones. To these must be added another important source, the cochineal insect, which before the invention of synthetic dyes was an important item of export from Peru and Mexico. There is also reason to believe that a shellfish dye secured from the concholepa was used.

Virtually nothing is known of dyeing procedures. Mordants were used to an undetermined extent and permanent brilliant and lovely colors were produced. The only attempt yet made to determine the mordants used chemically seems to confirm an early historic mention of the use of alum for this purpose.

As these ancient peoples possessed no carding 
equipment, the dyeing of raw wool stocks was not common, for the process is apt to tangle the fibers. Raw stock dyeing of cotton, unknown in modern industry until recent years, was practised, a technique which may explain the remark of a sixteenth century writer that a blue cotton was grown. He must have observed the several natural shades of cotton on the plants and seeing the natives spinning blue cotton, assumed that it was also grown. It was not mentioned by later writers, who were more familiar with the cotton plants and were not concerned with dyeing processes. In 1946 a possible explanation of this old error was found in the Museum collection in a Peruvian work basket that contained cones of dyed blue cotton prepared for spinning. In 1947 it was found that the practice survives, at least in the Chicama Valley. In order to prevent tangling of the fibers, the cotton is dyed with the seeds still attached. When dry, the subsequent handling of the fibers is no more difficult than the undyed cotton.

Some data on the chronology of dyes are available. Blue is the only dye found on the pre-ceramic textiles of Chicama. A red pigment was applied to yarn before weaving and to finished pieces, but this is not a true dye. No further advance has as yet been noted on the succeeding Cupisnique textiles, but in the old Supe and Ancón series a little true red dye is found in addition to the blue. In the Paracas Cavernas group, ten or twelve colors are noted; while in the Paracas Necropolis series, the range of colors reaches its maximum. In the oldest textile series from northern Chile, except for a single example of red and a questionable yellow, only natural shades of wool and cotton are found. Subsequently, there was a gradual increase in the use 
of dyes, with this maximum use so late that a marked time lag in their diffusion from the north is obvious.

\section{SPINNING}

The yarns of the oldest textiles are all rather coarse and uneven. The debris in which they occur in the Chicama Valley contains thousands of twigs and wood fragments; yet not a single recognizable spindle and no spindle whorls have been found. In the same valley, women are occasionally seen today twisting coarse yarn, using an unworked straight shoot of a local shrub for a spindle. In making coarse yarn they are used without a whorl. The lower ends are continually held and twisted by the fingers of the right hand while the left hand draws and lays the fibers from a bunch of cotton tied to the end of a stick or distaff. The identification of these simple spindles would be impossible unless found with yarn in place, so it may well be that the earliest spindles were similar.

In the interval between pre-ceramic time and this decadent modern survival spinning was developed to an art yielding yarns several times finer than are produced by modern machines using the same staples. The delicate spindles of wood and thorn nsed in spinning these fine yarns were equipped with whorls so small that their identity as such has been questioned. In operation, the lower end of the spindle rested in a special cup of pottery, gourd, or woorl which, as Crawford has emphasized, minimized vibration and strain, a requisite for fine spinning of cotton. This method is still used, though the spindles are crude by contrast and the yarn produced is heavier. 
In spinning wool the modern spinners all use freeswinging spindles, and though such spindles are found archaeologically, we do not know whether the finest of the old wool yarns were created in this way.

Whether the spindle is revolved clockwise ( $\mathrm{S}$ twist) or counterclockwise (Z twist) is, of course, optional, but preference is usually shown for one or the other. In doubling single ply yarns, the direction of twist was consistently reversed, so that the spinner's fingers were trained to work in both directions. As the fibers can be spun in either direction, there seems to be nothing to dictate direction of twist other than local custom. A small random sampling indicates that the $\mathrm{S}$ twist predominated in pre-ceramic and Cupisnique fabrics and was fairly common in later yarns on the North Coast, while in old Supe, Paracas, the North Chilean, and modern yarns the $\mathrm{Z}$ twist predominated. Sometimes $\mathrm{S}$ and $\mathrm{Z}$ twist yarns are combined in a single fabric, perhaps intentionally. A further recording of twist seems warranted and should yield useful comparative data.

Data on the use of distaffs are meager. In the sixteenth century, the Inca used a forked stick. More carefully made slotted wooden distaffs, one with wool still in place, have been found occasionally. Today one sees some spinners with a crude roving or roll of prepared cotton or wool looped about the left wrist and hand, drawing out and laying the fibers with the left fingers, while the right hand operates the spindle and stretches the fibers while spinning progresses. Others fasten a bunch of prepared cotton to the end of a reed, about thirty inches long, which is held between the left arm and body, leaving the hands free to manipulate the fibers. 
Some such simple distaff was perhaps used to hold the conical bunches of prepared cotton so frequently found with the late period work baskets. They may also have been wedged in the carved forked sticks, as portrayed in the sets of miniature spinning and weaving equipment made of silver.

When we marvel at the quality of the yarns produced with such simple tools, it is interesting to note that the use of hand-spun yarn is still economically justified in Peru. Hand spinners, according to Truman Bailey, can produce one hundred grams of yarn per day at a cost about thirty per cent less than similar but inferior machine-made yarn.

\section{LOOMS AND WEAVING}

As ret, no one has made a comprehensive study of the loom types still in use and of their distribution in Peru. Such a survey would be invaluable in interpreting the archaeological material.

It is generally agreed that most of the excavated fabrics were constructed on backstrap looms like the modern ones used in the Central and Coastal valleys. However, in the Southern Highlands and in Bolivia, the loom bars are tied to four stakes driven into the ground so that the warp lies horizontally. Less common is a frame-loom set vertically.

Of these three types, only the first permits the weaver to control the warp tension automatically, an important feature. In its essentials, this loom (Fig. 54) is an exceedingly simple device, consisting of two sticks, called loom bars, with the warp stretched between them. The lower bar, tied to a belt passing behind the weaver's back, rests above the lap, while the upper is suspended from a post or other support. As the work progresses on a 


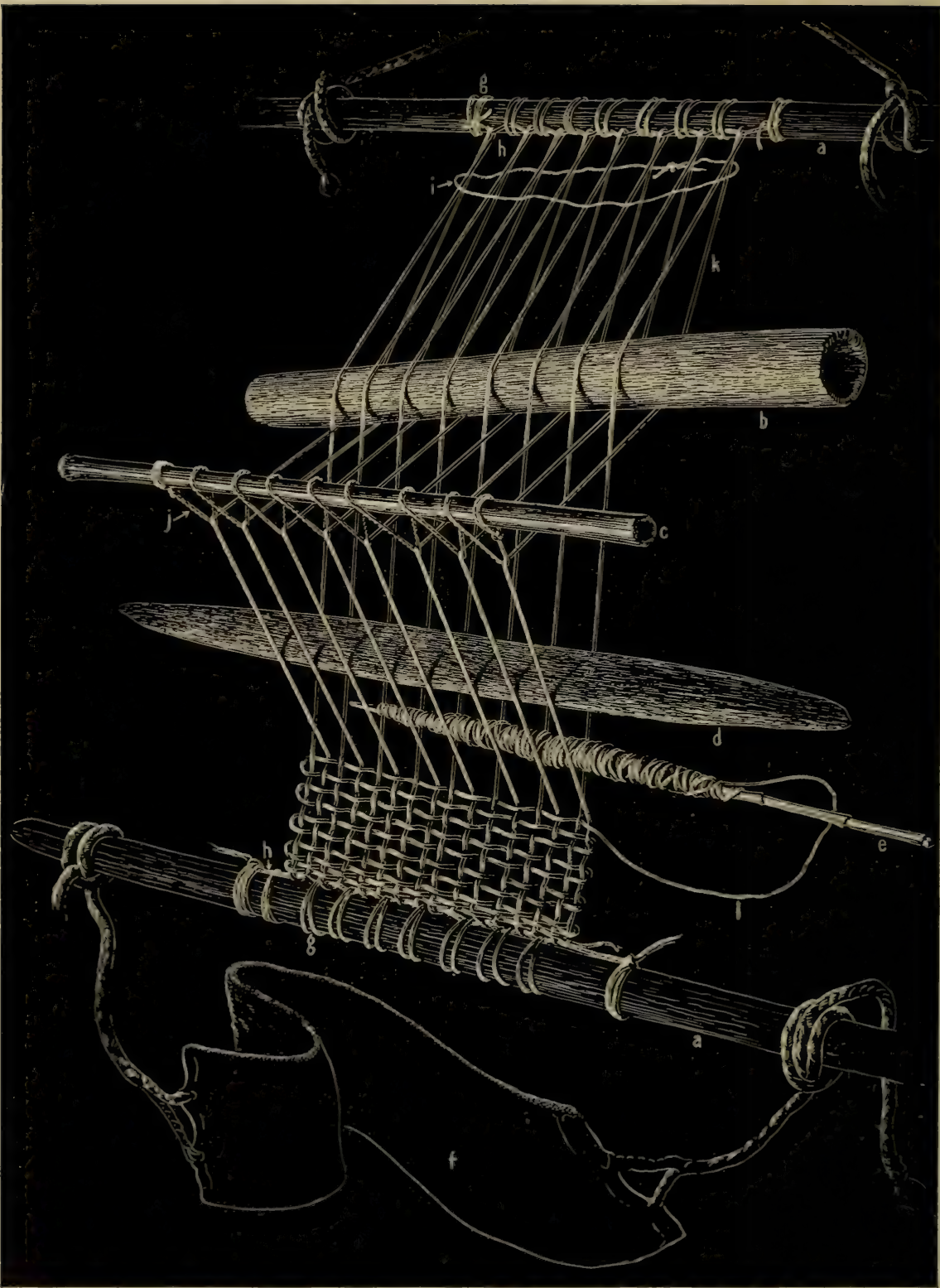

Fig. 54. Diagram of backstrap loom. a, Loom bars; b, Shed rod; c, Heddle rod; d, Batten or sword; e, Bolblin; f, Back strap; g, Warp lashing; h, Heading string; i, Lease cord; j, Leash cord; k, Warp; 1, Weft. 
long fabric, the warp is unrolled from the upper bar and the finished portion is rolled on to the lower.

In warping these looms, the yarn was, and still is, first wound with a figure-eight motion between two stakes. The figure-eight crossing, called the lease, automatically separates the alternate turns and creates two sheds, greatly simplifying the remainder of the preparatory work.

After the yarn has been warped off, it is laced fast to the loom bars in such a way that when completed, all four edges of the fabric are finished off, sometimes so uniformly that side and end selvages are indistinguishable. Usually, however, the end selvages incorporated the cord or yarn, which, with the lashing, held them against the loom bars.

For plain weares, the control of the warp sheds is accomplished with two sticks, one inserted between the alternate warps, holding them apart; the other, lying across the loom, attached with a looped cord to each yarn of the lower warp set. By lifting this heddle or heald rod, the lower warps are pulled up through the others and the alternate shed is thus opened.

For holding either shed open while the bobbin is passed through, a wooden batten or weave sword is inserted and turned on edge. The same implement is used to beat or press the newly inserted weft into place. Where the construction requires the separation of the warps into several sheds, two or more heddle rods are used. O'Neale has clearly shown by her analysis of certain examples of twill weaving that the necessary warp manipulations must have been made with at least three heddle rods. This demonstrates the use of the multiple heddle loom in the Mochica period. Probably a careful study of the double-cloths would supply further information 
on the antiquity and distribution of multiple heddle looms, and might show an even greater antiquity.

One of the limitations of the backstrap loom is the fact that a single individual cannot weave a fabric wider than the working span of the hands. Length is also limited by the amount of cloth which can be rolled and supported on the lower bar. Average maximum widths seem to be about thirty inches, so the occurrence of large fabrics like the Paracas Necropolis specimen, measuring fourteen feet seven inches wide by forty-seven feet five inches long, indicates that some other type of loom was used. Truman Bailey has recorded the use of a super backstrap loom which is roughly three times the normal width and was operated by three women working as a team. The limitations of such a loom would be in the length rather than in the width.

\section{WEAVING TECHNIQUES AND CHRONOLOGY}

Very recent excavation has vielded an adequate sample series of fabrics from the pre-ceramic horizon already referred to. Unfortunately, our data still depend on field notes and an analysis of uncleaned specimens as they were excavated. Cleaning and further study will add detailed information, but should not appreciably change the rate of occurrence for the techniques listed below:

Twining

Per Cent

Looping and loop coiling

78.3

Fish nets, knotted

10.1

Plain cloth, warp face

Plain eloth, warp face with warp floats

Netted pouches

(This list does not include matting and basketry.) 
Twining as a technique has been used with many materials other than spun yarns, and survives today mainly in mat and basket construction. From its world-wide distribution and some archaeological evidence, it is believed to be one of the oldest methods of ereating a fabric.

The principle is simple. The weft is always worked in pairs intertwined between the warp elements, and, if tightly twisted, they will remain in place even when the weft rows are widely spaced. In the old Peruvian material, the wefts are nearly all short, crossing the fabric only once; with their ends tied together at the selvage, forming a row of knots at the edge. There is no simple mechanical method of placing the weft; it must be done with the fingers, and, as the warp does not have to be manipulated, a heddle is useless.

Twining, as shown by these old fabrics, was highly developed. By crossing and arranging the warps, and by varying their size and grouping, differences in texture and pleasing effects were created. There are, however, no true designs nor anything approaching the complexity of the twined Chilkat blankets of North America, in which the wefts carry the pattern.

The contemporary woven pieces are surprisingly small. Eight inches is about the maximum width, and, except for belting, lengths do not seem to exceed twice the width. All are warp faced, i. e., the warp yarns, more closely spaced than the weft, predominate at the surface. In a few instances, portions of certain warps are left free or floating on the surface, creating simple patterns which seem to be the result of experimental play with the yarn rather 
than creative artistic expression with the yarns as a medium.

It is highly significant that in virtually all the woven pieces at least some detail is accomplished by twining. This may be limited to several compact twined rows to hold the warp ends together or, in addition, may appear as twined weft rows separating woven areas. In some textiles twining and weaving occur side by side, with the same weft yarns used in both areas. Other warp faced examples reveal the use of short wefts, with the ends tied in knots along one selvage, exactly as in the plain twining.

The impression from this material is that twining is definitely the predecessor of weaving; that the heddle was unknown, and that weaving did not evolve from twining, but developed with it as an outgrowth of the experimental manipulation of yarns. The invention of the heddle was, in all probability, the critical factor in further development, for without it weaving could not compete with twining.

A sudden increase in the frequency of woven pieces occurs in the Cupisnique, or Cultist Period debris lying above the primitive material mentioned. Their size and the less compact spacing of the warp imply the use of the heddle, while finished end or loom bar selvages and a number of techniques not used earlier mark a break in tradition. One would scarcely expect these techniques to appear simultaneously had the development occurred in the neighborhood of the Chicama Valley. As they first appear in the Chicama Valley associated with Cupisnique sherds, the first maize, warty squash, and a number of other culture elements, it is clearly inter- 
pretable as influence from another area in which weaving had evolved well beyond the pre-ceramic status of that time.

A careful analysis of material from this horizon is needed, but has not yet been made. The fairly common continued occurrence of twining may be a local feature resulting from cultural fusion or, perhaps, Cupisnique weavers were actually not far removed from the pre-pottery stage. Completely new at that time in Peru was gauze lace made by twisting: adjacent warps before inserting the weft. Design areas within the gauze are woven in to match the plain weave adjoining the gauze.

Another less practical device for creating design was to wrap cotton lint around certain portions of the weft just before it was laid in place, resulting in a compact figure set in a relatively loosely woven field. The popularity of this method was brief, for no examples have been found in later periods, though a parallel, called "facing," was sometimes used in later non-loom products, such as slings and hair nets. In these, yarn of one color is wrapped with a different-colored yarn at the points where change in color is desired.

Other regionally new constructions were tapestry, which can be briefly defined as the use of independent wefts for each color or pattern area of the design, and the use of paired single ply weft yarns. Also present are the simplest devices for varying the appearance of plain weaves: the use of warp or weft stripes and a combination of the two to form gingham.

The series of textiles from Supe, perhaps close in age to Cupisnique, add to the known technical data. As with Cupisnique, warp-faced fabries are in the 
minority, about thirty per cent of the total. Apparently a higher percentage of Supe fabrics has paired single ply wefts and some also have paired warps. Brocading, the insertion of secondary wefts in addition to the ordinary weft at the places where the pattern falls, was known, but embroidery seems to be lacking. Tapestry is more common than yet noted among Cupisnique fabrics and is found in several forms. One example, a Chavín stylized condor head set in a plain weave field, is cleverly executed with eccentric and slit techniques. At least three shades of naturally colored cotton were used in it, the overall effect enhanced by the contrast between the compact weft of the figure and the loose weave of the adjacent fabric. Others have interlocked geometric areas of loose tapestry in which, contrary to accepted tapestry procedure, the wefts are not beaten tightly together.

The Paracas Cavernas textiles here assigned to the Experimenter Period are probably not quite as old and among them, in addition to those mentioned for Cupisnique and Supe, are several more techniques. One, which became very popular much later, is double cloth. In this, two separate webs of contrasting colors, each with its own warp and weft, are woven together. Pattern is created by interlocking the two webs, a tedious procedure on any hand loom. The complexity of the oldest known examples shows complete mastery of the process and indicates an earlier developmental stage. This concept of double cloth was carried still farther by the Peruvians who produced a triple cloth and a narrow quadruple cloth belting.

This Cavernas lot also adds embroidery and warp float patterning to the list, comprising in all a re- 
markably broad range of techniques for such an early culture level. The contrast with the preceramic fabries is obvious. Plain twining survived in Chicama, while in the south twining was limited in the Paracas Cavernas material to basketry, matting, and elaborate twined lace. With wearing, the break is so marked that at present it can only be explained by postulating technical evolution outside the area, which would mean that the late pre-ceramic textiles were, in their time at least, outdated survivals. There is such slight chance of recovering old fabrics outside of Peru that if we are to locate the area of development, careful attention must be paid to the associated non-perishable items. Perhaps the answer lies along the potsherd trail which may ultimately reveal the origin of the CupisniqueChavín ceramic techniques and designs.

The textile development subsequent to the Cupisnique-Supe-Carernas stage shows marked differences by period and area, not so much the result of technical development as in the emphasis on and increasing perfection of some device already in use. An excellent example is the superb embroidery of the Paracas Necropolis period when this art became fashionable almost to the point of exclusion of other techniques (Fig. 55). Great numbers of intricate and complex embroideries were prepared and laid away with the dead; pieces which were never again equaled in quality or in the use of color.

The omission here of published data is not intended to slight or question the work of others. The identification of weaves and trends in the Mastereraftsmen and later periods is so comprehensive a topic with so many incomplete details that it is inadvisable to attempt to encompass it at present. As 

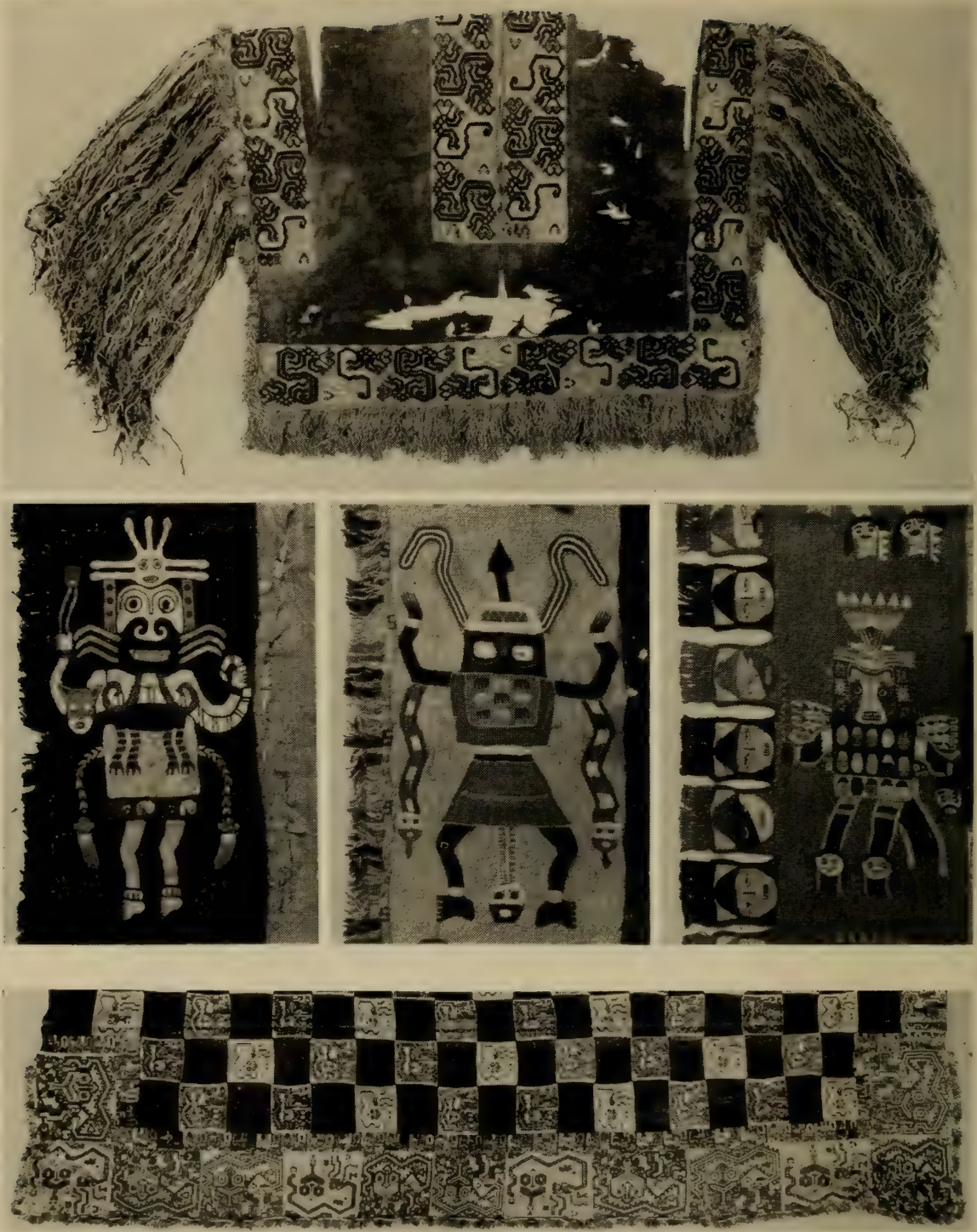

Fig. 55. Paracas Necropolis embroidery. Top, Poncho shirt with heavy shoulder fringe; center, Mantle borders, with foundation fabric completely hidden by the embroidery; bottom, Half of a large mantle. Center, Courtesy of Museo Nacional de Antropología y Arqueología de Peru. 
an alternative, some comments can be made on certain techniques which have not already been discussed.

Plain Cloth: Regional trends are well exemplified by comparing the products from the northern coasts of Peru and Chile made during the period of Inca control. At the time of the Spanish conquest and afterwards, an undetermined but high percentage of plain cloth from Chicama was made with paired elements, using single-ply cotton yarn, a custom well established at least as early as the Cultist Period.

On the North Chilean coast, where the influence of Inca culture was scarcely felt, sixteenth century and earlier plain weaves are entirely warp faced. Most of them are of two-ply wool yarn, and only one in a series of nearly eight hundred has paired wefts. This again is founded on long established local tradition, with a slight variation seen only among the oldest textiles, four per cent of which are square count, the rest warp faced.

At Pachacamac, plain cloth associated with Inca pottery is predominantly warp faced and made with two-ply yarns. Paired warps and wefts of single ply S spun yarns are elements apparently introduced from the north during this period. Cotton is six to eight times more frequent than wool, with the latter most abundant in the textiles associated with the highest concentration of Inca sherds.

Repp: Plain cloth in which the warps outnumber the wefts and predominate on the surface is referred to as warp faced. This generally has a ribbed appearance which can be accentuated by the use of heavier weft yarn. This effect, called repp, is sometimes mentioned as a feature of Peruvian fabrics 
and is indeed quite common. The term should perhaps be limited to those fabrics in which the weft is heavier than the warp and until some such distinction is made little can be said about it other than that it naturally follows the distribution of warp faced textiles.

Twill: The rarity of the occurrence of twill in existing collections has occasioned some speculation. O'Neale, in the only report on Peruvian twill, discusses the seventeen examples known to her. As its production required at least three heddle rods, the work of setting them up may have limited its popularity. Perhaps far more twill was woven than has been assumed for most of it was collected in Mochica tombs, notoriously poor in yielding textiles. In the light of our present knowledge, however, it is clear that though the Peruvians did master the application of this technique, its distribution is restricted.

Pattern Weaves: The creation of well executed, intricate patterns with the warp is a challenge to the weaver's ability; yet in spite of the difficulties involved, it became very popular and still remains so in the southern highlands. Though known to some degree throughout Peru in all periods, the finest warp patterns are generally from the South Coast and are relatively late. The similarity of designs in modern and fourteenth to sixteenth century specimens is often striking and should give a good check on the conservatism of such textile design. In North Chile this technique appears with the first painted pottery.

Weft or bobbin patterns are not so difficult to create and, though widely used, never were as popular as warp patterns. Much more common are the bro- 
cades, possibly because the use of supplementary wefts permits a more varied application of color than in plain bobbin patterns.

Tapestry: When the Spaniards entered Peru, tapestry was definitely in fashion as, in a sense, it then was in Europe. The Peruvian products, however, were technically far superior in every detail. Usually made with cotton warp and wool weft, they frequently have over two hundred weft per inch and some exceed two hundred and fifty. One with an average of 327 per inch has weft crowded together at the rate of 500 per inch in some details of the pattern. It would be impossible to create such a fabric without having perfect yarn for the warp. In this case a three-ply cotton yarn, with seventy twists per inch, was used. The warp count is sixty-seven to the inch. Roughly, contemporary European tapestry, by contrast, seldom exceeds eighty-five weft per inch, and modern examples much fewer.

In a sense, this is an unfair comparison, for the European products were primarily pictorial wall hangings in which fineness of weave and the condition of the under surface were not very important; whereas in Peru; tapestry was employed for clothing, belts, and bags. In these, careful finish of both sides and compact yet light construction were naturally appreciated. The extreme fineness of weave, however, is only one aspect of the Peruvian product. Every conceivable device applicable to tapestry construction was employed with care and skill. As an example, one finds in the Nazea area that the structural weakness of slit or kelim tapestry has been overcome by using hidden wefts. By using paired warps a fine hard-spun single-ply cotton can be woren in so it does not show through the wool weft 
of the pattern unless the fabric is torn or badly worn. These have sometimes been inaccurately classified as "embroidery to resemble tapestry." Actually, there is no recognized name for this technique and, as often happens with Peruvian material, one has to be suggested. In this case "reinforced kelim" seems adequate, if we can agree at which limit the construction is technically something else. Some pieces show the reinforcing yarns inserted only where the slits are largest. In others a continuous fine cotton weft is inserted regularly, with two or more pairs of tapestry weft between the picks of cotton weft. When only one pair of the pattern weft separates the fine cotton yarns, the latter are usually carried beyond the pattern and form a plain weave area. Such pieces are certainly not tapestry, although they reproduce its appearance exactly.

In addition to the more conventional types of tapestry, some very delicate pieces have been found showing interlocked tapestry construction in which warps and wefts are single-ply crepe twist, cotton. They are sometimes so loosely woven that, as far as texture goes, the fabric can be considered a voile, yet the construction is essentially that of tapestry. Since this technique has no parallel in modern weaving, again a term has to be proposed and in this case perhaps "sheer tapestry" is preferable to calling it interlocked plain weave. One of the two examples in the American Museum of Natural History is unique among known Peruvian fabrics in showing what is called "Swedish" or two-way interlock. In it, the locking' of the weft produces a ridge or wale on the reverse side of the fabric. In the other, the wefts interlock around a warp. 
The antiquity of tapestry has already been mentioned in comments on the Cupisnique-Chavin fabrics. As yet, we know little about it during the interval preceding the Tiahuanaco or Expansionist Period. In both known Paracas periods, it was virtually ignored, furnishing a good example of the influence of fashion on the occurrence of a technique. Certainly a people possessing such skill in spinning, dyeing, and weaving ignored it only by intention.

Somewhat later and far to the north there is some evidence for its use in the Mochica period. To what extent, remains to be discovered, but from then on, all down the coast, it appears with increasing frequency. The major development seems to have come with the spread of the Tiahuanaco influence from the southern highlands. Beautifully executed pieces with characteristic figures of this period are among the most easily identified of all Peruvian fabrics. Though the stylistic influence of Tiahuanaco faded in time, the manufacture of tapestry continued, receiving new support with the second wave of highland conquerors, the Inca. It is interesting to note that while the Inca ultimately dominated a larger area than their predecessors, they seem to have had less influence on the general textile development. The only marked Spanish influence on the Peruvian textile record immediately after the conquest was in tapestry design. The Spaniards recognized and appreciated the native product, if not the patterns, and soon had weavers making tapestry hangings and earpets for their homes. These products, in which ideas from two unrelated cultures have been blended, merit special study. 
Interlocked Warp Pattern: This construction which, like tapestry, can yield a pattern identical on both sides of the fabric is peculiar to Peru. It has sometimes been called "patchwork" or "weft scaffolding," but as the pattern is set up in the warp before inserting the weft, the term used here seems more appropriate.

A unique unfinished example in the American $\mathrm{Mu}$ seum collection has a rather intricate two-color pattern laid out with the aid of taut scaffolding yarns, set like the rungs of a ladder, parallel to the loom bars and presumably held in place by supplementary bars set at right angles to the regular ones (Fig. 56, lower right). Warping was done very much as one inserts the weft in one-way interlocked tapestry, with the warp spanning one or more "rungs" as the pattern required. The interlocking turns of the contrasting yarns also encircle the scaffold yarns. In other words, if all the warps were pulled out of a finished piece of interlocked tapestry, the weft would then resemble this type of interlocked warp fabric before the insertion of the weft. It is obvious that if the final product is to be smooth, warp tension must be perfectly distributed and, except for unusually large areas, the weft must be inserted without benefit of a heddle and in most cases was done with a needle.

Several types of interlocked warp are distinguishable on the basis of the weft manipulation. In the most elementary, the warp is close together and a single weft runs the full width of the fabric. In these the scaffold yarns are either left in place or the weft substituted for them. Others show the use of different weft colors, matching the colors used in the warp. In these the sides of the color areas may be 
woven as slits, then stitched up; or the different wefts may be interlocked between the warps.

The complexity of some of the patterns in this weave are astounding, considering the labor inrolved and the limitations of the plan by which they were laid out. In fact, they are excellent examples of the extremes to which Peruvians carried their loom work. The interlocked warp technique is found among Paracas Necropolis fabrics and continued to be made until historic times, demonstrating how fixed in their tradition was a willingness to attempt the difficult.

One justification for the term "patchwork" is to be seen in the garments made of small tie-dyed units. All the units in any one garment were warped together on scaffold yarns without interlocking the warp turns. After wearing in the wefts of each unit, the removal of the scaffold freed the "patches", for dyeing and left the warp end loops open for reuniting. So far, there is little to indicate that this "patchwork" was used before the Tiahuanaco period, and nothing to show that it was not consistently used with tie-dyeing:

Interlocked Darning: Another product which at first glance seems to belong to the interlocked warp group and has been called "interlocked plain weave" and "multicolored patchwork," was created entirely by darning without any preparatory warping. O'Neale has described one piece from the Paracas Necropolis period, which must have heen made by daming on a temporary grid of both vertical and horizontal scaffold yarns. Others seem to have been done with only horizontal yarns as a guide but until an unfinished example 
is found, there will be doubt about certain steps in the process.

As a group, they can be distinguished by the impossibility of identifying warp from weft. In any given area of the pattern, the yarn laid in one direction as "warp" turns and serves as "weft," as in darning. Parts of this "weft" may be used to extend the pattern and, in doing so, they become the "warp." Hence, warp and weft yarn is continuous in each area and the warp-weft counts are equal. The patterns are squared geometrically and the colors are clear and contrasting. One might expect such fabrics all to be small, yet a fragmentary example in the American Museum apparently measured thirty-two by eighty-eight inches when new.

Shaped Fabrics (weaving to shape): We are all so conditioned to cutting cloth to a desired size or shape that few of us realize what a relatively new concept this cutting is in terms of our total textile history. The Peruvians, like all ancient weavers, wove their fabrics to the length and width needed for a particular garment or purpose and never cut or tailored them. As the normal product was rectangular, this had a rather depressing effect on clothing styles. Their response to this limitation was to weave cloth to the shape desired. Examples of this practice constitute a larger and more important group than is generally realized.

Of several methods, the most rudimentary is based on a very simple principle; fanning or spreading of the warp between the loom bars, which, if evenly done, yields a trapezoidal product. The side selvages were curved as desired by varying the tension of the weft during weaving. Loin cloths, quite similar to very modern French bathing suits, were woven 
by keeping the center of the warp close together and spreading the ends so that the finished corners could be tied over the hips. Poncho shirts, some over twice as wide across the shoulders as at the bottom, were made by spreading the center of the warp before weaving. To aroid loose construction where the spreading became extreme, additional warps were laid in as needed. The Museum collection contains one large shirt of this type from North Chile (Fig. 56) ; woven in one piece, it is eighty-four inches across the shoulders by thirty-eight across the bottom. For every hundred warps running the full length of the loom, fifty more were added at the center.

Other irregularly shaped pieces were made by setting the loom bars so that one side selvage was longer than the other. Uniform construction was maintained by carrying some of the weft rows only part way across the loom. The same weft manipulation was used in pieces which appear to have been warped between two curved loom bars for the production of capes which are wider in the middle than at the ends.

Although no record has been made of the number of techniques employed in conjunction with shaping, the list includes tapestry, double cloth, twofaced warp pattern, and interlocked warp. The oldest occurrence yet noted is in pre-Tiahuanaco material from North Chile. By the time the Spaniards arrived with the concept of tailored garments, the shaped fabries were more widely used than has hitherto been realized. One cannot help wondering where this phase of costume design would have led had it not been interrupted. 


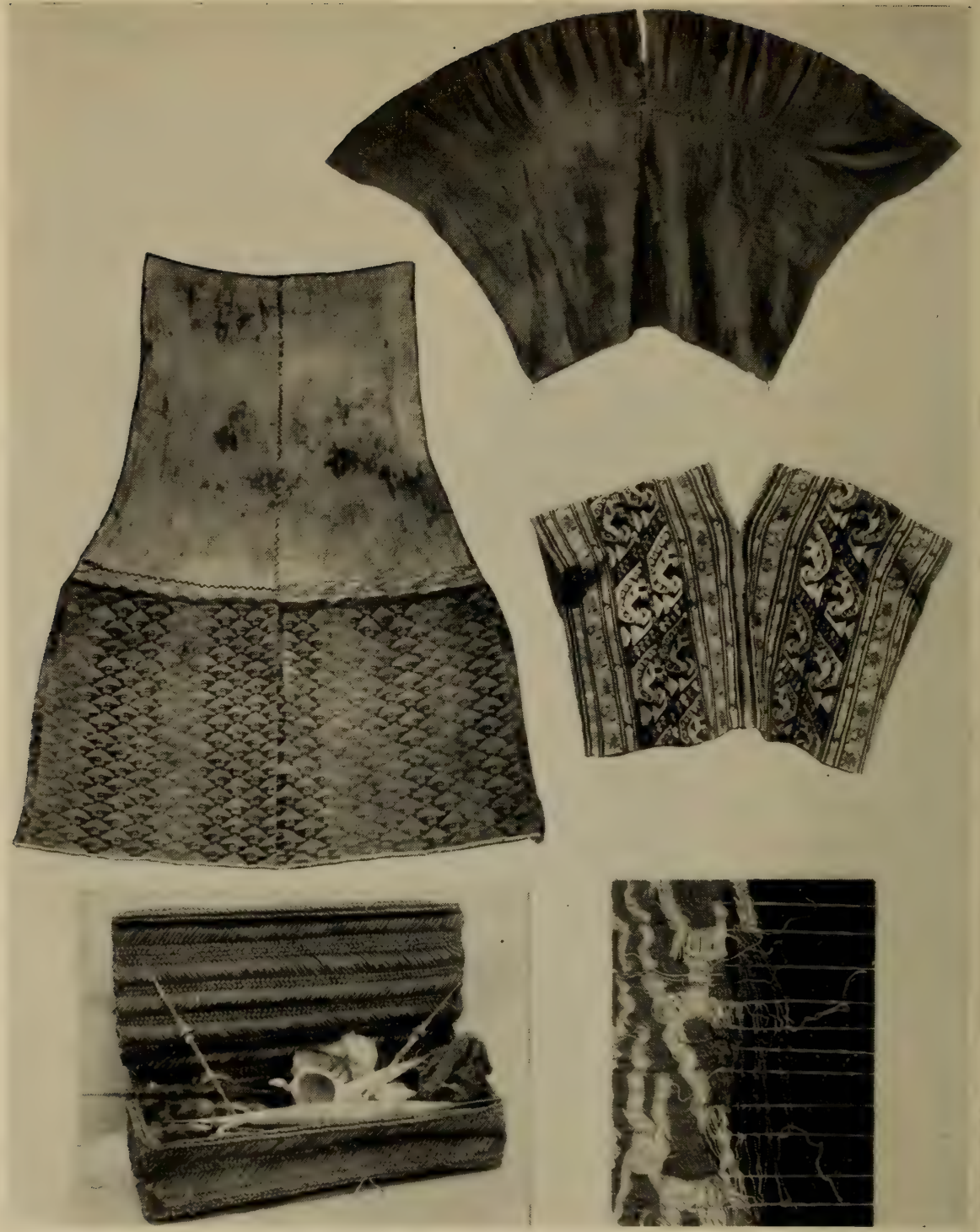

Fig. 56. Poncho shirt, shaped by inserting additional warp at center of fabric (North Chile); Cape, shaped by expanding the warp; upper half, cotton, warp faced, lower half, eccentric tapestry; Boy's shirt, tapestry; Woman's work basket; Detail of interlocked warp loom. 
Resist Dreing: Tie-dyeing or "plangue" has already been mentioned in connection with patchwork. This basically simple process consists of binding portions of a fabric with yarn or fiber before dyeing as protection from the dye, and thus creating a pattern. If a small portion of fabric is bunched and bound, then dye-free circles result. When the binding is applied to folded and rolled cloth, straight lines can be created. Several colors can be used successively by properly planning a sequence of dyes and bindings, but only two colors, in addition to the natural color, have so far been reported. The resist process with wax to stop the dye penetration, known as "batik," has not been found in Peru.

Ikat: Another and more complicated resist dyeing process is made by dyeing the pattern on the warp before weaving commences. For precise results, the whole fabric must be carefully planned in advance. The exact number of warp yarns required are calculated and these subdivided into lots which are grouped, tied, and dyed together for each division of the pattern row repeats.

From the present South American distribution of ikats, south central Chile, Bolivia, north Peru, and Fcuador, one might expect to find more examples from pre-spanish times than actually appear. Only a very few have been collected, all within the Chimu area, and none are older than the late Coastal Tiahuanaco pottery, if that old. This and other reasons suggest that it was introduced into Peru later than and independent of "plangue" tie-dye. Most pieces show retouching after weaving, when dyes were painted on parts of the design as if in 
an attempt to create the appearance of a polychrome ikat.

Both warp and weft ikat are known in Central America, but the latter has not been found in Peru.

Painting: This is an older method of decorating fabrics than resist dyeing. Though plain red pigment was used in lieu of a dye in pre-ceramic days, the creative application of pigments has not yet been reported earlier than Paracas Necropolis. Afterwards, it is found rather widely distributed in the different areas and periods. Perhaps its greatest use was in copying the effects achieved by some structural method such as the reproduction of tapestry designs. Rectangular wall hangings of cotton cloth with large poorly executed painted figures have been found in late Central Coast sites (Fig. 57).

Feather Work and other Surface Decoration: Quantities of feather-covered fabrics have been found, mostly in post-Tiahuanaco graves. In some cases, the feathers have been cemented fast but the more usual method was to attach the feathers to a cord and stitch this to a woven fabric row by row. Some of the feather work is strikingly colorful. Quite common are feathers from domesticated macaws and parrots, some of the latter a yellow variety which is now extinct. Other feathers are from tropical rain forest birds which must have been brought a considerable distance. A study of such material ought to yield information on trade contacts.

Correspondingly late fabrics are also occasionally decorated with sheet metal dises and plates. Most of these are of interest only in that they reveal a trend which has little real appeal from an esthetic 
viewpoint. Beaded fabrics are virtually unknown and are limited to a net construction.

After the Paracas period, embroidery declined in quality. Examples of a later use are the pieces which look like brocade, but are actually created by embroidery. The stitches do not overlay the surface but are inserted under the warp parallel to the weft. Selective choice of the warp creates a secondary pattern over the embroidery yarn unrelated to the figures formed by the latter. One example shows two such independent patterns on opposite faces of an area with the original weft completely hidden between them.

Miscellaneous Techniques: A number of special techniques or devices are employed only occasionally or for some particular purpose. As is true of most weaving processes, a description without detailed illustrations is almost wasted effort, so only a few of these special techniques will be mentioned, without attempting to explain fully the methods used.

Tubular weaving is a term applied to a group of belts and straps in which the weft, in passing the warps, forms a spiral so that the finished product is in the form of a flattened tube. Almost invariably, these have warp patterns with the pattern yarns carried along inside the tube and brought to the outer surface when needed. If the pattern units are spaced with plain weave areas and the pattern warps do not shunt too frequently. from one side to the other, the product is quite round in section. Where the pattern warps are used continuously and are frequently shifted from one side to the other, the result is a flat strong strap with rounded hollow edges. This latter, popular in late Inca times, was 
commonly used for coca bag straps and is still made in parts of Peru, Bolivia, and Chile. However, where a bold pattern was created with solid color areas, the fabric is virtually a double cloth woven with a single continuous weft.

Another tubular construction, but basically distinctive, appears as a finish on warp end loops. In these cases, the insertion of the weft does not stop at the heading cord or rod, if one was used, but is continued around it. Actually, the original heading cord must have been removed to provide working room. The final result is a tubular warp end finish, seldom over a quarter of an inch in diameter; yet, in spite of the small size, one finds carefully executed weft patterns in them.

Other special edgings, such as narrow woven ribbons with fringe, were created by carrying the weft out around one or more temporary warps just as fringes are made on power looms today. Late fabrics from the North Coast have loose spun weft so the finished fringe consists of open loops. The earlier Paracas Necropolis examples are of two ply weft which has been uniformly over-spun in the doubling so that after the temporary warps are removed each loop closes or twists shut. This, too, is still standard procedure for modern fringes of the same type and calls for carefully prepared yarn.

A rather common practice which sometimes leads to misunderstanding was the combination of several techniques in one fabric. A number of Late period shirts from the South Coast were set up in the looms with interlocked warp border units at each end, with the warp between them spaced in groups. When the weft was inserted, it remained exposed where it crossed the spaces between warp groups 
and this exposed yarn was, in turn, used as warp for the construction of tapestry rows so that a tapestry-on-weft was created. The same procedure is found in small bags from Nazca in which rows of fine warp pattern parallel the weft of such tapestry rows. Nearly identical specimens have rows of fine interlocked warp patterns instead of the tapestry rows; at least, that is what they appear to be.

A few examples of looped pile weave shirts of cotton have been found. The outer surface of the one in the Museum collection has rows of inch-long loops formed by drawing out a supplementary weft yarn from between each warp of one shed. The regularity of the loops implies the use of a gauge rod or stick and as the loop rows are well spaced with plain weave, it is clear that the objective was a shaggy-surfaced fabric which would not be too warm for comfort.

Pile construction in woven woolen fabrics is limited to a crude anomaly in extremely coarse, heavy, Late period, shirts and shawls (?) from northern Chile. They are warp-faced fabrics in which tufts of alpaca wool were wrapped twice about every other warp in each alternate shed as the weft was laid in. The free ends of each tuft were loosely twisted and are sometimes about ten inches long. A finished garment is about as handsome as a mangy bearskin, but is probably much warmer, if the American Museum specimen, weighing twelve pounds, is typical. One has only to experience the great diurnal temperature changes in the interior of the Atacama Desert to understand the reason for such heavy fabrics. 
The only compact and patterned pile is a nonloom product. Brightly colored spun wool yarns are caught in a tightly knotted web at each knot, and are trimmed off evenly a quarter of an inch or less above the surface. The ends, when untwisted, form a soft pile of good quality, completely hiding the base fabric. Actually, the technique had only a limited application in hats, headbands, and bags, most of which date from the period of Tiahuanaco expansion.

If, as it appears, the foundation for this pile was usually made by knotting various cords together, it differs from the bulk of the knotted and looped Peruvian products which were made with a single element. In these, a number of techniques were used; the commonest in most periods was netting, because of its use in fishing nets. It also had other, more refined application as in very delicate lace-like hair nets. Knitting and crocheting, the single element techniques most common today, were not used, which is rather surprising when one observes how both have been accepted since the conquest. The somewhat misleading term "needle knitting," used in reports on Peruvian textiles, refers to an embroidery stitch. Although it duplicates the turns and loops of knitting, it is not made by interlocking one loop with another. The direction of build-up is opposite to that in knitting and is accomplished by drawing the end of the yarn, threaded in a needle, through the necessary turns. Maximum perfection of this process is found in the "three dimensional needle knitting" of the Paracas Necropolis period: small, delicate, multicolored, elaborate figures in the round which must be seen to be believed.

Utilization of multiple elements, in braiding or 
plaiting, is found most commonly in slings, and ropes, and to a lesser degree in flat bands. As in weaving, nearly every conceivable elaboration was developed beyond the dictates of necessity. Anyone interested in plaiting should find in the Peruvian examples much more that is worthy of study than has yet been described.

In the preceding comments, the finished fabrics have been mentioned only incidentally. In view of the wide range of techniques, it is surprising to find such a limited range of loom products in terms of their use.

At the time of the conquest, a well-dressed Inca man might wear sandals, a loin cloth, a knee-length poncho shirt, a belt, a rectangular shawl or cape, and a headdress or headband. Lacking any form of pockets, he carried his chewing coca in a small cloth bag-giving in all only six separately woven fabrics, each created for its specific purpose and none cut from a larger piece.

His wife, if equally well dressed, might have five fabrics in her costume: a rectangular mantle worn wrapped around the body reaching from the shoulders to the ankles, a belt, a shawl similar to the man's, a headband, and a kerchief used for various purposes but mainly to carry things.

The number of items per person does not seem ever to have been appreciably larger. Marked regional and period variations of style, because of the absence of tailoring and the limitations of shaped weaving, are observable mainly in the application of structural or decorative techniques. Thus we find that almost every technique was at one time or another employed to some degree in every article of clothing. 
No one has so far secured figures showing the ratio of garments to other textiles. A guess of ninety-five per cent may well be conservative and, if this seems surprising, we must remember that items common in our culture, such as blankets and rugs, were virtually unknown. Past and present eridence indicates that many people slept in their clothes and had little other than mats for their beds. Perhaps next in number were the outer wrappings for the dead and these, like other fabrics for miscellaneous purposes, were virtually devoid of decorative techniques.

A final comment on the method of designing may be of interest. Lacking paper or any other simple medium for plotting and recording designs, the weaver depended mainly on memory. The artisan visualizing a new design had to formulate and remember all the details of construction as the work progressed. As an alternative, at times the process and details of design were worked out on a sampler. Only a small number of these have been collected and, like so many other aspects of Peruvian wearing, they remain undescribed. 


\section{SELECTED SOURCES}

This account has been based on the extensive archaeological bibliography for the Central Andes, on examination of many museum collections, and on unpublished field-work by the authors and others. Virtually no citations have been made in the résumé in view of the fact that many excellent bibliographies exist. The following list of publications is not intended to be a complete bibliography, but contains, rather, some selected suggestions for further reading on the specific topics and regions. Only a few references are given for each division, selected, where possible, because they are written in English, because they are good source material, and because they contain additional bibliography. The references for Part 1, The Setting, and Part 3, Techniques, follow the chapter order. For Part 2, The Central Andes, the sources are cited in terms of major geographical regions, and a few selected topics. Since few field reports are confined to one period or culture, a listing of sources in terms of the major time periods of this account would require considerable duplication.

\section{PART 1}

\section{GEOGRAPHY}

JAMES, Preston E.

1942. Latin America. New York, 1942.

\section{EARLY MIGRANTS}

BIRD, JTNIUS B.

1938. Antiquity and Migrations of the Early Inhabitants of Patagonia. Geographical Review, vol. 38, no. 2, pp. 250-275, New York, 1938. 
1943. Excavations in Northern Chile. Anthropological Papers, American Museum of Natural History, vol. 38, part HRDLičKa, Aleš

4, pp. 171-318, New York, 1943.

1912. Early Man in South America. Bureau of American Ethnology, Bulletin 52, Washington, 1912.

Sullivan, Louis R. and Milo Hellman

1925. The Punin Calvarium. Anthropological Papers, Ameriean Museum of Natural History, vol. 23, part 7, pp. 309-337, New York, 1925.

TSCHOPIK, HARRY, JR.

1946. Some Notes on Rock Shelter Sites near Huancayo, Peru. American Antiquity, vol. 12, no. 2, pp. 73-80, Menasha, 1946.

\section{PLANT DOMESTICATION}

Hutchinson, J. B., R. A. Silow and S. G. Stephens

1947. The Erolution of Gossypium and the Differentiation of the Cultivated Cottons. Oxford University Press, London, 1947.

Mangelsdorf, P. C. And R. G. Reeves

1939. The Origin of Indian Corn and Its Relatives. Texas Agricultural Experimental Station, Bulletin 574, College Station, May, 1939.

SAUer, CarL

1936. American Agricultural Origins: A Consideration of Nature and Culture. In Essays in Anthropology, presented to A. L. Kroeber, pp. 279-297, Berkeley, 1936.

\section{SOLTHERN HUNTERS}

STEWARD, JÜLIAN (Editor)

1946. Handbook of South Ameriean Indians, Volume 1, The Marginal Tribes. Bureau of American Ethnology, Bulletin 143, Washington, 1946.

TROPICAL AGRICULTURISTS

RAdin, PAUL

1942. Indians of South America. New York, 1942.

STEWARD, Julian (Editor)

1948. Handbook of South American Indians, Volume 3, The Tropical Forest Tribes. Bureau of American Ethnology, Bulletin 143, Washington, 1948. 
1948. Handbook of South American Indians, Volume 4, The Cireum-Caribbean Tribes. Bureau of Ameriean Ethnology, Bulletin 143, Washington, 1948.

\section{LOWLAND ARCHAEOLOGY}

How ARD, GeoreE D.

1947. Prehistoric Ceramic Styles in Lowland South America, their Distribution and History. Yale University Publications in Anthropology, no. 37, New Haven, 1947.

KIDDER, ALFRED 2ND

1944. Archaeology of Northwestern Venezuela. Papers, Peabody Museum of American Arehaeology and Ethnology, vol. 26, no. 1, Cambridge, 1944.

NoRdenskiöLd, ERLAND

1930. L'Archéologie du Bassin de l'Amazone. Ars Americana, vol. 1, pp. 1-67, Paris, 1930.

Osgood, Cornelius and George D. Howard

1943. An Archeological Survey of Venezuela. Yale University Publications in Anthropology, no. 27, New Haven, 1943.

Palmatary, Helen

1939. Tapajó Pottery. Ethnologiska Studier, no. 8, pp. 1-136, Göteborg, 1939.

ANDEAN FARM FRS

STEWARD, JULIAN (Editor)

1946. Handbook of South American Indians, Volume 2, The Andean Civilizations. Bureau of American Ethnology, Bulletin 143, Washington, 1946.

\section{NORTHERN ANDES}

Bexnet, Wendell C.

1944. Archeological Regions of Colombia: A Ceramie Surrey. Yale University Publications in Anthropology, no. 30, New Haven, 1944.

Colmier, Donald and John Murra

1943. Survey and Excavations in Southern Ecuador. Anthropological Series, Field Museum of Natural History, vol. 35, pp. 9-103, Chicago, 1943. 


\section{SOUTHERN ANDES}

Bennett, Wendell C., E. F. Bleiler and F. H. Sommer

1948. Northwest Argentine Archeology. Yale University PubliBird, Junius B.

$$
\text { cations in Anthropology, no. 38, New Haven, } 1948 .
$$

1943. Excavations in Northern Chile. Anthropological Papers, American Museum of Natural History, vol. 38, part 4, pp. 171-318, New York, 1943.

Boman, Eric

1908. Antiquités de la Région Andine de la République Argentine et du Désert d'Atacama. 2 vols., Paris, 1908. Montell, Gösta

1926. An Archaeological Collection from the Río Loa Valley, Atacama. Oslo Etnografiske Museums, Skrifter, vol. 5, hefte 1, pp. 1-46, Oslo, 1926.

\section{PART 2}

Bennett, Wendell C.

\section{CENTRAL ANDES GENERAL}

1946. The Archeology of the Central Andes. In Handbook of South American Indians, vol. 2, pp. 61-147, Bureau of American Ethnology, Bulletin 143, Washington, 1946.

Bennett, Wendell C. (Editor)

1948. A Reappraisal of Peruvian Archaeology. Society for American Arehaeology, Memoir No. 4, Menasha, 1948.

Kroeber, A. L.

1944. Peruvian Archeology in 1942. Viking Fund Publications Mead, Charles W. in Anthropology, no. 4, New York, 1944.

1924. Old Civilizations of Inea Land. Handbook Series, Ameriean Museum of Natural History, no. 11, New York, 1924.

Means, Philip A.

1931. Ancient Civilizations of the Andes. New York, 1931.

\section{RELATIVE DATING}

BiRd, JUNIUS

1948. Preceramic Cultures in Chicama and Virú. Society for American Archaeology, Memoir No. 4, pp. 21-28, Menasha, 1948. 
K'T'Bler, George

1948. Towards Absolute Time: Guano Archacology. Society for Ameriean Archaeology, Memoir No. 4, pp. 29-50, Menasha, 1948.

Rowe, JoHN H.

1945. Absolute Chronology in the Andean Area. American Antiquity, vol. 10, no. 3, pp. 265-284, Menasha, 1945.

WiLLEY, GoRdon R.

1945. Horizon Styles and Pottery Traditions in Peruvian Archaeology. American Antiquity, vol. 11, no. 1, pp. 49-56, Menasha, 1945.

\section{Bafssler, Arthi'r}

\section{ILLISTRATIVE SOIREES}

1902-3. Ancient Peruvian Art. 4 vols., Berlin and New York, $1902-3$.

KeLEMEN, PÁL

1943. Metieval American Art. 2 vols., New York, 1943.

Lehmann, Walter and Heinrich Doering

1924. The Art of Old Peru. New York, 1924.

Muelle, Jorge C. and Camilio Blas

1938. Muestrario de Arte Peruano Precolombino. Revista del

SCHмid, MAX

Museo Nacional, vol. 7, pp. 163-280, Lima, 1938.

1929. Kunst und Kultur von Peru. Berlin, 1929.

Bensett, Wendell C.

NORTH COAST OF PERU

1939. Archaeology of the North Coast of Peru. Anthropological Papers, American Museum of Natural History,

KROEBER, A. L. vol. 37, part 1, pp. 1-153, New York, 1939.

1925. The thle Pottery Collections from Moche. University of ('alifornia Publications in American Archaeology and Ethnology, vol. 21, pp. 191-234, Berkeley, 1925.

1926. Archaeologieal Explorations in Peru. Part I: Ancient Pottery from Trujillo. Anthropology, Memoirs, Field Museum of Natural History, vol. 2, no. 1, pp. 1-43, Chicago, 1926.

1930. Archaeological Explorations in Peru. Part II: The Northern C'oast. Anthropology, Memoirs, Field Museum of Natural History, vol. 2, no. 2, pp. 47-116, Chicago, 1930. 
Larco Hoyle, RaFael

1938-9. Los Mochicas. 2 vols., Lima, 1938-1939.

1941. Los Cupisniques. Lima, 1941.

1946. A Culture Sequence for the North Coast of Peru. In Handbook of South American Indians, vol. 2, pp. 149-176, Bureau of American Ethnology, Bulletin 143, Washington, 1946.

1948. Cronología Arqueológica del Norte del Perú. Buenos Tello, Julio C. Aires, 1948.

1938. Arte Antiguo Peruano. Inea, vol. 2, Lima, 1938.

CENTRAL COAST OF PERU

GaYton, A. H.

1927. The Uhle Collections from Nievería. University of California Publications in American Archaeology and Ethnology, vol. 21, no. 8, pp. 305-329, Berkeley, 1927.

Kroeber, A. L.

1925. The Uhle Pottery Collections from Supe. University of California Publications in American Archaeology and Ethnology, vol. 21, no. 6, pp. 235-264, Berkeley, 1925. 1926. The Uhle Pottery Collections from Chancay. University of California Publications in American Archaeology and Ethnology, vol. 21, no. 7, pp. 265-304, Berkeley, 1926.

Strong, William Duncan

1925. The Uhle Pottery Collections from Aneon. University of

California Publications in American Arehaeology and

Ethnology, vol. 21, no. 4, pp. 135-190, Berkeley, 1925.

Strong, William Duncan, Gordon R. Willey and John M. Corbett

1943. Archeological Studies in Peru, 1941-1942. Columbia Studies in Archaeology and Ethnology, vol. 1, New York, 1943.

Uhle, Max

1903. Pachacamac. Philadelphia, 1903.

\section{SOUTH COAST OF PERU}

Gatton, A. H. ANd A. L. Kroeber

1927. The Uhle Pottery Collections from Nazea. University of California Publications in American Archaeology and Ethnology, vol. 24, no. 1, pp. 1-46, Berkeley, 1927. 
KROEBER, A. L.

1937. Archaeologieal Explorations in Peru. Part IV: Canete Valley. Anthropology, Memoirs, Field Museum of Natural History, vol. 2, part 4, pp. 221-273, Chicago, 1937.

Krofber, A. L. ANd William Duncan Strong

19:4. The Uhle Collections from Chincha. University of California Publications in Ameriean Archaeology and Ethnology, vol. 21, no. 1, pp. 1-54, Berkeley, 1924.

1924. The Chle Pottery Collections from Ica. University of California Publications in American Archaeology and Ethnology, vol. 21, no. 3, pp. 95-133, Berkeley, 1924.

\section{NORTH HIGHLANDS OF PERU}

BexsetT, WeNdell C.

194:. Chavin Stone Carving. Yale Anthropological Studies, vol. 3, pp. 1-9, New Haven, 1942.

1944. The North Highlands of Peru. Anthropological Papers, American Museum of Natural History, vol. 39, part 1, New York, 1944.

MCCown, THEODORE D.

1945. Pre-Incaic Huamachueo: Survey and Excavations in the Region of Huamachuco and Cajabamba. University of California Publications in Ameriean Archacology and Ethnology, vol. 39, no. 4, pp. 223-400, Berkeley, 1945.

TenLo, Julio C.

1930. Andean Civilization: Some Problems of Peruvian Archacology. Proceedings, 23d International Congress of Americanists, New York, 1928, pp. 259-290, New York, 1930.

1943. Discovery of the Chavin Culture in Peru. American Antiquity, vol. 9, no. 1, pp. 135-160, Menasha, 1943.

\section{CENTRAL HIGHLANDS OF PERU}

\section{Bixghas, HiraM}

1930. Machu Picchu, a Citadel of the Ineas. New Haven, 1930. Fejos, Paut

1944. Archeolngical Explorations in the Cordillera Vileabamba, Southeastern Peru. Viking Fund Publications in Anthropology, no. 3, New York, 1944. 
Rowe, JoHN H.

1944. An Introduction to the Archaeology of Cuzco. Papers, Peabody Museum of American Archaeology and Ethnology, vol. 27, no. 2, pp. 3-69, Cambridge, 1944.

SOUTH HIGHLANDS OF PERU AND BOLIVIA

Bandelier, Adolph F.

1910. The Islands of Titicaca and Koati. New York, 1910. Bennett, Wendell C.

1934. Excavations at Tiahuanaco. Anthropological Papers, American Museum of Natural History, vol. 34, part 3, pp. 359-494, New York, 1934.

1936. Excavations in Bolivia. Anthropological Papers, American Museum of Natural History, vol. 35, part 4, pp. 329-507, New York, 1936.

KIDDER, ALFRED, 2ND

1943. Some Early Sites in the Northern Lake Titicaca Basin. Papers, Peabody Museum of American Archaeology and Ethnology, vol. 27, no. 1, pp. 3-48, Cambridge, 1943.

Posnansky, Arthur

1946. Tihuanacu. The Cradle of American Man. 2 vols., New York, 1946.

RYDÉN, STIG

1947. Archaeological Researches in the Highlands of Bolivia. Göteborg, 1947.

Tschopik, Marion H.

1946. Some Notes on the Archaeology of the Department of Puno, Peru. Papers, Peabody Museum of American Archaeology and Ethnology, vol. 27, no. 3, pp. 3-57, Cambridge, 1946.

LOCKE, L. LELAND

\section{QUIPU AND CALCULATION}

1923. The Ancient Quipu or Peruvian Knot-Record. New York, 1923.

NORDENSKiöLd, ERLAND

1925. Calculations with Years and Months in the Peruvian Quipus. Comparative Ethnographical Studies, vol. 6, part 2, Göteborg, 1925.

1925. The Secret of the Peruvian Quipus. Comparative Ethnographical Studies, vol. 6, part 1, Göteborg, 1925. 
WASSÉN, Hexry

1931. The Ancient Peruvian Abacus. Comparative Ethnograph. ical Studies, vol. 9, pp. 189-205, Göteborg, 1931.

KubLer, GEorge

\section{HISTORIC PERIOD}

1946. The Queehua in the Colonial World. In Handhook of South American Indians, vol. 2, pp. 331-410, Bureau of American Ethnology, Bulletin 143, Washington, 1946.

Means, Philip Ainsworth

1932. Fall of the Inea Empire. New York, 1932.

MishKin, BERNARD

1946. The Contemporary Quechua. In Handhook of South Ameriean Indians, vol. 2, pp. 411-476, Bureau of American Ethnology, Bulletin 143, Washington, 1946.

Rowe, JoHn Howland

1946. Inca culture at the Time of the Spanish Conquest. In

Handbook of South American Indians, vol. 2, pp. 183-330, Bureau of American Ethnology, Bulletin 143, Washington, 1946.

TSCHOPIK, HARRY, JR.

1946. The Armara. In Handbook of South Ameriean Indians, vol. 2, pp. 501-574, Bureau of American Ethnology, Bulletin 143, Washington, 1946.

\section{PART 3}

\section{TECHNIQIES}

('ERAMICS

Harcovrt, Raoul d' and Marie d' Harcourt

1924. La Céramique Ancienne du Pérou. Paris, 1924.

LINNÉ, S.

1938. The Terhnique of South American Ceramies. Göteborg, 1925.

TELLO, JuLio C.

1938. Arte Antiguo P'eruano. Inca, vol. 2, Lima, 1938.

METALLI'RGY

Bergsge, Paul

1937. The Metallurgy and Ter-hnology of Gold and Platinum among the Pre-Columbian Indians. Ingeniorviden- 
skabelige Skrifter, Nr. A 44, Copenhagen, 1937.

1938. The Gilding Process and the Metallurgy of Copper and Lead among the Pre-Columbian Indians. Ingeniørvidenskabelige Skrifter, Nr. A 46, Copenhagen, 1938.

LOTHROP, SAMUEL K.

1937a. Gold and Silver from Southern Peru and Bolivia. Journal, Royal Anthropological Institute of Great Britain and Ireland, vol. 67, pp. 305-325, London, 1937.

1937b. Coclé, An Archaeological Study of Central Panama. Part I, Historical Background. Excavations at the Sitio Conte. Artifacts and Ornaments. Memoirs, Peabody Museum of Archaeology and Ethnology, Harvard University, vol. 7, Cambridge, 1937.

Mead, Charles W.

1915. Prehistoric Bronze in South America. Anthropological Papers, American Museum of Natural History, vol. 12, pp. 15-52, New York, 1915.

NORDENSKIÖLD, ERLAND

1921. The Copper and Bronze Ages in South America. Comparative Ethnographical Studies, vol. 4, pp. 1-196, Göteborg, 1921.

Rivet, P. and H. ARsandaux

1946. La Métallurgie en Amérique Précolombienne. Travaux et Mémoires de l'Institut d'Ethnologie, vol. 39, Paris, 1946.

Root, William C.

n. d. The Metallurgy of the Southern Coast of Peru. Ms. SMith, Cyril

n. d. The Microscopic Examination of Some Peruvian Bronze Objects. Ms.

TEXTILES

Bailey, Truman

1944. Native Arts Shape the Native Future. Natural History, American Museum of Natural History, vol. 53, no. 6, New York, June, 1944.

n.d. The Manual Industries of Peru. The Museum of Modern Art, New York [No date].

Bird, Junius B.

1947. A Pre-Spanish Peruvian Ikat. Bulletin, Needle and Bobbin Club, vol. 31, nos. 1 and 2, pp. 73-77, New York, 1947. 
Crawrord, M. D. C.

1915. Peruvian Textiles. Anthropological Papers, Ameriean Museum of Natural History, vol. 12, part 3, pp. 53104, New York, 1915.

1916. Peruvian Fabries. Anthropologieal Papers, Ameriean Museum of Natural History, vol. 12, part 4, pp. 105191, New York, 1916.

Harcourt, RaOul D'

1934. Les Textiles Anciens du Pérou et leurs Techniques. Paris, 1934.

LEVILLIER, JeAN

1928. Paracas, a Contribution to the Study of Pre-Incaic Textiles in Ancient Peru. Paris, 1928.

Means, Philip A.

1930. Peruvian Textiles, Examples of the Pre-Incaic Period. New York, 1930.

Montell, Gösta

1929. Dress and Ornaments in Ancient Peru. Göteborg, 1929. O'Neale, Lila M.

1932. Tejidos del Período Primitivo de Paracas. Revista del Museo Nacional, vol. 1, no. 2, pp. 60-80, Lima, 1932.

1933. Peruvian "Needleknitting." American Anthropologist, new series, vol. 35, pp. 405-430, 1933.

1933. A Peruvian Multicolored Patehwork. American Anthropologist, new series, vol. 35, pp. 87-94, 1933.

1935. Pequeñas Prendas Ceremoniales de Paracas. Revista del Museo Nacional, vol. 4, no. 2, pp. 245-266, Lima, 1935.

1936. Wide-loom Fabrics of the Early Nazca Period. In Essays in Anthropology, presented to A. L. Kroeber, pp. 215-228, Berkeley, 1936.

1937. Archaeological Explorations in Peru. Part III: Textiles of the Early Nazea Period. Anthropology, Memoirs, Field Museum of Natural History, vol. 2, no. 3, pp. 119-218, Chicago, 1937.

1942. Textile Periods in Ancient Peru. II: Paracas Caverns and the Grand Necropolis. University of California Publications in American Archaeology and Ethnology, vol. 39, no. 2, pp. 143-202, Berkeley, 1942.

1946. Mochica (Early Chimu) and other Peruvian Twill Fab. ries. Southwestern Journal of Anthropology, I'niversity of New Mexico, vol. 2, no. 3, Albuquerque, 1946. 
O'Neale, Lila M. and Bonnie Jean Clark

1948. Textile Periods in Ancient Peru. III: The Gauze Weaves. University of California, Publications in American Archaeology and Ethnology, vol. 40, no. 4, pp. 143-222, Berkeley, 1948.

O'Neale, lila M. and A. L. Kroeber

1930. Textile Periods in Ancient Peru. I. University of California, Publications in American Archaeology and Ethnology, vol. 28, no. 2, pp. 23-56, Berkeley, 1930. Stafford, Cora Elder

1941. Paracas Embroideries. New York, 1941.

YACOVLEFF, E. AND J. G. Muthle

1934. Un Fardo Funerario de Paracas. Revista del Museo Nacional, vol. 3, nos. 1 and 2, pp. 63-163, Lima, 1934. Zimmern, Nathalie Herman

1944. The Tapestries of Colonial Peru. Brooklyn Museum Journal, 1943-1944, pp. 25-52, New York, 1944. 


\section{INDEX}

Acapana, mound, 185-186

Acknowledgments, 5

Age grades, Inea, 230, 233

Agricultural areas, South

Ameriea, 14

Agriculture, Amazon, 19-20 ; Andean Farmers, 65, 67; Central Andes, 95, 96-97, 117, 118; Colombia, 71 ; eontemporary Indian, 241, 243; Cultist period, 124, 125-126 ; development, 28; diffusion, 29; Experimenter period, 142; Inea, 221, 222-223 ; Mastereraftsman period, 155, 157, 158; Orinoeo, 20; Tropical Agriculturists, 42

Alacaluf, 32 ; house, 35,36

Alloys, 252, 253, 254

Alpaca, domestication, 32

Amazonia, archaeological sites, 58-63

Amazon lowlands, 19

Ancón, 114, 129, 131, 194 ; ceramics, 197; textile dyes, 262; textiles, 259

Andean Farmers, 20, 64-70; culture pattern, 80

Andes, 14; geographical divisions, 16

Antiquity, Andean Farmers pattern, 69-70; Cultist period, 124-125; plant domestication, 29-30; Venezuela sites, 57-58 Araucanians, 65; eulture, 92; dugouts and eanoes, 67 ; geographical distribution, 69; houses, 67 ; religion, 69

Arauquín, site, 58

Arawak, 41

Arawaks, spread to West Indies, 28

Archaeological techniques, 104105,106

Arehaeology, Northern Andean, 70-86; Southern Andean, 8687

Architecture, Central and South Highlands, 197; City Builders period, 206-208; Cultist period, 131-132; Inca, 223-226; Mastereraftsman period, 159163 ; Tiahuanaeo, 188

Arica, middens, 25

Artifacts, Atacameño, 87, 91; Calchaquí, 89; Chavín de Huántar, 132-133; City Builders period, 213 ; contemporary Indian, 242; Cultist period, 126 , 128 ; Experimenter period, 150 151 ; Huaca Prieta, 120 ; Inca, $87,228,229$; Nariño sites, 7576; Northern Chile, 25, 26; Peruvian, 199; Pichalo, 92; San Agustín, 80; South Chile eaves, 24, 25; southern Tierra del Fuego, 25; Tairona, 74

Ascope, eanal, 157

Aspero, 122, 123

Atacama desert, 18; occupation, (90) 
Atacameño, 65 ; ceramics, 210, 212 ; culture, $87,90-92,205$

Atahualpa, 239

Ayllu, 230, 231, 238

Aymara, 239-240 ; geographical distribution, 69

Aztec eivilization, 71

Backstrap loom, 265-268

Barama, River Caribs, 12

Bark eloth, Tropical Agriculturists, 47

Barreales, eulture, 89

Bast, use, Early Farmer period, 258 ; use, in textiles, 261

Beagle Channel, shell middens, 25

Belém type ceramies, 89

Belting, quadruple, 272

Black-White-Red Horizon, 110, 113, 198, 200

Blowgun, Guiana, 44-45 ; Tropieal Agriculturists, 53

Bobbin patterns, 276, 277

Bolas, 25, 68; Southern Hunters, 35

Bora, cannibalism; upper Amazon, 42

Bows and arrows, 68

Braiding, 291-292

Bridges, 220; Tropical Agriculturists, 49

Brocades, 276-277

Brocading, 272

Building, Cultist period, 134; materials, Experimenter period, 145 ; projects, Inca, 223

Burials, Central and South Coast, 198; City Builders period, 208; eremation, 24; Cultist period, 131; Experimenter pe- riod, 151; Mastereraftsman period, 164-166; Paracas Necropolis, 180 ; urn, Marajó, 60 ; Venezuela sites, 58

Cajamarea, 200

Cajamarquilla, 160, 206

Calama, site, 90 ; Tiahuanaco style, 194

Calasasaya ruin, 186

Calehaquí culture, 88

Calculation, system, Inca, 233234

Calendar, Inca, 233

Callejón de Huaylas, 97

Campa, upper Amazon, 42

Campsites, early, 23

Canals, Tiahuanaco, 188

Cañari, 64

Canella Indians, social organization, 39

Cannibalism, Tropical Agriculturists, 55,56

Canoe Indians, 34; elothing, 37; utensils and implements, 38

Canoes, Southern Hunters, 37; Tropical Agriculturists, 48-49 Cara, 64

Caribs, 28, 41

Carvings, Chavín de Huántar, 135; Cultist period, 134; Experimenter period, 151; Inca, 229 ; Pucara, 163-164; Recuay, 163; San Agustín, 78-79; Tiahuanaco, 188-191

Cassava, preparation, 43

Castes, Inca, 231-232, 237-238

"Castillo", 132, 133

Casting, metals, 253

Census, Inea, 217, 220, 230, 239 
Central Andes, 13, 16, 20-21, 95244; building materials, 67 ; cultiration of maize, 29 ; culture pattern, 92-93, 237; domesticated plants, 30 ; economy, 32

Central Coast, subdivisions, 98

Central Highlands, sites, 99; sites, Ecuador, 82-83

Central Valley, Chile, 18

Ceramics, Andean Farmers, 66, 68; Atacameño, 90-91; Barreales, 89-90 ; Calchaquí, $88-$ 89; Central Coast sites, 246; Central Highlands, Eeuador, 83; Chiripa, 143; City Builders period, 208-212; Colombia, 71-73; contemporary Indians, 242; Cultist period, 123, 127, 129; as eultural diagnosties, 102-103; decoration styles, 108-111; Early Cerro Narrío period, Eeuador, 84; Ecuador, 81; Experimenter period, 145149; Humahuaea, 88 ; Inea, 226 , 228-229; Late periods, Ecuador, 83; Mastereraftsman period, 166-171; Manabí, Ecuador, 86; Maracá, 62; Marajó, 59-61 ; Mirakanguéra, 61; Nariño sites, 75; Negative painting, 75; North Coast, 100; Pichalo, 92; Quimbaya, 76 ; Río Napo, 60, 61; Salinar, 144, 145; San Agustín, 80; Santarem, 61-63, 64; shapes, 250; shaping, 247; South Coast, 100; Tairona, 74; techniques, 245-250; Tiahuanaco, 191-192, 196, 197; Tierradentro, 78; Tropical Agrieultur- ists, 63; Upper Cauea Valley, 75; Venezuela, 58

Ceremonial organization, Tropieal Agriculturists, 52

Ceremonies, burial, 68; Chavín de Huántar, 136; Cultist period, 137; Inea, 232, 233, 235, 237; Southern Hunters, 39; Tropical Agriculturists, 56

Cerro Blanco, 132

Cerro Narrío period, Eeuador, 84

Cerro Sechín, carving, 135

Chama, Upper Amazon, 42

Chanapata, 140, 142, 145; ceramics, 147

Chaneay, ceramics, $146,147,205$, 210,211 ; graves, 151 ; metalwork, 150 ; sites, 140

Chaneay Black-on-White ceramies, 203

Chancay White-on-Red style, 139

('hanehan, arabesques, 207, 208; constructions, 197; site, 203, 205-206, 213

Charrua, 34

Chavín, ceramic techniques, 273 ; culture, 197; designs, 129, 130, 131, 132, 147; horizon, 108, $111,124,125,137$; style, 92 , $123,139,193,272$

Chavín de Huántar, 108, 114, 132-135, 136, 137, 140

Chibeha, Andean Farmers pattern, 70 ; eivilization, 71 ; eulture, 73,75 ; distribution, 64 ; goldwork, 77

Chicama Valley, Early Farmers, 258; textiles, 270-271, 273, 275

Chicha, 66

('hile, archaeology, 90-93 
Chilean-Diaguita culture, 92

Chimu, ceramies, 201, 205, 209 ; eulture, 181, 203; metalwork, 213

Chincha Empire, 203-204

Chiripa, 142, 143 ; ceramies, 147, 171; cultures, 140, 141; graves, 151 ; metalwork, 150

Chongoyape, goldwork, 130

Chronology, Central Andes, 103114 ; dyes, 262 ; weaving techniques, 268-293

Chuquimaneu Empire, 203

City Builder Period, 201-214

Clay, furnaces, 251 ; pottery-making, 246

Climate, Andes, 17-18; East Brazil highlands, 20; Central Valley, Chile, 18; coastal plain, 17

Clothing, Andean Farmers, 66, 67 ; Central Andes, 149 ; Cultist period, 130 ; contemporary Indian, 242; Inca, 229, 292; Mastercraftsman period, 173, 176; North Chile, 283, 284; Southern Hunters, 37; Tropical Agriculturists, 49

Coast Tiahuanaco, ceramies, 192 Coca, 292

Cochabamba, cemeteries, 194

Coconueo, 64

Coil technique, pottery making, 246-247

Colombia, archaeology, 70-80 ; houses, 67

Communication, Inea, 220

Confins Cave, 22-23

Construction units, Tiahuanaco, 185-188

Cooking, Southern Hunters, 34
Copacabana festival, 136

"Copper Man", North Chile, 251

Corn (maize), 117-118

Cotton, 117; use, Early Farmer period, 258; use in textiles, 262

Cotton-wool ratios, Peruvian textiles, 258-259

Craftsmanship, contemporary Indian, 242; Inca, 226

Cuismaneu Empire, 203

Cultist period, 140, 141; Central Andes, 123-137; religion, 151; sites, 116, 122, 124, 126; stone carving, 151; textiles, 270, 275 ; varieties of cotton, 259

Cults, Tropical Agriculturists, 56

Culture, area, Central Andes, 100-102; centers, Central Andes, 97; contacts, SpanishIndian, 240-241; development, Central Andes, 13; divisions, Mastercraftsman period, 154; divisions, South America, 33; periods, Central Andes, 110114; periods, Central Highland sites, Ecuador, 82-83; periods, North Highlands, Ecuador, 82; sequence, Experimenter period, 139-140; sites, Mastercraftsman period, 156

Culture pattern, Andean Farmers, 64-70 ; Central Andes, 9596, 101-102, 237; City Builder period, 203; contemporary Indian, 241; Mochica, 177179, 181; Imperialist period, 237; Inca, 216-217; Mastereraftsman period, 155-156; Nazca-Necropolis, $\quad 179-181$; 
South America, 20, 32; Southern Hunters, 34; Tiahuanaco, 181, 182-201; Tropical Agriculturists, 41, 42, 57, 58

Cupisnique, 130, 131, 139, 140 ; ceramies, 126, 250, 273; llama burials, 260; textile dyes, 262; textiles, 259, 270, 271, 272

Curare, preparation, 45

Cuzco, 114, 217, 220, 227 ; ceremonies, 235-236; polychrome ceramies, 110

Dating, 105; Central Andes. ehronology, 113-114; C it y Builders period, 205; Cultist period, 125; Experimenter period, 140 ; Mastereraftsman period, 153-155

Decoration, ceramies, 248, 249 ; fabries, 286-288; metals, 252253

Deformation, head, Experimenter period, 150 ; Mastereraftsman period, 174; Tropical Agriculturists, 50

Designs, Black-White-Red horizon, 110; Charín horizon, 108, 125; City Builders period, 209, 212; Cultist period, 129 ;

Inea horizon, 110; Negative horizon, 109; textile, 269, 271, 272, 293; Tiahuanaco, 196197; Tiahuanaco horizons, 109-110; White-on-Red horizon, 108-109

Diaguita, 65 ; culture, 88

Distaff, 264-265

Divination, Inea, 237
Domesticated animals, 131-132, 260 ; Andean Farmers, 66; Cultist period, 126; European, 14, 242; Experimenter period, 142; Mastereraftsman period, 158 ; pre-Spanish, 16 ; Tropieal Agriculturists, 45

Domesticated plants, 28-32, 117118; Andean Farmers, 65; Central Andes, 158; Cultist period, 126

Double eloth, 272, 289

"'Draconian", style, Barreales, 89-90

Dugouts, Tropieal Agriculturists, 48

Dyeing, yarns, 258, 261-263

Early Cerro Narrío period, Eeuador, 84

Early Farmer cultures, 92

Early Farmers, 116-123

Early Inea culture, 200, 204, 214, 215-216, 218

Early Lima culture, 156, 170

Early Migrants, 21-28, 92

Early Ronquín, 57-58

Early Tiahuanaco, 141, 156, 164 ; ceramies, 171

East Brazil, ceremonies, 39, 40 ; clothing, 37 ; highlands, 20 ; house type, 35 ; material equipment, 38 ; social organization, 39 ; weapons, 35

Economic system, Inea, 230

Economy, Canoe Indians, 34;

Foot Indians, 34; Tropical Agriculturists, 42-51

Ecuador, archaeology, 80-86; houses, 67

Edueation, Inea, 232, 233 
Elen Pata period, Ecuador, 83

El Purgatorio, eity, 206

Embroidery, 272, 273, 288, 291

Environment, Central Andean, 95, 96, 97; South America, 13-21

Esmeralda, 65

Esmeraldas, Ecuador, mounds, 84-85

European contacts, Southern Hunters, 40 ; Tropical Agriculturists, 57

Expansionist period, 182-201

Experimenter period, 137-153; textiles, 272

Fauna, extinct, Lagoa Santa, 22 ; Confins Cave, 22

Featherwork, 212, 286

Fell's Cave, stratified remains, 23-25

Fibers, 256, 258-261

Firemaking, Southern Hunters, 37

Firing methods, ceramies, 248249

Fishing, cultures, North Chile, 25-26; Inea, 223; methods, Tropical Agriculturists, 45

Food, economy, Andean Farmers, 65-66, 67 ; Inea, 221-222 ; plants, diffusion, 28; plants, wild, Andes, 17; preparation, Tropical Agriculturists, 43, 45-46; preservation, Experimenter period, 142

"Foot" Indians, 34

Fortifications, Andean Farmers, 68; Southern Andes, 87

Frame-loom, 265
Fresco, Mastercraftsman period, 160

Fringe, 289

Gallinazo, 140 ; culture, 145, 156 ; mounds, 160

Gateway of the Sun, Tiahuanaco, 109,186

Gauze lace, 271

Gê, 34

Gilding, metals, 253-254

Goajiro, Venezuela, 42

Gold. See Metalwork

Gran Chaco, 19

Grazing areas, Andes, 16

Ground sloth, 24

Guanaco, 24

Guano period, Ecuador, 83

Guaraní, Brazil, 42

Guinea pig, 31-32

Hair, nets, 291; use in textiles, 260-261

Hammocks, Tropical Agriculturists, $46-47$

Heddle, invention, 270; looms, 267-268

Herding, Andean Farmers, 66; Inea, 223

Hierarchy, Inca, 234

Highland Tiahuanaco, ceramics, 192

Horizon styles, defined, 107-108

Horse, American, 24; introduced to Southern Hunters, 40

Houses, Andean Farmers, 67; contemporary, Indian, 242; Experimenter period, 145; Inca, 223; Mastercraftsman period, 159; Southern Hunters, 
35; Tropical Agriculturists, 46

"Huaca de la Luna", 161

"Huaea del Sol"', 161, 196

Huaca Prieta, 118, 119, 120, 121

Huamachuco, 200

Huancayo, rock-shelters, 23, 116

Huaraz, 145

Huavalae period, Ecuador, 83

Humahuaca eulture, 65, 87-88

Hunting, Foot Indians, 34;

Mastereraftsman period, 158;

Pampas, 19 ; period sites, $116-$

117; Tropical Agriculturists, 43-45

Iea, ceramies, 210, 211; culture, 204

Ikat, 285-286

Imperialist period, 215-239

Implements, Cultist period, 126, 129 ; metal, 254, 255; Southern Hunters, 37 ; Tropical Agrieulturists, 47,48

Inea, ehronology, 113, 218; eivilization, 7i; elothing, 292; eulture, Central Andes, 13 ; distaff, 264; Empire, 13, 64, $67,86,157,215-239$; geographical distribution, 69; horizon, 110,113 ; influence, northwest Argentina, 87; labor, division of, 230-231; materials, Ecuador, 82; period, Eeuador, 83; period, textiles, 275 ; social organization, 68 ; textiles, 288

Indian eultures, contemporaneous, 240-244

Initiation, Tropical Agriculturists, 52
Interlocked darning, 281-282

Interlocked tapestry, 278

Interlocked warp pattern, 280281

Interlocking eulture, 124, 156 ; ceramies, $168-170$

Intoxicants, Tropieal Agriculturists, 45

Irrigation canals, Mastereraftsman period, 157

Jívaro, 42, 51; trophy heads, 5355

Kelim tapestry, 277-278

Knotting, technique, 277-278

La Barranea, eity, 206

La Candelaria eulture, 90

La Cabrera, site, 58

La Centinela, eity, 206

La Paya, site, 87

Lagoa Santa, human remains, 22-24

Lake Valencia region, archaeology, 57

Languages, contemporary Indian, 243

Lanzón, 133

Late Cerro Narrío period, Ecuador, 84

Late Ronquín, site, 58

Lile, 64

Linguistie stocks, Tropical Agriculturists, $41-42$

Llama, domestication, 32, 260

Looms, 265-268; Tropieal Agriculturists, 47

Looped pile weave, 290

L08 Barraneos, site, 58

Lowland archaeology, 57-64

Lueurmata site, 194 
Machu Picchu, 224, 225

Macusi, River Caribs, 42

Maize, origin, 29

Maku, 41

Manabí, Ecuador, ruins, 85-86

Manioe, preparation, 43

Manta, 65

Maracá, ceramies, 62 ; site, 63

Marajó, 58-61

Marca Huamachuco, 204

Masonry, Inea, 224, 226, 227;

Tiahuanaco, 188

Mastercraftsman period, 141, 153-181; weaving, 273,275

Medicinemen, Andean Farmers, 68-69; contemporary Indian, 243 ; Inea, 237 ; Southern Hunters, 40; Tropical Agriculturists, $56-57$

Metals, decoration of fabries, 286 ; source, 251

Metalwork, Andean Farmers, 66; Cultist period, 128, 130-131; Calchaquí, 89; City Builders period, 212-213; Colombia, 73 ; Esmeraldas, Ecuador, 84; Experimenter period, 150; Inca, 229; Mastereraftsman period, 174; Quimbaya, 7677 ; techniques, 251-256 ; Tiahuanaco, 193, 198

Middens, antiquity, 26

Middle period, Colombia, 75; Ecuador, 78

Migration routes, South America, 21-22, 26, 116

Military organization, Inea, 218219

Mirakanguéra, site, 61

Mirrors, 121, 130
Moche, constructions, 161 ; ruins, 162

Mochica, 114 ; ceramies, 149, 158, $159,161,166-168,171,176$, 177 ; clothing, 173-174; culture, 139, 156, 157, 200; culture pattern, 177-179, 181; graves, 165 ; ideographic writing, 175-176 ; metallurgy, 174175; multiple heddle loom, 267 ; textiles, 276

Modeling, ceramies, 250

Mojos, stratified mounds, 63

Mold-made ceramics, 247-248

Mordants, use, 261

Mounds, Amazonia, 58, 60 ; Venezuela, 58

Mountain ranges, South America, 14-16

Moxeke, 132

Musical instruments, Inea, 236; Mastercraftsman period, 176; Tropical Agriculturists, 56

Nareotics, Andean Farmers, 66; Inca, 222; Experimenter period, 142; Tropical Agriculturists, 45,57

Nariño eulture, $75,76,78,82,83$

Nazca, bags, 290 ; ceramics, 169 , 170 ; culture, 141, 156, 157 ; graves, 165 ; textiles, 172,173 , 277

Nazca-B style, 196

Nazca-Necropolis, culture patern, 179-181

Negative horizon, 109, 113, 142

Negative painting, pottery, 249250

Negative style, 139

Netting, 291 
North Chile, painted pottery, 276 ; textile dyes, 262; textiles, 260, 275, 283, 284, 290

North Coast, archaeological subdivisions, 98; ceramies, 100 ; Cultist period, ceramies, 129

Northern Andean archaeology, $70-86$

North Highlands, Cultist period, ceramics, 129 ; stone carving, 100 ; subdivisions, 99

Northwest Argentina, archaeology, 86, 87-90

Occupation periods, South Chile eaves, 25

Ocuea je, graves, 152

Ona, 32 ; artifaets, 25 ; ceremonies, 39 ; clothing, 37 ; firemaking, 37 ; secret societies, 39 ; utensils and implements, 38; windbreak, 35,36

Origin, Central Andes eultures, 116 ; domesticated plants, 2829, 117-118 .

Orinoco, 20

Orinoco River basin, archaeology, 57

Ornaments, metal, 254, 255

Pacatnamú, eity, 206

Pachacamae, 114, 136-137, 160. 194, 206 ; ceramies, 211; constructions, 197 ; textiles, 275

Pacheco, site, 194

Painting, pottery, 249; textiles, 286

Palacio, inclosure, 186

Palli Aike eave, stratified remains, 23-25

Pallka, 131
Palta, 65

Pampas, Argentine, 18-19; population spread, 22

Panpipes, Experimenter period, 151

Panzaleo, 64

Paracas Cavernas, 140, 145; eeramics, $147,148,149,250$; graves, 151; metalwork, 150; personal adornment, 150 ; textile dyes, 262; textiles, 149, 259 , 272, 273; weaving, 152 , 259

Paracas Necropolis, building, 159; burials, 165; eulture, 141, 156, 176; dyeing, 261; metallurgy, 175 ; textile dyes, 262 ; textiles, 172, 259, 268, 273, 274, 281, 286, 287, 288, 289,291

Paramonga, fortress, 204

Pasto, 64

Patagonia, early campsites, 23 ; environment, 18; population spread, 22; utensils and tools, 38

Pattern weaves, 276

Personal adornment, Andean Farmers, 67; Cultist period, 130; Experimenter period, 150; Mastereraftsman period, 174; Tropical Agriculturists, 50

Physical type, early, 26, 28

Pichalo, site, 92

Pile weave, 290-291

Pilgrimage centers, Cultist period, 136-137

Pisagua, middens, 25

Pizarro, Franciseo, 239

Plain eloth, 275 
Plaiting, 292

Plant domestication, 28-32. See also Domesticated Plants

Plant lists, Andean Farmers, 65; Central Andes area, 101; Experimenter period, 142; Highland area, 30-31; preceramic period, 120 ; South American lowlands, 28 ; tropieal forests, 42

Plating, metals, 254

Platinum, 254

Political organization, 229-230, 231; Andean Farmers, 68; City Builder period, 201, 203, 214; Inea, 215, 216, 220, 238;

Tropical Agriculturists, 51

Population, City Builder period, 203 ; Inca, 217 ; Mastereraftsman period, 177

Pottery-making process, 246-247. See Ceramies

Pre-Atacameño culture, Pichalo, 92

Pre-eeramie, horizons, weaving techniques, 268 ; sites, Central Andes, 117, 118; period, textiles, 271, 273

Priests, Andean Farmers, 69

Proto-Panzaleo I and II, Ecuador, 83

Pucara, earving, 151; ceramies, $147,148,171,250$; culture, 141, 156; graves, 165 ; temple, 162,163

Puelche, 32

Puerto Moorin culture, 139, 140

Puma Puneu, platform, 186

Puná, 65

Pungurí, 132

Punin skull, 23

Puruhá, 64 ; period, Ecuador, 83
Quechua, 69, 239

Querandí, 32

Quimbaya, 64; culture, 75, 78;

goldwork, 77; sites, 76-78

Quipu, Inea, 234

Rainfall, coastal plain, 18; Orinoco River area, 20

Rain forest, northern Andes, 16; Chile, 18

Recuay, 196; earving, 151; ceramics, 170-171, 211; culture, 156, 161, 163; graves, 165 ; houses, 159 ; style, 63,64

Refuse deposits, Central Andes, 113-114

Religion, Andean Farmers, 65, 69 ; contemporary Indian, 241, 243 ; Cultist period, 136 ; Experimenter period, 152; Imperialist period, 234; Inea, 220, 235 ; Mastereraftsman period, 176-177; Southern Hunters, 40; Tiahuanaco, 193; Tropical Agriculturists, 56-57

Religious pilgrimage pattern, Tiahuanaco, 193

Repp, 275-276

Resist dyeing, 285

Rio Mantaro basin, sites, 99

Río Napo, eeramies, 60 ; site, 61 Roads, Inea, 86-87

Rock-shelters, Huancayo, 116

Rulers, Inea, 218

Sacrifices, Inca, 235

Sacsahuamán, fortress, 227

Salinar, 152 ; ceramies, 146, 147 ; culture, 139, 140; graves, 151 ; metalwork, 150 ; personal adornment, 150

San Agustín sites, 78-80 
San José type ceramies, 89

Santa María style ceramies, 8889

Santa Marta, mountain range, 73

Santarem, 61-63

Shaped fabrics, 282-283

"Sheer tapestry", 278

Shell Fishhook culture, 26

Shiriana, 41

Sintering metals, 254

Sirionó, 41

Slip, pottery, 248

Smelting, metals, 251-252

Social organization, Andean

Farmers, 68; City Builders, period, 213-214 ; contemporary Indian, 243 ; Cultist period, 136; Experimenter period, 151-152; Inea, 229-230 ; Southern Hunters, 38-39; Tropical Agriculturists, 51

South Coast, ceramics, 100 ; subdivisions, 99 ; textiles, 276

Southern Andean arehaeology, 86-87

Southern Andes, extent, 16

Southern Hunters, 20, 32-41, 95

South Highlands, Ecuador, 83-

84; subdivisions, 99-100

Spanish conquest, 239-241

Spindle, modern, Chicama Valley, 263; operation, 263-264

Spinning, 258, 263-265; direetion of twist, 264; preceramic period, 263

Stone earvings, 104. See Carving

Stonework, Quimbaya, 76

Stratigraphy, 105-106; Chicama Valley, 138-139; Cultist period, 124,125
Subsistence patterns, 18; Andean Farmers, 65; Central Andes, 117; City Builder period, 203 ; contemporary Indian, 241; Cultist period, 124, 126; Experimenter period, 142 ; Huaca Prieta, 119-120; Inea, 221, 222-223 ; Mastereraftsman period, 157,158

Subterranean houses, 120, 159

Supe, 130, 131; textile dyes, 262 ; textiles, 259, 271, 273

Surface ruins, defined, 104

Tairona, 64, culture, 73-74, 75

Taltal, 25

Tambo Colorado, 206

Tapestry, 271, 272, 277-279; by periods, 279

Tapestry-on-weft, 290

Tapirapé, Brazil, 42

Tattooing, 174

Techniques, 245-293

Technology, Andean Farmers, 66; City Builders period, 208 ; Colombia, 71; Experimenter period, 141-142, 152-153; Inea, 216, 226-229; Mastereraftsman period, 155, 157, 166

Tehuelche, 32

Temper, pottery, 246

Temperature, Andes, 16; Atacama Desert, 290

Textiles, City Builders period, 212; Cultist period, 129-130; Experimenter period, 149; Huaca Prieta, 120; Inca, 229; Mastereraftsman period, 172174; Mochiea, 172; Nazea-Neeropolis, 180; South Coast, 
100 ; techniques, 198, 256293 ; Tiahuanaco, 193

Tiahuanaco, art style, 193 ; carving, 151 ; eeramies, 171; eulture, 156-157, 181, 182-201, 204; designs, 209; graves, 191; horizon, 89, 109-110, 113, $137,155,180-181,196,200-$ 201; late style, 63-64; masonry, 162 ; site, 184-191; stonework, 193; textiles, 281, 291 ; type burials, Calama, 91

Tie-dyeing, 281, 285

Tierra del Fuego, population spread, 22

Tierradentro eulture, 78

Time sequence, Central Andes, 110-114

Tobaceo, Tropical Agriculturists, 45,46

Topography, South America, 1421

Trade, Andean Farmers, 66; Inca, 223; Tropical Agriculturists, 48

Transportation, Amazon, 19; Andean Farmers, 67; Andes, 17; Southern Hunters, 35, 37; Inea, 220; Tropical Agrieulturists, 48-49

Traps, Tropical Agriculturists, 45

Trephining, Mastereraftsman period, 176

Triple cloth, 272

Trophy heads, 177; Tropical Agriculturists, 52, 53-55

Tropical Agriculturists, 20, 4157 ; antiquity, 63-64; Colombian eultures compared, 71; culture pattern, 95
Tubular weaving, 288-289

Tuncahuán period, Ecuador, 83

Tupí, personal decoration, 50

Tupí-Guaraní, 41

Tupinamba, Brazil, 42 ; cannibalism, 55

Twill, 276

Twining technique, 269-270, 273

Upper Cauea Valley, archaeological sites, 74-75

Utensils, Experimenter period, 150; Southern Hunters, 37; Tropical Agriculturists, 47

Uro, 240

Valencia, site, 58

Venezuela, archaeological sites, $57-58$

Village plans, Tropical Agriculturists, 46

Villages, City Builder period, 205-206 ; Mastercraftsman period, 160

Viracocha, Inca, 234

Viru, Early Farmers, 258; sites, 103-104, 195-196

Wapisiana, River Caribs, 42

Warfare, 182; Andean Farmers, 68 ; Southern Hunters, 35, 4041; Tropical Agriculturists, 52-53, 55-56

Wari, 194, 200; graves, 198

Warp faced textiles, 269, 270, 271-272, 275-276; patterns, $271,272,288$

Warrau, 41

Watereraft, 21; Andean Farmers, 67 
Weapons, Andean Farmers, 68; Experimenter period, 150; Inca, 219-200); Southern Hunters, 34-35; Tropical Agrieulturists, 43-44, 52-53

Weaving, $265-268$; Andean Farmers, 66; City Builders period, 21:; contemporary Indian, 242; Cultist period, 123, 129-130 ; Experimenter period, 149-150; Inea, 229; Mastereraftsman period, 172-174; Nazea-Necropolis, 180; prehistorie Colombia, 73; techniques, 258; Tropical Agriculturists 47,63

Weft, patterns, 271,276
White-on-Red horizon, 108-109, $113,124,139,141-142$ Wilkawain, 195; architecture, 197; ceramies, 197; stratigraphy, 196

Witoto, cannibalism, 55; upper Amazon, 42

Woodwork, Inea, 229

Wool, spinning, 264; use in textiles, 258, 259-260

Workshop sites, 111, 117

Yagua, upper Amazon, 42

Yahgan, 32, 34; ceremonies, 39 ; firemaking, 37 ; social organization, 38 




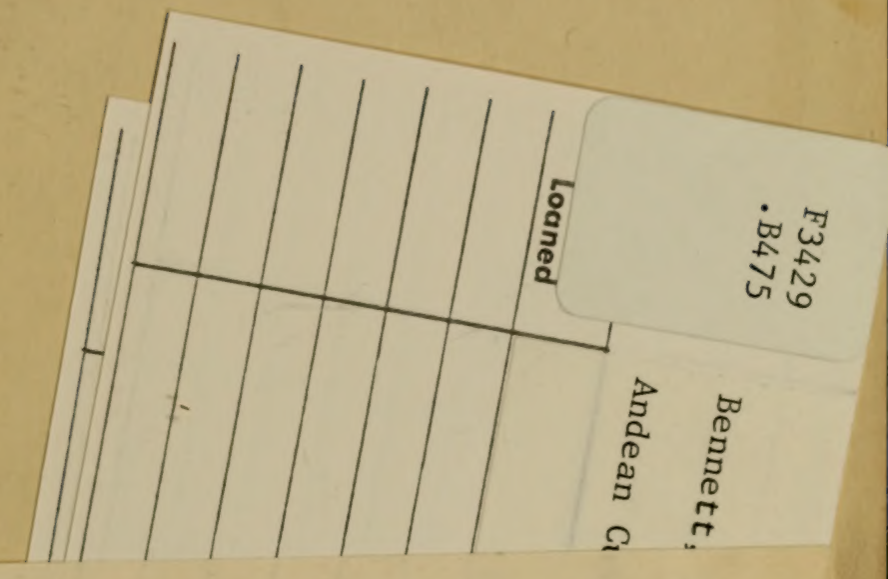


